\title{
Response of Continuous Steel I-Girder Bridges Subject to Temperature Variation
}

Christopher L. Beckett

West Virginia University

Follow this and additional works at: https://researchrepository.wvu.edu/etd

\section{Recommended Citation}

Beckett, Christopher L., "Response of Continuous Steel I-Girder Bridges Subject to Temperature Variation" (2013). Graduate Theses, Dissertations, and Problem Reports. 214.

https://researchrepository.wvu.edu/etd/214

This Dissertation is protected by copyright and/or related rights. It has been brought to you by the The Research Repository @ WVU with permission from the rights-holder(s). You are free to use this Dissertation in any way that is permitted by the copyright and related rights legislation that applies to your use. For other uses you must obtain permission from the rights-holder(s) directly, unless additional rights are indicated by a Creative Commons license in the record and/ or on the work itself. This Dissertation has been accepted for inclusion in WVU Graduate Theses, Dissertations, and Problem Reports collection by an authorized administrator of The Research Repository @ WVU.

For more information, please contact researchrepository@mail.wvu.edu. 


\title{
Response of Continuous Steel I-Girder Bridges Subject to Temperature Variation
}

\author{
Christopher L. Beckett
}

\begin{abstract}
Dissertation submitted
to the Benjamin M. Statler College of Engineering and Mineral Resources at West Virginia University

in partial fulfillment of the requirements for the degree of
\end{abstract}

Doctor of Philosophy in

Civil Engineering

\author{
Dr. Samir Shoukry, Ph.D., Chair \\ Dr. Gergis William, Ph.D., Co-Chair \\ Dr. David Martinelli, Ph.D. \\ Dr. John Quaranta, Ph.D. \\ Dr. Jacky Prucz, Ph.D.
}

Department of Civil and Environmental Engineering

Morgantown, West Virginia

2013

Keywords: finite element analysis, steel I-girder bridges, substructure flexibility, thermal loading, thermal stresses, bridge bearings 


\section{ABSTRACT \\ Response of Continuous Steel I-Girder Bridges Subject to Temperature Variation}

\section{Christopher L. Beckett}

Thermal deformation of the superstructure in continuous slab-on-girder bridges must be freely permitted to avoid potential adverse behavior due to the development of thermal forces. The use of fixed and guided bearings can introduce a significant amount of restraint against thermal deformation that, if not accommodated by the supporting piers, will lead to thermal stresses throughout the structure, most notably in substructure elements (piercaps, bearing assemblies, bearing anchor bolts). The potential effects of restrained thermal deformation in steel I-girder bridges have not been clearly demonstrated. Additionally, the method provided in AASHTO specifications for orienting guided expansion bearings on horizontally curved bridges could foster the development of thermal stresses.

The main goal of this work is to demonstrate and quantify the effect of restrained thermal deformation in an in-service horizontally curved continuous steel I-girder bridge. A second goal is to determine what bearing arrangement scheme is most preferable for minimizing thermal forces. The study presented here includes a comprehensive background discussion, detailed literature review on current concepts regarding the behavior of horizontally curved bridges subject to thermal loads, consequences of inhibited thermal deformation, findings from a field investigation of an in-service steel Igirder bridge, and finite element analysis (FEA).

Finite element analysis is utilized to verify whether or not behaviors documented during a field investigation of the in-service bridge are a result of restrained thermal deformation of the steel I-girder superstructure. During the field inspection, several unfavorable conditions were observed including bent bearing anchor bolts, deformation around the bearing devices, and significant cracking of the reinforced concrete support piers. To investigate these behaviors, 3D finite element modeling of the bridge was completed. Analysis of the FEA study indicates that these behaviors likely result from restrained thermal deformation of the bridge's superstructure. It is found that while lateral pier flexure allows thermal stresses in the superstructure to remain at an acceptable level, stresses in the substructure exceed critical values.

Additionally, FEA is employed to determine what bearing arrangement scheme is preferred for maximizing thermal deformation of the bridge's horizontally curved superstructure, thereby minimizing the possibility that harmful effects may develop. The bridge's geometry, span configuration and location of the support piers remain unchanged so that only the boundary conditions are modified. The study shows that placing fixed bearing assemblies near the bridge's point of zero movement and employing expansion bearing devices at all other support locations results in the most preferable state of stress throughout the bridge. 


\section{ACKNOWLEDGEMENTS}

First and foremost, I must offer my sincerest thanks to Dr. Samir Shoukry for providing me the opportunity to pursue graduate studies. Without his direction and constant guidance, this work would not have been possible. Thank you for always having faith in me and never doubting my abilities.

I must also express tremendous gratitude toward Dr. Gergis William. Without his endless support and advice, completion of this dissertation would not have been possible. Thank you for always being there to answer the most obvious of questions and for helping shape my problem-solving abilities.

Thank you to the members of my examining committee for agreeing to lend a helping hand during this work. Graduate school has taught me that time is precious, and I appreciate you offering a little of yours.

Thanks are also reserved for Dr. Eduardo Sosa and Dr. Mourad Riad, whose assistance with this work was infinitely valuable.

Lastly, I must give mention to my parents. Without their endless encouragement for me to see this journey through, I am almost certain it would not have been achieved. 


\section{TABLE OF CONTENTS}

ACKNOWLEDGEMENTS

TABLE OF CONTENST

LIST OF FIGURES $\quad$ V

LIST OF TABLES Vi

CHAPTER ONE - INTRODUCTION 1

1.1 Overview 1

1.2 Motivation and Problem Statement 4

$\begin{array}{ll}1.3 \text { Research Goal } & 6\end{array}$

1.4 Research Objectives and Approach 6

1.5 Dissertation Outline 9

CHAPTER TWO - BACKGROUND 10

2.1 Introduction $\quad 10$

2.2 Response of Steel Girder Bridges to Temperature Variations 11

2.3 The Influence of Substructure Flexibility on the Thermal Response of Steel $\begin{array}{ll}\text { I-Girder Bridges } & 17\end{array}$

2.4 Review of Pertinent Past Work 18

2.5 AASHTO Design Provisions and Foreign Guide Notes Relating to

Thermal Deformation $\quad 25$

$\begin{array}{ll}2.6 \text { Summary } & 27\end{array}$

CHAPTER THREE - MAN BRIDGE DESCRIPTION and FIELD INVESTIGATION 29

3.1 Introduction 29

3.2 Bridge Description $\quad 30$

3.3 Bridge Bearing Arrangements $\quad 32$

3.4 Field Investigation of the Man Bridge $\quad 35$

3.4.1 Introduction $\quad 35$

3.4.2 Anchor Bolt Deformation $\quad 35$

3.4.3 Support Pier Cracking 40

3.5 Conclusion $\quad 45$

CHAPTER FOUR - FINITE ELEMENT MODELING of the MAN BRIDGE 47

4.1 Introduction 47

4.2 Finite Element Model Progression 48

4.3 Model Overview - Superstructure Modeling $\quad 49$

4.4 Initial Substructure Modeling $\quad 54$

4.5 Substructure Modifications $\quad 57$

4.5.1 Bearing Details Modifications $\quad 57$

$\begin{array}{ll}\text { 4.5.2 Masonry Plates } & 58\end{array}$

$\begin{array}{ll}\text { 4.5.3 Bearing Anchor Bolts } & 60\end{array}$

4.5.4 Support Pier Modification $\quad 65$

4.6 Material Model 67 
4.7 Model Validation $\quad 69$

4.7.1 Spring Element Validation - Single Girder Model 69

4.7.2 Spring Element Validation - Full-Scale FE Model 74

$\begin{array}{ll}4.8 \text { Conclusion } & 76\end{array}$

CHAPTER FIVE - FEA of the MAN BRIDGE and ASSESSMENT versus FIELD OBSERVATIONS $\quad 77$

5.1 Introduction 77

5.1.1 Calculation of Uniform Thermal Loads 78

$\begin{array}{ll}\text { 5.2 Superstructure Translation at the Bearings } & 79\end{array}$

$\begin{array}{lr}5.3 \text { Shear Force in the Bearing Anchor Bolts } & 90\end{array}$

5.4 Effect of Pier Flexibility 100

5.5 Flange Stress at the Bearings $\quad 110$

5.6 Stresses in the Support Piers $\quad 119$

5.6.1 Stresses in the Piercaps 122

5.6.2 3D Solid Model 126

5.6.3 3D Solid Model Results 133

5.7 Summary and Conclusions 136

CHAPTER SIX - FEA CASE STUDY 138

6.1 Introduction 138

6.2 New Bearing Arrangement Schemes 139

6.3 Superstructure Translation at the Bearings 141

6.4 Shear Force in the Bearing Anchor Bolts 149

6.5 Flange Stress at the Bearings 153

6.6 Stresses in the Support Piers 158

6.7 Summary and Conclusions 163

CHAPTER SEVEN - CONCLUSIONS, RECOMMENDATIONS and FUTURE WORK 166

7.1 Conclusions 166

7.1.1 FEA of the Man Bridge $\quad 167$

7.1.2 FEA Case Study 169

$\begin{array}{ll}\text { 7.2 Recommendations for Minimizing Thermal Forces } & 170\end{array}$

$\begin{array}{ll}7.3 \text { Future Work } & 171\end{array}$

$\begin{array}{ll}\text { REFERENCES } & 174\end{array}$ 


\section{LIST OF FIGURES}

Figure 1.1 Horizontally Curved Steel I-Girder Bridges $\quad 1$

Figure 2.1 HLMR pot bearing (fixed bearing) 13

Figure 2.2 HLMR pot bearing (free bearing) $\quad 13$

Figure 2.3 HLMR pot bearing (guided bearing) 13

Figure 2.4 Guided bearings on a continuous straight structural member 14

Figure 2.5 Tangential orientation of guided expansion bearings 16

Figure 2.6 Chordal orientation of guided expansion bearings 16

Figure 3.1 The Man Bridges 29

Figure 3.2 Overhead view the Man Bridge $\quad 30$

Figure 3.3 Unit 1 layout $\quad 31$

Figure 3.4 Unit 2 layout $\quad 32$

Figure 3.5 Pot bearing employed on the Man Bridge 33

Figure 3.6 Designed bearing arrangement for Unit 1 34

Figure 3.7 Designed bearing arrangement for Unit 2 34

Figure 3.8 Bent anchor bolts at Abutment 1

Figure 3.9 Bent anchor bolts at Pier 5 36

Figure 3.10 Undeformed anchor bolts $\quad 37$

Figure 3.11 Visualization of the extent to which anchor bolts are deformed $\begin{array}{ll}\text { out-of-plane } & 37\end{array}$

Figure 3.12 Anchor bolts bent parallel to the girders 38

Figure 3.13 Typical reinforced concrete hammerhead pier $\quad 40$

Figure 3.14 Structural crack originating under the bearings 41

Figure 3.15 Cracks found on Pier 1

Figure 3.16 Cracks found on Pier 2

Figure 3.17 Cracks found on Pier 4

Figure 3.18 Cracks found on Pier 5

Figure 3.19 Man Bridge concentric girders illustration $\quad 44$

Figure 4.1 Man Bridge FE models $\quad 52$

Figure 4.2 Man Bridge FE model, Abutment 2 53

Figure 4.3 Man Bridge FE model, Pier 10

Figure 4.4 Typical support pier $\quad 54$

Figure 4.5 Initial substructure representation $\quad 55$

Figure 4.6 Local axes at the bearings $\quad 56$

Figure 4.7 Bridge bearing schematics and FE model representation 58

Figure 4.8 Masonry plate and bearing anchor bolts $\quad 59$

Figure 4.9 Solution for transferring vertical load through the masonry plates 59

Figure 4.10 Anchor bolt cross-section representation $\quad 62$

Figure 4.11 New bridge bearing model $\quad 64$

$\begin{array}{ll}\text { Figure 4.12 Bearing representation } & 64\end{array}$

Figure 4.13 Bearing stiffness $\quad 65$

Figure 4.14 Stress concentration area in a previous FE model 66 
Figure 4.15 Circular cross-section discretization

Figure 4.16 Single girder model used for FE validation $\quad 70$

Figure 4.17 Spring element application in single girder model $\quad 72$

Figure 4.18 Single girder model thermal expansion results $\quad 73$

Figure 4.19 LVDT data for G3 and G2 at Abutment 1

Figure 4.20 Bearing translation at Abutment 1

Figure 5.1 Expansion bearing orientation, Unit 1

Figure 5.2 Expansion bearing orientation, Unit 2

Figure 5.3 Thermal movement of Unit 1 under the $+60^{\circ} \mathrm{F}$ thermal load 83

Figure 5.4 Thermal movement of Unit 2 under the $+60^{\circ} \mathrm{F}$ thermal load 83

Figure 5.5 Thermal movement of Unit 1 under the $-70^{\circ} \mathrm{F}$ thermal load 84

Figure 5.6 Thermal movement of Unit 1 under the $-70^{\circ} \mathrm{F}$ thermal load 84

Figure 5.7 Comparison between design thermal movement range and FE model predictions 89

Figure 5.8 Development of shear force in the bearing anchor bolts and beam element convention 91

Figure 5.9 Shear force per anchor bolt $\left(+60^{\circ} \mathrm{F}\right)$

Figure 5.10 Shear force per anchor bolt $\left(-70^{\circ} \mathrm{F}\right) \quad 93$

Figure 5.11 Approximate location of stationary point in Unit 1

Figure 5.12 Comparison of theoretical superstructure thermal deformation vs FE model predictions $\left(+60^{\circ} \mathrm{F}\right) \quad 102$

Figure 5.13 Comparison of theoretical superstructure thermal deformation vs FE model predictions $\left(-70^{\circ} \mathrm{F}\right) \quad 102$

Figure 5.14 Cantilever member $\quad 106$

Figure 5.15 Fixed pot bearing assembly 111

Figure 5.16 Effective stress in the bottom flanges at the bearings 112

Figure 5.17 Percentage of yield strength consumed by thermal stress 114

Figure 5.18 Orientation of longitudinal and transverse axes 115

Figure 5.19 Longitudinal stress in the bottom flanges at the bearings 116

Figure 5.20 Transverse stress in the bottom flanges at the bearings 117

Figure 5.21 Stress development under anchor bolt shear force 122

Figure 5.22 Sample contour plots - Pier 2 123

Figure 5.23 Maximum principal stress contour plots - Pier 1,5 124

Figure 5.24 Maximum principal stress contour plots - Pier 7,10 124

Figure 5.25 3D solid model of a typical piercap $\quad 128$

Figure 5.26 Solid model anchor bolts 129

$\begin{array}{ll}\text { Figure 5.27 Solid model piercap dimensions } & 129\end{array}$

Figure 5.28 Solid model mesh $\quad 130$

Figure 5.29 Grounded spring elements representing pier column stiffness $\quad 132$

Figure 5.30 Application of nodal forces acting on each bolt 132

Figure $5.31 \sigma_{1}$ development in the concrete surrounding the anchor bolts 133

Figure 5.32 $\sigma_{1}$ under Girder 4 at Pier $5 \quad 134$

Figure $5.33 \sigma_{1}$ under Girder 1 at Pier $5 \quad 134$ 
Figure 6.1 Bearing arrangement modification Case 1

Figure 6.3 Case 1 thermal movement under the $+60^{\circ} \mathrm{F}$ load 143

Figure 6.4 Case 2 thermal movement under the $+60^{\circ} \mathrm{F}$ load 143

Figure 6.5 Case 1 thermal movement under the $+60^{\circ} \mathrm{F}$ load $\quad 144$

Figure 6.6 Case 2 thermal movement under the $+60^{\circ} \mathrm{F}$ load $\quad 144$

Figure 6.7 Bearing displacement under the $+60^{\circ} \mathrm{F}$ load 146

Figure 6.8 Bearing displacement under the $-70^{\circ} \mathrm{F}$ load 146

Figure 6.9 Maximum bearing displacement range - Case 1 148

Figure 6.10 Maximum bearing displacement range - Case 2 148

Figure 6.11 Shear force acting at each bearing under the $+60^{\circ} \mathrm{F}$ load - Case $1 \quad 150$

Figure 6.12 Shear force acting at each bearing under the $-70^{\circ} \mathrm{F}$ load - Case 1

Figure 6.13 Shear force acting at each bearing under the $+60^{\circ} \mathrm{F}$ load - Case 2

Figure 6.14 Shear force acting at each bearing under the $-70^{\circ} \mathrm{F}$ load - Case $2 \quad 152$

Figure 6.15 Total shear force acting at each support under the $+60^{\circ} \mathrm{F}$ load $\quad 152$

Figure 6.16 Total shear force acting at each support under the $-70^{\circ} \mathrm{F}$ load 153

Figure 6.17 Effect stress at the bearings under the $+60^{\circ} \mathrm{F}$ load 154

Figure 6.18 Effect stress at the bearings under the $-70^{\circ} \mathrm{F}$ load 154

Figure 6.19 Longitudinal stress at the bearings under the $+60^{\circ} \mathrm{F}$ load 155

Figure 6.20 Longitudinal stress at the bearings under the $-70^{\circ} \mathrm{F}$ load 155

Figure 6.21 Transverse stress at the bearings under the $+60^{\circ} \mathrm{F}$ load 156

Figure 6.22 Transverse stress at the bearings under the $-70^{\circ} \mathrm{F}$ load 156

$\begin{array}{ll}\text { Figure 6.23 Effective stress contour plots of Pier } 7 & 160\end{array}$ 


\section{LIST OF TABLES}

Table 4.1 Spring element application for each bearing type 56

Table 4.2 Anchor bolt cross-sectional data $\quad 63$

Table 4.3 LVDT vs FE model bearing translations 76

Table 5.1 Design longitudinal translation 85

Table 5.2 Design transverse translation $\quad 85$

Table 5.3 FE model bearing displacement for $+60^{\circ} \mathrm{F}$ load case $\quad 86$

Table 5.4 FE model bearing displacement for $-70^{\circ} \mathrm{F}$ load case $\quad 87$

Table 5.5 Total shear force per bolt group $\left(+60^{\circ} \mathrm{F}\right.$ thermal load $) \quad 92$

Table 5.6 Total shear force per bolt group $\left(-70^{\circ} \mathrm{F}\right.$ thermal load $) \quad 92$

Table 5.7 Anchor bolt shear force comparison $\left(+60^{\circ} \mathrm{F}\right) \quad 95$

Table 5.8 Anchor bolt shear force comparison $\left(-70^{\circ} \mathrm{F}\right) \quad 96$

Table 5.9 Anchor bolt shear stress comparison $\left(+60^{\circ} \mathrm{F}\right) \quad 97$

Table 5.10 Anchor bolt shear stress comparison $\left(-70^{\circ} \mathrm{F}\right) \quad 98$

Table 5.11 Imbalance between work done and strain energy in the support piers $\begin{array}{ll}\text { under the }+60^{\circ} \mathrm{F} \text { load case } & 107\end{array}$

Table 5.12 Imbalance between work done and strain energy in the support piers $\begin{array}{ll}\text { under the }-70^{\circ} \mathrm{F} \text { load case } & 107\end{array}$

Table 5.13 Magnitude of thermal stress at each support 113

Table 5.14 Magnitude of longitudinal thermal stress at each support 118

Table 5.15 Maximum principal stress in each piercap 126

Table 6.1 Theoretical vs FE predicted bearing displacement - Case 1 147

Table 6.2 Theoretical vs FE predicted bearing displacement - Case 2 147

Table 6.3 Effective stress at each pier 161

Table 6.4 Maximum principal stress at each pier 162 


\section{CHAPTER ONE}

\section{Introduction}

\subsection{Overview}

Given the aging, often deficient state of highway infrastructure throughout the United States, specifically the nation's numerous steel bridge structures, the inevitability of new construction is on the horizon, if not more urgent. Many of these bridges will require very considerable upgrading while many more need replaced altogether. A popular design solution among bridge designers are continuous steel I-girder bridges. These slab-on-girder type structures are an attractive design choice for several reasons including long-term economy, aesthetics and most notably, geometric freedom. Steel Igirders can be designed to traverse nearly any layout while requiring a relatively small footprint when placed on individual support piers. Specifically, the use of horizontally curved steel I-girder bridges has become quite commonplace over the last few decades, especially in scenarios where horizontal curvature is needed, such as in urban areas and within highway interchanges, as shown in Figure 1.1.

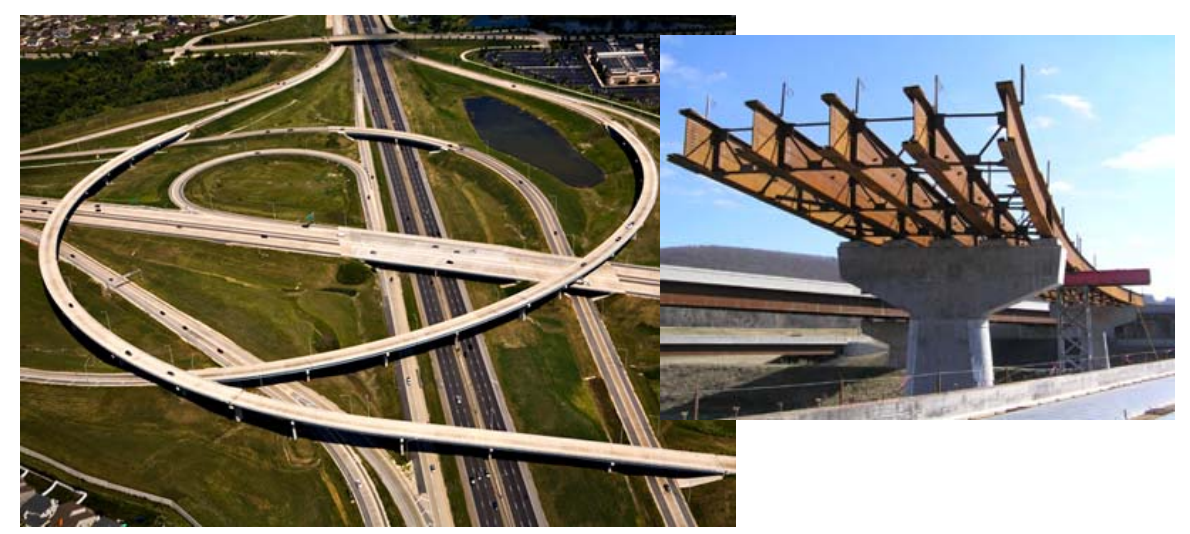

Figure 1.1. Horizontally curved steel I-girder bridges 
An important design aspect within continuous steel girder bridges is effectively permitting the superstructure (steel girders, concrete bridge deck) to undergo thermal movements (expansion and contraction) when subjected to temperature variations (i.e. thermal loading). If thermal deformation of a bridge's steel superstructure is not freely allowed, or if thermal movements become restrained during the life of the structure, thermal force effects will develop throughout a continuous bridge, negatively influencing its structural integrity. William et al. (2005) and McBride (2013) showed that when restrained, thermal expansion of a steel girder superstructure can lead to relatively large thermal stresses that reduce the expected structural capacity of the steel I-girders. Additionally, these thermal forces are transmitted to various substructure elements and may lead to unfavorable responses (Moorty and Roeder 1992a, Moorty and Roeder 1992b, Croft 1994).

On a typical steel I-girder bridge, various types of bridge bearings are strategically employed to allow the superstructure to undergo a full range of thermal movements, thereby minimizing the potential development of thermal forces. Bridge expansion bearings are normally selected to accomplish this. Selection and alignment of bridge bearing devices is vital to minimizing thermal stresses throughout a bridge system, especially in relatively lengthy structures. A simple examination of the equation for calculating longitudinal displacement of structural members subject to a thermal load (Equation 1.1) reveals that as the length of a member increases, the magnitude of thermal displacement increases as well. In a structure with continuous members, the magnitude of thermal displacement can be quite large and accommodating these movements becomes increasingly difficult (Emanuel and Hulsey 1985). Proper alignment of the 
expansion bearings during bridge construction is a vital procedure if thermal forces (and stresses) are to be avoided. In straight bridges, this initial alignment is relatively straight forward by utilizing Equation 1.1.

$$
\Delta_{T}=\alpha_{T} L\left(T_{2}-T_{1}\right)
$$

On a horizontally curved structure, orienting bridge expansion bearings can be an arduous process due to the complex nature of thermal movement within curved structural members. A lack of detailed guidance makes the process of orienting expansion bearings on horizontally curved bridges even more difficult. In recent American Association of State Highway and Transportation Officials (AASHTO) bridge design specifications (AASHTO 2003, 2007), minimal guidance is provided concerning the behavior of horizontally curved bridges subjected to thermal loads. The sole equation specified for calculating the magnitude of thermal deformation (1.1) is only applicable to straight girders. As well, no actual design specification is provided governing horizontally curved steel members subjected to thermal loading. Commentary found within design codes pertaining to curved members relies on a generalization of curved member behavior.

Little aid is provided to assist bridge designers with the selection and orientation of bearing devices. Furthermore, foreign guide notes discussed in Hendy and Iles (2010) prefer a method that is contrary to AASHTO. This difference regarding the preferred orientation of guided expansion bearings confirms that suitable accommodation of thermal deformation within horizontally curved steel girder bridges is not well established. 
Thermal movement of a bridge's superstructure is typically permitted by the employment of bridge expansion bearings, as just discussed. However, if the selected bearing devices are inadequate in allowing thermal deformation of a bridge's superstructure, engineers often recognize the capability of the bridge's substructure to accommodate thermal movements. Generally, this means lateral deflection of the supporting piers. If the bearing devices are overly constraining, the support piers will deflect, effectively permitting thermal deformation of the superstructure and minimizing thermal stresses. Such a scenario is encountered when fixed bearings are employed at multiple consecutive support locations. However, this action is only preferable if thermal stresses throughout the superstructure and substructure can be minimized. Hulsey and Emanuel (1978), however, found that stresses in the superstructure can remain significant, in comparison to vertical loads. While thermal stresses within the superstructure may be mitigated, significant levels of stress may persist in the substructure, especially in the vicinity of the bearing devices. Evidence has been documented showing that thermal movement of a steel girder superstructure can have negative effects on elements within a bridge's substructure, including deformation around the bearings, bearing anchor bolt deformation, and cracking in concrete supports (Chapter Three). Understanding how thermal forces affect substructure components is a significant concern to bridge integrity and long-term economy.

\subsection{Motivation and Problem Statement}

Bridge expansion bearings and substructure flexibility (e.g. lateral pier deflection) are the means through which thermal deformation of a bridge's superstructure must take 
place. If substructure flexibility is to be taken advantage of, individual substructure components (i.e. bridge bearings, anchor bolts, supporting piers) must have the capacity to safely resist the additional forces imparted to them. Additionally, substructure rigidity must not be so large as to cause resistance against thermal deformation of the attached superstructure.

To date, little research has been conducted specifically examining substructure behavior due to thermal movement in steel I-girder bridges, hence, no guidance is provided within AASHTO design specifications and current literature to assist bridge designers in dealing with potential adverse behaviors due to the development of thermal forces. Field investigations by Moorty and Roeder (1992b) and Croft (1994) have shown that thermal movement of a steel girder superstructure can lead to undesirable behavior in substructure components. The prospective harmful effects of restrained thermal deformation need to be clearly demonstrated so that future bridge designs can avoid such outcomes. A comprehensive investigation into the impact of superstructure thermal movement on substructure behavior in continuous steel I-girder bridges is needed.

Orientation of bridge expansion bearings is a crucial task during the design and construction of horizontally curved continuous steel I-girder bridges. If the expansion bearings are aligned in a manner that impedes thermal deformation of the steel I-girder superstructure, lateral pier deflection must occur in order to lessen the magnitude of thermal stresses throughout the bridge. Moorty and Roeder (1992a) found that the method for orienting expansion bearings suggested in AASHTO is not necessarily preferable. Similar conclusions were offered by Chen (2008), who also noted that the method for aligning expansion bearings put forth in AASHTO is less preferable when 
substructure rigidity is low. Nonetheless, the studies cited above, and most additional works exploring the thermal response of curved bridges rely on results provided by relatively small structures (three spans or less). It is not uncommon for steel girder bridges to consist of up to six or more spans, and so, a more complete understanding of the thermal response of horizontally curved steel girder bridges is needed in order to more effectively employ bridge expansion bearings and lessen the potential influence of thermal forces. From this, recommendations can be proposed regarding how best to accommodate thermal deformation in these structures.

\subsection{Research Goal}

The primary goal of this work is to demonstrate that restrained thermal deformation of a bridge's steel girder superstructure can result in detrimental conditions within its substructure. A second goal of this work is to expand the current knowledge regarding the thermal response of horizontally curved continuous steel I-girder bridges. Implicit in this work is a demonstration that restrained thermal movement of a bridge's superstructure can lead to unfavorable conditions throughout the substructure, a behavior not discussed in detail within current design specifications.

\subsection{Research Objectives and Approach}

The first part of this work consists of providing evidence, through a field investigation, that constrained thermal movement within a steel I-girder superstructure has resulted in undesirable conditions in substructure components (e.g. support piers, 
bearings, anchor bolts). Finite element modeling and analysis (FEM, FEA) is employed to substantiate these findings.

Secondly, FEA is utilized to examine the thermal response of a horizontally curved steel I-girder bridge under various boundary conditions (i.e. bearing arrangements). The study aspires to determine the most favorable bearing arrangement for minimizing thermal forces throughout a horizontally curved continuous steel I-girder bridge system. The following objectives and tasks characterize the approach employed to accomplish the goals of this work.

Objective 1 - Demonstrate that constrained thermal deformation of a bridge's steel Igirder superstructure can result in detrimental behavior within its substructure. This objective will be pursued through completion of the following tasks:

1. Provide evidence, through a field investigation of an in-service steel I-girder bridge located in southern West Virginia, that restrained thermal expansion (and contraction) of the steel superstructure has resulted in adverse conditions within the substructure. Primarily, attention is placed upon 1) cracking of reinforced concrete support piers and 2) deformation of the bearing anchor bolts. Both of these phenomena have been observed and documented on the structure.

2. Modify an existing finite element model of the chosen structure in order to more accurately represent the bridge bearing devices. Specifically, the method for connecting the superstructure (bottom flange) to the supporting piers will be altered so that thermal force effects are transmitted through a mechanism that more accurately models a typical bridge bearing. 
3. Extract the appropriate data from the FE model(s) to determine whether or not the predicted stress state within the bearings and support piers corroborates the findings documented during the field investigation.

Objective 2 - Establish what type of bearing arrangement is most favorable for minimizing thermal stresses in a horizontally curved continuous steel I-girder bridge. To meet this objective the following tasks will be completed:

1. Modify the FE model to reproduce the boundary conditions associated with two additional bearing arrangements schemes that could be applicable to the actual structure. The two arrangements adhere strictly to AASHTO (2003, 2007) recommendations by implementing fixed bearings at a single location, maximizing potential thermal deformation of the superstructure.

2. Analyze and compare stresses in the bearings and piers among the FE models under the two bearing arrangements to verify which set of boundary conditions provides the most acceptable stress state.

Objective 3 - Put forward detailed recommendations and instruction on how best to minimize thermal stresses in a horizotnally curved continuous steel I-girder bridge based on outcomes from Objectives 1 and 2. 


\subsection{Dissertation Outline}

Chapter Two presents an thorough discussion on the current knowledge regarding the thermal response of horizontally curved continuous steel I-girder bridges. Within this discussion is information relating to provisions of the AASHTO LRFD Bridge Design Specifications and foreign guide specifications on how thermal deformation is accommodated in a typical horizontally curved slab-on-girder bridge system. A literature review covering topics such as the thermal response of curved steel I-girder bridges, proper orientation of guided-type expansion bearing devices, the effect of substructure flexibility on bridge response, and the adverse effects of restrained thermal deformation in steel girder bridges is also provided.

Chapter Three provides a detailed description of the selected in-service bridge around which this work is performed. Additionally, Chapter Three presents the findings document during a field investigation of the selected structure. In Chapter Four the extensive finite element modeling undertaken to complete this work is reviewed, and validation of the modeling strategy is provided.

Chapter Five and Chapter Six present the results and analysis produced by the FE model(s). In Chapter Five, displacement of the superstructure under thermal loads, stresses at the bearings, shear force in the anchor bolts, and stresses in the support piers are analyzed and contrasted against the findings documented during the field investigation (Chapter Three). In Chapter Six, the results from two sets of boundary conditions are compared amongst one another. Chapter Seven contains conclusions established during this work and puts forth recommendations regarding the thermal response of steel I-girder bridges. 


\section{CHAPTER TWO}

\section{Background and Literature Review}

\subsection{Introduction}

Temperature variations (i.e. thermal loading) can have a significant impact on the behavior of continuous steel slab-on-girder bridges. Yet, the effects of thermal loading are not given significant consideration during the bridge design process. Research pertaining to the response of steel girder bridge systems subjected to thermal loading is sparse, with very limited literature available studying the behavior of the superstructure and substructure collectively. The vast majority of investigations have focused on 1) determining the effects of temperature distribution through the depth of composite slabon-girder bridge and 2) stresses in only the superstructure (Emanuel and Hulsey 1976, Theopcharti 1977, Hulsey and Emanuel 1978, Rahman and George 1979, Rahman and George 1980,, Kennedy and Soliman 1987, Emanuel and Taylor 1985, Moorty 1990, Tao 2009). These, and other related studies, are very valuable; however, a detailed analysis of stresses in the substructure were neglected. Furthermore, the majority of these works discuss thermal stresses caused by nonlinear temperature distributions, rather than support restraint. The few authors that have studied the practical effects of thermal loads on steel girder bridge systems, including field investigations, have provided evidence that improper handling of such loads can have significant consequences on bridge integrity and economy (Croft 1994, Moorty and Roeder 1992b, William et al. 2005, McBride 2013). 
Before beginning any meaningful investigation into the behavior of steel girder bridges, sufficient background information must first be covered. This chapter presents detailed explanations regarding the thermal response of continuous steel I-girder bridges with and without horizontal curvature. Also included is a detailed review of the most pertinent literature related to the thermal response of steel girder bridges with horizontal

curvature. Work relating to thermal movements in steel girder bridges is covered, as well as the effects that may occur if thermal movements are not properly accommodated. Lastly, a description of the methods relied upon in $\operatorname{AASHTO}(2003,2007)$ and foreign works for accommodating thermal movements in steel I-girder bridges is discussed.

\subsection{Response of Steel Girder Bridges to Temperature Variations}

Due to daily and seasonal temperature fluctuations (i.e. thermal loading), the superstructure of a steel girder bridge undergoes a certain range of thermal deformation. Thermal expansion of a steel superstructure takes place when the temperature in the environment surrounding a bridge increases relative to a particular ambient value. Conversely, thermal contraction occurs as the temperature decreases. Thermal deformation of a bridge's superstructure consists of displacements and rotations. Effectively permitting thermal deformation is a very significant consideration when designing a steel I-girder bridge. If the steel superstructure is not adequately allowed to undergo a full range of thermal movement, unfavorable behavior may develop throughout the bridge due to the development of internal thermal forces and stresses. Such behaviors include damage to the bearing devices and bridge substructure (i.e. support piers, abutments, bents). Additionally, restrained thermal deformation has been 
found to negatively affect the structural capacity of the steel girders themselves in studies by William et al. (2005) and McBride (2013). Preventing, or at the least minimizing, the development of thermal stresses in a steel girder bridge system is generally accomplished through the strategic employment of bridge expansion bearings. The implementation of expansion bearings seeks to lessen the magnitude of thermal force effects by freely allowing thermal deformation of the superstructure to take place. Bridge bearings are categorized by two primary types of assembly: high-load multirotational (HLMR) bearings and elastomeric bearings. High-load multirotational bearing devices can be categorized into three main types: pot bearings, spherical bearings, and disc bearings. Each particular bearing type provides distinct advantages and disadvantages. The particular type of bearing assembly selected mostly depends on the magnitude of thermal deformation anticipated. This dissertation focuses on a steel I-girder bridge that utilizes HLMR pot bearings.

High-load multirotational pot bearings, as with the other types of HLMR bridge bearings can be further classified into three categories: multidirectional bearings (i.e. free), unidirectional bearings (i.e. guided), and fixed bearings. A fixed bearing, Figure 2.1, restrains thermal displacement of the superstructure while allowing the necessary rotations. Multidirectional and unidirectional bearing assemblies, shown respectively in Figures 2.2 and 2.3, are termed "expansion bearings", as they permit thermal expansion of the attached superstructure. Multidirectional bearing devices (termed "free bearings" herein) allow in-plane horizontal translation in any direction. Unidirectional bearing devices (termed "guided bearings" herein) allow horizontal translation along a single axis while preventing movements in a transverse direction. 


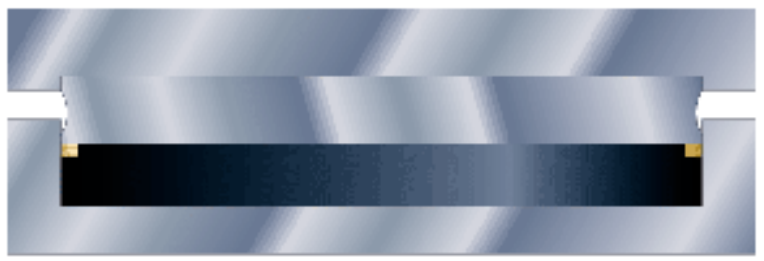

FIXED

Figure 2.1. HLMR pot bearing (fixed bearing)

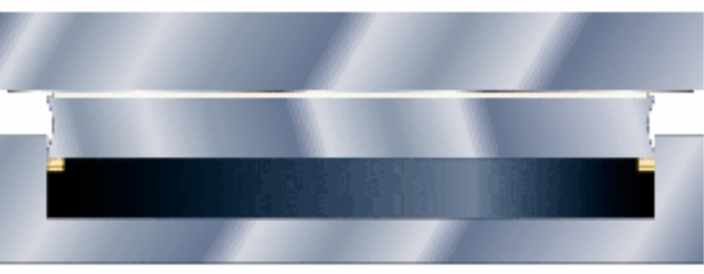

MULTI-DIRECTIONAL

Figure 2.2. HLMR pot bearing (free bearing)

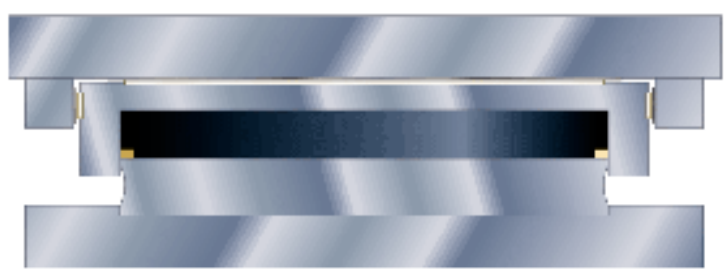

UNI-DIRECTIONAL EDGE-GUIDED

Figure 2.3. HLMR pot bearing (guided bearing) 
Understanding the thermal response of a particular bridge is vital when selecting a suitable bearing arrangement, meaning a bearing arrangement that does not restrain thermal deformation of a bridge's superstructure. An accurate prediction of the magnitude and direction of thermal deformation of a bridge's superstructure is essential, especially when orienting the guided bearings. If not properly aligned during installation, the guided bearings will restrain thermal deformation of the superstructure. Determining how a straight (or tangent) non-skewed steel girder bridge responds to thermal loading is rather straightforward. Thermal deformation occurs primarily along a longitudinal axis (Figure 2.4) and the guided bearings are oriented in a manner that allows superstructure displacement to freely take place. Insignificant displacement in a transverse direction is do occur, but is generally only observed in very wide bridges.

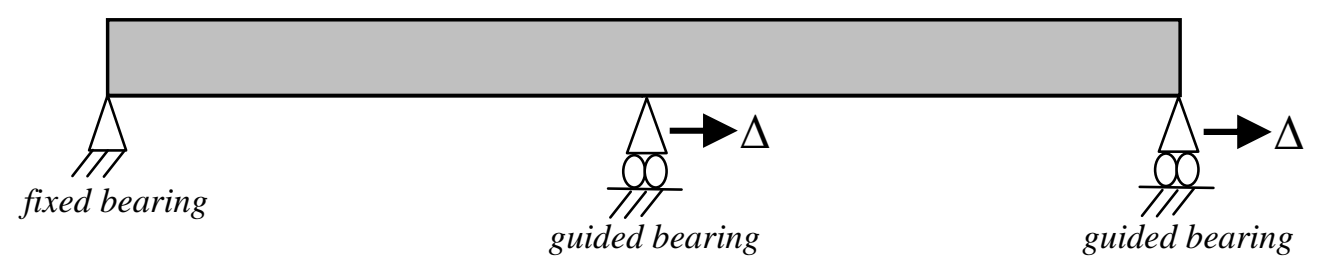

Figure 2.4. Guided bearings on a continuous straight structural member

The thermal response of continuous horizontally curved steel I-girder bridges is drastically different compared to their straight counterparts. As illustrated in Figure 2.5, structural members with horizontal (in-plane) curvature undergo thermal deformation in multiple directions. Horizontal curvature adds a significant degree of complexity to a steel I-girder bridge's behavior when subjected to thermal loading, and therein lays a 
significant challenge for bridge designers. Due to the potential for over-constraining thermal deformation, numerous fixed bearings cannot be implemented. The use of too many free bearings would create stability issues within a structure. Therefore, guided expansion bearings must be used. Due to thermal deformation occurring in multiple directions and guided bearings allowing only unidirectional translation, determining their appropriate orientation is a difficult task.

Several researchers have put forth particular design approaches for calculating the displacement response of horizontally curved girder bridges. Li et al. (2007) and Li and Zao (2009) used closed-form solutions and finite element analysis to determine the inplane response of curved bridges subjected to thermal loads. While this work is in-depth and highly theoretical, the results they provided are difficult to implement in design codes. Roeder $(2002 a, b)$, proposes simple design equations for the response of bridges to thermal loads based on Equation 1.1. This work is the basis for AASHTO (2007) design provisions and commentary. However, curved bridges are not given specific attention.

Traditionally, two principal schemes are followed when orienting guided bearings on horizontally curved girder bridges. The tangential scheme permits thermal deformation of the superstructure at the bearings in a manner tangential to the horizontal curve, while radial movement is restrained. This method is illustrated in Figure 2.5. Minimization of thermal stresses in a steel superstructure is mostly disregarded with this type of alignment. Rather, the superstructure is forced to follow a particular path while undergoing thermal deformation. A major disadvantage with this method is that large transverse forces are produced and must be designed for, which can decrease bridge 
economy. Shown in Figure 2.6, a chordal orientation of the guided bearings permits longitudinal movement at the bearing on a ray directed toward a fixed bearing. The chordal method attempts to minimize thermal forces by aligning the guided bearings so as to permit superstructure movement in a manner that closely mimics its in-plane displacement response. Theoretically, the absence of thermal forces is anticipated under this scheme according to AASHTO $(2003,2007)$. However, in reality, such a state cannot be achieved due to numerous factors.

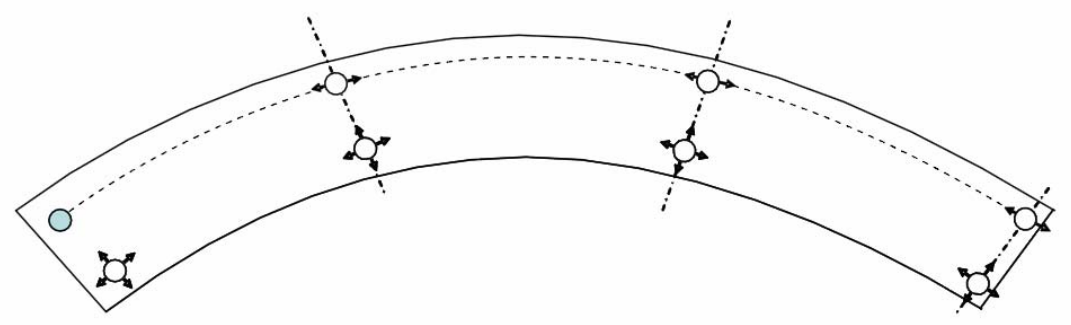

Figure 2.5. Tangential orientation of guided expansion bearings

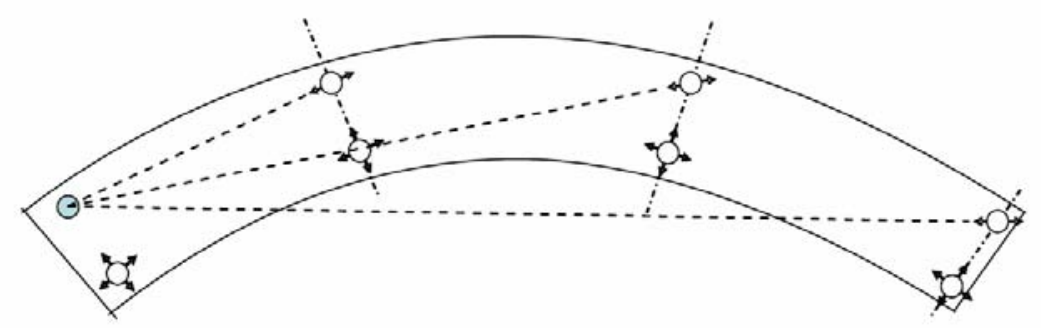

Figure 2.6. Chordal orientation of guided expansion bearings 
First, the thermal deformation a steel member in a chordal manner only applies to uniform temperature variation, where as all bridges actually experience temperature gradients. Second, a locating fixed bearing devices at a stationary point within the structure is required, which may be impossible to achieve. For instance, site conditions or span configuration may prevent erecting a support pier at the necessary location. Thirdly, the rigidity of the concrete bridge deck and superelevation typically prevent thermal deformation from occurring as expected.

\subsection{The Influence of Substructure Flexibility on the Thermal Response of Steel I- Girder Bridges}

In addition to expansion bearings, bridge designers recognize substructure flexibility as a mechanism for accommodating thermal movement of a bridge's superstructure (Hulsey and Emanuel 1978, Moorty and Roeder 1992b, Chen 2008). This is especially true for continuous structures. Lateral deflection of the support piers leads to a state of flexure within the pier columns, and allows thermal deformation of the steel superstructure to occur. Relying on pier flexibility to assist in accommodating thermal deformation of a bridge's superstructure has made the use of multi-span, continuous steel girder superstructures an attractive design choice. However, the use of fixed bridge bearings has become more commonplace as well. Fixed bearings, which do not permit free thermal deformation, introduce a signifcant amount of restraint into a bridge. If numerous fixed bearings are employed, lateral pier deflection becomes the sole means through which internal thermal stresses within the superstructure are prevented. 
This can only occur assuming the piers are not so rigid as to resist lateral deflection. For example, if the supporting piers are too stiff, or rigid, thermal stresses will develop in a bridge. In the superstructure, the expected load-carrying capacity of the steel girders can be reduced due to elevated compression flange stresses near the fixed bearings (McBride 2013). Additionally, thermal stresses will also manifest in the substructure as the in-plane horizontal forces are transmitted to the support piers through the bearing assemblies and bearing anchor bolts. Possible adverse effects include unanticipated shear force and deformation in the anchor bolts, deformation of the bearing devices, and fracture within the concrete supports (Croft 1994). These types of behaviors have not been investigated in a detailed manner. Particularly for horizontally curved bridges, these behaviors may also occur at guided expansion bearings due to their unidirectional functionality. If thermal deformation of the superstructure differs relative to the manner in which the bearings are aligned, thermal forces will develop.

Typically, the potential of the above behaviors to actually occur is neglected as thermal forces are assumed minimal. Substructure flexibility may not only aid in accommodating thermal deformation of a bridge's superstructure, it can be a hindrance to effectively orienting guided expansion bearings as well. As already discussed, guided bearings are given an initial alignment based on a fixed point. However, due to lateral movement of the supporting piers, the location of this point may be highly variable as the bridge undergoes thermal movements. Roeder (2002a, 2002b), which serves as the basis for current design specifications even avoid such scenarios. Therefore, properly orientating the guided bearings in a manner that eliminates the development of thermal stresses may not be feasible for every design situation. 


\subsection{Review of Pertinent Past Work}

Hulsey and Emanuel (1978) used finite element analysis to investigate the thermal response of a slab-girder bridge under varying substructure flexibilities. Three substructure types were considered, including frictionless bearings, non-integral abutment supports, and integral abutments, each modeled using spring elements. After determining an appropriate substructure stiffness for each spring (assuming the piers behave elastically), heat flow calculations were completed in order to apply a temperature load to a slab-stringer FE model. The stringers were modeled as beam elements. The superstructure consisted of four spans of $11 \mathrm{~m}, 26 \mathrm{~m}, 26 \mathrm{~m}$, and $11 \mathrm{~m}(35 \mathrm{ft}, 86 \mathrm{ft}, 86 \mathrm{ft}$, and $35 \mathrm{ft})$, while the pier heights were approximately $5.5 \mathrm{~m}(18 \mathrm{ft})$.

Results from this study showed that as substructure stiffness increases, or as bridge length increases, horizontal forces can develop in non-integral type bridges. Under $\mathrm{a}+34^{\circ} \mathrm{C}\left(60^{\circ} \mathrm{F}\right)$ temperature change, maximum compressive stress in the beams was $33,715 \mathrm{kN} / \mathrm{m}^{2}(4.9 \mathrm{ksi})$ while tensile stresses were minimal. Under a $-55^{\circ} \mathrm{C}\left(-100^{\circ} \mathrm{F}\right)$ temperature change, maximum tensile stress was $49,573 \mathrm{kN} / \mathrm{m}^{2}(7.0 \mathrm{ksi})$ for the nonintegral support type bridge structure. Stress values are almost identical when compared to a frictionless bearing condition. Maximum horizontal thrust values at the pier supports of the non-integral structure were $3,216 \mathrm{kN}$ (7.1 kips) and 2,627 kN (5.8 kips) for the temperature decrease and increase, respectively. Horizontal forces at the piers were shown to be mostly unaffected by the type of abutment.

Moulton (1983) performed a large study documenting behaviors observed on many bridges throughout North America. The purpose of the study was to correlate bridge movements with observed structural damage. It was found that bridges which 
experienced horizontal movements had a high frequency of damage. Under relatively small horizontal movements, damage to the bearing devices and superstructure deformations were noted. Specific bridge types were not discussed, however, the study concluded that damage to bridge components resulting from horizontal movements of the superstructure can be severe.

Through experimental analysis and field observations, Moorty and Roeder (1992a) found that thermal movement in curved steel girder bridges not necessarily be tangential or chordal (as widely recognized and suggest in AASHTO), but may consist of a radial component or be solely radial in direction, depending on bridge geometry. Using a beam element model, it was determined that orienting guided expansion bearings in a chordal manner relative to a fixed point is acceptable for accommodating thermal expansion in a curved steel girder bridge, as reflected in AASHTO $(2003,2007)$ but emphasized that true bridge behavior differs substantially from the simple line element model used. Additionally, a survey of state bridge engineers uncovered that several significant signs of distress had manifested in curved girder bridges, possibly related to thermal deformation of the superstructure. These included anchorage pull-out, concrete spalling of supports and bearing failures. Further evidence of unexpected thermal movement in curved bridges was evidenced by locked finger-joints within several concrete bridge decks. Finger joints are free to move in a tangential direction in order to accommodate the thermal expansion of the superstructure, however, they had become locked on several bridges. Damage to bridge bearing guides was also reported on several curved bridges. These latter two actions are almost certainly the result of radial movement of the superstructure during thermal expansion. 
Moorty and Roeder (1992b) performed a broad parametric study to determine the effect of bridge geometric characteristics, expansion bearing orientation, and substructure stiffness on the thermal response of horizontally curved bridges. A three-span, four girder FE model was created using ANSYS software. Fixed bearings were located at an end abutment, while expansion bearings were located at all other support locations. The total length of the bridge was $600 \mathrm{ft}$ with a central angle of $40^{\circ}$, giving a bridge radius of around $860 \mathrm{ft}$.

Analysis showed that when the expansion bearings are aligned in a tangential manner, radial movement is accommodated by the piers. Tangential displacements of up to 2.14 in. were recorded at the abutment, while a maximum radial displacement of 0.54 in. occurred near the center of the bridge, between the piers. When the expansion bearings were oriented in a chordal manner with respect to the fixed bearings at the abutment thermal expansion occurred mainly along these chords, with a magnitude of translation roughly equal to tangential translation from the previous case. Radial displacement increased with distance away from the fixed bearings. A maximum radial displacement of 0.8 in. occurred near the midspan between the second abutment and nearer pier. At this pier, radial displacement increased by $75 \%$. It was also found that when bearing stiffness is relatively large, thermal movement is accommodated by pier flexure. When pier stiffness is relatively large, displacement takes place through the bearings.

Moorty and Roeder (1992b) also provided findings from a field investigation on the Sutton Creek Bridge in Montana, a $657 \mathrm{ft}$ continuous curved girder bridge, where the effects of thermal loading were explored. Fixed bearings are located at an end abutment 
and consecutive pier while all other support locations utilize tangentially aligned expansion bearings. Observations showed that thermal movement is mostly accommodated by lateral pier deflection, not bearing translation, with radial displacement comparable in magnitude to tangential displacement. At the pier with fixed bearings, significant deflection had occurred. Additionally, it was determined that large bearing stiffness resulted in large radial movements, showing that thermal expansion in a curved steel girder bridge will take place through substructure movement if not accommodated by the expansion bearings.

During field investigations on continuous straight skewed bridges in Wyoming, Croft (1994) found signs of distress in several bridges. The C\&NW RR Overpass, a three-span continuous bridge, had bent bearing bolts at an abutment with fixed bearings. The UPR Overpass, also a three-span continuous bridge, had fixed bearings at an interior pier and expansion (rocker) bearings at all other support locations. Extensive cracking was observed at both abutment walls, and there appeared to be some flexibility in the pier where the fixed bearings were located, suggesting that the point of fixity for the structure was not at the pier. As well, larger than expected longitudinal translation occurred in the expansion bearings at one abutment, while smaller than expected longitudinal translation occurred at the other abutment. Girder translations were approximately $1 / 2$ in. with a bridge deck temperature of $25-30^{\circ} \mathrm{C}$.

The three-span, continuous Laramie River Bridge - Curtis Street and Casper Creek Bridge were both found to be in poor condition. Each bridge employs fixed bearings at one end abutment, with expansion (rocker) bearings placed at the other support locations. On both structures, bent bearing bolts were found at the fixed 
bearings. On the Laramie River Bridge, overall longitudinal movement of the superstructure was very poor. The expansion bearings were designed to allow $0.44 \mathrm{in}$. of translation, however, observation found that they were at their maximum rotational limit after minimal translation. The fixed bearings had translated up to $0.20 \mathrm{in}$. On the Casper Creek Bridge, small transverse translation was observed at an abutment expansion bearing due to loss of substructure stiffness at the fixed abutment end.

The BNRR Overpass, a three-span continuous bridge, was in very poor condition as well. An abutment with expansion (rocker) bearings displaced, due to soil settlement issues, causing the expansion joint in the concrete deck to become locked, restraining thermal expansion of the superstructure. The fixed bearing bolts at the opposite abutment were found to be bent, providing evidence that the thermal expansion was significantly restrained at this location.

Samaan et al. (2002) used FEA to study the thermal movement of a curved, spread-box girder bridge with expansion bearings aligned in a chordal manner to a fixed point and tangent to the curve. Using two-span, four-girder FE models, it was found that radial reactions due to thermal loading are much larger when guided expansion bearings are oriented tangentially, compared to in a chordal manner. The largest horizontal reactions occurred when fixed bearings were located at the interior pier and tangentially aligned expansion bearings were placed at the two abutments.

The New York Department of Transportation, NYDOT (2005), determined that function loss in an expansion (rocker) bearing causing restrained longitudinal movement was blamed for the partial failure of the Dunn Memorial Bridge. In 1987, an inspection report found that certain bearings, at different supporting piers, had displaced $1.7 \mathrm{in}$. and 
0.9 in. respectively, in the same direction. Air temperature at this time was $45^{\circ} \mathrm{F}$. In 1990, inspection records showed that the bearings supporting Span 12 were titled 2.56 in., while Span 11 bearings were tilted 1.75 in. An inspection report in 2003 showed that the bearings supporting a particular span were tilted 3.4 in., 0.9 greater than the design limit, while other bearings were tilted $1.0 \mathrm{in}$. Under the temperature conditions at the time, all rocker bearings should have been approximately vertical.

Shifting of the superstructure, due to vehicle braking, temperature loads, etc., likely caused the rocker bearings to become misaligned and "frozen" in one span, thereby requiring all thermal movement to be accommodated by a relatively slender supporting pier. As the pier deflected over time, the rocker bearings over-rotated and became unstable, causing the superstructure to collapse down onto the pier. Nonlinear finite element analysis of the deflected pier found that concrete cracking initiated once the pier deflected 2.5 in, corresponding to a horizontal load of 141 kips.

Chen (2008) performed extensive finite element analysis to examine the effect of bearing orientation, bearing stiffness, and substructure flexibility on the response of curved steel box-girder bridges subjected to thermal loading. It was determined that locating fixed bearings at an interior pier leads to more preferable bridge behavior under thermal loading, and orienting guided expansion bearings toward the bridge's stationary point resulted in lower resultant horizontal forces in the bearing guides. Guide forces were largest when bearings are oriented toward a pier with fixed bearings that did not coincide with the bridge's stationary point. When expansion bearings are aligned tangent to the curve, radial movement is primarily accommodated by lateral deflection of the supporting piers. Perhaps most significant, it was determined that expansion bearings 
oriented in the chordal manner become less accommodating of superstructure thermal movement as pier flexibility increases. This shows that the method for expansion bearing orientation in AASHTO $(2003,2007)$ may only be preferable when bearing stiffness is significantly lower than pier stiffness.

\subsection{AASHTO Design Provisions and Foreign Guide Notes Relating to Thermal Deformation}

Over the past two decades, AASHTO has sought to provide specifications and recommendations for bearing selection and guided bearing orientation on horizontally curved steel girder bridges. The Federal Highway Administration (FHWA) created the Consortium of University Research Teams (CURT) in the 1960s to develop design specifications for horizontally curved bridges. The Curved Steel Bridge Research Project (CSBRP) was initiated in 1992 to improve upon the specifications developed by CURT. While these two initiatives are widely recognized for their respective efforts to provide design specifications for curved bridges, thermal response was not examined extensively. It wasn't until works several works Moorty (1990) and Moorty and Roeder (1990, 1992a, 1992b) that the thermal response of curved bridges was investigated in detail. Results from their respective works are reflected in past and current AASHTO design specifications.

The 1993 AASHTO Guide Specifications for Horizontally Curved Steel Highway Bridges, (AASHTO 1993), was the second set of guide specifications adopted by AASHTO providing design provisions for curved steel girder bridges. Within these provisions, it is stated that thermal movement should be allowed in directions radiating 
from fixed points, and if properly accounted for, these movements will not affect the state of stress in the superstructure. It is stated that thermal forces may be disregarded during superstructure design in curved bridges with practical proportions, but note, "practical proportions" were not specified. It is not uncommon for steel I-girder structures to have span lengths approaching $250 \mathrm{ft}$.

Similar, albeit more detailed commentary is found in the 2003 AASHTO Guide Specifications for Horizontally Curved Steel Girder Highway Bridges (AASHTO 2003). Within these specifications, slightly more detail is provided regarding the thermal response of curved I-girder bridges. AASHTO 2003 states that thermal forces resulting from uniform temperature loads are fully mitigated if guided expansion bearings are aligned along a ray directed toward a "fixed point" (i.e. aligned in a chordal manner). The 2007 AASHTO LRFD Bridge Design Specifications (AASHTO, 2007) mirror AASHTO (2003) stating that when guided expansion bearings are aligned in such a manner no thermal forces are generated when the superstructure is subject to uniform temperature changes.

The fixed point referenced in AASHTO $(2003,2007)$ is typically recognized as a fixed bearing at an interior support pier or end abutment, but is not clearly stated. Theoretically, this point is a singular location within the structure that experiences no translation as the bridge undergoes thermal deformation. In reality, temperature variations and distribution throughout a bridge is not uniform, and the location (or even existence) of a fixed point is highly variable depending on bridge geometry, boundary conditions, and substructure flexibility. If the fixed bearings towards which the guided bearings are aligned are not stationary during thermal movements, the guided bearings 
will not function as expected. If located at an interior pier, the fixed bearings are likely to move as the pier deflects. Chen (2008) noted that a chordal orientation of the guided expansion bearings on a curved bridge becomes less accommodating of thermal deformation as substructure rigidity decreases. Furthermore, the influence of substructure flexibility on the thermal response of steel girder bridges is not given much consideration as it pertains to bearing orientation. AASHTO (2007) acknowledges this, noting that aligning the guided bearings toward a single fixed point is often impractical in many bridges.

Contrary to information in American bridge design specifications, available foreign guide notes recommend a different orientation scheme for guided bearings on horizontally curved bridges. The Steel Bridge Group within the Steel Construction Institute, located in Great Britain, recommends orienting guided expansion bearings in a tangential manner. This type of arrangement was illustrated in Figure 2.5. The reasoning behind this is discussed in Hendy and Iles (2010). With this type of bearing arrangement, thermal deformation of the superstructure is forced, by design, to follow the curve and is preferred because installation of the bearing devices is simplified. However, since radial displacement of the superstructure is not permitted and thermal deformation is required to follow a certain path, large forces are likely to develop in the bearing guides and substructure elements. The chordal orientation recommended in AASHTO is considered acceptable, but is not considered ideal. According to Hendy and Iles (2010), a major disadvantage with the chordal orientation of guided bearings is that the expansion joints will experience transverse movements and this behavior is not easily accommodated. 


\subsection{Summary}

The literature reviewed in this chapter mostly supports the recommendations provided in AASHTO (2003, 2007) pertaining to expansion bearing orientation for continuous horizontally curved steel I-girder bridges. However, these studies generally rely on relatively small sample structures (e.g. three spans or fewer) and points of fixity at a single location. In addition, while chordal alignment of the guided expansion bearings may be preferable to any other orientation scheme, Moorty and Roeder $(1992 a, b)$ showed that thermal forces are not fully prevented. Chen (2008) demonstrated that the method for orienting expansion bearings for minimizing thermal stresses given in AASHTO is only appropriate under certain conditions and that the substructure must accommodate unexpected thermal movements. The method recommended by the Steel Construction Institute (Hendy and Iles 2010) has been shown to allow the development of large thermal forces, compared to the scheme favored in AASHTO.

It was also shown that detrimental behaviors within a bridge's substructure can occur if thermal deformation of the superstructure is hindered. Croft (1994) provided evidence from several slab-on-girder type bridges that retrained thermal movements had led to undesirable consequence such as bearing anchor bolt deformation and damage to supporting elements (i.e. piers, abutments). NYDOT (2005) showed that thermal movements within a steel girder bridge may not occur as predicted and such unanticipated movements do affect structure integrity and safety. Also, substructure flexibility, pier flexure specifically, is highly influential to the manner in which a bridge responds to thermal loading. 


\section{CHAPTER THREE}

\section{Man Bridge Description and Field Investigation}

\subsection{Introduction}

The Man Bridges, seen in Figure 3.1, are a pair (one Northbound, one Southbound) of continuous horizontally curved steel I-girder bridges located in southern West Virginia, designed and constructed in 2005. Each nearly identical twelve-span structure is divided into two, six span units separated by an expansion joint. The superstructures are continuous slab-on-girder structures with four steel plate I-girders in cross-section. The bearing arrangements on each unit employ numerous fixed and guided expansion bearings, providing a significant level of restraint against in-plane superstructure deformation.

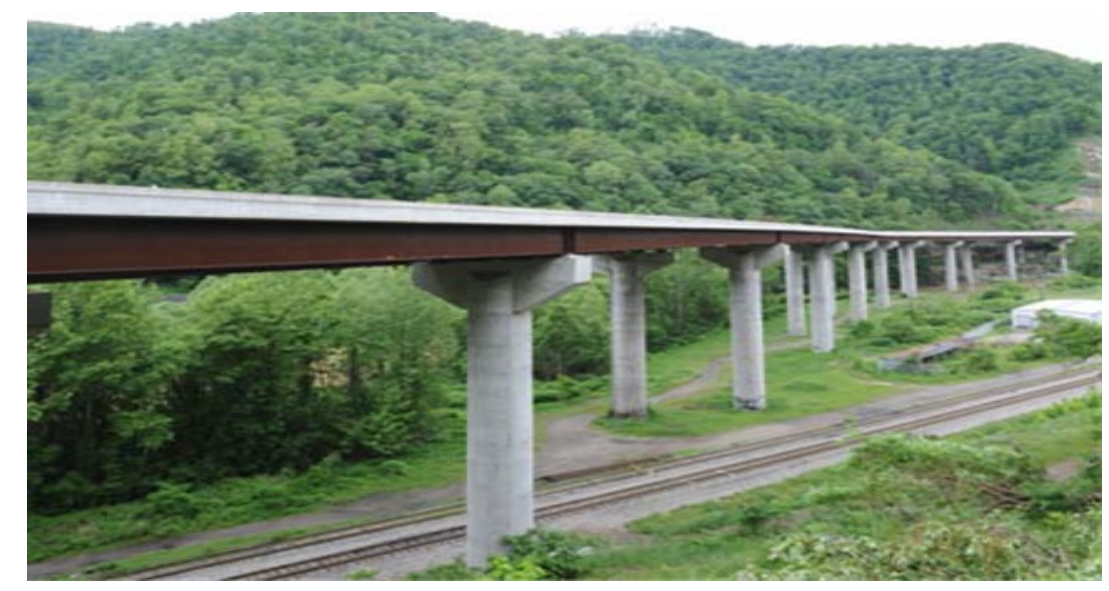

Figure 3.1. The Man Bridges

For the purpose of this dissertation, focus is placed on the Northbound structure (closest pictured in Figure 3.1). Due to the bridge's complex geometry and the number of fixed and guided bridge bearings employed, it serves as an excellent model to perform 
the needed investigations in order to accomplish the goals and objectives of this study. A detailed description of this particular structure, from herein referred as the "Man Bridge", is provided in this chapter, along with findings made during a field investigation assessing the bridge's condition.

\subsection{Bridge Description}

As mentioned previously, the Man Bridge is divided into two, six span units. Unit 1 consists of Spans 1-6, resting on Piers 1-6 and Abutment 1. The geometry of Unit 1 is somewhat complex, consisting of a horizontal curve with a radius of $1,528 \mathrm{ft}$, two spiral curves, and a chorded (straight) section. The total length is $1,130 \mathrm{ft}$. Unit 2 consists of Spans 7-12, resting on Piers 6-11 and Abutment 2. A small portion of Span 7 in Unit 2 consists of a spiral curve, while the rest of the structure is on a horizontal curve with a radius of 1,650 ft.. Unit 2 has a total length of 1,068 ft. These characteristics can be seen in Figures 3.2-3.4.

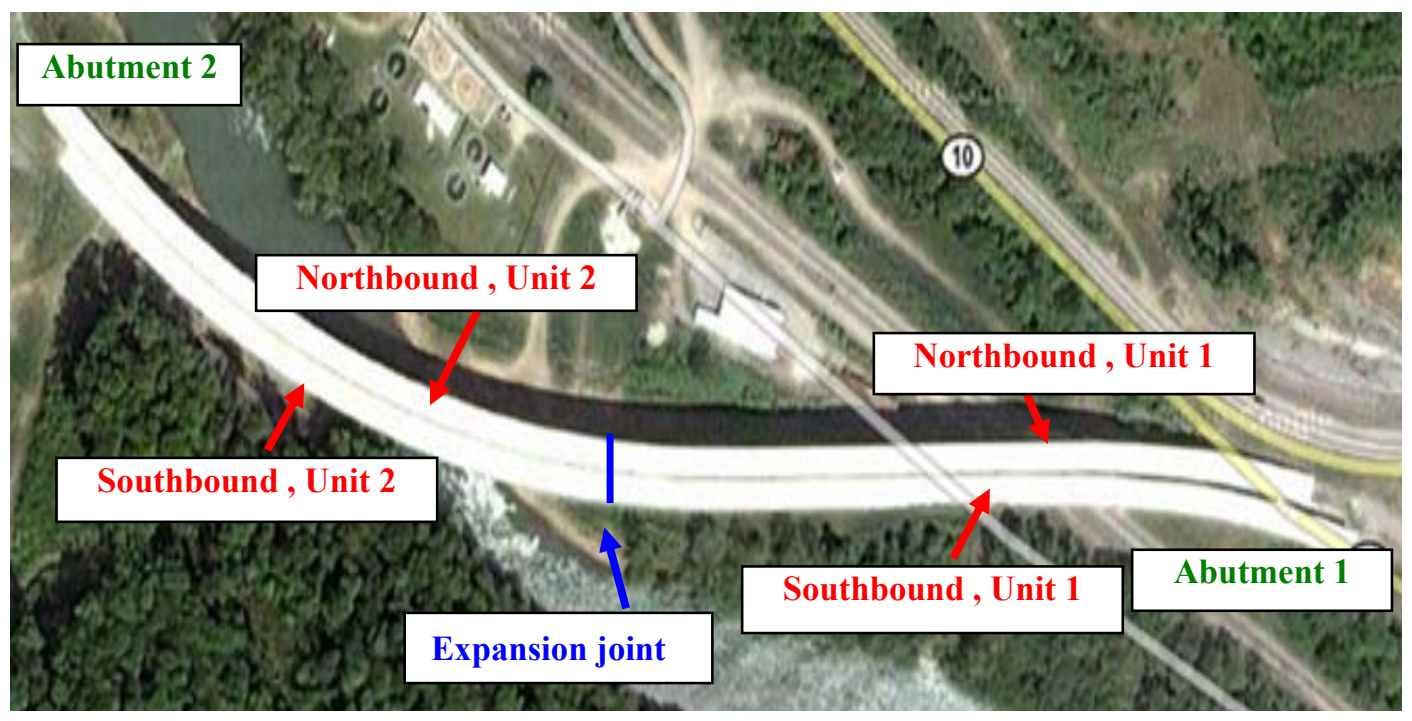

Figure 3.2. Overhead view of the Man Bridge (provided by Google Maps) 
Basic dimensional layouts of Unit 1 and Unit 2 are shown in Figures 3.3 and 3.4, respectively. Some basic characteristics of the structures include lengthy spans, deep web plates, tall pier columns, and significant deck superelevation. The bridge consists of four steel I-shaped plate girders in cross-section. Web depth varies from 78 in. to 99 in. throughout the length of the bridge, while span length varies from $149 \mathrm{ft}$. to $237 \mathrm{ft}$. Each unit rests on six reinforced concrete hammerhead style piers and an end abutment. Pier 6 is shared between the two units; however, the superstructure is discontinuous at this location. The support piers are aligned in a radial manner. Height of the supporting piers ranges from $35 \mathrm{ft}$ to $88 \mathrm{ft}$ and diameter of the pier columns are $10 \mathrm{ft}$ or $12 \mathrm{ft}$.


Figure 3.3. Unit 1 layout 


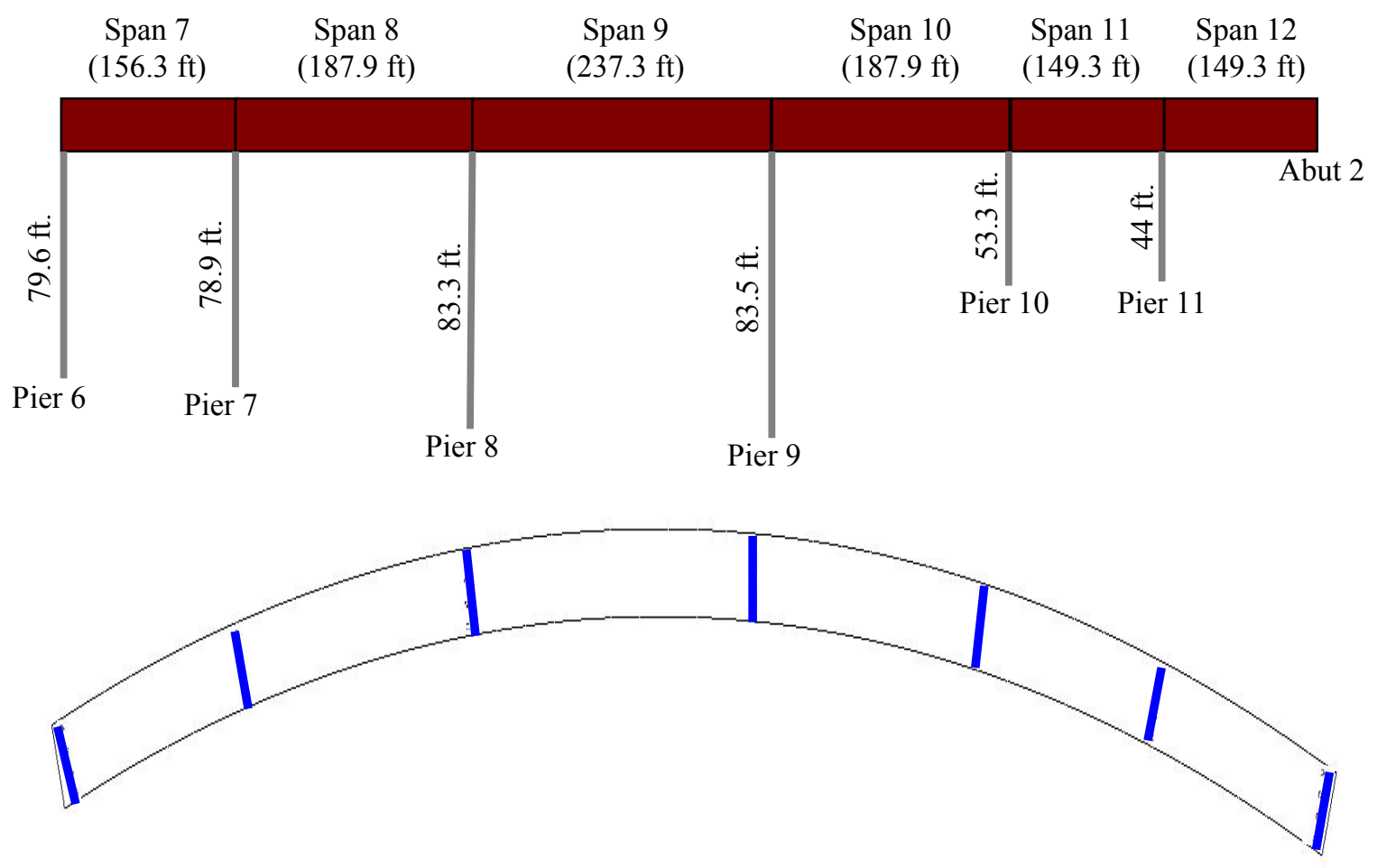

Figure 3.4. Unit 2 layout

\subsection{Bridge Bearing Arrangements}

The main focus of this study lies with examining the behavior of the Man Bridge at the support locations, in the vicinity of the bearing devices. This includes investigating the influence that the designed bearing arrangement has on the response of the bridge when subjected to uniform thermal loads. Hence, a detailed overview of the bearing arrangement implemented on the Man Bridge is discussed here. A sample pot bearing, as used on the Man Bridge, is shown in Figure 3.5. A total of 56 pot bearings are utilized on the bridge, consisting of fixed, non-guided (free) and guided expansion bearings. 


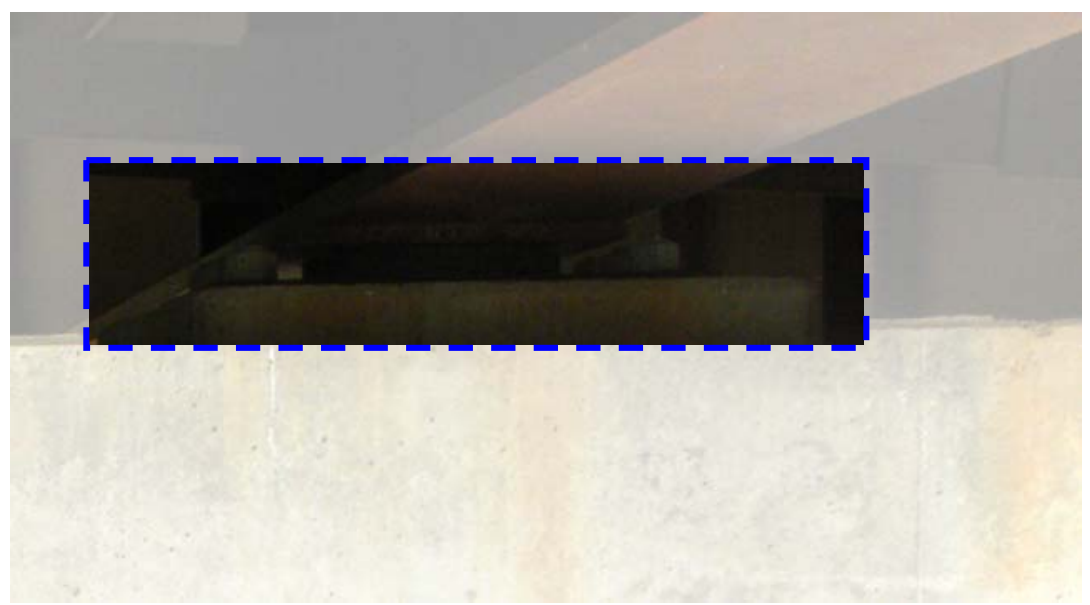

Figure 3.5. Pot bearing(s) employed on the Man Bridge

The bearing arrangements for Unit 1 and Unit 2 are shown in Figures 3.6 and 3.7, respectively. Fixed bearings are located at Piers 2-5 in Unit 1 and at Piers 7-9 in Unit 2. Guided and non-guided expansion bearings are located at all other support locations. It is apparent from Figures 3.6 and 3.7 that a significant amount of restraint against thermal expansion of the steel superstructure is inherent in the Man Bridge due to the numerous fixed and guided bearings. Thus, the designed bearing arrangement is not accommodating of thermal movement within the superstructure, and so, lateral deflection of the supporting piers must occur in order to minimize the development of thermal stresses (within the superstructure). Without contacting the bridge's designer, it is impossible to determine whether or not the supporting piers are intended to behave in such a manner. Nonetheless, it is a certainty that the supporting piers play a signifcant role in how the bridge system responds to thermal loads. Additionally, since fixed bearings are located at many support piers, proper initial orientation of the guided bearings is not straight-forward. 




Figure 3.6. Designed bearing arrangement for Unit 1

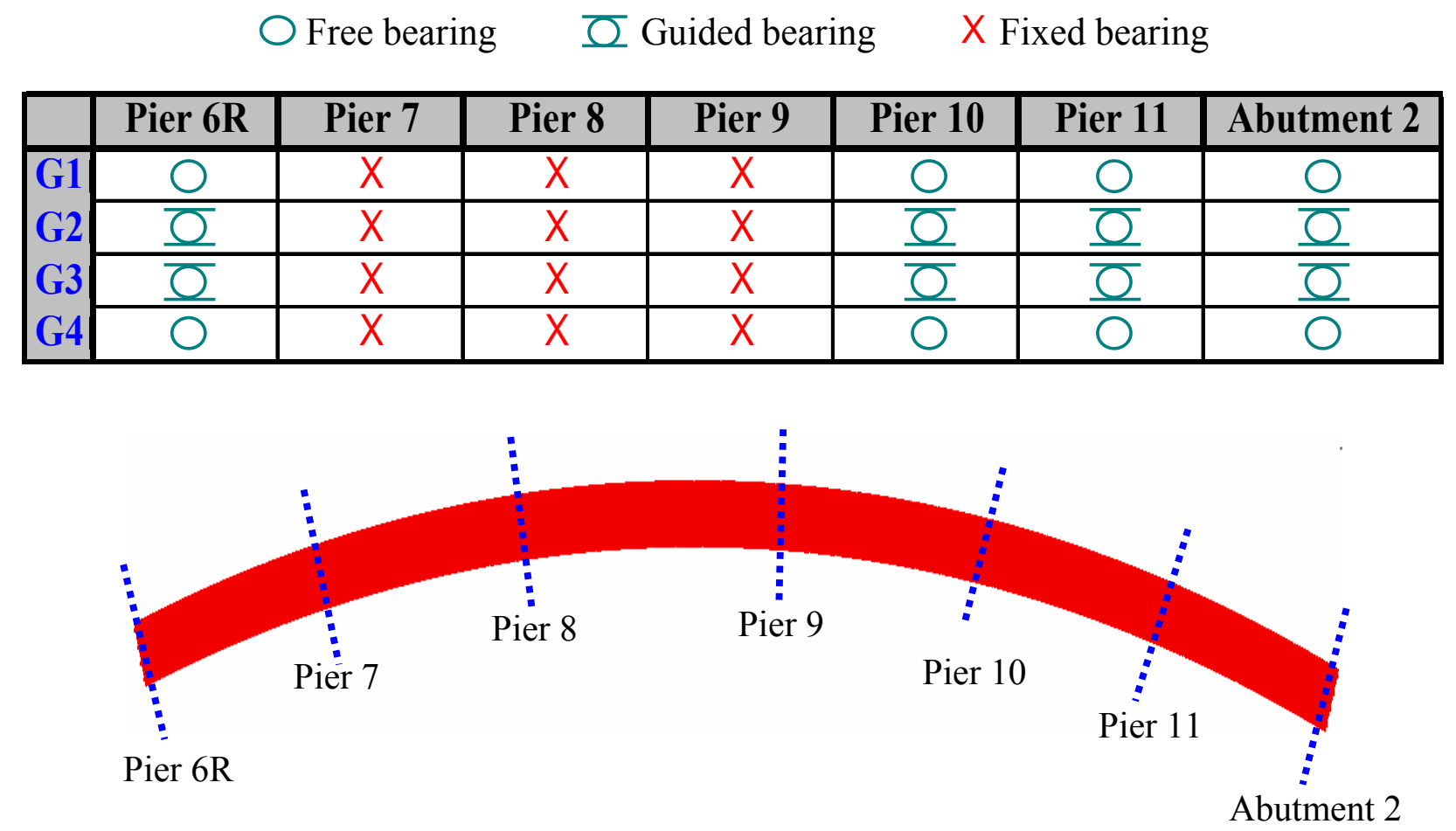

Figure 3.7. Designed bearing arrangement for Unit 2 


\subsection{Field Investigation of the Man Bridge}

\subsubsection{Introduction}

Shortly after construction of the Man Bridge was completed, several peculiar observations were made during subsequent inspections of the structure. Among them were out-of-plane deformation of the steel I-girder web plates, significant cracking in the concrete support piers, deformation at several bearings and deformed bearing anchor bolts. All of these phenomena occurred prior to the bridge being opened to traffic. Therefore, the structure could have only been subjected to construction live loads, selfweight dead load, and environmental loads (i.e. temperature loads). Given the restraining nature of the designed bearing arrangement, it is believed that restrained thermal movement of the steel I-girder superstructure has resulted in the observed behaviors.

A field investigation of the Man Bridge was completed by Dr. Samir Shoukry and his research team in July of 2009 to assess its condition and document the unfavorable behaviors. The investigation focused on examining the bearings and anchor bolts, cracking in the concrete support piers, and measuring the deformation of the steel I-girder web plates. A full report of the findings can be found in Shoukry et al. (2012). For the purpose of this study, only findings regarding behavior at the bearings (translation and deformation), deformation of the anchor bolts, and cracking in the support piers is presented.

\subsubsection{Anchor Bolt Deformation}

At many of the support locations throughout the bridge, several of the steel bearing anchor bolts had undergone out-of-plane deformation (i.e. lateral bending) at the 
time of the field investigation. Examples of this behavior are shown in Figures 3.8, 3.9, and 3.11. The magnitude of out-of-plane deformation of the bolts was not measured, however, the figures below provide significant insight on the extent to which the bolts are deformed. It is important to realize that separation of bearing components seen in Figures 3.8-3.11 is not permitted. Thus, separation of the various bearing components is very unlikely to have been present at the time of installation. For reference, Figure 3.10 is a good example of how bearing components ought to be.

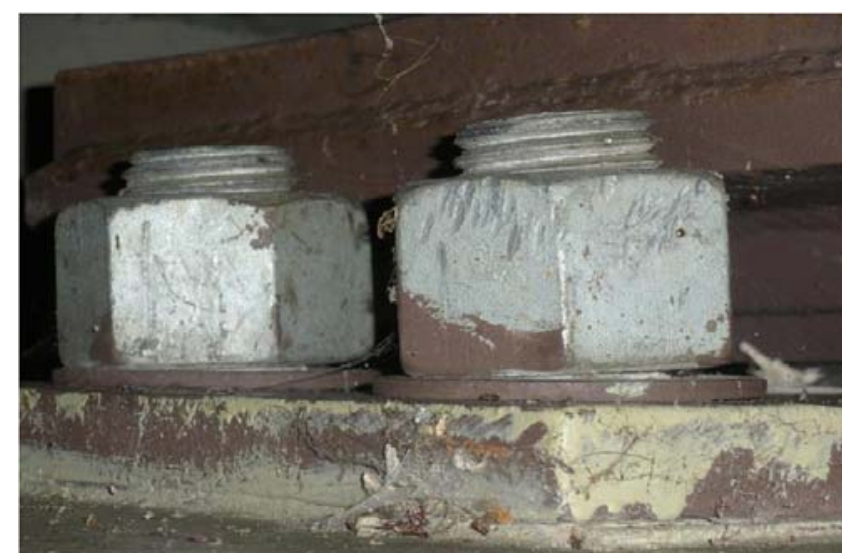

Figure 3.8. Bent anchor bolts at Abutment 1 (Girder 3) (Guided bearing)

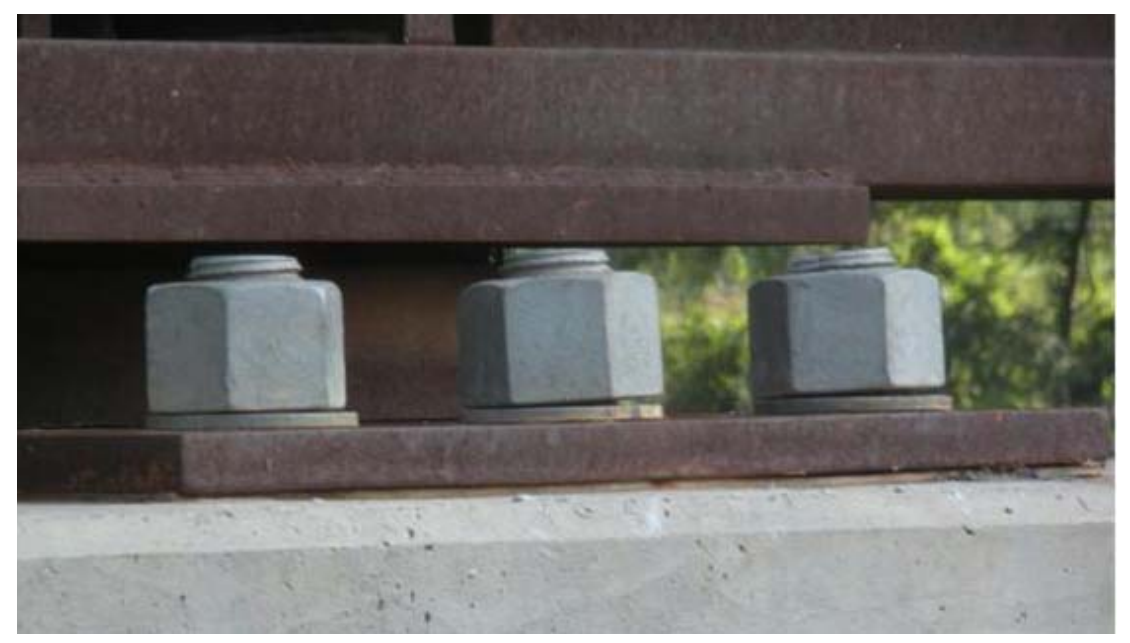

Figure 3.9. Bent anchor bolts at Pier 5 (Girder 2) (Fixed bearing) 


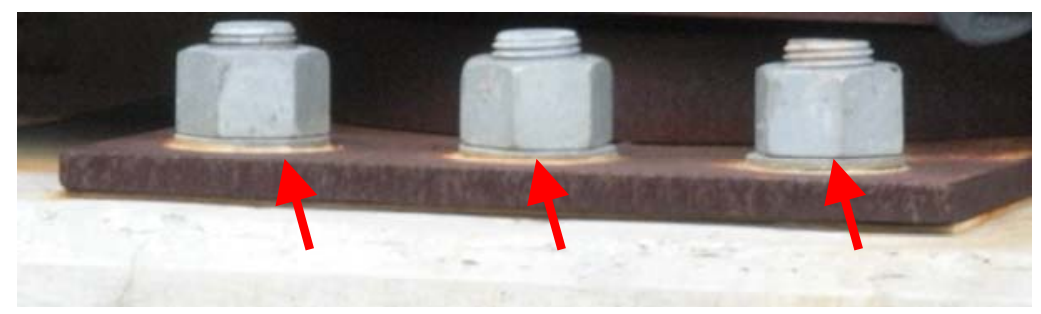

Figure 3.10. Undeformed anchor bolts.

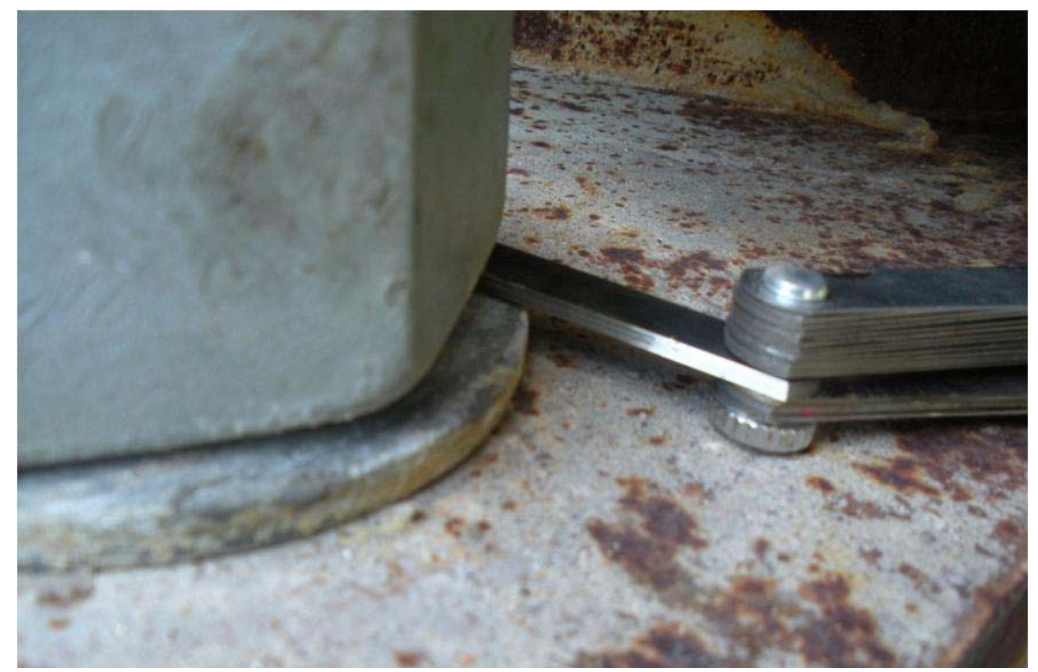

Figure 3.11. Visualization of the extent to which some anchor bolts are bent out-of-plane (Pier 5, Girder 4, fixed bearing)

As seen in Figures 3.8, 3.9, and 3.11 deformation of the bearing anchor bolts has undeniably occurred at several locations throughout Unit 1 of the bridge. Unfortunately, deck superelevation throughout a portion of the bridge did not allow for safe underbridge access, by way of a snooper truck, to the majority of Northbound Unit 2. However, under-bridge access to the Southbound Unit 2 structure was achievable. Similar to Northbound Unit 1, anchor bolt deformation was observed at several bearing 
locations. Due to geometric and design similarities shared by the Northbound and Southbound structures, it can be stated with confidence that deformed anchor bolts would likely be found throughout Northbound Unit 2 as well.

Outside of any large, unforeseen external loads being applied to the anchor bolts, the only forces capable of causing such deformation are horizontal loads. Such loads include environmental loads (i.e. thermal loads due to temperature variations), seismic loads, and wind loads. Seismic activity leading to the observed bolt conditions may be disproved after reviewing seismicity reports around the time after bridge construction. Using data from the Southeastern U.S. Seismic Network (Chapman et al. 2007), it was found that no seismic activity took place that could have affected the Man Bridge with any significance prior to the first time the adverse conditions were observed.

Through simple examination of the deformation pattern, wind load as a probable cause for such behavior can be disproved. The deformed bolts are bent in a manner parallel to the bottom flange of the I-girders, as shown in Figure 3.12. Also, it is highly unlikely, if not impossible, for wind loads to act on the structure in such a way, and with a large enough resultant force to cause the anchor bolts to deform in the manner observed.

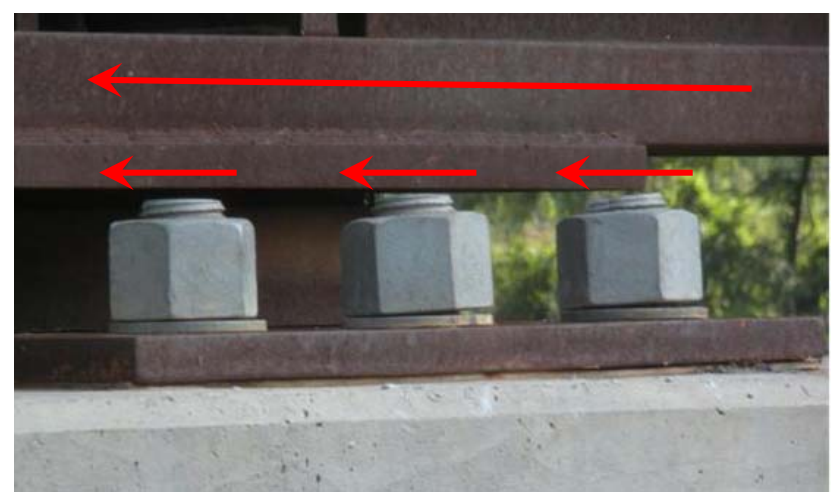

Figure 3.12. Anchor bolts bent in a manner parallel to the girders 
Thus, reactionary horizontal forces due to restrained thermal movement of the steel I-girder superstructure remains the only likely means through which the anchor bolts could have deformed in the manner observed. In the preliminary, this hypothesis is based on 1) the manner in which the bolts are bent and 2) in the absence of strong seismic activity, leaving only thermal loads having capability of producing large horizontal forces.

The presence of bent anchor bolts is similar to behavior found by Croft (1994), where it was determined that deformed bearing anchor bolts were a result of restrained thermal movement of the superstructure on several steel girder bridges. Finding bent anchor bolts at the locations of fixed bearings (Figures 3.9, 3.11) is not unexpected. If the rigidity of the support piers is relatively large and the bearing device does not permit translation of the superstructure (e.g. fixed bearings), deformation of the anchor bolts, support pier cracking (discussed in Section 3.4.3), or a combination of these actions becomes the means through which internal stresses due to thermal loads are alleviated. Otherwise, thermal stresses will develop in the steel girders, negatively impacting the load carrying capacity of the superstructure.

Interestingly, deformed anchor bolts were observed at locations employing guided expansion bearings as well. Bent anchor bolts were found at Abutment 1 (Figure 3.8) and Pier 6 (Southbound), indicating that thermal movement of the superstructure is restrained at the expansion bearings too. This provides evidence that the guided expansion bearings, oriented in accordance with AASHTO $(2003,2007)$, are not accommodating thermal movement of the superstructure. Ultimately, any thermal 
movement not permitted by the bridge bearings will be accommodated by the support piers, and lead to the development of thermal stresses throughout the substructure.

\subsubsection{Support Pier Cracking}

In addition to the deformed anchor bolts, many of the reinforced concrete piers supporting the bridge's superstructure presented significant cracking. The high amount of restraint inherent in the bridge due to the numerous fixed and guided bearings means that the supporting piers play a considerable role in accommodating thermal movement of the superstructure. The piers accommodate this movement through lateral deflection. However, if the rigidity of the piers is relatively large, resistance to lateral deflection will result in the development of thermal forces, ultimately leading to undesirable conditions, such as cracking in the concrete media at the top of the piercap. Consequently, according to observations made during the field investigation of Unit 1, it seems that such behavior has taken place.

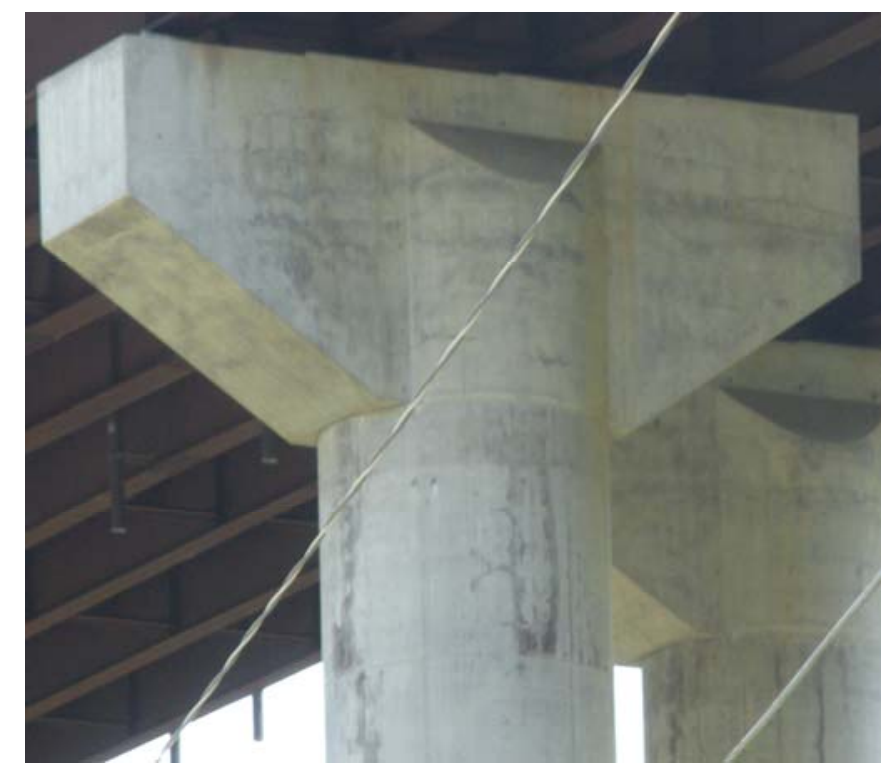

Figure 3.13. Typical reinforced concrete hammerhead pier. 
Concrete cracking, not attributable to shrinkage or other internal effects within the concrete media, were found on a majority of support piers that were accessible. This behavior is prevalent throughout the piercaps and is especially notable in the vicinity of the bearings. Figure 3.14 shows a significant crack emanating from underneath a bridge bearing. A crack of this size and in this approximate location was found on every pier examined. The crack originates beneath the masonry plate and propagates towards the edge of the piercap and down the outer surface.
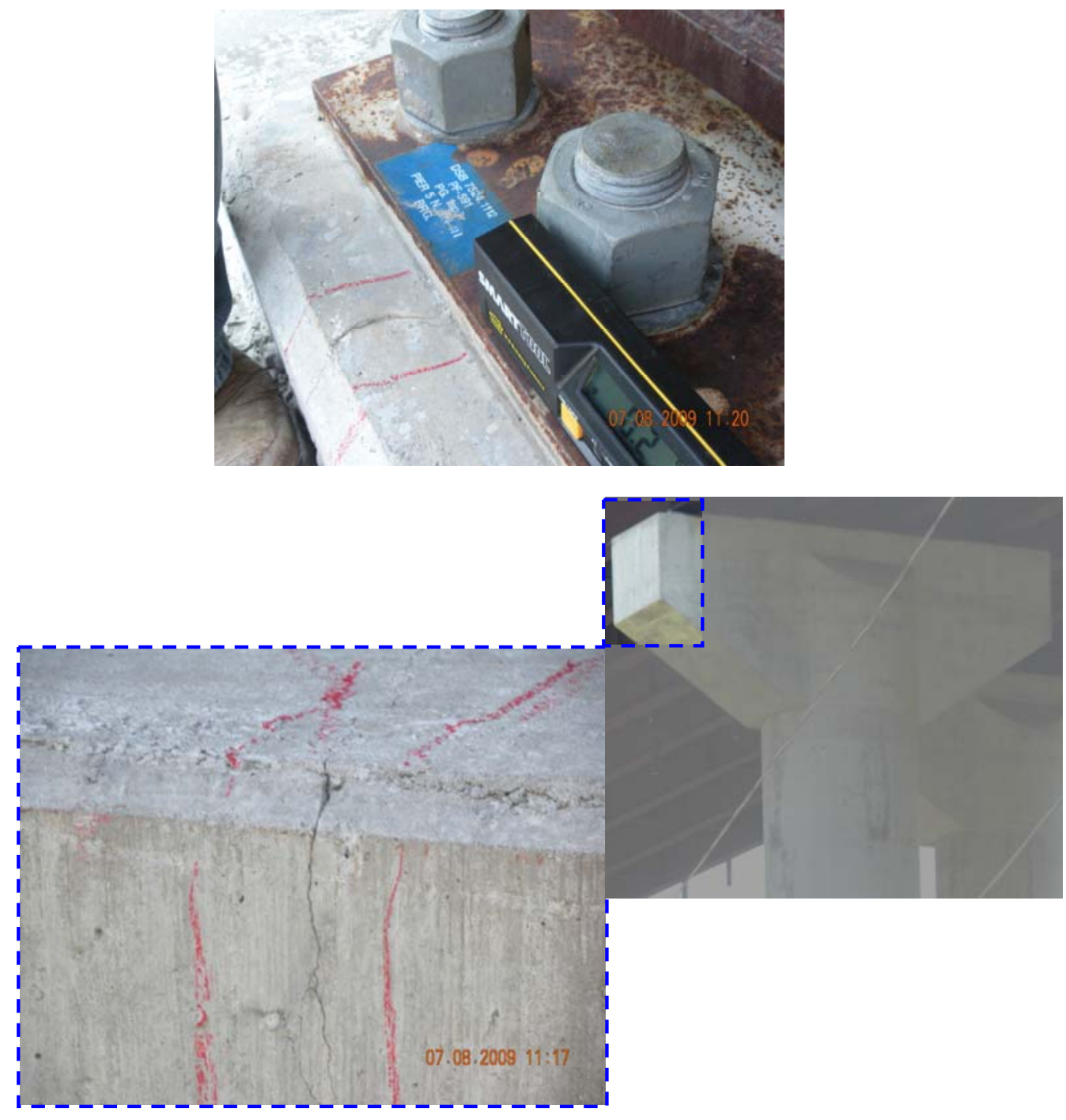

Figure 3.14. Structural crack originating under the bearings, found on every pier 
Figures 3.15-3.18 provide further evidence of the cracks found in the piers throughout Unit 1. These piers include Pier 1, Pier 2, Pier 4, and Pier 5. Within these figures, cracks similar to those shown in Figure 3.14, as well as cracks in other locations on the piercaps are shown.
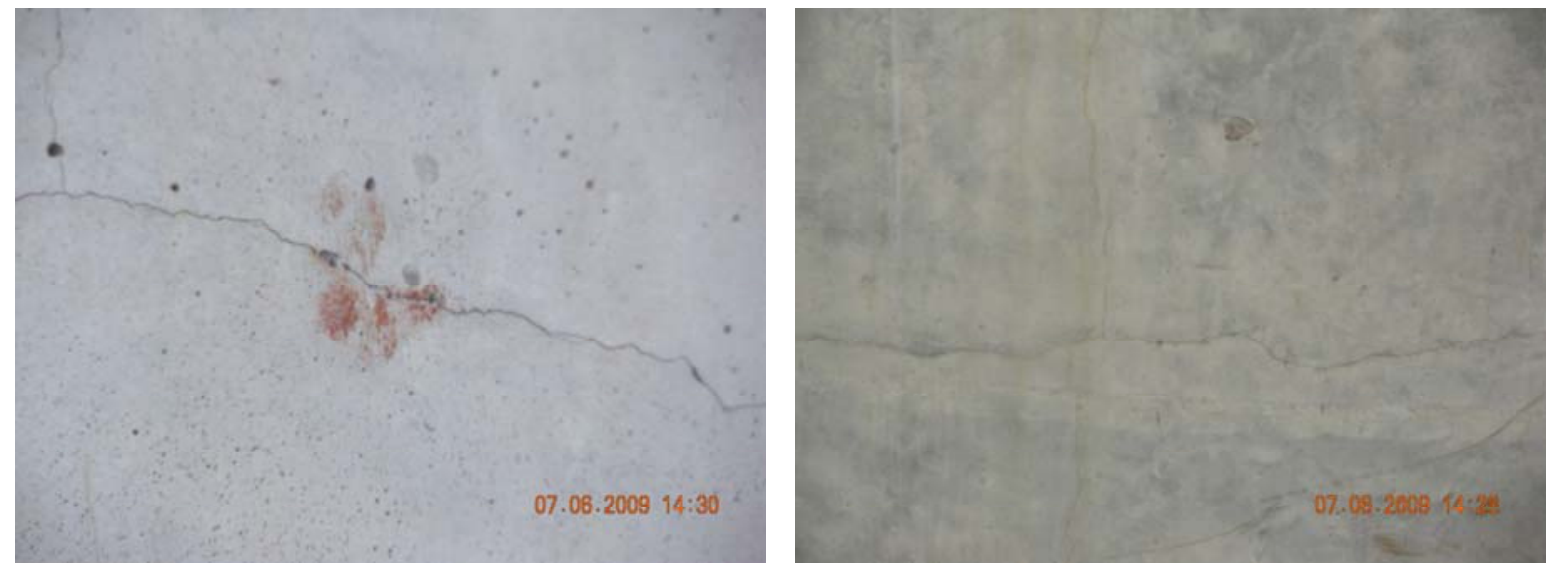

Figure 3.15. Cracks found on Pier 1
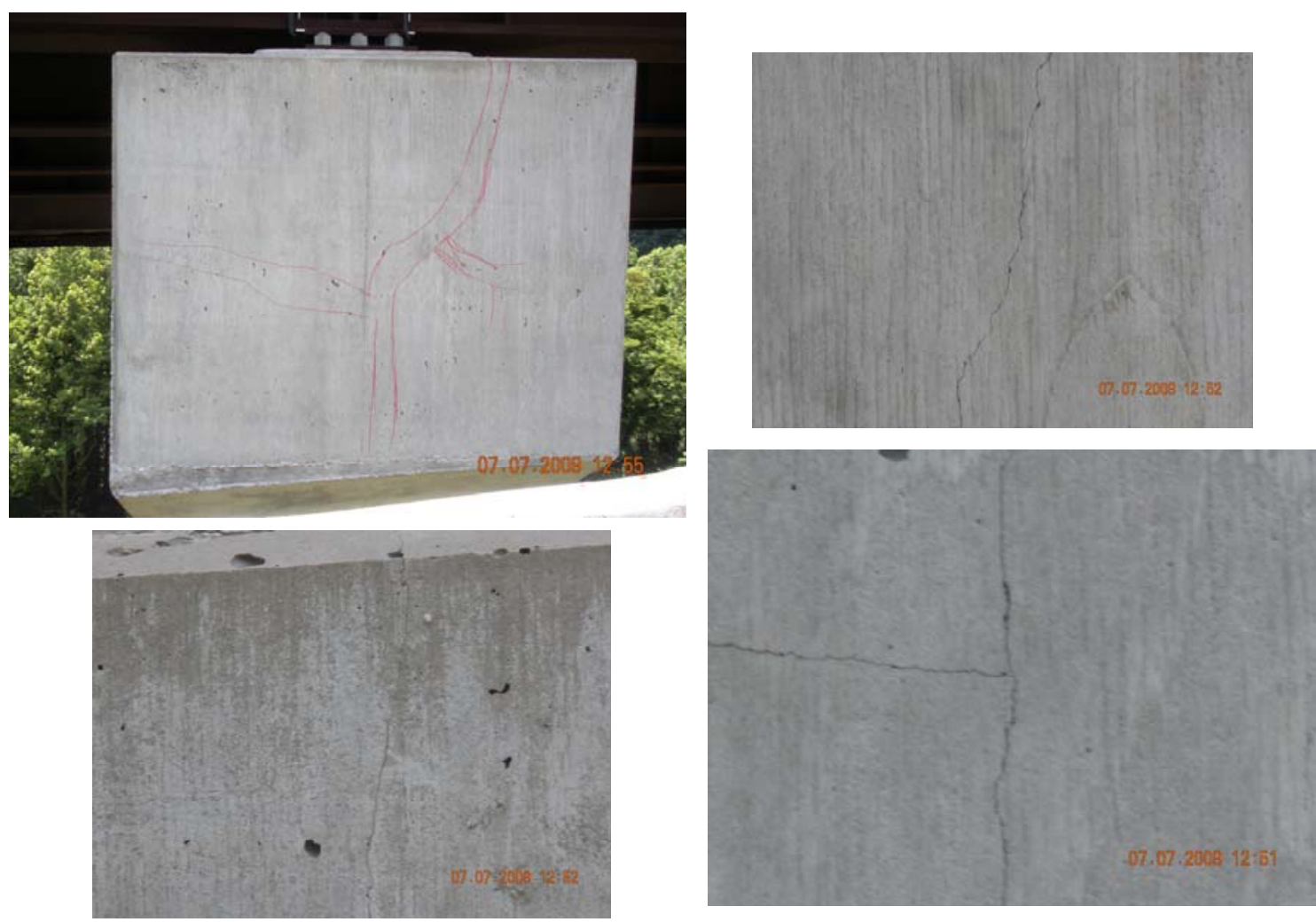

Figure 3.16. Cracks found on Pier 2 


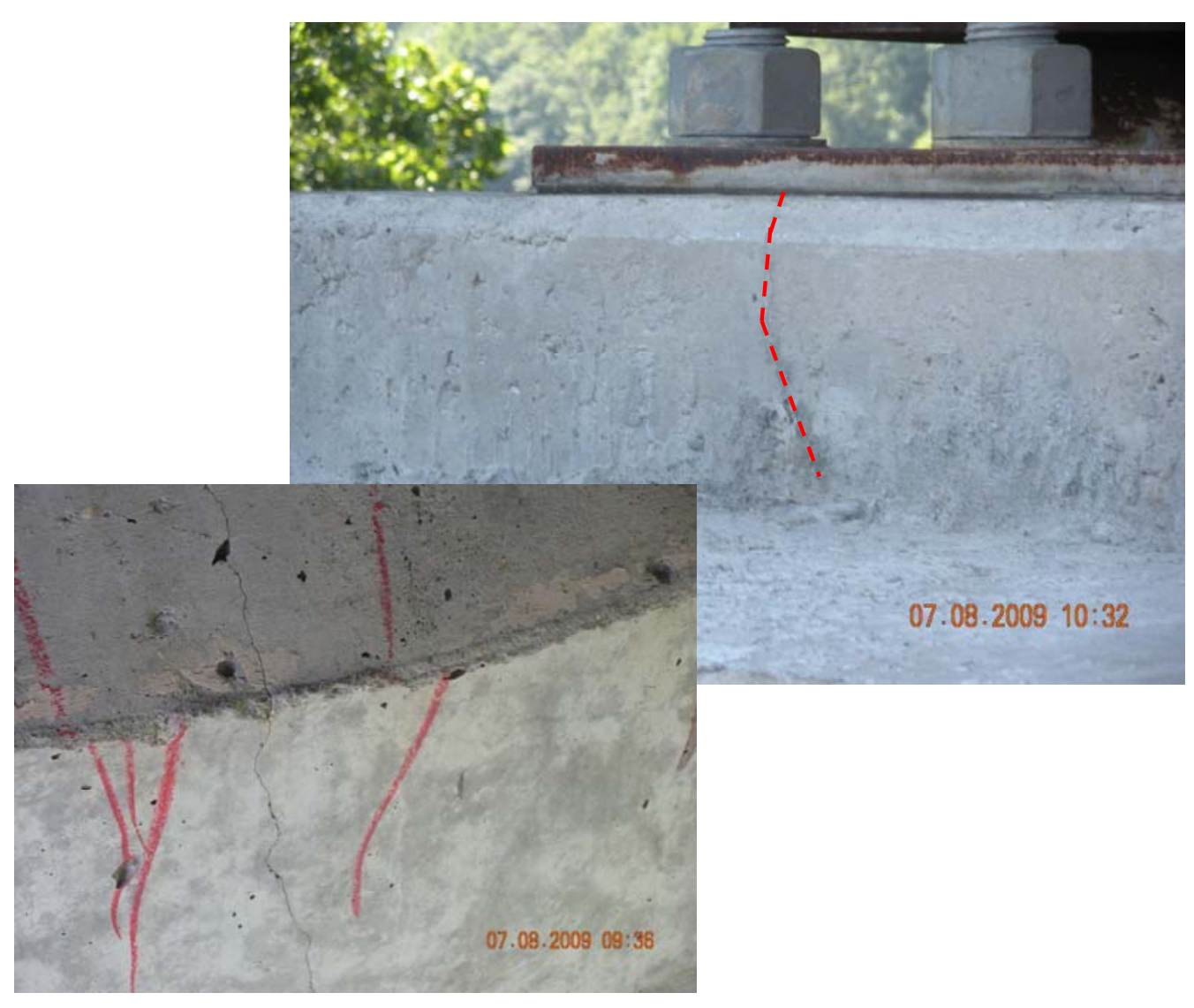

Figure 3.17. Cracks found on Pier 4

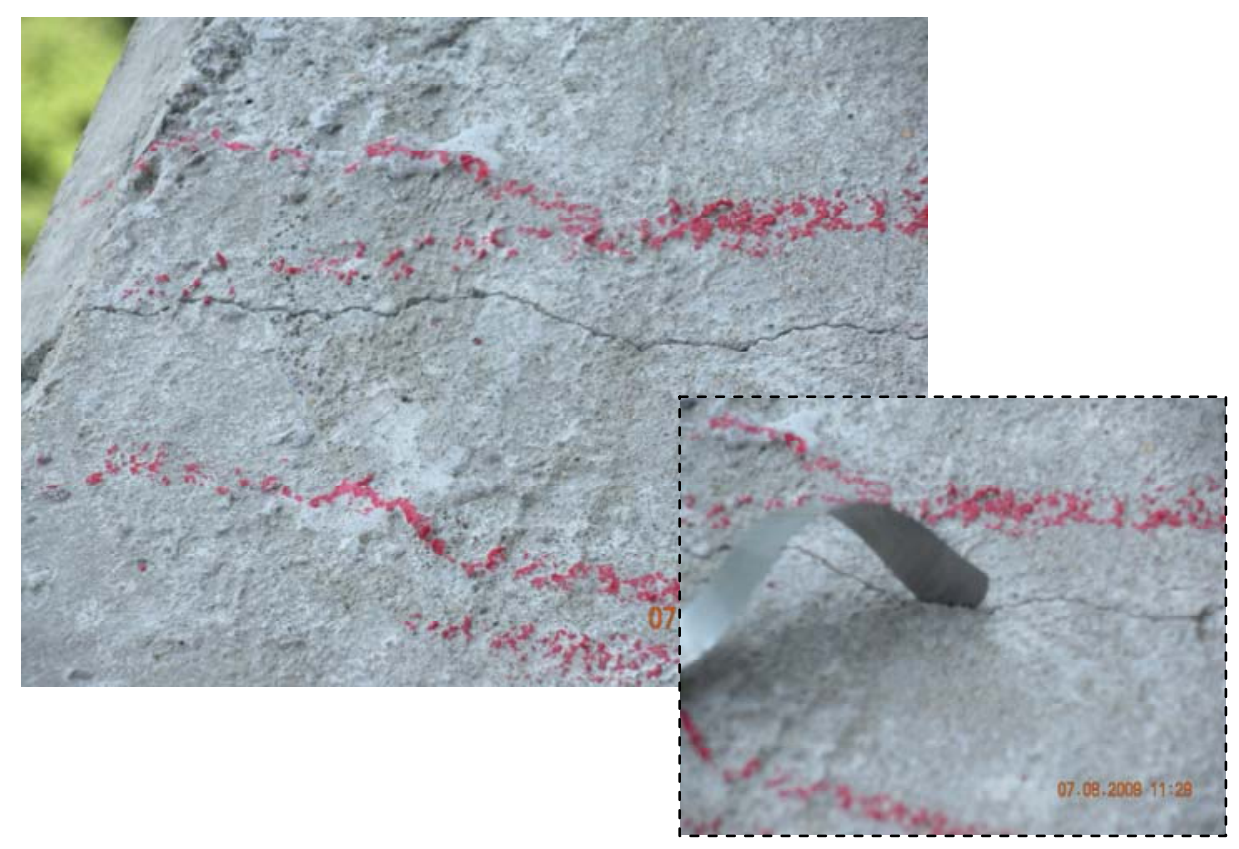

Figure 3.18. Cracks found on Pier 5 
As apparent from Figures 3.15-3.18, the cracks discovered in the support piers of the Man Bridge are not insignificant. Figure 3.18 demonstrates just how large some of the cracks had grown up until the date of the field investigation. In this figure, a 0.008 " filler gauge is inserted, revealing the approximate width of the crack. In addition to the cracks propagating from underneath the bearing masonry plates, similar size cracks are found throughout the piercaps. It is restated here that access to Piers 6-10 on Unit 2 Northbound was not safely achievable; however, both units (Unit 1 and Unit 2) share similar bearing arrangements. Therefore, with a high degree of confidence it can be expected that the cracks found in the piers supporting Unit lare also present in the piers supporting Unit 2. The two crack patterns seen in Figures 3.15-3.18 may be explained after close assessment the bridge's geometry and boundary conditions (i.e. bearing arrangement). The entirety of Unit 2 and majority of Unit 1 lie on either a horizontal or spiral (transition) curve. The four steel I-girders making up the superstructure are concentric with respect to the centers of curvature. As well, the supporting piers are aligned radially, meaning that their centerlines are directed toward the centers of curvature. Under this scenario, a torsional force effects would develop in the piers. This is illustrated in Figure 3.19.

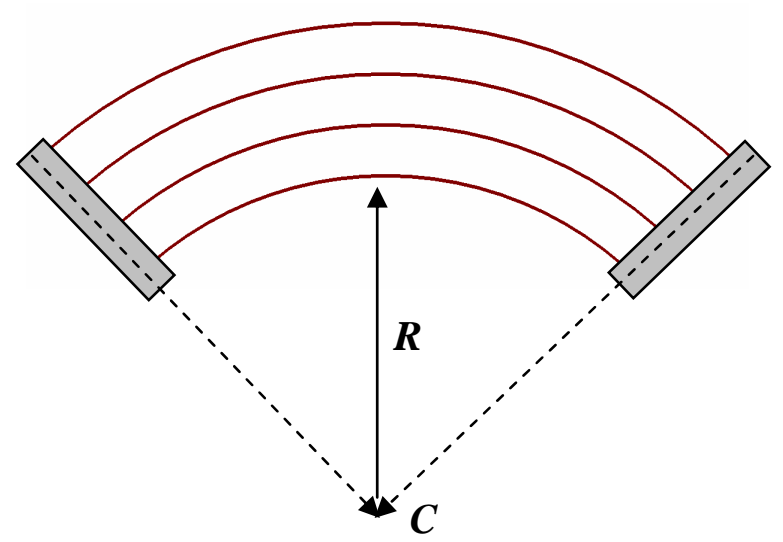

Figure 3.19. Man Bridge concentric girders illustration 
In addition to the global torsional force effects experienced by the piers, large local stresses develop around the bearing anchor bolts due to thermal deformation of the superstructure. This is evidenced by the cracks seen originating and propagating from underneath the masonry plates (see Figure 3.14). Thermal movement of the superstructure transmits large horizontal shear forces to the bolts leading to out-of-plane bending (i.e. deformation). Since the anchor bolts are embedded a certain depth into the top of the concrete piers, this bending action in the bolts is transmitted into the surrounding concrete media, resulting in material rupture. The cyclical nature of thermal loading on the bridge has allowed the initial cracks to propagate to the state observed during the field investigation.

\subsection{Conclusion}

The field investigation discussed in this chapter took place approximately four years after bridge construction concluded. Until this time, the only loads that the structure would have been exposed to include construction loads, self-weight dead load, wind loads, and thermal loads. The findings made during the investigation led to the hypothesis that such conditions are the result of restrained thermal movement within the steel superstructure. Vertical loads cannot be the cause of behaviors such as deformation around the bearings, bent bearing anchor bolts, or cracking in the concrete piers for numerous reasons. First, the manner in which the bearing anchor bolts are deformed, parallel with the bottom flange of the girders, could not have occurred due to vertical loads. Second, vertical loads (construction loads and bridge self-weight) are included in 
the design loads, and so, the support piers should have been designed to safely resist the stresses resulting from them..

The conditions documented on the Man Bridge are, however, consistent with phenomena that could occur under relatively large horizontal (i.e. lateral) loading conditions, such as seismic loads, wind loads and thermal loads. Once seismic loads and wind loads are invalidated, the only remaining horizontal force that could have led to the adverse conditions found on the Man Bridge is from thermal loading (i.e. temperature variation). The fixed and guided expansion bearings, in conjunction with relatively rigid support piers, are restraining thermal deformation of the superstructure and so, large internal force effects are developing. Ultimately, these forces are transmitted to the substructure resulting in the undesirable behaviors observed. 


\section{CHAPTER FOUR}

\section{Finite Element Modeling of the Man Bridge}

\subsection{Introduction}

The unfavorable conditions within substructure components of Man Bridge, presented in Chapter Three, are hypothesized to be a result of restrained thermal deformation of the bridge's steel superstructure. Thermal movement of the steel I-girder superstructure is highly restrained due to numerous fixed and guided bridge bearings, in conjunction with relatively rigid reinforced concrete support piers. As a consequence, large thermal forces, in the form of horizontal shear, are transferred from the steel superstructure to the concrete substructure through the bearing anchor bolts. Since the steel anchor bolts are embedded a considerable depth into the top of the concrete support piers, the horizontal force resisted by the bolts is transferred to the surrounding concrete media.

Findings made during the field investigation of the bridge suggest that the stress state within the concrete media induced by this transfer of horizontal force is large enough that fracture has occurred, among other unfavorable responses. In order to study this action, substantiate the findings made during the field investigation, and explore the general behavior of the bridge when subjected to uniform thermal loads, rigorous threedimensional finite element modeling (3DFEM) of the entire bridge system was initiated. This included modeling of the steel I-girder superstructure, concrete bridge deck, concrete support piers, and bridge bearing devices. 


\subsection{Finite Element Model Progression}

Finite element modeling of the Man Bridge was a vast, time-consuming undertaking. The principal characteristic of the FE model is the high level of detail with which all bridge components are recreated. The final model employed for this study was completed in three incremental steps, with each subsequent step introducing an increasing degree of complexity to the overall model. The details describing the development of the Man Bridge FE model using ADINA 8.6.1 FEA software are presented here.

The first step in creating an FE model of the Man Bridge included recreating the bridge's steel I-girder superstructure and reinforced concrete bridge deck from the design drawings. The most difficult task during this phase was reproducing the bridge's complex geometry and dealing with the overall size of the structure (four I-girders, nearly $1 / 2$ mile in length over 12 spans). Particulars regarding the strategy employed to model the superstructure are presented in Beckett (2011), so only a brief overview will be presented in this chapter. The usefulness of this original FE model (consisting of only the superstructure) was limited due to the manner in which the boundary conditions were applied. Since substructure components were not included, the supports were assumed infinitely rigid. Data provided by this model was far from indicative of true bridge behavior under thermal loading, and so, this original FE model required significant modification.

The second step in creating an accurate FE model was a rudimentary attempt to introduce the substructure components, including the bridge bearings and concrete support piers. Accurately modeling bearing behavior and the bearing-pier connection 
within the limitations of the selected FEA software proved quite difficult. Due to computation time and model creation becoming overly burdensome, certain features had to be simplified to a great extent. Particulars regarding such initial substructure features are discussed in Section 4.4. Nonetheless, data collected from this intermediate FE model was valuable, in that it provided insight on how the substructure affects overall bridge behavior.

The primary focus of this current work relies on examining the behavior at the bridge bearings and throughout the concrete support piers (in the vicinity of the bearing anchor bolts), in addition to investigating the structure's response under various boundary conditions (i.e. bearing arrangements). With this in mind, the FE model needed to be modified once more, introducing a more correct re-imagining of how to represent the bridge bearings and support piers. Details regarding this final modification are thoroughly discussed in Section 4.5.

\subsection{Model Overview - Superstructure Modeling}

As discussed in Chapter Three, this study places focus on the northbound section of the Man Bridge. This particular bridge consists of two continuous six-span structures, termed "units", joined by a bridge expansion joint. Each unit contains varying degrees of horizontal curvature, forcing the modeling process to be more laborious than if the structure were a geometrically comparable straight girder bridge. Certain details of the steel superstructure, such as non-uniform placement of web stiffeners, abrupt web and flange thickness variations, varying web depth, and inclusion of the bolted field splices made the modeling process very painstaking. However, the inclusion of such features 
was deemed necessary in order to replicate as accurately as possible the true behavior of the structure. Every effort was made to create an FE model that represented the exact geometry and details of the Man Bridge as presented in the design drawings.

To save on computation time and keep the FE model from becoming too cumbersome to effectively use, each unit is modeled independently. Modeling the superstructures individually was deemed acceptable due to the discontinuity provided by the expansion joint between Span 6 and Span 7. Figure 4.1a,b presents the final, most up-to-date FE models of Unit 1 and Unit 2, respectively. These models are shown at this time so that the steel superstructures may be presented. Each six span structure rests on six hammerhead style concrete support piers and one end abutment. All steel superstructure components including steel I-girder webs and flanges, web stiffeners, and cross-frame connection plates are modeled using 4-node shell elements. The applied mesh generated on the surface geometries representing the steel I-girders ranged from 6 in. element edge lengths near the midspans to 2 in. element edge lengths near the supports. The reinforced concrete bridge deck is modeled using 4-node three-layer shell elements so that future studies using this FE model may include more detailed steel reinforcement representation to accurately replicate bridge deck characteristics. The 'rigid link' option in ADINA was utilized to connect the concrete deck to the top flange of the steel I-girders. Simple two-node beam elements were selected to represent the 'W' and 'WT' shape rolled steel cross-frame members (Beckett 2011).

The first Man Bridge FE model included only the steel superstructure, and so, the affect of pier flexibility and bearing flexibility was not reflected. All substructure components (i.e. bridge bearings, support piers) were assumed infinitely rigid in 
directions where superstructure movement was not permitted by the designed bearing arrangement. For example, guided-type bridge expansion bearings do not permit translation in a transverse direction; therefore, boundary conditions were applied such that no transverse displacement could occur, but the ability for reaction forces to develop in the girders was preserved.

This modeling strategy allowed for relatively large magnitudes of thermal stresses to develop at the bearings, especially locations where fixed bridge bearings are located. While this initial FE model proved useful at the time, the need to include the substructure eventually became clear. The introduction of substructure components including the support piers, anchor bolts, and simplistic bearing assemblies into the FE model is a modeling strategy that has not been implemented prior to this study. Past research studies using FEM to study the thermal behavior of continuous bridges have used spring elements to represent substructure stiffness. This modeling procedure does not allow a detailed investigation into thermal force effects in the bearing anchor bolts and support piers. The FE models described throughout this chapter is a very accurate re-creation of an entire in-service bridge system, permitting a comprehensive investigation of its response to thermal loads. 



Figure 4.1. Man Bridge FE models. 


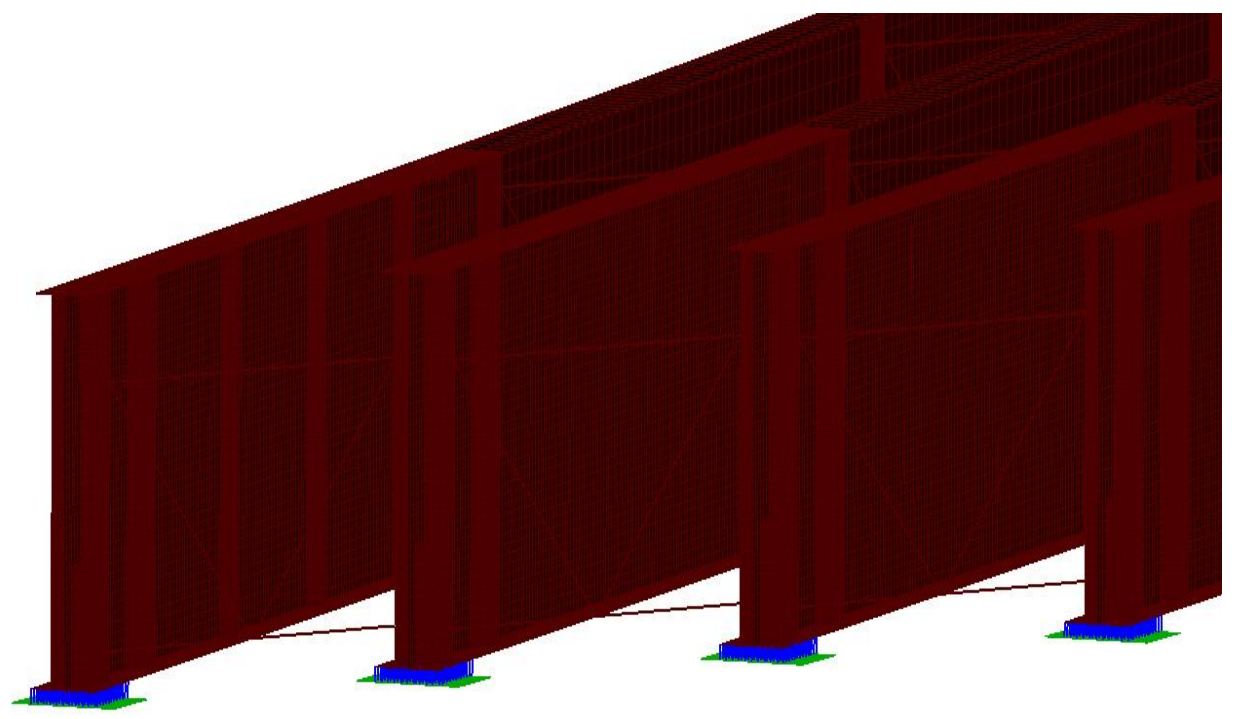

Figure 4.2. Man Bridge FE model, Abutment 2

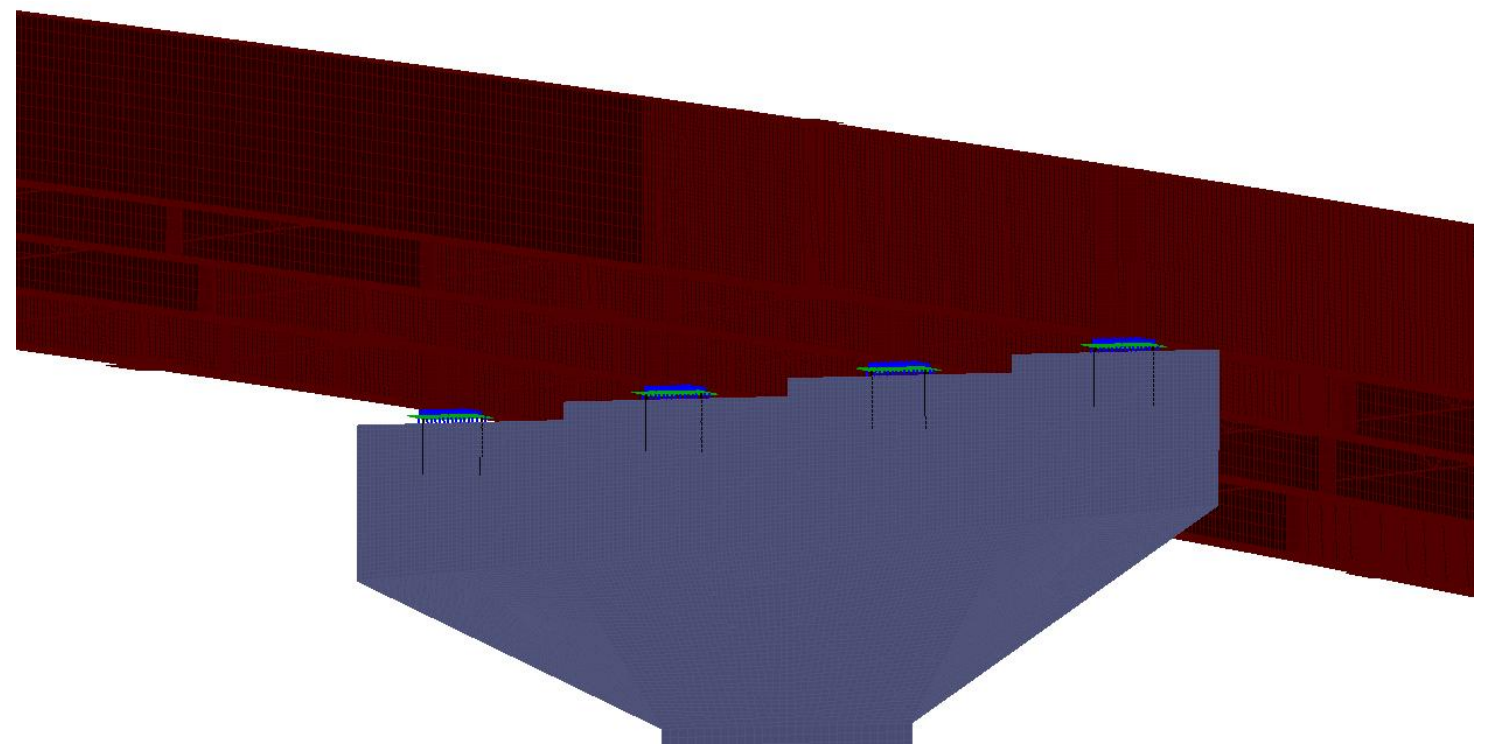

Figure 4.3. Man Bridge FE model, Pier 10 


\subsection{Initial Substructure Modeling}

It is well-known within the bridge design community that the development of thermal forces can be significantly lessened through lateral deflection of the support piers and deformation of the bearing pads (typically consisting of neoprene or elastomeric material), together termed "substructure flexibility". These actions were not available in the original FE model, which consisted of only the Man Bridge's superstructure. Thus, the second phase of modeling the Man Bridge consisted of introducing the substructure components to the FE model.

A typical hammerhead style reinforced concrete support pier is pictured in Figure 4.4. The pier columns, ranging from 10-12 ft. in diameter, were modeled as two-node beam elements with a mesh subdivision of 6 in. Four-node shell elements were chosen to represent the hammerhead shaped piercaps (highlighted in Figure 4.4), which range from $7 \frac{1}{2}-10 \mathrm{ft}$. in width. These particular element selections were made mainly for expediency purposes. Beam elements were chosen for the circular pier columns as they could be easily input in ADINA using basic cross-sectional information provided in the design drawings. Shell elements were chosen for the piercaps, rather than solid elements, to expedite modeling and computation time.
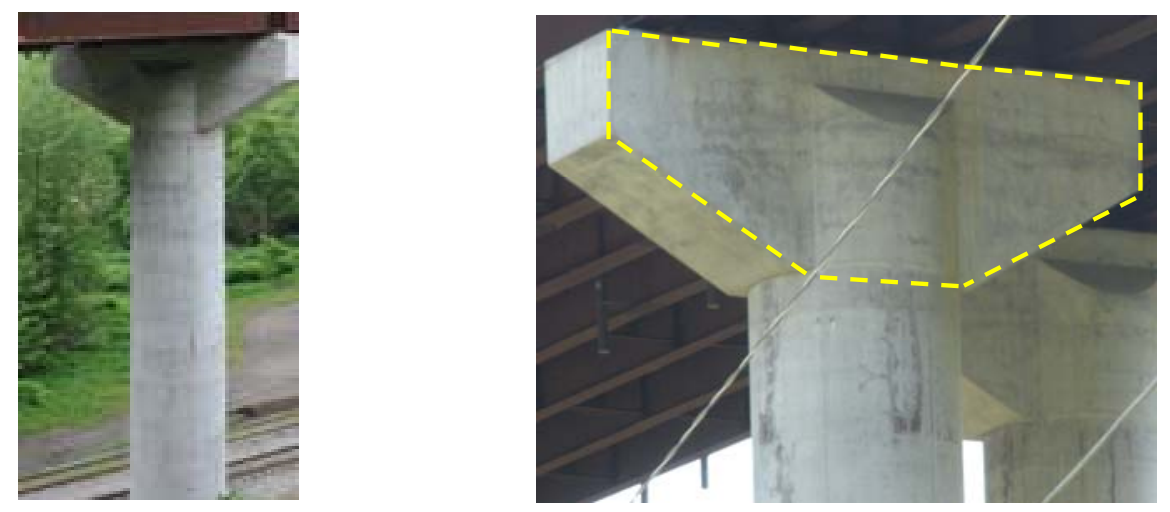

Figure 4.4. Typical support pier 
Linear springs were input to replicate the action of the bridge bearing devices. Each bridge bearing was represented by a line of linear spring elements applied on each node along the full width of the bottom flange at each bearing location. The spring elements connected the bottom flange to a set of nodes on the top of the piercap, a distance of approximately $8 \mathrm{in}$. This modeling strategy is shown below in Figure 4.5 and in Figure 4.7b.
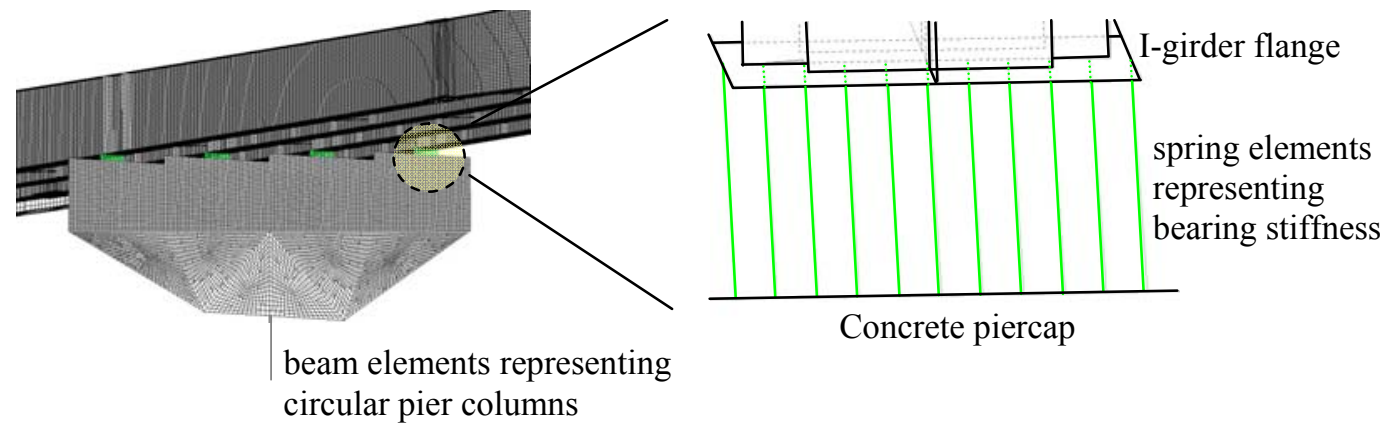

Figure 4.5. Initial substructure representation

To replicate the boundary conditions outlined in the bridge bearing arrangement found in the design drawings, the spring elements were applied in a manner according to the type of bridge bearing being modeled. In ADINA, each of the six degrees-offreedom (DOFs), three translational and three rotational, is represented by one spring element. This concept is best visualized using Figure 4.6. For example, to represent a fixed bearing where all translation is restrained, spring elements were input so as to provide stiffness for the translational DOFs (1-transverse, 2-longitudinal, 3-vertical). When a guided-type bearing or free bearing is needed, the necessary spring element(s) is 
removed to recreate the needed boundary condition by allowing or restraining translation in the appropriate directions. Spring element stiffness application for each bearing type is shown in Table 4.1. As apparent from Table 4.1, all bearings employed on the Man Bridge allow rotations about all three axes shown in Figure 4.6.

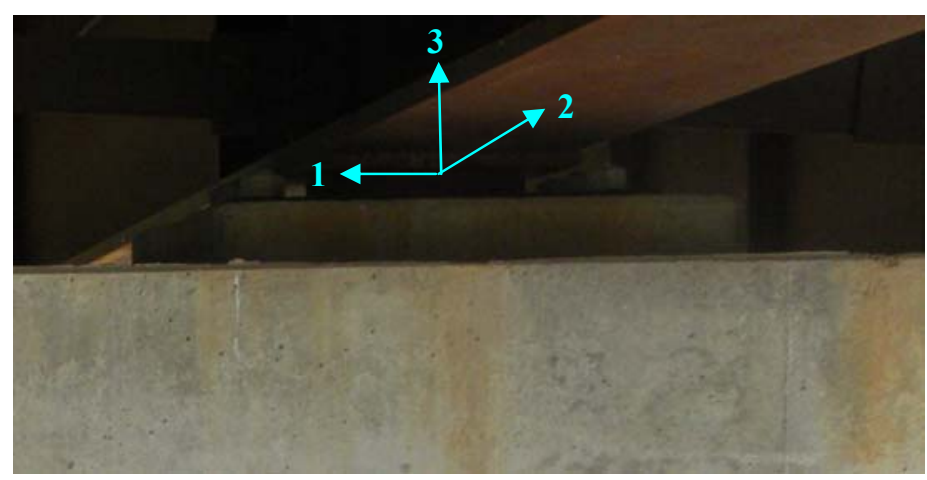

Figure 4.6. Local axes at the bearings

Table 4.1 Spring element application for each bearing type.

\begin{tabular}{r|cccccc|}
\multicolumn{7}{c}{ DOF } \\
\hline Bearing type & $\mathbf{1}$ & $\mathbf{2}$ & $\mathbf{3}$ & $\theta_{1}$ & $\theta_{2}$ & $\theta_{3}$ \\
\hline Fixed & $\mathrm{k}_{\text {spring }}$ & $\mathrm{k}_{\text {spring }}$ & $\mathrm{k}_{\text {spring }}$ & - & - & - \\
Guided & - & $\mathrm{k}_{\text {sppring }}$ & $\mathrm{k}_{\text {spring }}$ & - & - & - \\
Free & - & - & $\mathrm{k}_{\text {spring }}$ & - & - & -
\end{tabular}

Selecting an appropriate linear stiffness value " $k$ " to be applied to the spring elements was somewhat complicated. For instance, if the springs were too stiff, they would prevent forces from being transmitted from the superstructure to the substructure. If not stiff enough, superstructure displacement due to thermal movement would be too great, and unrealistic compared to the actual behavior of the Man Bridge. A linear spring stiffness value of $\mathrm{k}=1 \times 10^{16}$ was input into ADINA. The reasoning behind selecting this $\mathrm{k}$ value is discussed in Appendix A. 


\subsection{Substructure Modifications}

\subsubsection{Bearing Details Modification}

The main goal of this work involves examining the behavior of the Man Bridge at the bearing locations when subjected to uniform thermal loads. In order to appropriately perform the needed investigations, the Man Bridge FE model required significant modification with the intention of more accurately reproducing the bridge bearing devices. Therefore, the FE model was modified a second time for use in this study, the details of which are presented here.

A typical bridge bearing schematic is shown in Figure 4.7a. Figure 4.7b presents a sketch of how the bridge bearings were idealized in a previous version of the Man Bridge FE model; the flange is connected directly to top of the pier cap using spring elements. This scheme allowed for numerous areas of stress concentration to develop in the flange and around the nodes at the top of the piercaps, which does not correctly represent bridge behavior. The development of unrealistic stress concentrations is due to the boundary conditions (spring elements) being applied along a single line of nodes. In reality, the bridge bearings support the superstructure across a specific amount of surface area under the bottom flange and so, stress concentrations rarely develop.

Additionally, horizontal forces that develop at the bearings are transferred to the supporting pier through a defined number of embedded bearing anchor bolts (see Figure 4.8), not through several points across the top of the pier (see Figure 4.7b). An important objective of this study is to determine the magnitude of horizontal shear force resisted by the bearing anchor bolts as the superstructure undergoes thermal movements. The previous FE model was unable to capture this behavior in a functional manner. 
Given the limitations of the previous FE model, a new approach for modeling the bridge bearings and bearing-pier connection is needed so that stress concentrations in the flange can be eliminated and horizontal forces in the anchor bolts can be determined.

Shown in Figure 4.7c, the selected bearing modifications introduce the masonry plate, so that the superstructure is supported over a large surface area, and a method for representing the anchor bolts.

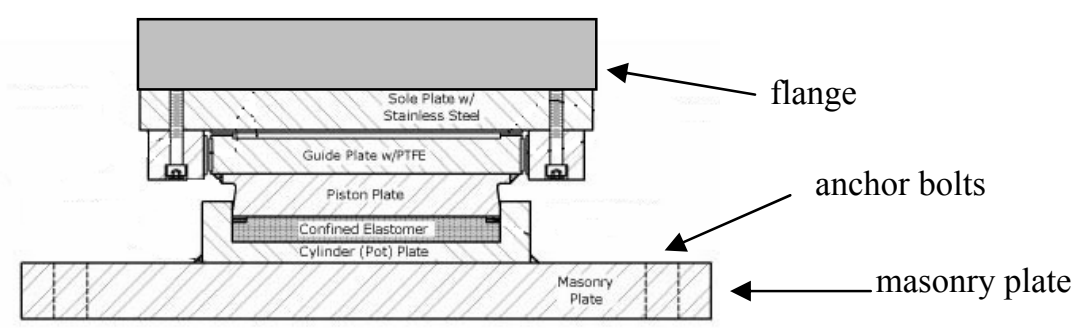

a. Bridge bearings schematic
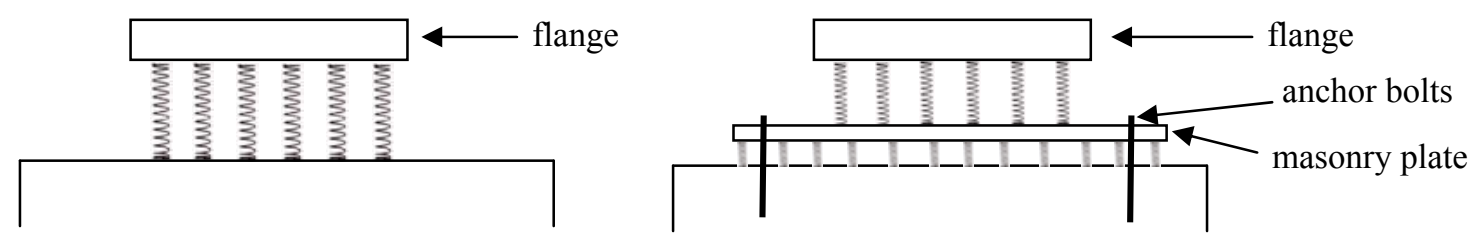

b. Previous 3DFEM bearing detail

c. Current bearing detail modification

Figure 4.7. Bridge bearings schematics and FE model representation

\subsubsection{Masonry Plates}

In a bearing device, the primary purpose of the masonry plate is to distribute vertical loads (structure self-weight, live loads, etc.) from the superstructure to the top of supporting piers across a large surface area, reducing the effect of stress concentrations. 
A masonry plate as photographed on the Man Bridge is highlighted in Figure 4.8. A masonry plate, as now included in the Man Bridge FE model, is shown in Figures 4.10 and 4.11 .

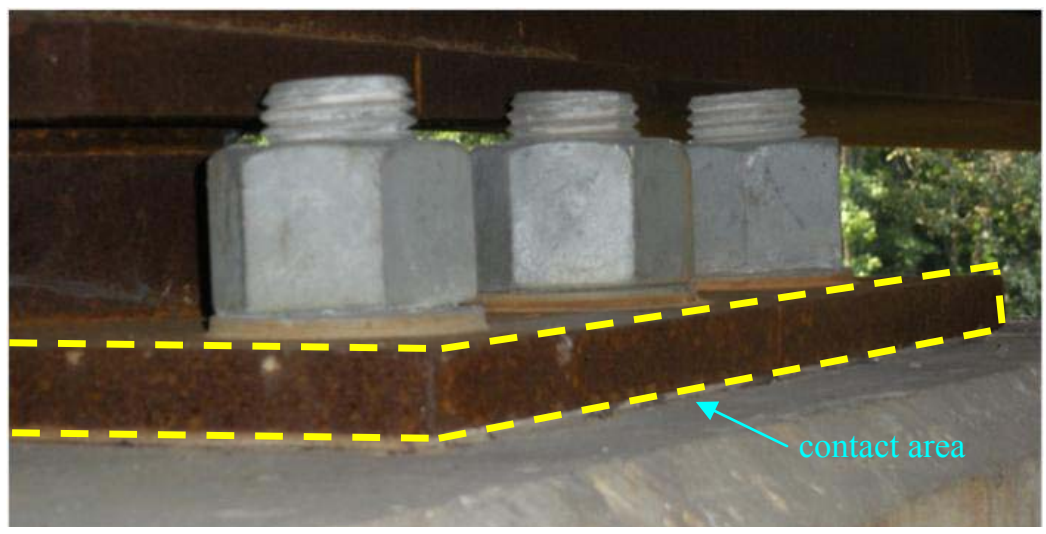

Figure 4.8. Masonry plate and bearing anchor bolts

When introducing the masonry plates to the FE model, certain aspects of their behavior were forfeited, chief among them the contact that occurs between the masonry plates and supporting piers (see Figure 4.8). The masonry plates are modeled as 4-node shell elements, similar to the piercaps, however, these elements do not share a common contact surface (the surface geometries are perpendicular to one another). This is visualized in Figure 4.9.
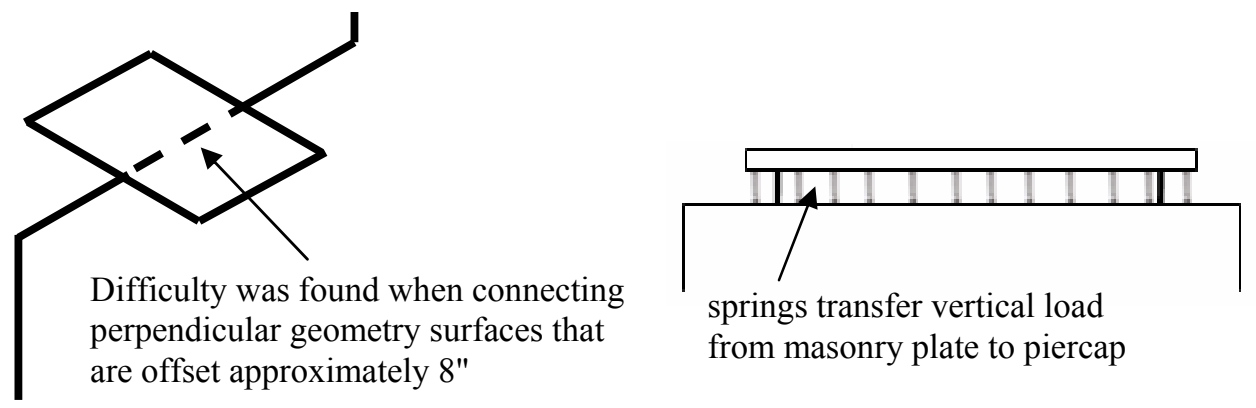

Figure 4.9. Solution for transferring vertical load through the masonry plates 
In order for vertical loads from the superstructure to be transmitted through the masonry plates to the supporting piers, linear spring elements are introduced across the full width of the plates, connecting them to the top of the piers. This can be seen in Figure 4.7c and, in Figures 4.9 and 4.10. It is recognized that this modeling technique is somewhat similar to the previous FE model (see Figure 4.5), but is deemed acceptable for two reasons. First, stresses in the masonry plates are not of great concern in this study. Second, only vertical loads are transferred through these specific sets of springs, and so, these springs have no influence on horizontal forces or reactions.

\subsubsection{Bearing Anchor Bolts}

The primary design responsibility of the embedded bearing anchor bolts (see Figure 4.8) is to securely affix the bearing devices to the supporting piers. In addition, they must have the capacity to resist any horizontal forces that may be imposed during the life of the structure. In the updated Man Bridge FE model, the bearing anchor bolts are represented by 2-node beam elements so that cross-sectional data and resultant forces can easily be input and extracted from ADINA. Within ADINA, the cross-sectional area, second moment of inertia, and torsional moment of inertia are needed to properly define a beam element cross-section. All of this data is easily calculated using only the diameter of each bolt, which is provided in the bridge design drawings. The appropriate calculations are represented by Equations 4.1-4.3, where $\mathrm{d}_{\mathrm{b}}$ is the bolt diameter. 


$$
\begin{array}{ll}
A_{b}=\pi \frac{d_{b}^{2}}{4} & \text { area of a circular cross-section } \\
I_{x, y}=\pi \frac{d_{b}^{4}}{64} & \begin{array}{l}
\text { second moment of inertia for } a \\
\text { circular cross-section }
\end{array} \\
R=\pi \frac{d_{b}^{4}}{32} & \begin{array}{l}
\text { torsional moment of inertia for } a \\
\text { circular cross-section }
\end{array}
\end{array}
$$

As with the masonry plates, some modeling accuracy is forfeited with regards to the bearing anchor bolts as well. In the updated FE model, the anchor bolts (beam elements) connect to a single node on the masonry plates (shell elements), creating the possibility of a large stress concentration to develop in the masonry plates and pier caps. In reality, the anchor bolts extend through holes cut out in the masonry plates and a nut and washer are installed, as seen in Figure 4.8. These aspects would have been overly difficult to include and are not considered in this FE model. Since horizontal forces are transferred to the anchor bolts only by translation of the masonry plates, the described method for attaching the anchor bolts to the plates is sufficient. Any in-plane movement of the masonry plates resulting from superstructure translation will cause horizontal shear forces to develop in the anchor bolts. This is the primary behavior needing to be captured.

Determining the magnitude of these horizontal shear forces is a crucial task in this study, however, another significant modeling difficulty could not be overcome when implementing the new bearing details. Due to the method used to model the concrete support piers (shell elements), multiple rows of anchor bolts (as seen in Figure 4.8) could not be replicated. To include the anchor bolts in some way in the FE model, the cross- 
sectional properties of multiple bolts are summed in order to form a single element representative of the entire bolt line at each particular bearing. In order to model the anchor bolts in this manner, a significant assumption is made: when subject to lateral loads, horizontal forces are distributed evenly among all bolts in the bolt line. While this may not be fully correct, the assumption must be made here to simplify the modeling process.

The cross-sectional properties are summed among the number of anchor bolts called for in the design drawings and input into ADINA as a single cross-section. On the Man Bridge, rows of two and three bolts are typical. The described scheme for inputting bolt information for a row of three bolts is shown in Figure 4.10. Table 4.2 provides the beam element cross-sectional data input into ADINA for each bolt line as called for in the bridge's design drawings
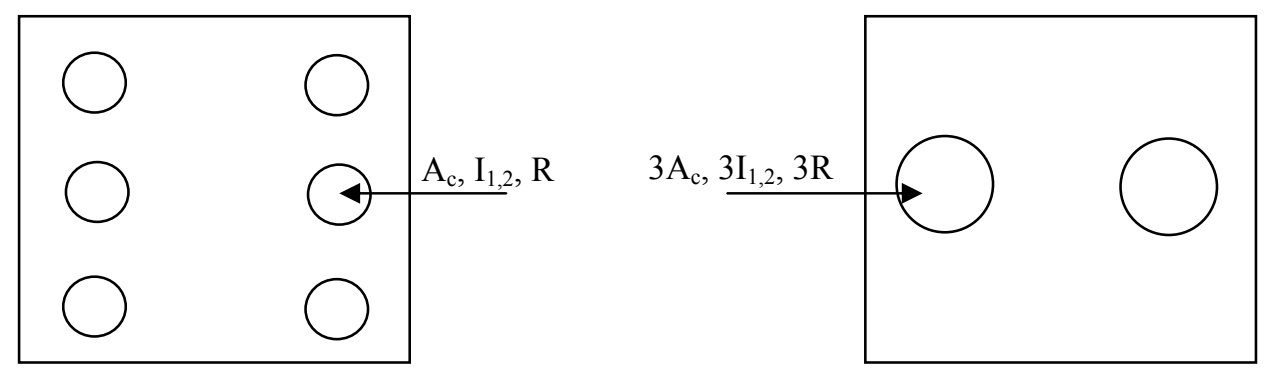

Figure 4.10. Anchor bolt cross-section representation 
Table 4.2. Anchor bolt cross-sectional data

\begin{tabular}{|c|c|c|c|c|c|c|c|c|c|c|c|}
\hline & \multicolumn{5}{|c|}{ Properties of one bolt } & \multirow[b]{2}{*}{$\begin{array}{c}\text { \# Bolts } \\
\text { per bolt line }\end{array}$} & \multicolumn{4}{|c|}{ Properties of bolt line } \\
\hline & & $d_{b}\left(i^{2}\right)$ & $A_{b}\left(i^{2}\right)$ & Ix $\left(\right.$ in $\left.^{4}\right)$ & Iy $\left(\right.$ in $\left.^{4}\right)$ & $R\left(\right.$ in $\left.^{4}\right)$ & & $A_{b}\left(i^{2}\right)$ & Ix $\left(\right.$ in $\left.^{4}\right)$ & Iy (in $\left.{ }^{4}\right)$ & $R\left(\right.$ in $\left.^{4}\right)$ \\
\hline \multirow{4}{*}{ Abutment 1} & G1 & 1.5 & 1.77 & 0.248 & 0.248 & 0.497 & 2 & 3.53 & 0.50 & 0.50 & 0.99 \\
\hline & G2 & 1.5 & 1.77 & 0.248 & 0.248 & 0.497 & 2 & 3.53 & 0.50 & 0.50 & 0.99 \\
\hline & G3 & 1.5 & 1.77 & 0.248 & 0.248 & 0.497 & 2 & 3.53 & 0.50 & 0.50 & 0.99 \\
\hline & G4 & 1.5 & 1.77 & 0.248 & 0.248 & 0.497 & 2 & 3.53 & 0.50 & 0.50 & 0.99 \\
\hline \multirow{4}{*}{ Pier 1} & G1 & 1.5 & 1.77 & 0.248 & 0.248 & 0.497 & 2 & 3.53 & 0.50 & 0.50 & 0.99 \\
\hline & G2 & 2 & 3.14 & 0.785 & 0.785 & 1.570 & 3 & 6.28 & 1.57 & 1.57 & 3.14 \\
\hline & G3 & 2 & 3.14 & 0.785 & 0.785 & 1.570 & 3 & 6.28 & 1.57 & 1.57 & 3.14 \\
\hline & G4 & 1.5 & 1.77 & 0.248 & 0.248 & 0.497 & 2 & 3.53 & 0.50 & 0.50 & 0.99 \\
\hline \multirow{4}{*}{ Pier 2} & G1 & 2.25 & 3.97 & 1.257 & 1.257 & 2.515 & 3 & 7.95 & 2.51 & 2.51 & 5.03 \\
\hline & G2 & 2.25 & 3.97 & 1.257 & 1.257 & 2.515 & 3 & 7.95 & 2.51 & 2.51 & 5.03 \\
\hline & G3 & 2.25 & 3.97 & 1.257 & 1.257 & 2.515 & 3 & 7.95 & 2.51 & 2.51 & 5.03 \\
\hline & G4 & 2.25 & 3.97 & 1.257 & 1.257 & 2.515 & 3 & 7.95 & 2.51 & 2.51 & 5.03 \\
\hline \multirow{4}{*}{ Pier 3} & G1 & 1.75 & 2.40 & 0.460 & 0.460 & 0.920 & 2 & 4.81 & 0.92 & 0.92 & 1.84 \\
\hline & G2 & 1.75 & 2.40 & 0.460 & 0.460 & 0.920 & 2 & 4.81 & 0.92 & 0.92 & 1.84 \\
\hline & G3 & 1.75 & 2.40 & 0.460 & 0.460 & 0.920 & 2 & 4.81 & 0.92 & 0.92 & 1.84 \\
\hline & G4 & 1.75 & 2.40 & 0.460 & 0.460 & 0.920 & 2 & 4.81 & 0.92 & 0.92 & 1.84 \\
\hline \multirow{4}{*}{ Pier 4} & G1 & 1.75 & 2.40 & 0.460 & 0.460 & 0.920 & 2 & 4.81 & 0.92 & 0.92 & 1.84 \\
\hline & G2 & 1.75 & 2.40 & 0.460 & 0.460 & 0.920 & 2 & 4.81 & 0.92 & 0.92 & 1.84 \\
\hline & G3 & 1.75 & 2.40 & 0.460 & 0.460 & 0.920 & 2 & 4.81 & 0.92 & 0.92 & 1.84 \\
\hline & G4 & 1.75 & 2.40 & 0.460 & 0.460 & 0.920 & 2 & 4.81 & 0.92 & 0.92 & 1.84 \\
\hline \multirow{4}{*}{ Pier 5} & G1 & 2 & 3.14 & 0.785 & 0.785 & 1.570 & 3 & 6.28 & 1.57 & 1.57 & 3.14 \\
\hline & G2 & 2 & 3.14 & 0.785 & 0.785 & 1.570 & 3 & 6.28 & 1.57 & 1.57 & 3.14 \\
\hline & G3 & 2 & 3.14 & 0.785 & 0.785 & 1.570 & 3 & 6.28 & 1.57 & 1.57 & 3.14 \\
\hline & G4 & 2 & 3.14 & 0.785 & 0.785 & 1.570 & 3 & 6.28 & 1.57 & 1.57 & 3.14 \\
\hline \multirow{4}{*}{ Pier 6L } & G1 & 1.5 & 1.77 & 0.248 & 0.248 & 0.497 & 2 & 3.53 & 0.50 & 0.50 & 0.99 \\
\hline & G2 & 2 & 3.14 & 0.785 & 0.785 & 1.570 & 2 & 6.28 & 1.57 & 1.57 & 3.14 \\
\hline & G3 & 2 & 3.14 & 0.785 & 0.785 & 1.570 & 2 & 6.28 & 1.57 & 1.57 & 3.14 \\
\hline & G4 & 1.5 & 1.77 & 0.248 & 0.248 & 0.497 & 2 & 3.53 & 0.50 & 0.50 & 0.99 \\
\hline \multirow{4}{*}{ Pier 6R } & G1 & 1.5 & 1.77 & 0.248 & 0.248 & 0.497 & 2 & 3.53 & 0.50 & 0.50 & 0.99 \\
\hline & G2 & 2 & 3.14 & 0.785 & 0.785 & 1.570 & 2 & 6.28 & 1.57 & 1.57 & 3.14 \\
\hline & G3 & 2 & 3.14 & 0.785 & 0.785 & 1.570 & 2 & 6.28 & 1.57 & 1.57 & 3.14 \\
\hline & G4 & 1.5 & 1.77 & 0.248 & 0.248 & 0.497 & 2 & 3.53 & 0.50 & 0.50 & 0.99 \\
\hline \multirow{4}{*}{ Pier 7} & G1 & 2 & 3.14 & 0.785 & 0.785 & 1.570 & 3 & 6.28 & 1.57 & 1.57 & 3.14 \\
\hline & G2 & 2 & 3.14 & 0.785 & 0.785 & 1.570 & 3 & 6.28 & 1.57 & 1.57 & 3.14 \\
\hline & G3 & 2 & 3.14 & 0.785 & 0.785 & 1.570 & 3 & 6.28 & 1.57 & 1.57 & 3.14 \\
\hline & G4 & 2 & 3.14 & 0.785 & 0.785 & 1.570 & 3 & 6.28 & 1.57 & 1.57 & 3.14 \\
\hline \multirow{4}{*}{ Pier 8} & G1 & 2 & 3.14 & 0.785 & 0.785 & 1.570 & 3 & 6.28 & 1.57 & 1.57 & 3.14 \\
\hline & G2 & 2 & 3.14 & 0.785 & 0.785 & 1.570 & 3 & 6.28 & 1.57 & 1.57 & 3.14 \\
\hline & G3 & 2 & 3.14 & 0.785 & 0.785 & 1.570 & 3 & 6.28 & 1.57 & 1.57 & 3.14 \\
\hline & G4 & 2 & 3.14 & 0.785 & 0.785 & 1.570 & 3 & 6.28 & 1.57 & 1.57 & 3.14 \\
\hline \multirow{4}{*}{ Pier 9} & G1 & 2 & 3.14 & 0.785 & 0.785 & 1.570 & 3 & 6.28 & 1.57 & 1.57 & 3.14 \\
\hline & G2 & 2 & 3.14 & 0.785 & 0.785 & 1.570 & 3 & 6.28 & 1.57 & 1.57 & 3.14 \\
\hline & G3 & 2 & 3.14 & 0.785 & 0.785 & 1.570 & 3 & 6.28 & 1.57 & 1.57 & 3.14 \\
\hline & G4 & 2 & 3.14 & 0.785 & 0.785 & 1.570 & 3 & 6.28 & 1.57 & 1.57 & 3.14 \\
\hline & G1 & 1.5 & 1.77 & 0.248 & 0.248 & 0.497 & 2 & 3.53 & 0.50 & 0.50 & 0.99 \\
\hline Pier 10 & G2 & 2 & 3.14 & 0.785 & 0.785 & 1.570 & 2 & 6.28 & 1.57 & 1.57 & 3.14 \\
\hline 1 & G3 & 2 & 3.14 & 0.785 & 0.785 & 1.570 & 2 & 6.28 & 1.57 & 1.57 & 3.14 \\
\hline & G4 & 1.5 & 1.77 & 0.248 & 0.248 & 0.497 & 2 & 3.53 & 0.50 & 0.50 & 0.99 \\
\hline & G1 & 1.5 & 1.77 & 0.248 & 0.248 & 0.497 & 2 & 3.53 & 0.50 & 0.50 & 0.99 \\
\hline Pier 11 & $\mathrm{G} 2$ & 2 & 3.14 & 0.785 & 0.785 & 1.570 & 2 & 6.28 & 1.57 & 1.57 & 3.14 \\
\hline Pier 11 & G3 & 2 & 3.14 & 0.785 & 0.785 & 1.570 & 2 & 6.28 & 1.57 & 1.57 & 3.14 \\
\hline & G4 & 1.5 & 1.77 & 0.248 & 0.248 & 0.497 & 2 & 3.53 & 0.50 & 0.50 & 0.99 \\
\hline & G1 & 1.5 & 1.77 & 0.248 & 0.248 & 0.497 & 2 & 3.53 & 0.50 & 0.50 & 0.99 \\
\hline Abutmont? & G2 & 1.5 & 1.77 & 0.248 & 0.248 & 0.497 & 2 & 3.53 & 0.50 & 0.50 & 0.99 \\
\hline Abutment 2 & G3 & 1.5 & 1.77 & 0.248 & 0.248 & 0.497 & 2 & 3.53 & 0.50 & 0.50 & 0.99 \\
\hline & G4 & 1.5 & 1.77 & 0.248 & 0.248 & 0.497 & 2 & 3.53 & 0.50 & 0.50 & 0.99 \\
\hline
\end{tabular}


Modeling the bearing stiffness is achieved in a similar manner to the previous FE model. Linear spring elements are introduced, representing the desired DOFs to be restrained for each type of bearing, as described in Figure 4.13. With the new bearings details, many spring elements are applied at each bearing location greatly reducing the effect of stress concentrations. A description of the new bearing details is given in Figure 4.11 .

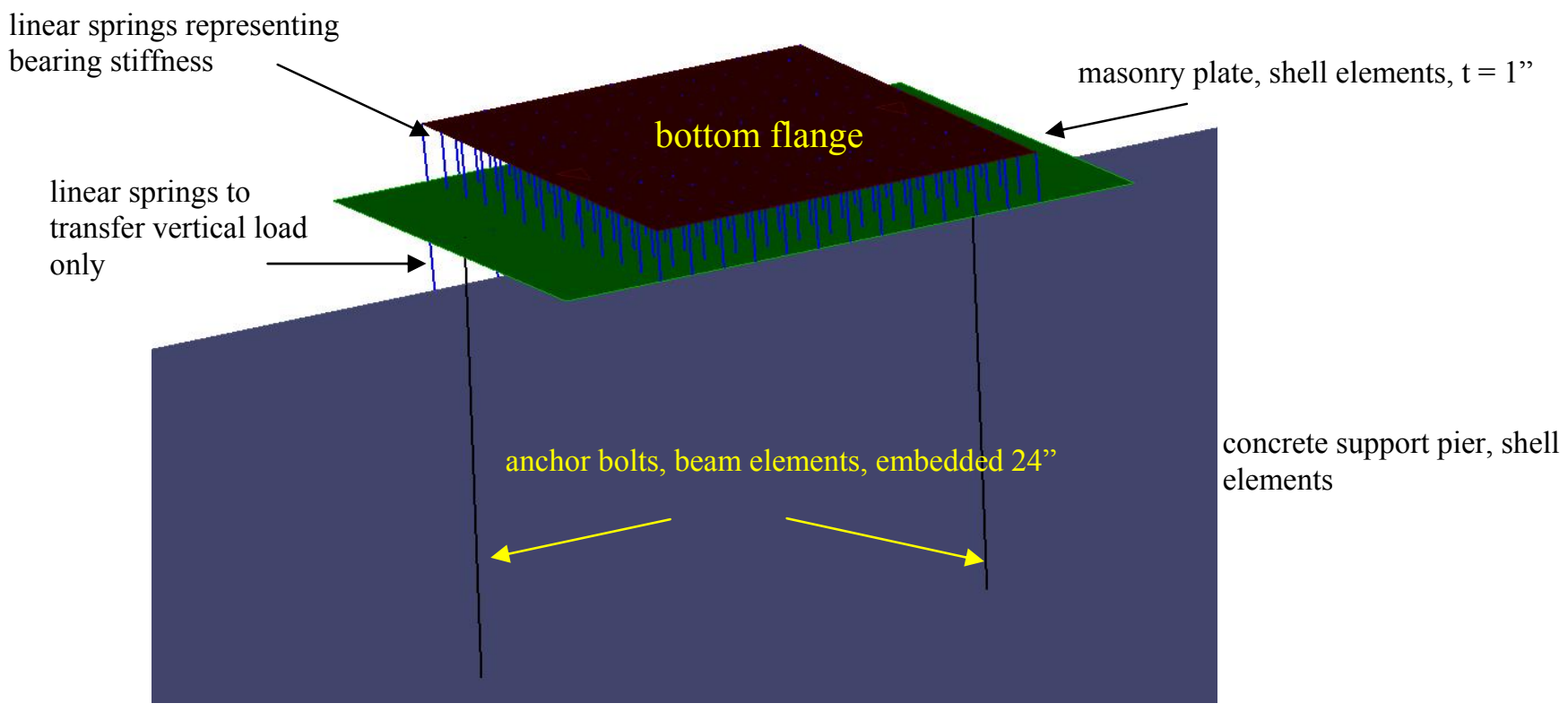

Figure 4.11. New bridge bearing model

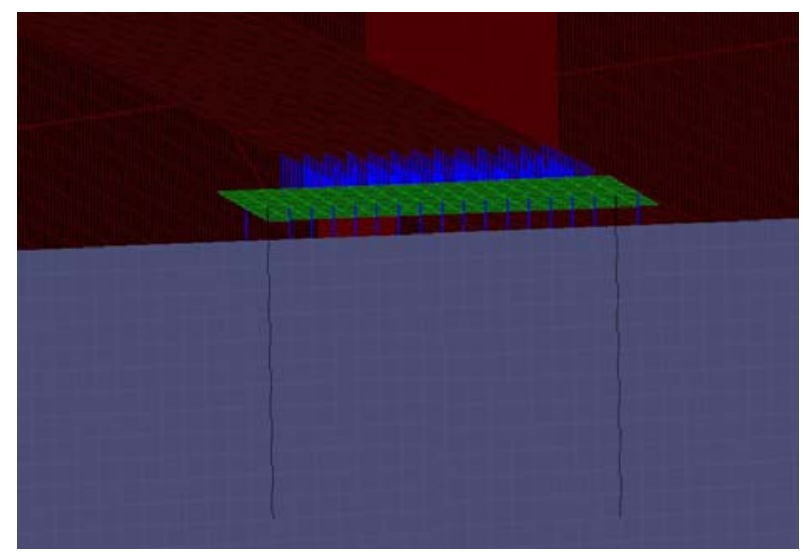

Figure 4.12. Bearing representation (Pier 10) 


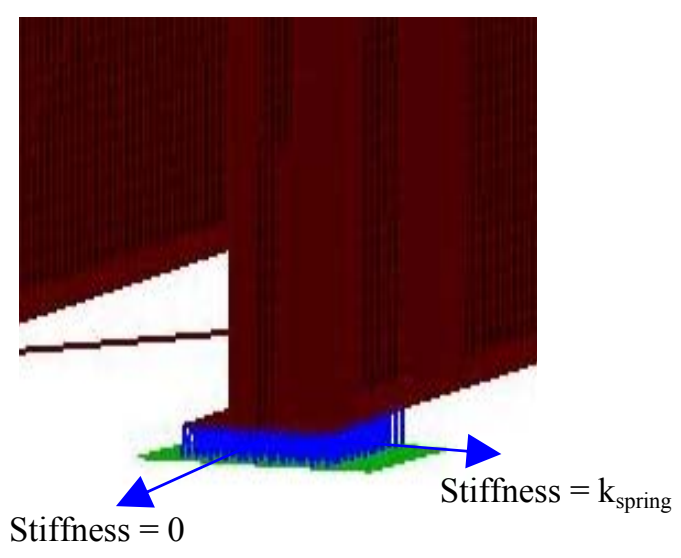

(a)

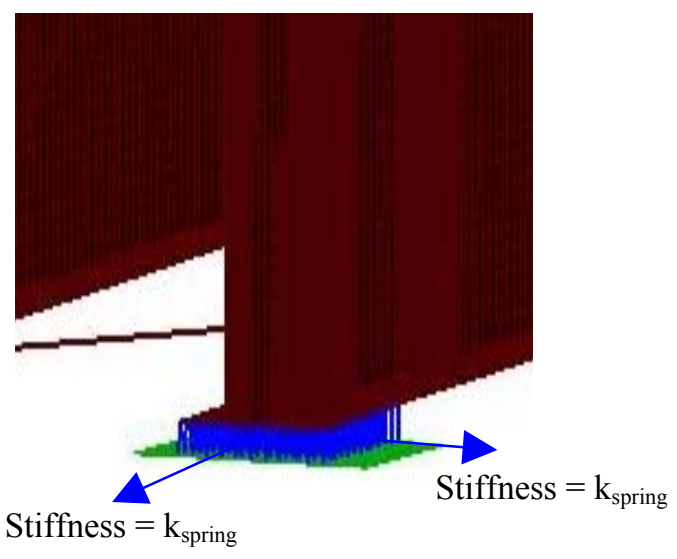

(b)

Figure 4.13. Bearing stiffness a) guided bearing b) fixed bearing

\subsubsection{Support Pier Modification}

In addition to modifying how the bridge bearings are represented in the FE model, the support pier columns were revised as well. Initially, beam elements were chosen to represent the circular pier columns. Consequently, having the pier columns in such a way resulted in the development of significant stress concentrations at the point where the piercap and pier column unite. This stress concentration was a result of the manner in which the beam element at the top of the pier column connected to the shell element(s) at the bottom of the piercap, as shown in Figure 4.14. At this location, the beam and shell elements shared only a single node, making the likelihood of a stress concentration very probable. To remedy this scenario, the elements representing the pier columns were changed from beam elements to shell elements so that all nodes along the bottom of the 
piercap would share nodes across the full width of the pier column. The main difficulty using shell elements was accurately reproducing the circular cross-section of the pier columns.
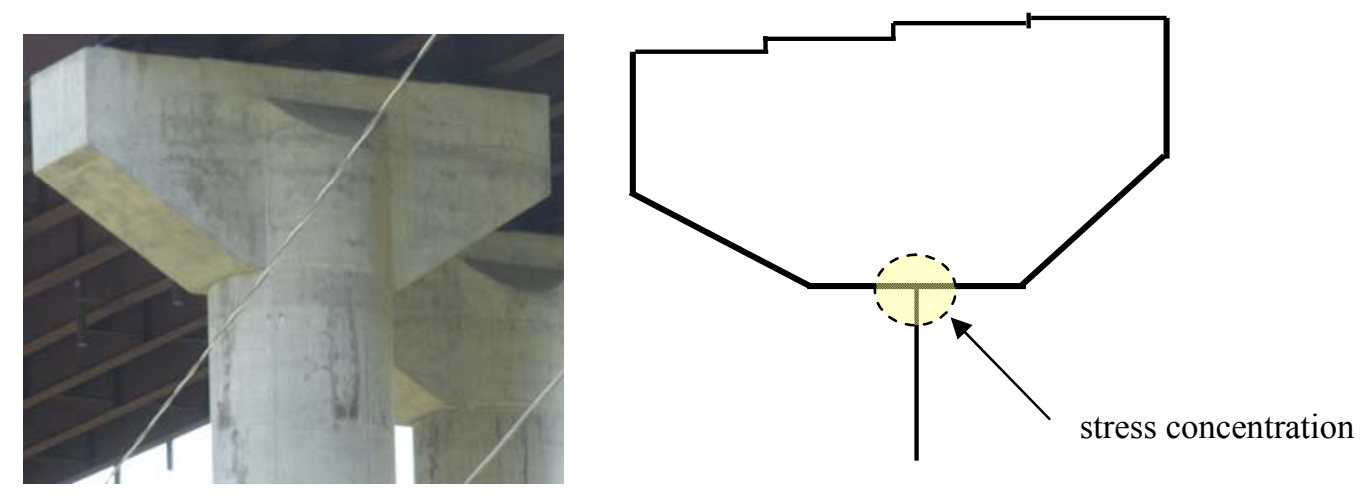

Figure 4.14. Stress concentration area in a previous FE model

To eliminate the possibility of a stress concentration at this location, each pier column was discretized along its diameter. This is shown in Figure 4.15. A line of shell elements representing the diameter of the circular cross-section was input and their individual thicknesses were adjusted accordingly to achieve an approximate circular geometry representing the columns. The term " $\mathrm{d}_{\text {column}}$ " is equal to the prescribed shell thickness. The shell elements have a maximum edge length of 6 in., so a $12 \mathrm{ft}$. diameter column has 24 elements across is diameter, and a $10 \mathrm{ft}$. diameter column has 20 elements. A sample mesh applied to the support piercap and newly modified pier column is shown in Figure 4.15. 


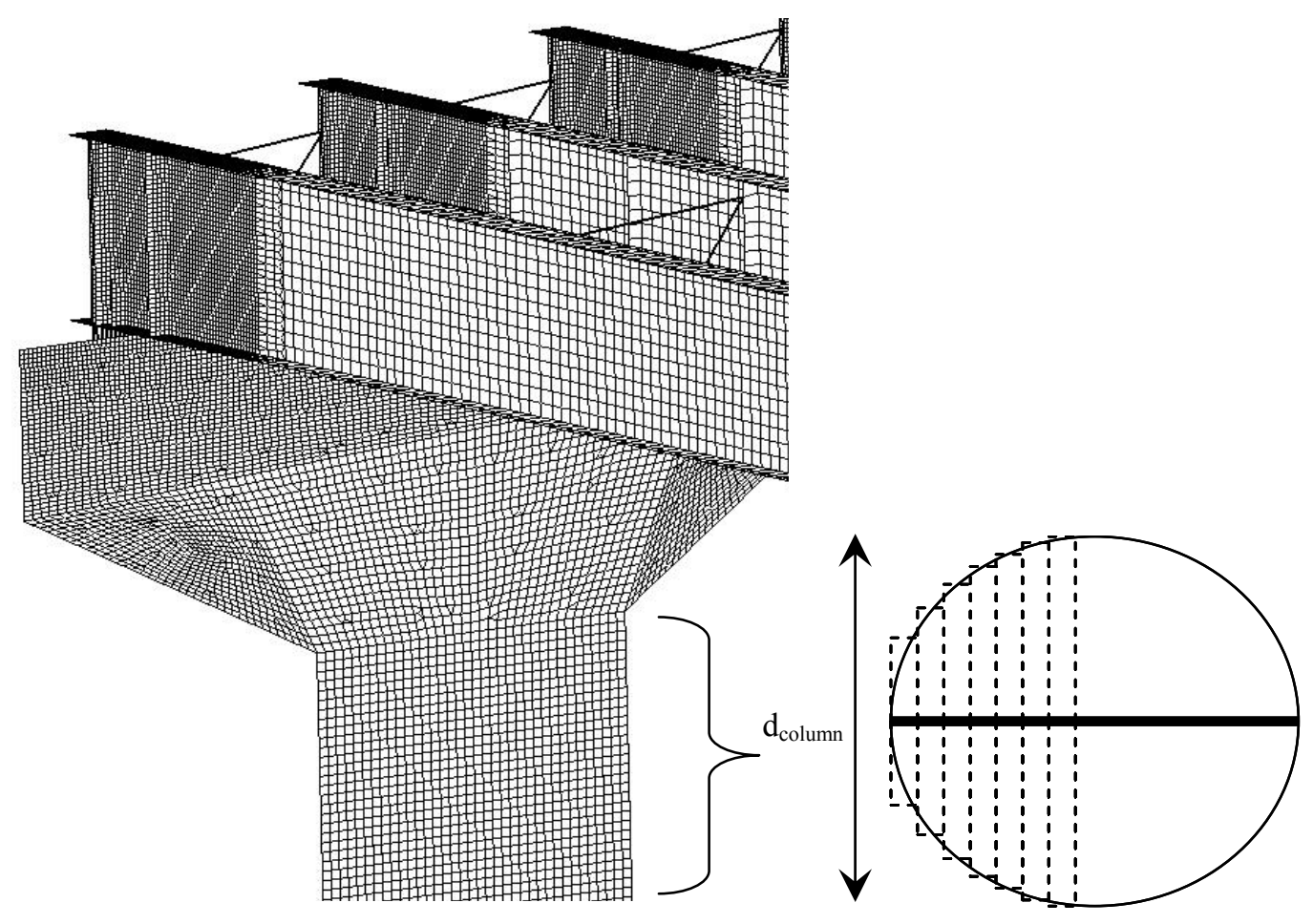

Figure 4.15. Circular cross-section discretization

\subsection{Material Model}

Selecting an appropriate material model is crucial to any structural investigation that relies on FE analysis. If the material model input into the FE program does not accurately replicate the actual material used on the structure, its the model may not generate correct behavior. The steel I-girders are constructed from two types of weathered steel. AASHTO M270 Grade 50 and HPS 70W, having yield strengths of 50 ksi and $70 \mathrm{ksi}$, respectively. Preliminary trial simulations of the FE model indicated that inelastic behavior within the steel members is unlikely due to relatively low magnitudes of stress. Therefore, a linear-elastic material model was chosen for the steel I-girders in the current Man Bridge FE model. 
A similar material model was selected for the bridge bearing anchor bolts. While the deformation observed in the anchor bolts is likely indicative of inelastic behavior, a linear-elastic material model is used. The focus of this study, as it pertains to the anchor bolts, is a determination of whether or not the shear forces produced in the FE model may lead to inelastic behavior. This can be accomplished by comparing the shear strength of the bolts with the forces produced by the FE model. This can be accomplished using a linear-elastic material model.

A linear-elastic material model was also selected to represent the concrete support piers. A major goal of this work is to determine whether or not the stress state in the concrete piers is conducive to the cracking detailed in Chapter Three. In a general sense, failure in a concrete member is typically considered to have occurred once the material fractures. This is due to concrete material's brittle nature. For brittle materials that fail by fracture rather than yielding, the maximum principal stress criterion (i.e. Rankine's criterion) may adequately predict tension fracture (Boresi and Schmidt 2003). This failure criterion states that yielding commences when the maximum principal stress at any point in a structural member reaches a value equal to its yield strength in either tension or compression. Taking the tensile strength of the concrete material as the yield strength and assuming elastic behavior until this point, the use of a linear-elastic material is acceptable. In actuality, this will prove to be a conservative assumption. According to Chen and Yan (2007) the elastic limit of concrete material is approximately $60-80 \%$ of its ultimate tensile strength, after which unstable crack propagation begins. Rankine's criterion assumes unstable crack prorogation will begin when the maximum principal stress reaches $100 \%$ of the tensile strength, which is what this work will investigate. 


\subsection{Model Validation}

One of the most essential steps during the finite element analysis of a structural system is ensuring that the newly constructed FE model behaves in a manner similar to the actual structure it is meant to represent. More simply, it must be determined whether or not data produced by the FE model is accurate. To achieve this, output from an FE model is regularly compared to actual physical measurements obtained in the field or to certain values provided in a bridge's design drawings. For this study, data from the Man Bridge FE model is compared to measurements recorded on the actual structure determined during the field investigation.

\subsubsection{Spring Element Validation - Single Girder Model}

The most significant characteristic of the Man Bridge FE model is the manner with which the bridge bearings are represented. The spring elements are the sole means through which all forces, most importantly horizontal forces, are transmitted from the superstructure to the substructure. It is essential that these elements are input appropriately into ADINA and respond in a manner consistent with the actual bearings on the structure. To validate the application of the spring elements, two comparisons are performed. First, a small-scale study of a single steel I-girder is completed. The trial girder has similar dimensions to the I-girders on the Man Bridge, and the boundary conditions (spring elements) and thermal loads are applied in a similar manner to the Man Bridge FE model. Second, bearing displacement data produced by the Man Bridge FE model is compared to experimental measurements taken using LVDTs during the field investigation. 


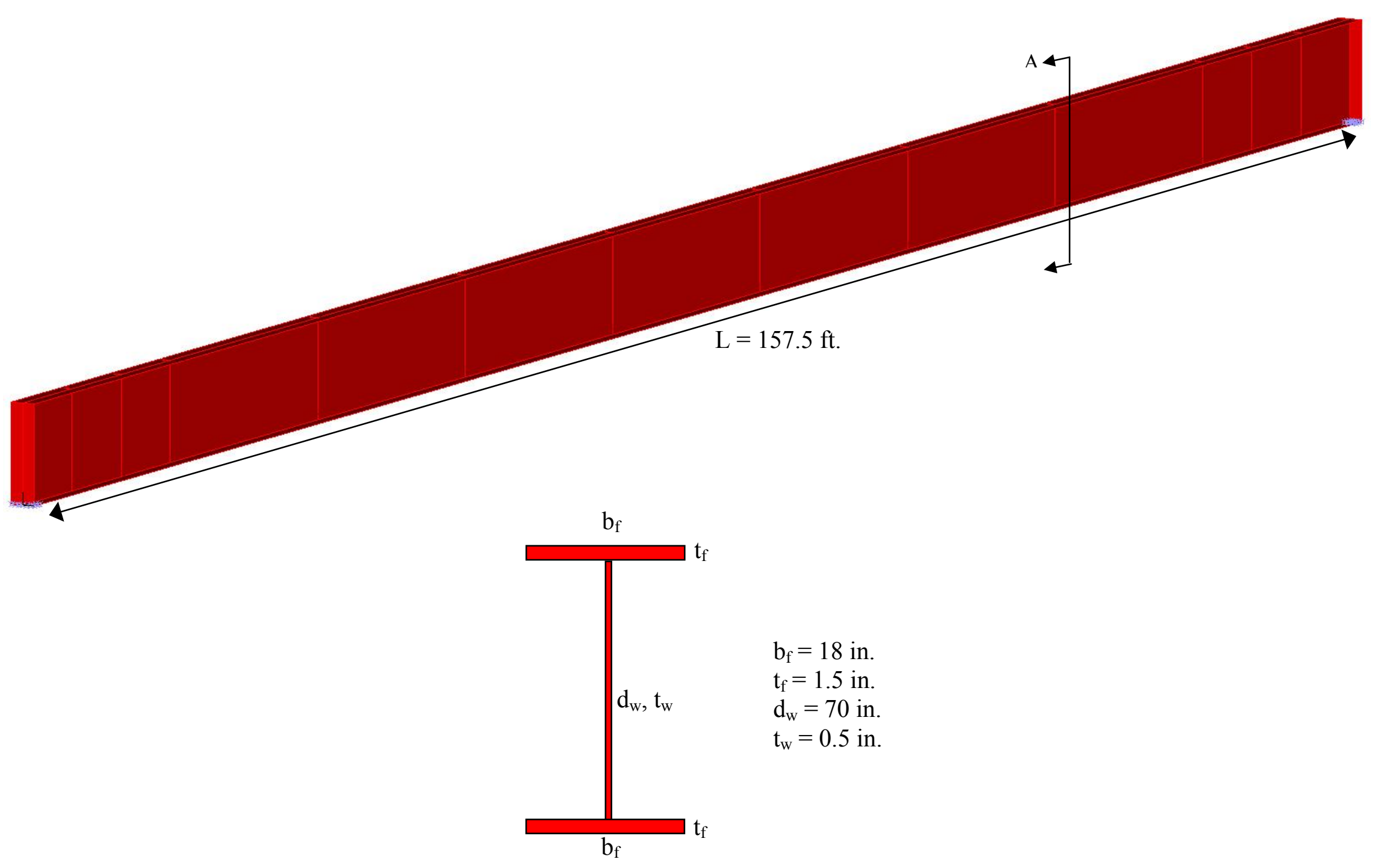

Figure 4.16. Single girder model used for FE validation 
Figure 4.16 presents the geometry of the single girder model. The span length is $157.5 \mathrm{ft}$. Cross-sectional dimensions of the I-girder are provided. The material model is linear elastic with the following properties:

- Young's Modulus E = 29,000 ksi.

- Density $\rho=0.2835 \mathrm{lb} / \mathrm{in}^{3}$

- Poisson's Ratio $v=0.30$

- Coefficient of thermal expansion $\alpha_{\mathrm{T}}=6.5 \times 10^{-6} \mathrm{in} / \mathrm{in} /{ }^{\circ} \mathrm{F}$

The spring elements applied as boundary conditions are shown in Figure 4.17 (outlined in yellow). A spring stiffness of $\mathrm{k}=1 \times 10^{16}$, identical to the Man Bridge FE model, is input as a reference value, but can be adjusted to represent varying bearing stiffnesses. The girder is simply-supported, as shown in Figure 4.16. Longitudinal translation is only permitted at one support location while transverse translation is not permitted at either support. Note that the spring elements highlighted in Figure 4.16 are applied using the "GROUND" option in ADINA. This allows a spring element to be applied to only a single node, thereby providing the specified stiffness. Within the actual Man Bridge FE model each spring element connects two separate nodes. However, there is no difference in the response of the structure between these two options. 


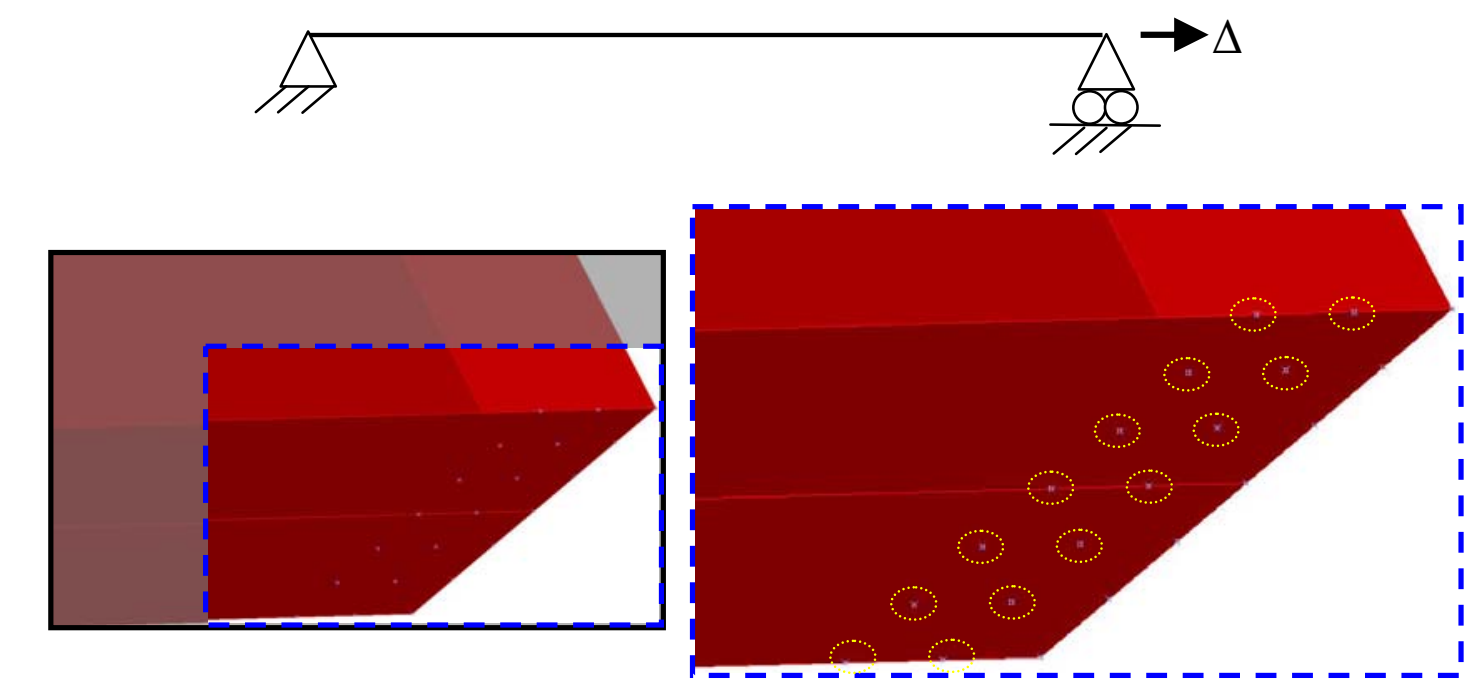

Figure 4.17. Spring element application in single girder model

A uniform temperature load of $+60^{\circ} \mathrm{F}$ was applied to each surface geometry making up the girder. The $+60^{\circ} \mathrm{F}$ temperature load represents a $60^{\circ} \mathrm{F}$ temperature increase from an arbitrarily selected initial temperature (in this case $0^{\circ} \mathrm{F}$ ). Results from this single girder model are presented in Figure 4.18. The magnitude of thermal expansion generated at the expansion bearing is 0.7365 in. This result may be compared to the closed-form solution for the magnitude of thermal expansion calculated using Equation 3.1, where $\alpha_{\mathrm{T}}=6.5 \times 10^{-6} \mathrm{in} / \mathrm{in} /{ }^{\circ} \mathrm{F}, \mathrm{L}=1890$ in. $(157.5 \mathrm{ft}), \mathrm{T}_{2}=+60^{\circ} \mathrm{F}$ and $\mathrm{T}_{1}=$ $0^{\circ} \mathrm{F}$. Substituting these values produces the $\Delta_{\mathrm{T}}$ shown below.

$$
\begin{gathered}
\Delta_{T}=\alpha_{T} L\left(T_{2}-T_{1}\right) \\
\Delta_{\mathbf{T}}=6.5 \times 10^{-6} \times 1890 \times(60-0)=\mathbf{0 . 7 3 7 1} \mathrm{in} .
\end{gathered}
$$




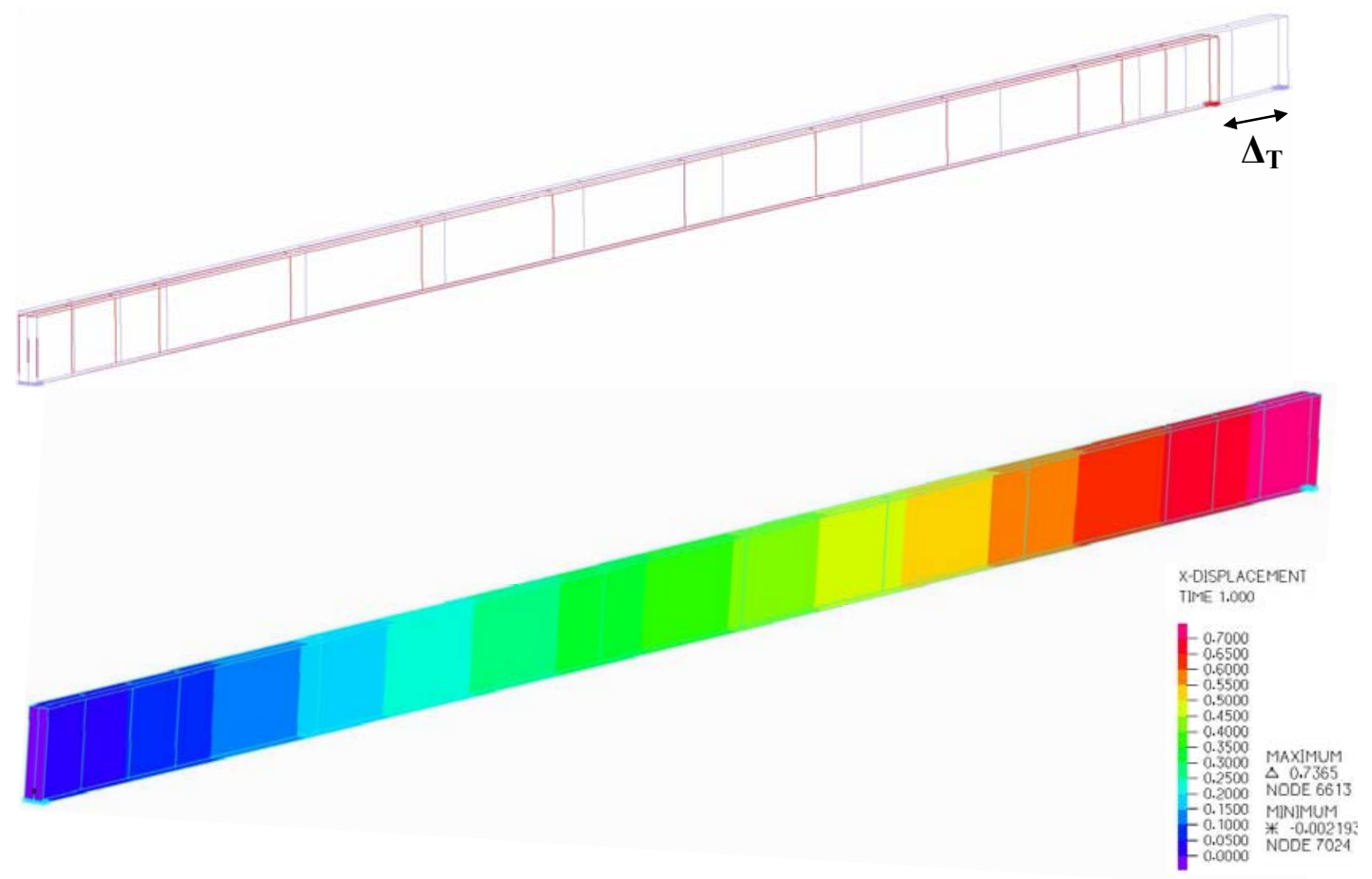

Figure 4.18. Single girder model thermal expansion results

The magnitude of thermal expansion determined using the closed-form solution is $0.7371 \mathrm{in}$. This value is compared to the value produced by the single girder model, where the magnitude of thermal expansion is 0.7365 in. A discrepancy of $0.0814 \%$ exists between the closed-form solution and single girder FE model. This investigation has shown that the method selected for representing the bridge bearings in the Man Bridge FE model is correct, at least on this relatively small scale. The next logical step is to validate the use of the spring elements for the full-scale Man Bridge FE model. 


\subsubsection{Spring Element Validation - Full-Scale FE Model}

The single girder model just presented verified, on a small scale, that using linear spring elements to represent the boundary conditions required by the Man Bridge's

designed bearing arrangement is acceptable. However, to truly determine the accuracy of the Man Bridge FE model, this method must now be validated by comparing results from the Man Bridge FE model to experimental measurements. To accomplish this, LVDT displacement data pertaining to translation of the guided bearings at Abutment 1 is compared to values produced by the FE model at the same location. Figure 4.19 shows displacement data of the guided bearings (Girder 3, Girder 2) at Abutment 1 over a period of approximately 250 days. This time period involves seasonal variations in temperature, and so, large variations are present. Also, since a temperature cycle from summer to winter has occurred it is likely that the bridge has experienced its full range thermal movement.

Close examination of the LVDT data (Shoukry et al. 2012) shows a translation of approximately 2.8 in. in Girder 3 (G3) and 2.6 in. in Girder 2 (G2). These movements are in accordance with a temperature variation of $-55^{\circ} \mathrm{F}\left(80^{\circ} \mathrm{F}-25^{\circ} \mathrm{F}\right)$ from late August 2009 through late February 2010. These values are compared to data produced by the Man Bridge FE model when the steel superstructure is subjected to a $-55^{\circ} \mathrm{F}$ uniform temperature load. Nodal displacements at Girder 2 and Girder 3 are approximately 2.6 in. and 2.5 in., respectively. This data is summarized in Table 4.3 and shows that the FE model produces smaller bearing displacements compared to experimental values. An approximate 7\% difference occurs in Girder 3, which is deemed acceptable. 


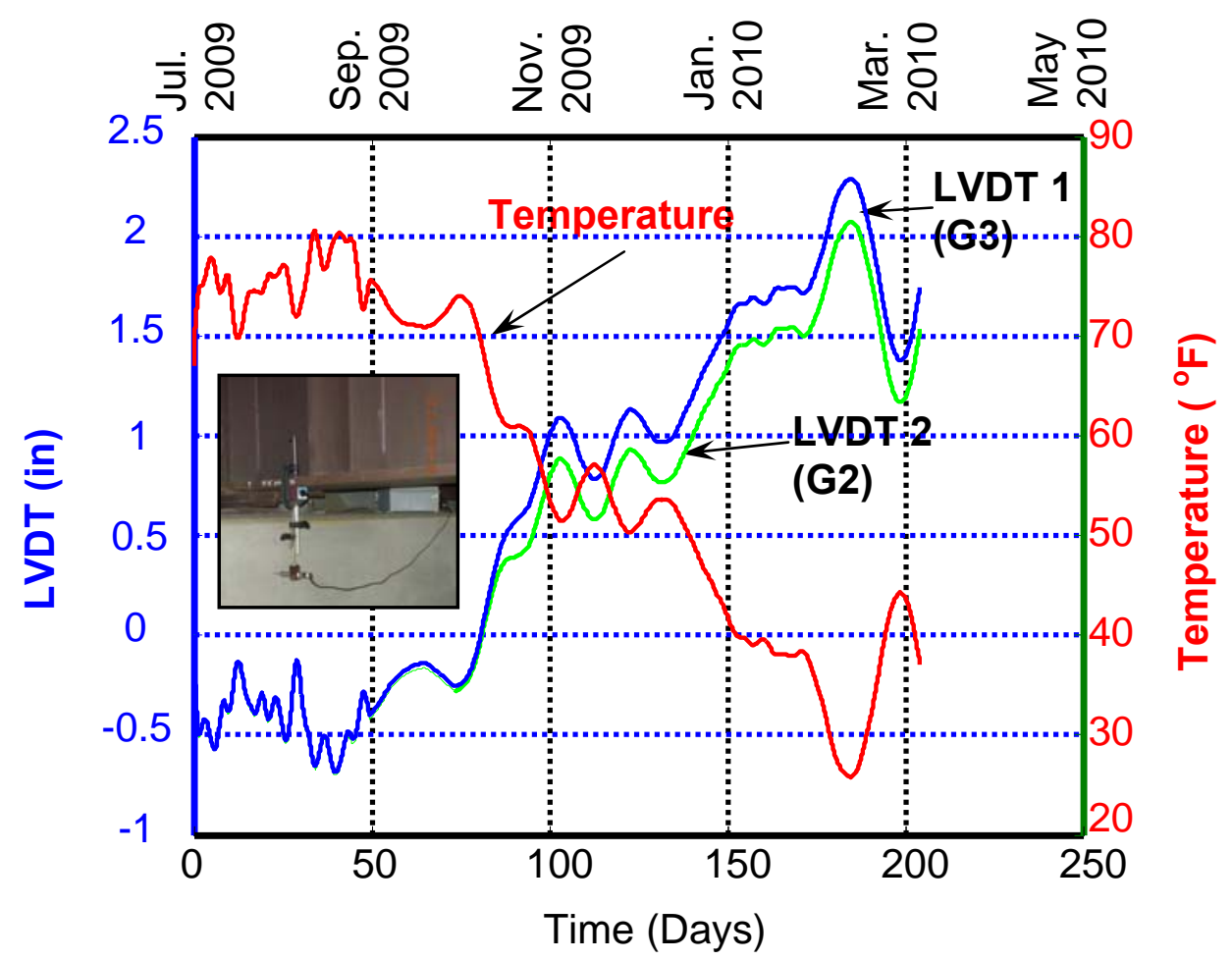

Figure 4.19. LVDT instrumentation data for translation of Girder 2 and Girder 3 at Abutment 1 (Shoukry et al. 2012)

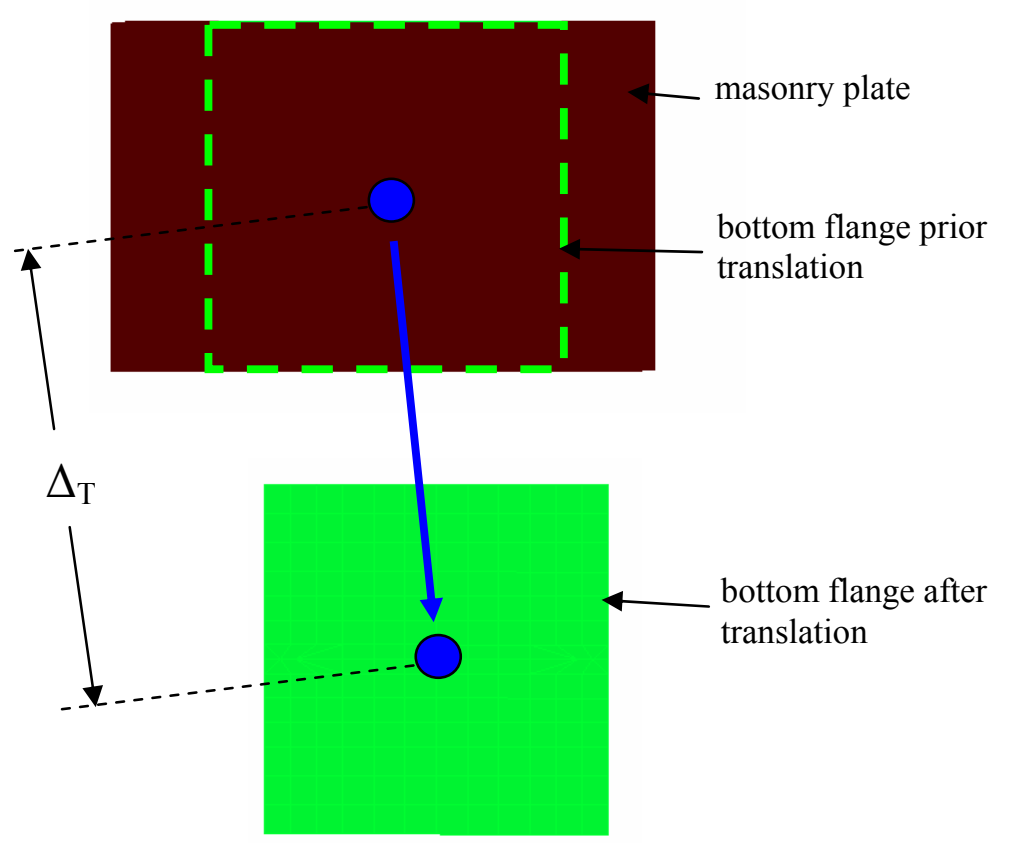

Figure 4.20. Bearing translation at Abutment 1 
Table 4.3. LVDT vs FE model bearing displacement

\begin{tabular}{|l|c|c|}
\hline & \multicolumn{2}{|c|}{ Translation (in) } \\
\hline & LVDT & FE model \\
\hline Girder 2 (G2) & 2.6 & 2.5 \\
\hline Girder 3 (G3) & 2.8 & 2.6 \\
\hline
\end{tabular}

The LVDT data was gathered over a period of approximately 250 days, encompassing seasonal and daily effects due to temperature variations including creep, fatigue behavior, etc. These types of effects cannot be captured by the Man Bridge FE model without introducing initial loading conditions. Also, the thermal load applied in the FE model represent a mostly seasonal temperature variation, and so, effects due to daily temperature variations are not included. Additionally, the FE model is free from any initial displacements or distortions which were present in the actual structure prior to the collection of the physical measurements. When considering the influence that these particular details provide, increasing the displacements at throughout the bridge, the response of the Man Bridge FE model agrees very well with the that of the actual bridge.

\subsection{Conclusion}

With the modifications to the bearings and support piers discussed in this chapter, a very accurate representation of the Man Bridge has been recreated within an FE environment. The details outlined here, combined with the general description of the bridge given in Chapter Three, provide an extensive overview of the FE model utilized for this study. LVDT data for bearing displacement at Abutment 1 was used to validate the response of the FE model, which was shown to produce very agreeable behavior. 


\section{CHAPTER FIVE}

\section{FEA of the Man Bridge and Assessment versus Field Observations}

\subsection{Introduction}

The primary goal of this work is to demonstrate that restrained thermal deformation of a steel girder superstructure has lead to unfavorable conditions throughout the substructure of an in-service slab-on-girder bridge. A detailed field inspection of the Man Bridge, presented in Chapter Three, produced evidence leading to the hypothesis that restrained thermal deformation of the bridge's superstructure is the main reason for the development of such conditions Now, to substantiate the validity of this assumption and study the behavior of the bridge, comprehensive and detailed 3D finite element analysis (FEA) was undertaken. In this chapter, the results produced by this 3D FEA are discussed and closely compared to the observations made during the field investigation from Chapter Three.

Finite element analysis was conducted in order to investigate the response of the bridge to uniform thermal loads. The results presented in this chapter describe the response of the Man Bridge FE model with boundary conditions implemented in adherence with the bearing arrangement provided in the design drawings. Data pertaining to superstructure displacement at the bearings, stresses in the bottom flanges near the bearing devices, horizontal shear force in the bearing anchor bolts, lateral deflection of the support piers, and stresses in the support piers is examined. The FEA responses predicted here are used to substantiate the findings made during the field 
investigation and offer tentative evidence that thermal deformation in steel I-girder bridges can lead to significant, detrimental effects in certain structural components.

\subsubsection{Calculation of Uniform Thermal Loads}

The magnitude of the uniform thermal loads applied to the superstructure of the Man Bridge FE model were calculated in accordance with Procedure B in Article 3.12.2 of the AASHTO (2007) bridge design specifications where maximum and minimum design temperature loads, $\mathrm{T}_{\text {MaxDesign }}$ and $\mathrm{T}_{\text {MinDesign, }}$ are selected using Figures 3.12.2.2-3 and 3.12.2.2-4, respectively. $\mathrm{T}_{\text {MaxDesign }}$ and $\mathrm{T}_{\text {MinDesign }}$ represent temperature extremes that the structure is likely to be subject to over a 70 year return period. These values are used in order to define a design temperature range for use in Equation 5.1, which calculates the design thermal movement range, $\Delta_{\mathrm{T}}$, where $\alpha$ is the coefficient of thermal expansion for the steel I-girders. This value represents the absolute maximum displacement the superstructure may experience. Using Figures 3.12.2.2-3 and 3.12.2.2-4, $\mathrm{T}_{\text {MaxDesign }}$ and $\mathrm{T}_{\text {MinDesign }}$ were determined to be $110^{\circ} \mathrm{F}$ and $-10^{\circ} \mathrm{F}$, respectively. This gives an bridge design temperature range of $120^{\circ} \mathrm{F}$.

$$
\Delta_{T}=\alpha L\left(T_{\text {MaxDesign }}-T_{\text {MinDesign }}\right)
$$

An absolute temperature range of $130^{\circ} \mathrm{F}$ is applied to the $\mathrm{FE}$ model through uniform thermal loads of $+60^{\circ} \mathrm{F}$ (a temperature increase) and $-70^{\circ} \mathrm{F}$ (a temperature decrease). These uniform temperature values represent departures from a design installation temperature, or reference temperature, of $60^{\circ} \mathrm{F}$. For example, since the design 
installation temperature is $60^{\circ} \mathrm{F}$, when subject to a $-70^{\circ} \mathrm{F}$ temperature load the air temperature around the bridge would be $-10^{\circ} \mathrm{F}$. This temperature value is equal in magnitude to $\mathrm{T}_{\text {MinDesign. }}$. Similarly, the $+60^{\circ} \mathrm{F}$ thermal load implies an air temperature of $120^{\circ} \mathrm{F}$, representing a probable extreme event. In ADINA the reference temperature is $0^{\circ} \mathrm{F}$, so the magnitude of the applied thermal loads is $+60^{\circ} \mathrm{F}$ and $-70^{\circ} \mathrm{F}$.

\subsection{Superstructure Translation at the Bearings}

A detailed analysis of superstructure displacement as predicted by the FE model provides important information regarding bridge behavior. Bearing displacements produced by the FE model can be compared to the design thermal movement range provided in the bridge's design drawings. Performing these comparisons allows a determination on whether or not the thermal response of the steel I-girder superstructure occurs as expected. Additionally, the recommendations in AASHTO $(2003,2007)$ regarding the orientation of guided expansion bearings can be evaluated on a relatively large structure. As discussed in Chapter Two, previous investigations concerning thermal movement of horizontally curved girder bridges have been limited to structures having few spans and supports. The current study involves two geometrically different structures, each consisting of six continuous spans.

Also, quantifying the displacement of the superstructure at the fixed bearings, in conjunction with an analysis of pier rigidity, permits a preliminary assumption regarding the effect of substructure flexibility on thermal movement of the steel I-girders. A rough analysis can be conducted by comparing bearing displacements with the rigidity provided by the support pier columns. If the rigidity of pier columns is large in comparison to the 
expected magnitude of thermal expansion of the steel I-girders, it is likely that thermal stresses have developed around the bearings and in the piers. A more detailed analysis of stresses in the piers follows in Section 5.6. This section presents a comprehensive examination and analysis of the thermal movement of the superstructure as predicted by the Man Bridge FE model.

Recalling the designed bearing arrangements outlined in Chapter Three (Figures 3.5 and 3.6), the four steel I-girders of the Man Bridge superstructure rest on fixed bearings at Piers 2-5 and Piers 7-9. The outer girders (G1, G4) rest on free expansion bearings at these locations. Initially, a global coordinate system (X-Y) is provided at the fixed and free bearings. When needed, displacement at these bearings is discussed relative to a more useful cylindrical coordinate system utilizing radial and tangential components (R-T).

The inner two girders (G2, G3) rest on guided expansion bearings at Abutment 1, Pier 1, Pier 6L, Pier 6R, Pier 10, Pier 11 and Abutment 2. Figures 5.1 and 5.2 illustrate the orientation of the guided expansion bearings in Unit 1 and Unit 2, respectively. The guided expansion bearings are aligned in a chordal manner with respect to the nearest fixed bearing, requiring the creation of a separate coordinate system at each bearing location. A total of 14 coordinate systems were created using the "SKEW SYSTEMS" option in ADINA, which essentially introduces a local coordinate system where necessary. The "SKEW SYTEMS" command was chosen because longitudinal and transverse degrees-of-freedom (DOFs) can be directly specified during pre-processing and displacement values easily output during post-processing, eliminating the need to perform coordinate transformation calculations 


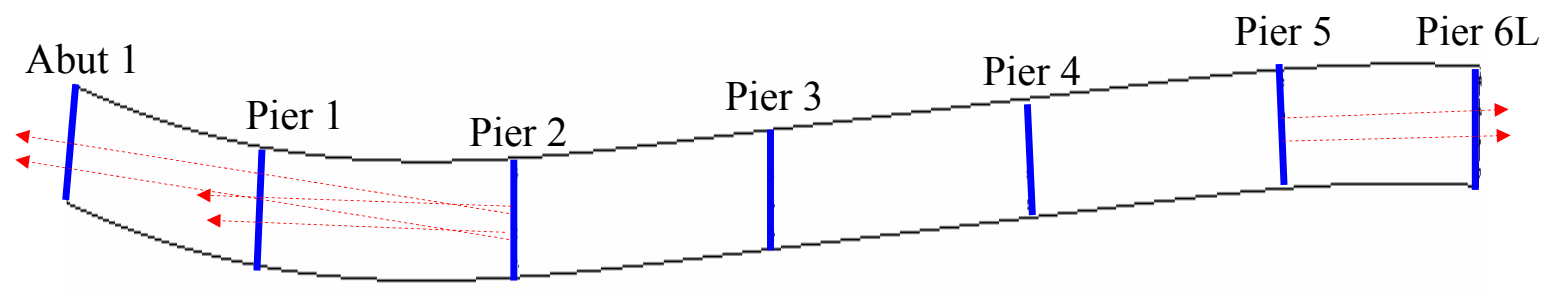

Figure 5.1. Expansion bearing orientation, Unit 1

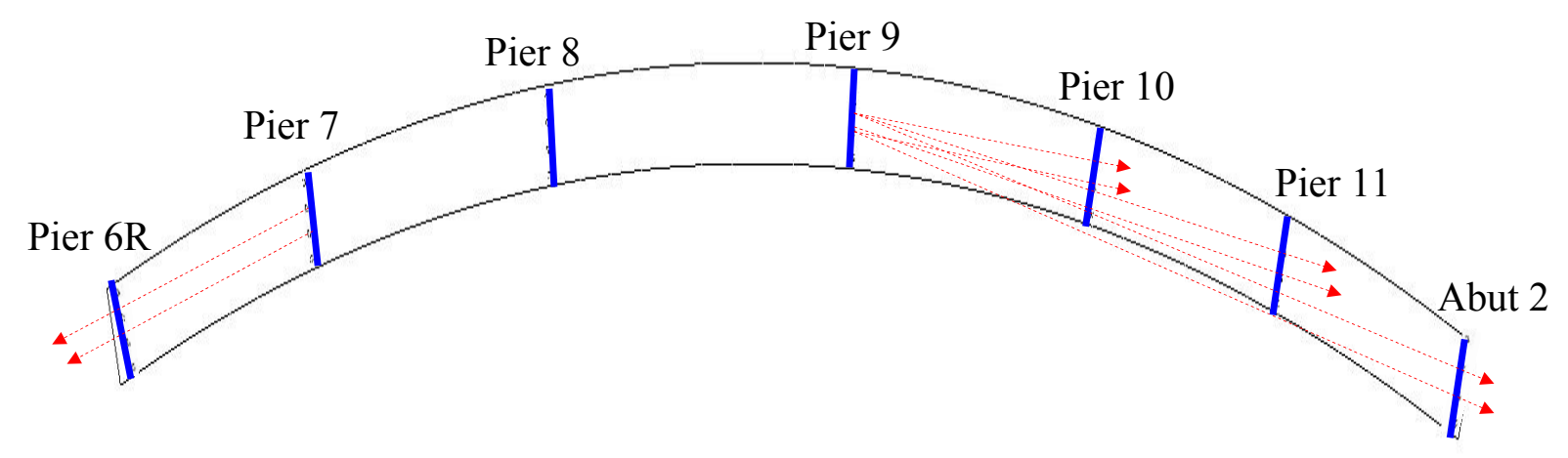

Figure 5.2. Expansion bearing orientation, Unit 2 
Figures 5.3-5.4 illustrate the in-plane translation of the concrete bridge deck when the underlying steel I-girder superstructure is subjected to the $+60^{\circ} \mathrm{F}$ thermal load. Likewise, Figures 5.5-5.6 show the in-plane translation of the bridge deck with the $-70^{\circ} \mathrm{F}$ thermal load applied. The solid black outline represents the structure in its undeformed state, while the deformed shape is outlined in red. A broad understanding of superstructure behavior can be ascertained simply by studying these deformed shapes.

First, the location of a "stationary point" within each structure can be approximated. Recall from Chapter Two that the stationary point is a location in the structure where no translation takes place as the superstructure undergoes thermal deformation. In Unit 1, this point is located in Span 4, near Pier 3 when the superstructure undergoes thermal expansion. This is similar as the superstructure experiences contraction. In Unit 2, this stationary point is located in Span 9 near Pier 8 during both thermal expansion and contraction.

In both units, it appears that thermal deformation of the steel superstructure is occurring in a manner consistent with that discussed in AASHSTO $(2003,2007)$. That is to say that translations takes place along rays emanating from the fixed bearings Even so, the stationary point is not located precisely at a support location and the alignment of the guided bearings may be affected. Unfortunately, Figures 5.3-5.6 cannot relay information regarding the magnitude of superstructure displacement or lateral pier deflection. Likewise, the development of thermal forces at the bearings and in the substructure is unclear at this point. The adequacy of the bearing arrangement in accommodating thermal deformation of the superstructures cannot be fully determined without investigating these details. 




Figure 5.3. Thermal movement of Unit 1 under the $+60^{\circ} \mathrm{F}$ thermal load

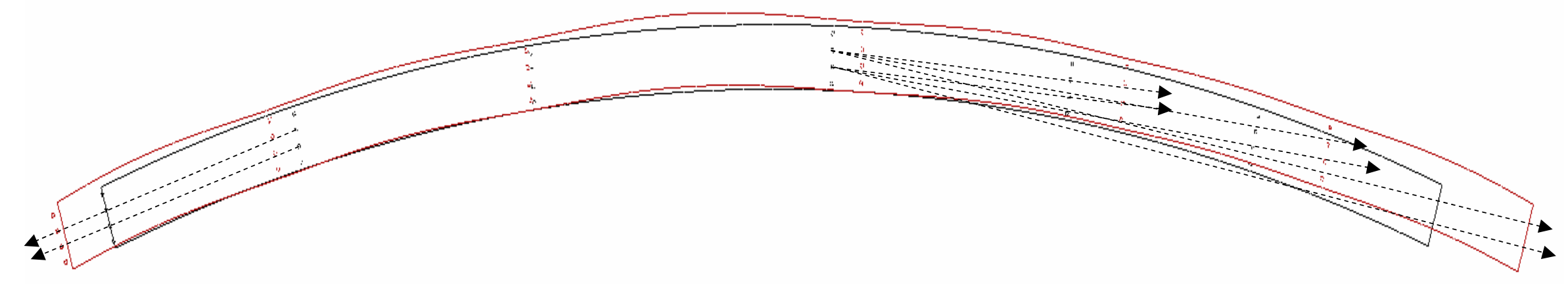

Figure 5.4. Thermal movement of Unit 2 under the $+60^{\circ} \mathrm{F}$ thermal load 




Figure 5.5. Thermal movement of Unit 1 under $-70^{\circ} \mathrm{F}$ thermal load



Figure 5.6. Thermal movement of Unit 2 under $-70^{\circ} \mathrm{F}$ thermal load 
Tables 5.1 and 5.2 present the design temperature movement ranges for each bearing as provided in the bridge's design drawings. Tables 5.3 and 5.4 present the longitudinal and transverse displacement of each bearing as predicted by the FE model. Prior to beginning an analysis regarding thermal movement of the bridge, a short explanation of the coordinate systems used in the FE model is useful. Due to the technique used to construct the model, the fixed and free bearings were not assigned a particular coordinate system and thus, displacement data is output in a global coordinate system. Results concerning these bearing locations is transformed into a more functional cylindrical coordinate system so that tangential (i.e. longitudinal) and radial (i.e. transverse) displacement data could be easily illustrated relative to the curved geometry of the bridge. Displacement data from the guided bearings needed no such coordinate transformation as results were output from ADINA in an appropriate manner.

Table 5.1 Design longitudinal translation

\begin{tabular}{|c|c|c|c|c|c|c|c|c|c|c|c|c|c|c|}
\hline & \multicolumn{14}{|c|}{ Design Longitudinal Movement (in) } \\
\hline & Abut 1 & Pier 1 & Pier 2 & Pier 3 & Pier 4 & Pier 5 & Pier 6L & Pier 6R & Pier 7 & Pier 8 & Pier 9 & Pier 10 & Pier 11 & Abut 2 \\
\hline G1 & 9.75 & 8.125 & - & - & - & - & 8.0 & 6.625 & - & - & - & 8.0 & 9.75 & 11.375 \\
\hline G2 & 9.75 & 8.125 & - & - & - & - & 8.0 & 6.625 & - & - & - & 8.0 & 9.75 & 11.375 \\
\hline G3 & 9.75 & 8.125 & - & - & - & - & 8.0 & 6.625 & - & - & - & 8.0 & 9.75 & 11.375 \\
\hline G4 & 9.75 & 8.125 & - & - & - & - & 8.0 & 6.625 & - & - & - & 8.0 & 9.75 & 11.375 \\
\hline
\end{tabular}

Table 5.2 Design transverse translation

\begin{tabular}{|c|c|c|c|c|c|c|c|c|c|c|c|c|c|c|}
\hline & \multicolumn{14}{|c|}{ Design Longitudinal Movement (in) } \\
\hline & Abut 1 & Pier 1 & Pier 2 & Pier 3 & Pier 4 & Pier 5 & Pier 6L & Pier 6R & Pier 7 & Pier 8 & Pier 9 & Pier 10 & Pier 11 & Abut 2 \\
\hline G1 & 2.0 & 2.0 & - & - & - & - & 2.0 & 2.0 & - & - & - & 2.0 & 2.0 & 2.0 \\
\hline G2 & - & - & - & - & - & - & - & - & - & - & - & - & - & - \\
\hline G3 & - & - & - & - & - & - & - & - & - & - & - & - & - & - \\
\hline G4 & 2.0 & 2.0 & - & - & - & - & 2.0 & 2.0 & - & - & - & 2.0 & 2.0 & 2.0 \\
\hline
\end{tabular}


Table 5.3. FE model bearing displacement for $+60^{\circ} \mathrm{F}$ load case

\begin{tabular}{|c|c|c|c|c|c|}
\hline \multirow{2}{*}{\multicolumn{2}{|c|}{ Temp $+60^{\circ} \mathrm{F}$}} & \multicolumn{4}{|c|}{ Displacement (in) } \\
\hline & & Transverse & Longitudinal & Global X & Global Y \\
\hline \multirow{4}{*}{ Abut 1} & G4 & & & 0.230 & -2.762 \\
\hline & G3 & 0.075 & -2.752 & 0.222 & -2.744 \\
\hline & G2 & 0.087 & -2.741 & 0.209 & -2.734 \\
\hline & G1 & & & 0.199 & -2.733 \\
\hline \multirow{4}{*}{ Pier 1} & G4 & & & 0.304 & -2.010 \\
\hline & G3 & 0.020 & -2.028 & 0.286 & -2.008 \\
\hline & G2 & 0.023 & -2.023 & 0.282 & -2.003 \\
\hline & G1 & & & 0.268 & -1.999 \\
\hline \multirow{4}{*}{ Pier 2} & G4 & 0.020 & -1.077 & 0.227 & -1.053 \\
\hline & G3 & 0.019 & -1.075 & 0.225 & -1.051 \\
\hline & G2 & 0.016 & -1.074 & 0.222 & -1.051 \\
\hline & G1 & 0.014 & -1.076 & 0.220 & -1.053 \\
\hline \multirow{4}{*}{ Pier 3} & G4 & 0.018 & -0.290 & 0.079 & -0.280 \\
\hline & G3 & 0.016 & -0.290 & 0.077 & -0.280 \\
\hline & G2 & 0.013 & -0.291 & 0.074 & -0.281 \\
\hline & G1 & 0.011 & -0.292 & 0.073 & -0.283 \\
\hline \multirow{4}{*}{ Pier 4} & G4 & 0.040 & 0.496 & -0.066 & 0.494 \\
\hline & G3 & 0.038 & 0.495 & -0.067 & 0.492 \\
\hline & G2 & 0.036 & 0.494 & -0.069 & 0.490 \\
\hline & G1 & 0.034 & 0.494 & -0.071 & 0.490 \\
\hline \multirow{4}{*}{ Pier 5} & G4 & 0.035 & 1.308 & -0.223 & 1.290 \\
\hline & G3 & 0.034 & 1.305 & -0.224 & 1.287 \\
\hline & G2 & 0.031 & 1.306 & -0.226 & 1.287 \\
\hline & G1 & 0.029 & 1.308 & -0.229 & 1.288 \\
\hline \multirow{4}{*}{ Pier 6L } & G4 & & & -0.327 & 2.100 \\
\hline & G3 & -0.020 & 2.116 & -0.345 & 2.087 \\
\hline & G2 & -0.018 & 2.123 & -0.347 & 2.093 \\
\hline & G1 & & & -0.362 & 2.112 \\
\hline \multirow{4}{*}{ Pier 6R } & G4 & & & 0.153 & -1.575 \\
\hline & G3 & -0.007 & -1.595 & 0.151 & -1.587 \\
\hline & G2 & -0.005 & -1.610 & 0.151 & -1.603 \\
\hline & G1 & & & 0.147 & -1.624 \\
\hline \multirow{4}{*}{ Pier 7} & G4 & -0.029 & -0.764 & -0.002 & -0.765 \\
\hline & G3 & -0.031 & -0.765 & -0.004 & -0.765 \\
\hline & G2 & -0.035 & -0.765 & -0.008 & -0.766 \\
\hline & G1 & -0.037 & -0.765 & -0.009 & -0.766 \\
\hline \multirow{4}{*}{ Pier 8} & G4 & -0.060 & -0.098 & -0.067 & -0.093 \\
\hline & G3 & -0.061 & -0.102 & -0.069 & -0.097 \\
\hline & G2 & -0.062 & -0.106 & -0.070 & -0.101 \\
\hline & G1 & -0.061 & -0.111 & -0.070 & -0.105 \\
\hline \multirow{4}{*}{ Pier 9} & G4 & -0.057 & 0.920 & 0.150 & 0.909 \\
\hline & G3 & -0.059 & 0.925 & 0.149 & 0.915 \\
\hline & G2 & -0.063 & 0.929 & 0.146 & 0.920 \\
\hline & G1 & -0.065 & 0.934 & 0.145 & 0.925 \\
\hline \multirow{4}{*}{ Pier 10} & G4 & & & 0.467 & 1.646 \\
\hline & G3 & 0.000 & 1.716 & 0.464 & 1.652 \\
\hline & G2 & 0.015 & 1.730 & 0.402 & 1.682 \\
\hline & G1 & & & 0.404 & 1.690 \\
\hline \multirow{4}{*}{ Pier 11} & G4 & & & 0.728 & 2.164 \\
\hline & G3 & 0.010 & 2.283 & 0.710 & 2.169 \\
\hline & G2 & 0.010 & 2.299 & 0.692 & 2.175 \\
\hline & G1 & & & 0.684 & 2.177 \\
\hline \multirow{4}{*}{ Abut 2} & G4 & & & 1.111 & 2.834 \\
\hline & G3 & 0.012 & 2.975 & 1.083 & 2.843 \\
\hline & G2 & 0.008 & 2.996 & 1.087 & 2.854 \\
\hline & G1 & & & 1.092 & 2.881 \\
\hline
\end{tabular}


Table 5.4. FE model bearing displacement for $-70^{\circ} \mathrm{F}$ load case

\begin{tabular}{|c|c|c|c|c|c|}
\hline \multirow{2}{*}{\multicolumn{2}{|c|}{ Temp $-7^{\circ} \mathrm{F}$}} & \multicolumn{4}{|c|}{ Displacement (in) } \\
\hline & & Transverse & Longitudinal & $\mathbf{X}$ & $\mathbf{Y}$ \\
\hline \multirow{4}{*}{ Abut 1} & G4 & & & -0.323 & 2.916 \\
\hline & G3 & -0.002 & 2.923 & -0.314 & 2.906 \\
\hline & G2 & -0.017 & 2.920 & -0.298 & 2.905 \\
\hline & G1 & & & -0.286 & 2.913 \\
\hline \multirow{4}{*}{ Pier 1} & G4 & & & -0.377 & 2.216 \\
\hline & G3 & 0.016 & 2.244 & -0.355 & 2.216 \\
\hline & G2 & 0.016 & 2.239 & -0.354 & 2.211 \\
\hline & G1 & & & -0.330 & 2.206 \\
\hline \multirow{4}{*}{ Pier 2} & G4 & -0.030 & 1.232 & -0.266 & 1.203 \\
\hline & G3 & -0.030 & 1.227 & -0.265 & 1.198 \\
\hline & G2 & -0.031 & 1.223 & -0.265 & 1.195 \\
\hline & G1 & -0.030 & 1.222 & -0.264 & 1.193 \\
\hline \multirow{4}{*}{ Pier 3} & G4 & 0.001 & 0.320 & -0.067 & 0.313 \\
\hline & G3 & 0.000 & 0.320 & -0.067 & 0.313 \\
\hline & G2 & -0.001 & 0.318 & -0.068 & 0.311 \\
\hline & G1 & 0.000 & 0.319 & -0.068 & 0.312 \\
\hline \multirow{4}{*}{ Pier 4} & G4 & 0.042 & -0.591 & 0.166 & -0.568 \\
\hline & G3 & 0.043 & -0.591 & 0.167 & -0.568 \\
\hline & G2 & 0.042 & -0.591 & 0.166 & -0.568 \\
\hline & G1 & 0.042 & -0.592 & 0.167 & -0.570 \\
\hline \multirow{4}{*}{ Pier 5} & G4 & 0.059 & -1.436 & 0.341 & -1.396 \\
\hline & G3 & 0.060 & -1.436 & 0.341 & -1.396 \\
\hline & G2 & 0.059 & -1.439 & 0.341 & -1.399 \\
\hline & G1 & 0.060 & -1.445 & 0.343 & -1.405 \\
\hline \multirow{4}{*}{ Pier 6L } & G4 & & & 0.377 & -2.167 \\
\hline & G3 & 0.021 & -2.187 & 0.397 & -2.150 \\
\hline & G2 & 0.021 & -2.188 & 0.398 & -2.152 \\
\hline & G1 & & & 0.416 & -2.167 \\
\hline \multirow{4}{*}{ Pier 6R } & G4 & & & -0.153 & 1.606 \\
\hline & G3 & 0.002 & 1.609 & -0.148 & 1.601 \\
\hline & G2 & 0.000 & 1.607 & -0.145 & 1.601 \\
\hline & G1 & & & -0.136 & 1.605 \\
\hline \multirow{4}{*}{ Pier 7} & G4 & 0.045 & 0.910 & 0.013 & 0.911 \\
\hline & G3 & 0.048 & 0.915 & 0.015 & 0.916 \\
\hline & G2 & 0.053 & 0.920 & 0.020 & 0.922 \\
\hline & G1 & 0.054 & 0.926 & 0.021 & 0.927 \\
\hline \multirow{4}{*}{ Pier 8} & G4 & 0.102 & 0.026 & 0.104 & 0.018 \\
\hline & G3 & 0.106 & 0.022 & 0.107 & 0.013 \\
\hline & G2 & 0.112 & 0.018 & 0.113 & 0.009 \\
\hline & G1 & 0.114 & 0.014 & 0.115 & 0.005 \\
\hline \multirow{4}{*}{ Pier 9} & G4 & 0.101 & -0.973 & -0.118 & -0.971 \\
\hline & G3 & 0.104 & -0.971 & -0.115 & -0.970 \\
\hline & G2 & 0.107 & -0.970 & -0.112 & -0.969 \\
\hline & G1 & 0.107 & -0.969 & -0.111 & -0.969 \\
\hline \multirow{4}{*}{ Pier 10} & G4 & -0.535 & -1.837 & -0.535 & -1.837 \\
\hline & G3 & -0.011 & -1.915 & -0.529 & -1.841 \\
\hline & G2 & -0.027 & -1.926 & -0.458 & -1.871 \\
\hline & G1 & -0.458 & -1.877 & -0.458 & -1.877 \\
\hline \multirow{4}{*}{ Pier 11} & G4 & & & -0.869 & -2.510 \\
\hline & G3 & -0.009 & -2.665 & -0.848 & -2.527 \\
\hline & G2 & -0.007 & -2.678 & -0.827 & -2.544 \\
\hline & G1 & & & -0.827 & -2.554 \\
\hline \multirow{4}{*}{ Abut 2} & G4 & & & -1.195 & -3.048 \\
\hline & G3 & -0.001 & -3.199 & -1.159 & -3.041 \\
\hline & G2 & -0.007 & -3.201 & -1.157 & -3.039 \\
\hline & G1 & & & -1.152 & -3.055 \\
\hline
\end{tabular}


In Tables 5.3 and 5.4, the sign convention associated with longitudinal displacements can be disregarded. Due to how the coordinate systems were input in FE program, negative (-) values of displacement simply represent movement away from the point through which the guided bearings are oriented. Additionally, displacement of the free bearings is neglected as it is indistinguishable from the displacement of the accompanying guided bearings.

The design longitudinal displacement range varies among each support location, as expected. A maximum of $11.375 \mathrm{in}$. is calculated at Abutment 2, while a minimum of 6.625 in. is calculated at Pier 6R. Throughout the bridge, the magnitude of longitudinal bearing displacement predicted by the FE model is $42-55 \%$ less than the design thermal movement range given in the design drawings. This is plotted in Figure 5.7. After comparing the values, it is apparent that the bearing arrangement is not allowing the expected magnitude of thermal deformation. A certain level of discrepancy between the FE model and design values was anticipated, but such large differences are quite extraordinary. The designed bearing arrangement implemented on the Man Bridge is greatly restraining thermal deformation of the superstructure.

Within AASHTO, load factors, which increase the effect of the applied loads, are routinely applied to certain nominal load values in order to establish final design values. However, a load factor is not applied directly to the design thermal movements. When determining the effect of temperature loads (uniform temperature load TU, temperature gradient TG), a load factor is applied to the force effects resulting from the design temperature movements. A load factor is not incorporated in to the thermal movement 
design values, therefore, a direct comparison between FE predictions of bearing displacement and design thermal movements as presented here is acceptable.

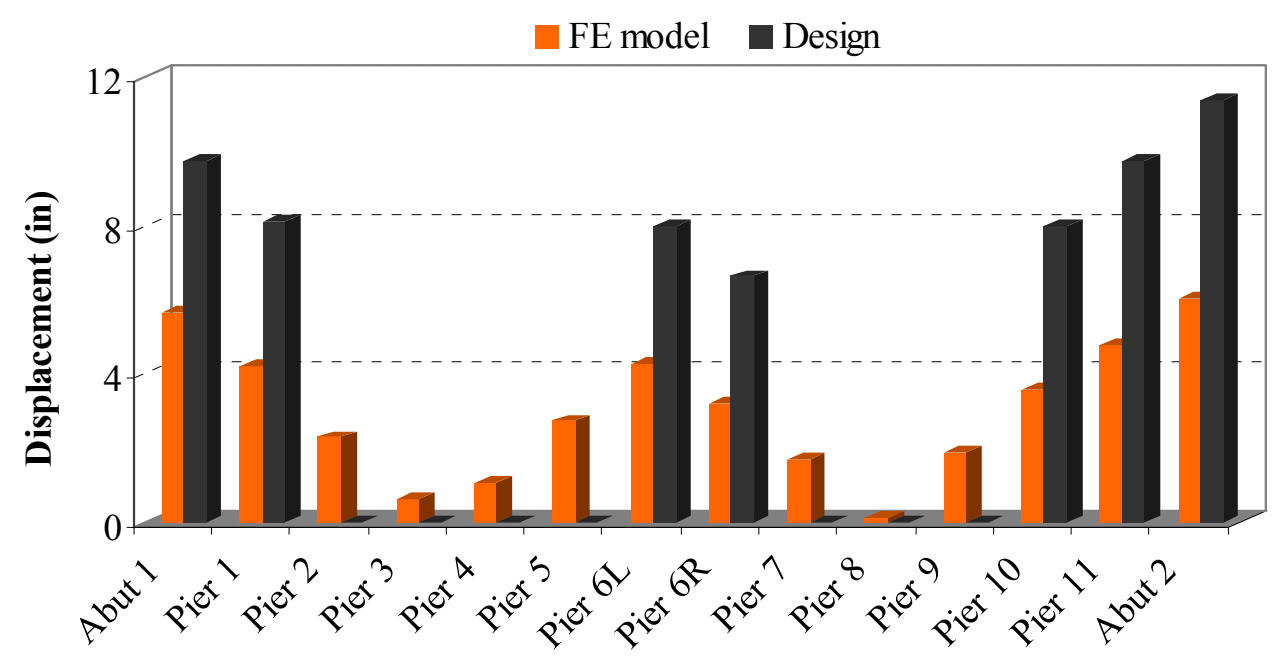

Figure 5.7. Comparison between the design thermal movement range and FE model predictions

AASHTO (2007) states that Procedure B in Article 3.12.2 is based on concepts proposed in Roeder (2002b), however, the equation seen in AASHTO (2007) (Eq. 5.1) is not found within the specific literature. More specifically, determining an appropriate value for the expansion length $L$ is vague. Typically, $L$ is measured relative to the fixed point within a bridge, however, when multiple fixed points exist this process is more complex. It is unknown whether $L$ should be measured relative to the nearest fixed support, as the FE model is and AASHTO (1993) permits, or measured relative to the centroid of fixed points, as is generally accepted in modern practice. Pier stiffness can complicate accurate prediction of thermal movement of the superstructure as well, typically reducing the magnitude of thermal movement. For these reasons, the work by 
Roeder (2002b) excluded bridges employing fixed bearings at multiple interior piers.

Without definitive knowledge of how the design thermal movements were determined, an accurate theoretical explanation for the large discrepancy between the FE model predictions and actual design values cannot be definitely confirmed.

\subsection{Shear Force in the Bearing Anchor Bolts}

Examination of the magnitude of horizontal shear force that develops in the bearing anchor bolts when the superstructure is subjected to thermal loads can provide information regarding any restraint against thermal movement provided by the bearings. More specifically, large shear forces in the anchor bolts signify that the bearing arrangement is not accommodating thermal deformation in the manner anticipated during design. Reaction forces due to restrained thermal deformation are transferred through the bearing anchor bolts and into the concrete support piers. As documented during the field investigation in Chapter Three, deformed bearing anchor bolts were found at numerous locations throughout the bridge, indicating that horizontal forces acting on the bolts are quite large. This section looks closely at the magnitude of shear force that develops in the bearing anchor bolts.

Figure 5.8 illustrates how shear forces develop in the anchor bolts and provides the convention used by ADINA to define the beam elements. Horizontal force components along an s- and t-axis provide shear force in the respective directions. The beam elements are oriented so that force in the t-direction represents longitudinal shear force, and force in the s-direction represents transverse shear force. It is important to note that a major assumption must be made at this point. That is, horizontal shear force 
acts equally on each bolt within a particular bolt group. This assumption is made for two reasons. First, it greatly simplifies the analysis. Second, it is necessary given that a single line of beam elements was defined in order to model each bolt line. Due to this simplification, any force differential that may develop among the bolts cannot be captured by the FE model. Tables 5.5-5.6 summarize the shear force that develops at each bearing within the FE model.
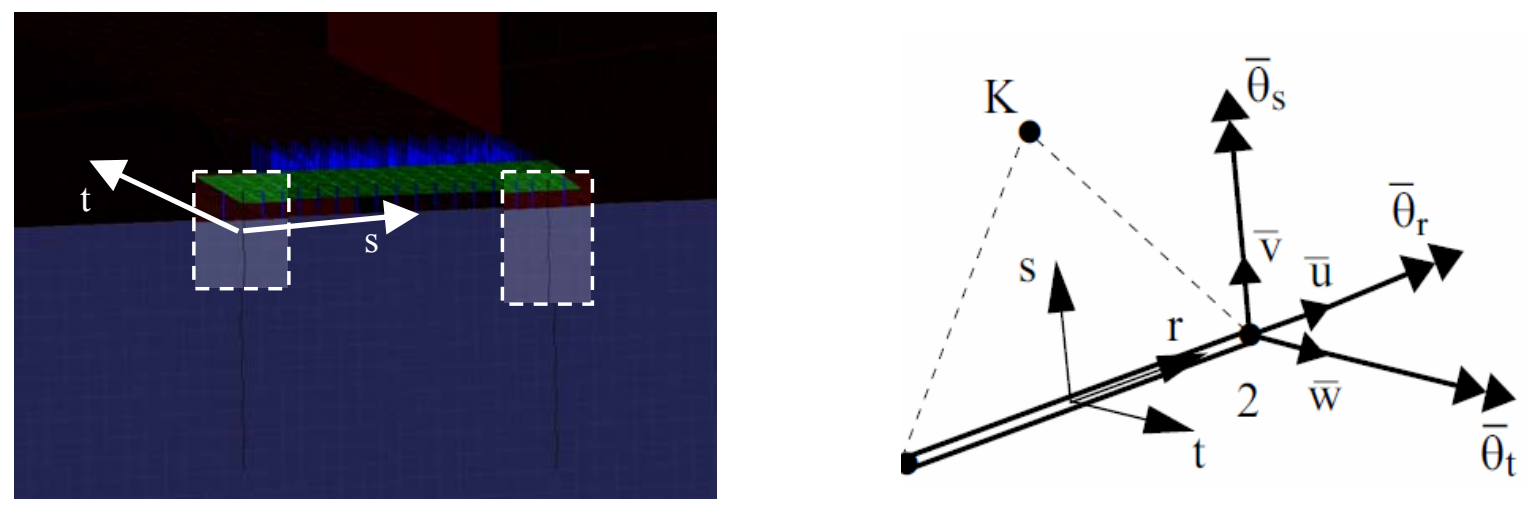

Figure 5.8. Development of shear force in the bearing anchor bolts and beam element convention 
Table 5.5. Total shear force per bolt group (Temp $+60^{\circ} \mathrm{F}$ thermal load)

\begin{tabular}{|c|c|c|c|c|c|c|c|c|c|c|c|c|}
\hline \multicolumn{13}{|c|}{ Horizontal Force acting on each bolt GROUP (kip) } \\
\hline & Pier 1 & Pier 2 & Pier 3 & Pier 4 & Pier 5 & Pier 6L & Pier 6R & Pier 7 & Pier 8 & Pier 9 & Pier 10 & Pier 11 \\
\hline G1 & & 109 & 144 & 58 & 84 & & & 121 & 88 & 174 & & \\
\hline G2 & 125 & 57 & 40 & 37 & 51 & 93 & 69 & 133 & 66 & 155 & 110 & 80 \\
\hline G3 & 147 & 72 & 37 & 31 & 45 & 110 & 65 & 138 & 59 & 140 & 100 & 74 \\
\hline G4 & & 282 & 69 & 161 & 274 & & & 153 & 60 & 109 & & \\
\hline \# bolts & $6 @ 2 "$ & $6 @ 2.25$ & (a) 1.7: & (a) 1.75" & $6 @ 2 "$ & $4 @ 2 "$ & $4 @ 2 "$ & $6 @ 2 "$ & $6 @ 2 "$ & $6 @ 2 "$ & $4 @ 2 "$ & $4 @ 2 "$ \\
\hline
\end{tabular}

Table 5.6. Total shear force per bolt group (Temp $-70^{\circ} \mathrm{F}$ thermal load)

\begin{tabular}{|c|c|c|c|c|c|c|c|c|c|c|c|c|}
\hline \multicolumn{13}{|c|}{ Horizontal Force acting on each bolt GROUP (kip) } \\
\hline & Pier 1 & Pier 2 & Pier 3 & Pier 4 & Pier 5 & Pier 6L & Pier 6R & Pier 7 & Pier 8 & Pier 9 & Pier 10 & Pier 11 \\
\hline G1 & & 44 & 78 & 17 & 32 & & & 195 & 68 & 107 & & \\
\hline G2 & 165 & 29 & 25 & 29 & 40 & 111 & 76 & 173 & 42 & 140 & 115 & 76 \\
\hline G3 & 148 & 45 & 30 & 26 & 53 & 115 & 72 & 144 & 24 & 161 & 115 & 71 \\
\hline G4 & & 204 & 22 & 102 & 185 & & & 122 & 65 & 188 & & \\
\hline \# bolts & 6@2" & $6 @ 2.25$ & (a) 1.7. & (a) 1.75" & 6@2" & $4 @ 2 "$ & $4 @ 2 "$ & $6 @ 2 "$ & $6 @ 2^{\prime \prime}$ & $6 @ 2 "$ & $4 @ 2 "$ & $4 @ 2 "$ \\
\hline
\end{tabular}

In Unit 1, the maximum shear force produced in any anchor bolt is 47 kips in one of the fixed bearings at Pier 2. Magnitudes of 46 kips, 40 kips and 36 kips are found in fixed bearings at Piers 5,4, and 3, respectively. As for the guided bearings, shear forces are greater than 28 kips at Pier 1 and Pier 6. The range of shear force is not as pronounced in Unit 2, compared to Unit 1. A maximum shear force of 33 kips occurs in a fixed bearing at Pier 7. The guided bearings develop shear forces of up to 29 kips (Pier 10). Figures 5.11-5.12 break Tables 5.9-5.10 down and plot the magnitude of shear force acting on each individual anchor bolt. The number of anchor bolts at each bearing varies between 4 or 6 . All guided bearings and the fixed bearings at Pier 3 and Pier 4 are fixed to the support piers using 4 anchor bolts, while 6 bolts are at the remaining fixed bearings. 


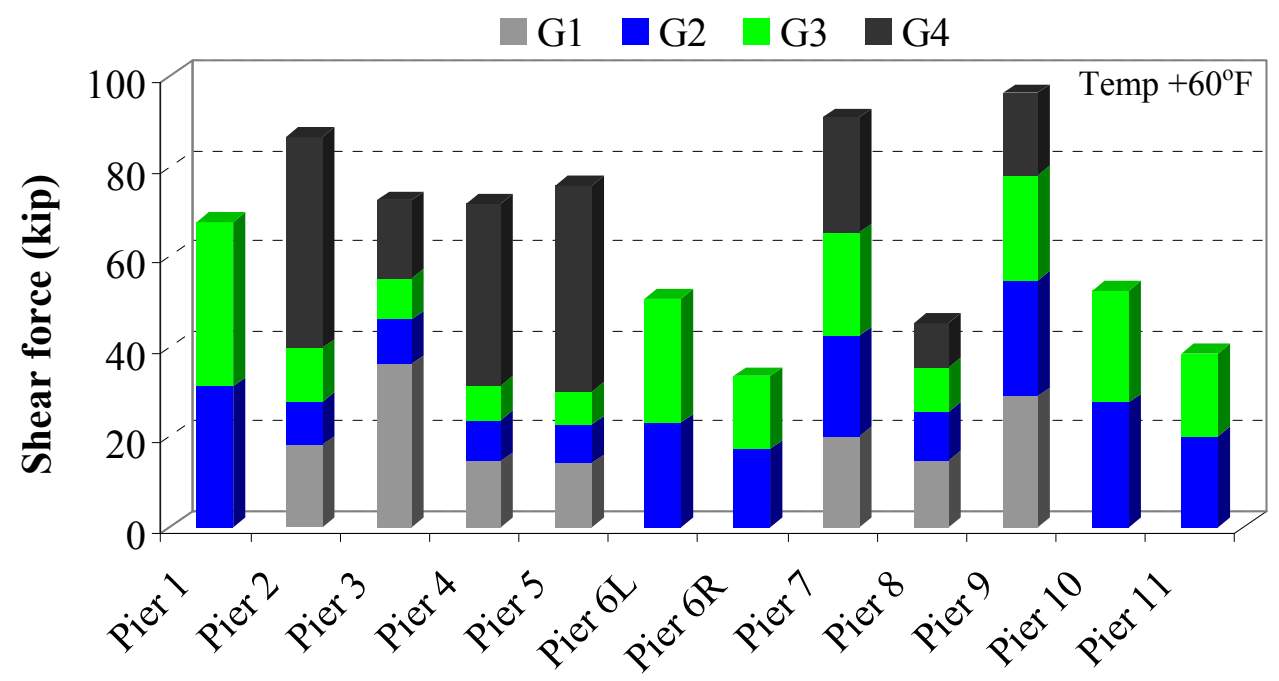

Figure 5.9. Shear force per anchor bolt (Temp $\left.+60^{\circ} \mathrm{F}\right)$



Figure 5.10. Shear force per anchor bolt (Temp $\left.-70^{\circ} \mathrm{F}\right)$ 
The shear force in each anchor bolt given by the FE model can be compared to minimum horizontal design loads to gain an understanding of how thermal forces may have been considered during the design process. Tables 5.7 and 5.8 show the magnitude of shear force that develops in the anchor bolts at the guided and fixed bearings, which is compared to unfactored horizontal design load. The unfactored design load in several anchor bolts is exceeded by over $100 \%$, with an extreme case in Girder 4 at Pier 4 , where the design load is exceeded by $300 \%$. At all guided bearings, shear force produced in the FE model exceeds design values. At the fixed bearings in Unit 2, the design loads are also significantly less than FE predictions. While the minimum horizontal design loads have been surpassed at several bearings, the computation of shear capacity of the anchor bolts as dictated by AASHTO will tell whether or not the shear forces generated in the FE model are at critical levels.

In AASHTO (2007), shear resistance of anchor bolts is governed by Article 6.13.2.7, which provides Equation 5.2 below. The nominal shear resistance of a bolt group is dependent on cross-sectional area $A_{b}$, ultimate tensile strength of the bolts $F_{u b}$, and the number of bolts $N_{s}$. To compute the nominal shear strength of a single bolt, take $N_{s}$ equal to 1 . Inputting $F_{u b}$ equal to $60 \mathrm{ksi}$ and cross-sectional area $A_{b}$, the shear strength of the anchor bolts is compared to the FE model shear force as presented Tables 5.9 and 5.10.

$$
R_{n}=0.48 A_{b} F_{u b} N_{s}
$$


Table 5.7. Anchor bolt shear force comparison $\left(\mathrm{Temp}+60^{\circ} \mathrm{F}\right)$

\begin{tabular}{|c|c|c|c|c|}
\hline \multicolumn{5}{|c|}{ Shear Force (kips) } \\
\hline & & FE model & Design & $\%$ Design/FE \\
\hline \multirow{2}{*}{ Pier 1} & G2 & 31 & 14 & -121 \\
\hline & G3 & 37 & 14 & -164 \\
\hline \multirow{4}{*}{ Pier 2} & G1 & 18 & 18 & 0 \\
\hline & G2 & 10 & 18 & 44 \\
\hline & G3 & 12 & 18 & 33 \\
\hline & G4 & 47 & 18 & -161 \\
\hline \multirow{4}{*}{ Pier 3} & G1 & 36 & 11 & -227 \\
\hline & G2 & 10 & 11 & 9 \\
\hline & G3 & 9 & 11 & 18 \\
\hline & G4 & 17 & 11 & -55 \\
\hline \multirow{4}{*}{ Pier 4} & G1 & 15 & 10 & -50 \\
\hline & G2 & 9 & 10 & 10 \\
\hline & G3 & 8 & 10 & 20 \\
\hline & G4 & 40 & 10 & -300 \\
\hline \multirow{4}{*}{ Pier 5} & G1 & 14 & 15 & 7 \\
\hline & G2 & 8 & 15 & 47 \\
\hline & G3 & 8 & 15 & 47 \\
\hline & G4 & 46 & 15 & -207 \\
\hline \multirow{2}{*}{ Pier 6L } & G2 & 23 & 11 & -109 \\
\hline & G3 & 28 & 11 & -155 \\
\hline \multirow{2}{*}{ Pier 6R } & G2 & 17 & 12 & -42 \\
\hline & G3 & 16 & 12 & -33 \\
\hline \multirow{4}{*}{ Pier 7} & G1 & 20 & 12 & -67 \\
\hline & G2 & 22 & 12 & -83 \\
\hline & G3 & 23 & 12 & -92 \\
\hline & G4 & 26 & 12 & -117 \\
\hline \multirow{4}{*}{ Pier 8} & G1 & 15 & 16 & 6 \\
\hline & G2 & 11 & 16 & 31 \\
\hline & G3 & 10 & 16 & 38 \\
\hline & G4 & 10 & 16 & 38 \\
\hline \multirow{4}{*}{ Pier 9} & G1 & 29 & 14 & -107 \\
\hline & G2 & 26 & 14 & -86 \\
\hline & G3 & 23 & 14 & -64 \\
\hline & G4 & 18 & 14 & -29 \\
\hline \multirow{2}{*}{ Pier 10} & G2 & 28 & 12 & -133 \\
\hline & G3 & 25 & 12 & -108 \\
\hline \multirow{2}{*}{ Pier 11} & G2 & 20 & 12 & -67 \\
\hline & G3 & 19 & 12 & -58 \\
\hline
\end{tabular}


Table 5.8. Anchor bolt shear force comparison $\left(\mathrm{Temp}-70^{\circ} \mathrm{F}\right)$

\begin{tabular}{|c|c|c|c|c|}
\hline \multicolumn{5}{|c|}{ Shear Force (kips) } \\
\hline & & FE model & Design & $\%$ FE/Design \\
\hline \multirow{2}{*}{ Pier 1} & G2 & 41 & 14 & -193 \\
\hline & G3 & 37 & 14 & -164 \\
\hline \multirow{4}{*}{ Pier 2} & G1 & 7 & 18 & 61 \\
\hline & G2 & 5 & 18 & 72 \\
\hline & G3 & 8 & 18 & 56 \\
\hline & G4 & 34 & 18 & -89 \\
\hline \multirow{4}{*}{ Pier 3} & G1 & 20 & 11 & -82 \\
\hline & G2 & 6 & 11 & 45 \\
\hline & G3 & 7 & 11 & 36 \\
\hline & G4 & 6 & 11 & 45 \\
\hline \multirow{4}{*}{ Pier 4} & G1 & 4 & 10 & 60 \\
\hline & G2 & 7 & 10 & 30 \\
\hline & G3 & 6 & 10 & 40 \\
\hline & G4 & 26 & 10 & -160 \\
\hline \multirow{4}{*}{ Pier 5} & G1 & 5 & 15 & 67 \\
\hline & G2 & 7 & 15 & 53 \\
\hline & G3 & 9 & 15 & 40 \\
\hline & G4 & 31 & 15 & -107 \\
\hline \multirow{2}{*}{ Pier 6L } & G2 & 28 & 11 & -155 \\
\hline & G3 & 29 & 11 & -164 \\
\hline \multirow{2}{*}{ Pier 6R } & G2 & 19 & 12 & -58 \\
\hline & G3 & 18 & 12 & -50 \\
\hline \multirow{4}{*}{ Pier 7} & G1 & 33 & 12 & -175 \\
\hline & G2 & 29 & 12 & -142 \\
\hline & G3 & 24 & 12 & -100 \\
\hline & G4 & 20 & 12 & -67 \\
\hline \multirow{4}{*}{ Pier 8} & G1 & 11 & 16 & 31 \\
\hline & G2 & 7 & 16 & 56 \\
\hline & G3 & 4 & 16 & 75 \\
\hline & G4 & 11 & 16 & 31 \\
\hline \multirow{4}{*}{ Pier 9} & G1 & 18 & 14 & -29 \\
\hline & G2 & 23 & 14 & -64 \\
\hline & G3 & 27 & 14 & -93 \\
\hline & G4 & 31 & 14 & -121 \\
\hline \multirow{2}{*}{ Pier 10} & G2 & 29 & 12 & -142 \\
\hline & G3 & 29 & 12 & -142 \\
\hline \multirow{2}{*}{ Pier 11} & G2 & 19 & 12 & -58 \\
\hline & G3 & 18 & 12 & -50 \\
\hline
\end{tabular}


Table 5.9. Anchor bolt shear resistance comparison $\left(\mathrm{Temp}+60^{\circ} \mathrm{F}\right)$

\begin{tabular}{|c|c|c|c|c|}
\hline \multicolumn{5}{|c|}{ Shear Force (kips) } \\
\hline & & $V_{\text {FE Model }}$ & $\mathbf{R}_{\mathbf{n}}$ & $\% \mathrm{FE} / \mathrm{R}_{\mathrm{n}}$ \\
\hline \multirow{2}{*}{ Pier 1} & G2 & 31 & 90 & 34 \\
\hline & G3 & 37 & 90 & 41 \\
\hline \multirow{4}{*}{ Pier 2} & G1 & 18 & 115 & $\overline{16}$ \\
\hline & G2 & 10 & 115 & 9 \\
\hline & G3 & 12 & 115 & 10 \\
\hline & G4 & 47 & 115 & 41 \\
\hline \multirow{4}{*}{ Pier 3} & G1 & 36 & 69 & 52 \\
\hline & G2 & 10 & 69 & 14 \\
\hline & G3 & 9 & 69 & 13 \\
\hline & G4 & 17 & 69 & 25 \\
\hline \multirow{4}{*}{ Pier 4} & G1 & 15 & 69 & 22 \\
\hline & G2 & 9 & 69 & 13 \\
\hline & G3 & 8 & 69 & 12 \\
\hline & G4 & 40 & 69 & 58 \\
\hline \multirow{4}{*}{ Pier 5} & G1 & 14 & 90 & 15 \\
\hline & G2 & 8 & 90 & 9 \\
\hline & G3 & 8 & 90 & 9 \\
\hline & G4 & 46 & 90 & 51 \\
\hline \multirow{2}{*}{ Pier 6L } & G2 & 23 & 90 & 25 \\
\hline & G3 & 28 & 90 & 31 \\
\hline \multirow{2}{*}{ Pier 6R } & G2 & 17 & 90 & 19 \\
\hline & G3 & 16 & 90 & 18 \\
\hline \multirow{4}{*}{ Pier 7} & G1 & 20 & 90 & 22 \\
\hline & G2 & 22 & 90 & 24 \\
\hline & G3 & 23 & 90 & 25 \\
\hline & G4 & 26 & 90 & 29 \\
\hline \multirow{4}{*}{ Pier 8} & G1 & 15 & 90 & 17 \\
\hline & G2 & 11 & 90 & 12 \\
\hline & G3 & 10 & 90 & 11 \\
\hline & G4 & 10 & 90 & 11 \\
\hline \multirow{4}{*}{ Pier 9} & G1 & 29 & 90 & 32 \\
\hline & G2 & 26 & 90 & 29 \\
\hline & G3 & 23 & 90 & 25 \\
\hline & G4 & 18 & 90 & 20 \\
\hline \multirow{2}{*}{ Pier 10} & G2 & 28 & 90 & 31 \\
\hline & G3 & 25 & 90 & 28 \\
\hline \multirow{2}{*}{ Pier 11} & G2 & 20 & 90 & 22 \\
\hline & G3 & 19 & 90 & 21 \\
\hline
\end{tabular}


Table 5.10. Anchor bolt shear resistance comparison $\left(\mathrm{Temp}-70^{\circ} \mathrm{F}\right)$

\begin{tabular}{|c|c|c|c|c|}
\hline \multicolumn{5}{|c|}{ Shear Force (kips) } \\
\hline & & $V_{\text {FE Model }}$ & Design & $\% \mathrm{FE} / \mathrm{R}_{\mathrm{n}}$ \\
\hline \multirow{2}{*}{ Pier 1} & G2 & 41 & 90 & 45 \\
\hline & G3 & 37 & 90 & 41 \\
\hline \multirow{4}{*}{ Pier 2} & G1 & 7 & 115 & 6 \\
\hline & G2 & 5 & 115 & 4 \\
\hline & G3 & 8 & 115 & 7 \\
\hline & G4 & 34 & 115 & 30 \\
\hline \multirow{4}{*}{ Pier 3} & G1 & 20 & 69 & 29 \\
\hline & G2 & 6 & 69 & 9 \\
\hline & G3 & 7 & 69 & 10 \\
\hline & G4 & 6 & 69 & 9 \\
\hline \multirow{4}{*}{ Pier 4} & G1 & 4 & 69 & 6 \\
\hline & G2 & 7 & 69 & 10 \\
\hline & G3 & 6 & 69 & 9 \\
\hline & G4 & 26 & 69 & 38 \\
\hline \multirow{4}{*}{ Pier 5} & G1 & 5 & 90 & 6 \\
\hline & G2 & 7 & 90 & 8 \\
\hline & G3 & 9 & 90 & 10 \\
\hline & G4 & 31 & 90 & 34 \\
\hline \multirow{2}{*}{ Pier 6L } & G2 & 28 & 90 & 31 \\
\hline & G3 & 29 & 90 & 32 \\
\hline \multirow{2}{*}{ Pier 6R } & G2 & 19 & 90 & 21 \\
\hline & G3 & 18 & 90 & 20 \\
\hline \multirow{4}{*}{ Pier 7} & G1 & 33 & 90 & 36 \\
\hline & G2 & 29 & 90 & 32 \\
\hline & G3 & 24 & 90 & 27 \\
\hline & G4 & 20 & 90 & 22 \\
\hline \multirow{4}{*}{ Pier 8} & G1 & 11 & 90 & 12 \\
\hline & G2 & 7 & 90 & 8 \\
\hline & G3 & 4 & 90 & 4 \\
\hline & G4 & 11 & 90 & 12 \\
\hline \multirow{4}{*}{ Pier 9} & G1 & 18 & 90 & 20 \\
\hline & G2 & 23 & 90 & 25 \\
\hline & G3 & 27 & 90 & 30 \\
\hline & G4 & 31 & 90 & 34 \\
\hline \multirow{2}{*}{ Pier 10} & G2 & 29 & 90 & 32 \\
\hline & G3 & 29 & 90 & 32 \\
\hline \multirow{2}{*}{ Pier 11} & G2 & 19 & 90 & 21 \\
\hline & G3 & 18 & 90 & 20 \\
\hline
\end{tabular}


Calculations in Tables 5.9 and 5.10 show that shear forces acting on the anchor bolts in the FE model consume up to 58\% of the bolts' shear capacity (Pier 4, Girder 4). At many bearings, this value exceeds $20 \%$. However, while the minimum design loads are exceeded, as shown in Tables 5.7 and 5.8, the shear capacity of the individual anchor bolts exceeds that of the applied shear forces. Close examination of Tables 5.7-5.10 reveals that the magnitude of shear force in the anchor bolts at the guided bearings throughout the bridge is roughly equal to the shear force in the anchor bolts at the fixed bearings. An explanation for this is that at the piers with guided bearings only two bearing devices are available to resist thermal forces, while at piers with fixed bearings thermal forces are divided among four bearing devices. The key finding here is that up to $32 \%$ of anchor bolt shear strength is consumed by thermal forces at the guided bearings, demonstrating that thermal deformation of the superstructure is not freely permitted by the expansion devices. 


\subsection{Effect of Pier Flexibility}

To minimize the development of thermal forces in the superstructure, a full range of thermal deformation must be allowed to take place. Often, bridge designers recognize to the capability of supporting elements to deflect, thereby accommodating superstructure movements. This action is especially necessary when fixed bearings are employed at multiple consecutive support locations within a continuous slab-on-girder type bridge. Intrinsic to this concept is that the supporting elements cannot be so rigid as to prevent movement of the superstructure. In order to establish whether or not the piers are restraining thermal deformation of the steel I-girder superstructure within the Man Bridge, bearing displacement predicted by the FE model is compared to theoretical bearing displacement values calculated using Equation 5.1. If the bearing displacement predicted by the FE model is less than the calculated theoretical displacement that the steel superstructure should experience, then it can be proven that the piers are in fact restraining thermal deformation.

To perform the needed investigation, a point of reference for use in Equation 5.1 is required. This is necessary so that a proper value for the expansion length $L$ can be determined. The expansion length is measured relative to the point of zero movement within each unit of the bridge, as illustrated in Figure 5.11. A sample calculation is shown below for Pier 5. The point of zero movement within Unit 1 is located near Pier 3. In Unit 2, this point is near Pier 8. Theoretical bearing displacement is calculated using Equation 5.1 for every support location. These values are plotted and compared to FE predictions in Figures 5.12 and 5.13 for each case of thermal load. The magnitude of lateral pier deflection is plotted alongside values for bearing displacement. 


$$
\begin{aligned}
& \Delta_{T}=\alpha L\left(T_{\text {MaxDesign }}-T_{\text {MinDesign }}\right) \\
& \alpha=0.0000065 \mathrm{in} / \text { in } /{ }^{\circ} \mathrm{F} \\
& \mathrm{L}=389.5 \mathrm{ft} .(4675 \mathrm{in} .) \\
& \mathrm{T}_{\text {MaxDesign }}=+60^{\circ} \mathrm{F} \\
& \mathrm{T}_{\text {MinDesi gn }}=-70^{\circ} \mathrm{F} \\
& \Delta_{T}=0.0000065 \times 4675 \times(60-(-70))=3.95 \mathrm{in} .
\end{aligned}
$$

Pier 5



Figure 5.11. Approximate location of stationary point in Unit 1 
$\square$ FE model $\square$ Theoretical $\square$ Pier movement

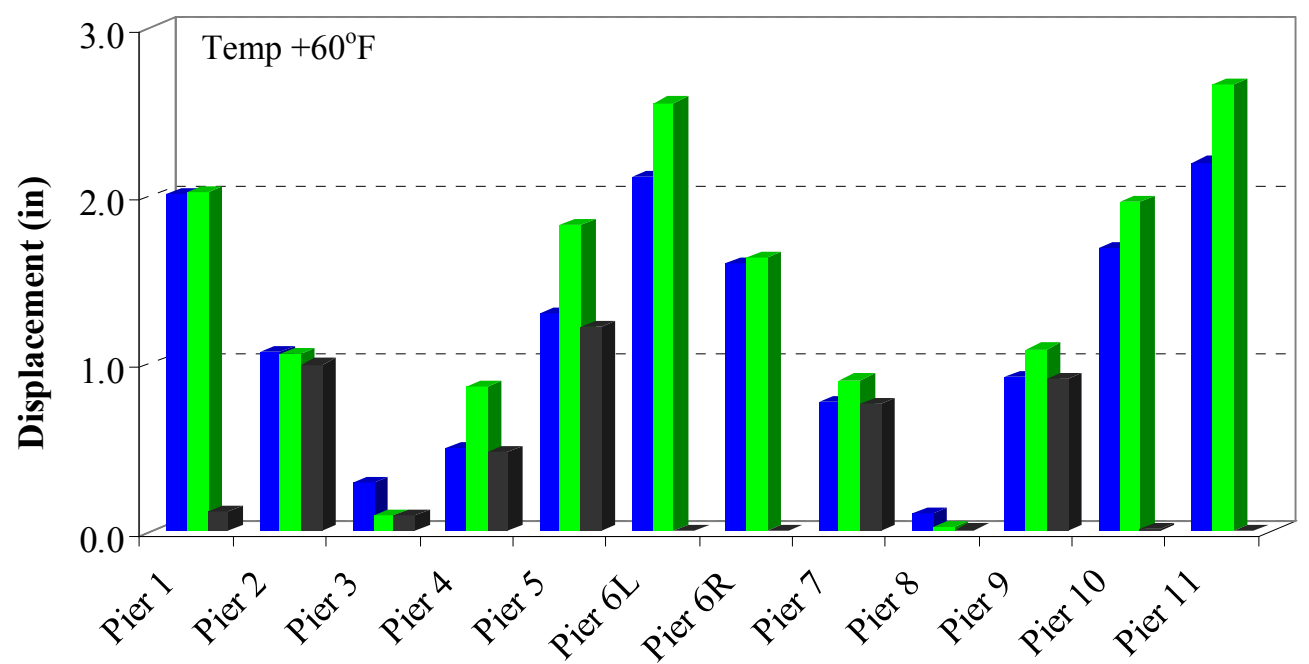

Figure 5.12. Comparison of theoretical superstructure thermal deformation vs. FE model predictions (Temp $\left.+60^{\circ} \mathrm{F}\right)$

$\square$ FE model $\square$ Theoretical $\square$ Pier movement

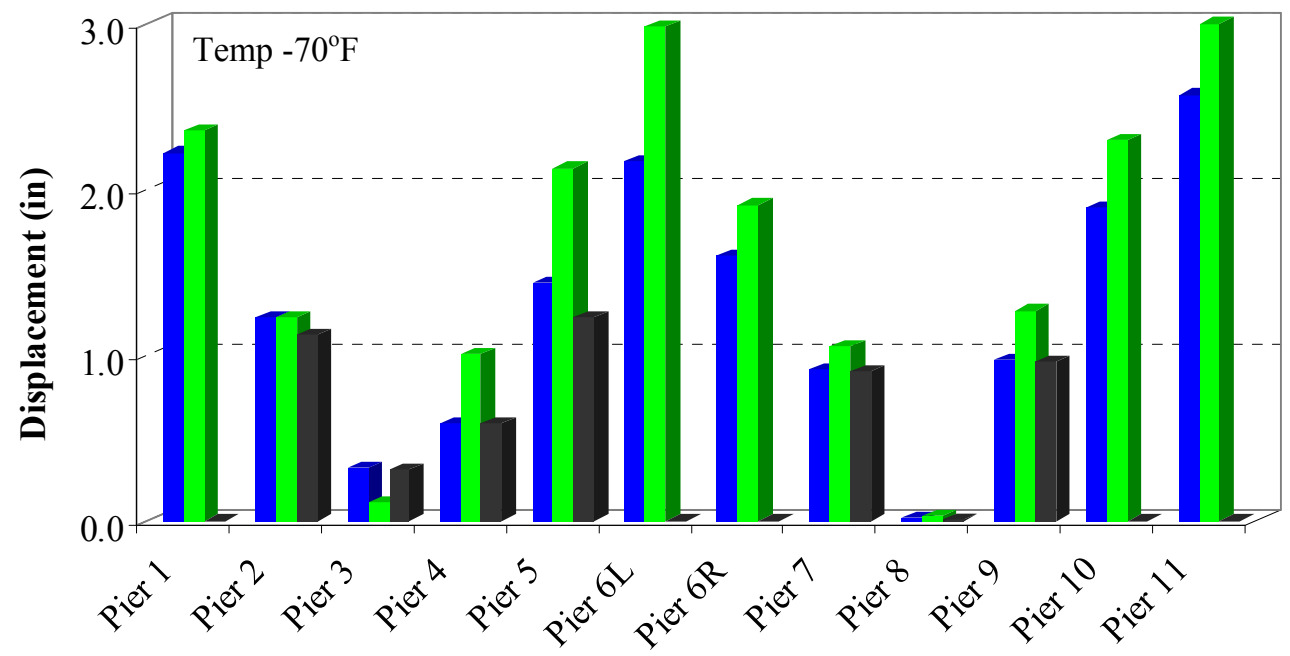

Figure 5.13. Comparison of theoretical superstructure thermal deformation vs. FE model predictions (Temp $-70^{\circ} \mathrm{F}$ ) 
Close examination of Figures 5.12 and 5.13 reveals three key pieces information significant to this study. First, the magnitude of longitudinal pier deflection is practically zero where guided bearings are located, demonstrating that all thermal movement of the superstructure is accommodated by the bearing devices. An exception to this is notable at Pier 1 , under the $+60^{\circ} \mathrm{F}$ load case, where a pier deflection of $0.12 \mathrm{in}$. is produced. Second, excluding support Piers 2 and 5, displacement of the fixed bearings is approximately equal to the magnitude of longitudinal pier deflection as predicted by the FE model. At these locations, thermal deformation of the superstructure is fully accommodated by the substructure. Third, and most significant, theoretical longitudinal bearing displacement is greater than values produced by the FE model, indicating that the steel superstructure is unable to undergo its full range of thermal deformation due to the rigidity offered by the support piers.

Inequality between theoretical and FE predicted bearing displacement values implies that thermal deformation of the superstructure is not fully accommodated through pier flexure and, that residual thermal forces exist throughout the superstructure and substructure. Several possible responses to thermal forces include cracking in the concrete piercaps, elevated longitudinal stresses in the bottom flanges, and bending in the bearing anchor bolts. The development of such behaviors can be demonstrated using basic work and energy principles commonly utilized in structural mechanics, including strain energy and conservation of energy concepts.

The strain energy of a structural member can be defined as the amount of energy stored in a member as it undergoes deformation due to external forces, such as pier flexure due to shear forces acting on the top of the concrete support. The simplest 
concept offered by the principle of conservation of energy is that energy cannot be created or destroyed. As it applies to structural members, the principle of the conservation of energy states that the work performed on an elastic structural member, in equilibrium, due to external forces is equal to the strain energy that develops in the member. Thus, work done on a structural member by external forces must be equal to the strain energy of the member in its deformed state. This is represented by Equation 5.4, where $W$ is the amount of work done on a member by an external force and $U$ is the strain energy of the member in its deformed state.

$$
W=U
$$

This principle is easily applied to the current investigation to approximate the work done by thermal forces to deflect the piers and the amount of strain energy that develops due to bending in the pier columns. To appropriately utilize the conservation of energy principle, the bearing devices, bearing anchor bolts, steel I-girders, and individual support piers must be considered a single structural system. Using data from the FE model, if the amount of strain energy $(U)$ in the system due to bending is larger than the work done determined using the predicted deflection of the support pier $(W)$, it can be stated that a certain amount of strain energy is stored in components other than the pier column itself. In such a case, strain energy may develop in the steel I-girders, bearing devices, bearing anchor bolts, and at the top of the concrete piercaps. As a result, several actions can occur simultaneously. Strain energy in the steel I-girders would lead to elevated stresses in the bottom flanges at the bearings and in the bearing devices 
themselves. As seen in Chapter Three, deformation of the bearing anchor bolts has occurred. Thus, some strain energy within the system could contribute to this action. Lastly, large amounts of strain energy may localize in the concrete piercaps. Strain energy and strain energy release are significant topics in fracture mechanics. While a detailed fracture mechanics analysis is outside the scope of this work, the stress state in the piercaps and the potential for fracture is investigated in a later section. For now, it is only determined whether or not the amount of work done on the deflected piers by the external thermal forces is equal to the amount of strain energy in the system.

Idealizing the support piers as linear-elastic cantilever members illustrated in Figure 5.14, the amount of work done to produce deflection $\Delta$ and strain energy $U$ can be calculated using basic formulas from structural mechanics shown by Equations 5.5-5.8. Equation 5.5 is the amount of work done on the member by force $P$. Strain energy in the member due to bending is computed using Equation 5.6. Bending moment $\mathrm{M}$ is given by Equation 5.7. With distance $x$ equal to member length $L$, the strain energy formula in Equation 5.6 can be simplified to Equation 5.8. Please note that the strain energy due shear deformation is not included as it is typically insignificant compared to bending effects. The variables for pier deflection $\Delta$ (i.e. fixed bearing displacement) and horizontal thermal force $P$ are extracted from the FE model. Horizontal force $P$ is the total force that develops among all bearings at the piers. These values were discussed in Sections 5.2 and 5.3. Pier column length $L$, modulus of elasticity $E$, and moment of inertia $I$ are found directly from information provided in the bridge's design drawings. Tables 5.11 and 5.12 calculate $W$ and $U_{M}$ at each support location. 

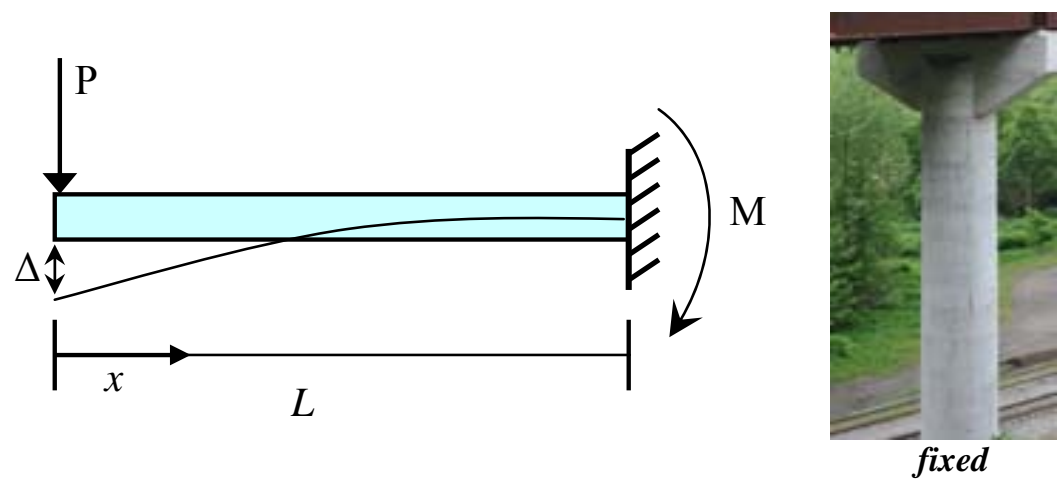

Figure 5.14. Cantilever member

$$
\begin{gathered}
W_{P}=\frac{1}{2} P \Delta \\
U_{M}=\int_{0}^{L} \frac{M^{2}}{2 E I} d x \\
M=P(L-x) \\
U_{M}=\frac{P^{2} L^{3}}{6 E I}
\end{gathered}
$$


Table 5.11. Imbalance between work done and strain energy in the support piers under the $+60^{\circ} \mathrm{F}$ load

\begin{tabular}{|l|cccccc|c|}
\hline \multicolumn{2}{|c|}{ EI (lbf-ft' $\left.{ }^{2}\right)$} & L (ft) & $\mathbf{P}(\mathbf{l b})$ & $\boldsymbol{\Delta}(\mathbf{f t})$ & $\mathbf{U}_{\mathbf{M}}(\mathbf{f t}-\mathbf{l b f})$ & $\mathbf{W}_{\mathbf{P}}(\mathbf{f t}-\mathbf{l b f})$ & $\mathbf{U}_{\mathbf{M}^{-}}-\mathbf{W}_{\mathbf{P}}$ \\
\hline Pier 2 & $6.60 \mathrm{E}+11$ & 87.6 & 519409 & 0.089 & 45826 & 23157 & $\mathbf{- 2 2 6 6 9}$ \\
Pier 3 & $6.60 \mathrm{E}+11$ & 87.8 & 289996 & 0.024 & 14383 & 3504 & $\mathbf{- 1 0 8 7 9}$ \\
Pier 4 & $6.60 \mathrm{E}+11$ & 100.5 & 286939 & 0.041 & 21118 & 5858 & $\mathbf{- 1 5 2 6 0}$ \\
Pier 5 & $6.60 \mathrm{E}+11$ & 95.6 & 454340 & 0.108 & 45574 & 24610 & $\mathbf{- 2 0 9 6 4}$ \\
Pier 7 & $6.60 \mathrm{E}+11$ & 90.9 & 545210 & 0.064 & 56415 & 17492 & $\mathbf{- 3 8 9 2 3}$ \\
Pier 9 & $6.60 \mathrm{E}+11$ & 95.5 & 577568 & 0.077 & 73417 & 22140 & $\mathbf{- 5 1 2 7 7}$ \\
\hline
\end{tabular}

Table 5.12. Imbalance between work done and strain energy in the support piers under the $-70^{\circ} \mathrm{F}$ load

\begin{tabular}{|l|cccccc|c|}
\hline & EI (lbf-ft') & $\mathbf{L}(\mathbf{f t})$ & $\mathbf{P}(\mathbf{l b})$ & $\mathbf{\Delta}$ (ft) & $\mathbf{U}_{\mathbf{M}}(\mathbf{f t}-\mathbf{l b f})$ & $\mathbf{W}_{\mathbf{P}}(\mathbf{f t}-\mathbf{l b f})$ & $\mathbf{U}_{\mathbf{M}^{-}}-\mathbf{W}_{\mathbf{P}}$ \\
\hline Pier 2 & $6.60 \mathrm{E}+11$ & 87.6 & 322851 & 0.103 & 17705 & 16546 & $\mathbf{- 1 1 5 9}$ \\
Pier 3 & $6.60 \mathrm{E}+11$ & 87.8 & 155432 & 0.027 & 4132 & 2072 & $\mathbf{- 2 0 5 9}$ \\
Pier 4 & $6.60 \mathrm{E}+11$ & 100.5 & 173879 & 0.049 & 7755 & 4275 & $\mathbf{- 3 4 8 0}$ \\
Pier 5 & $6.60 \mathrm{E}+11$ & 95.6 & 310239 & 0.120 & 21249 & 18614 & $\mathbf{- 2 6 3 5}$ \\
Pier 7 & $6.60 \mathrm{E}+11$ & 90.9 & 633718 & 0.076 & 76219 & 24028 & $\mathbf{- 5 2 1 9 0}$ \\
Pier 9 & $6.60 \mathrm{E}+11$ & 95.5 & 596061 & 0.081 & 78193 & 24091 & $\mathbf{- 5 4 1 0 3}$ \\
\hline
\end{tabular}

Tables 5.11 and 5.12 clearly show that the amount work done by thermal forces to cause lateral deflection of the piers is less than the strain energy associated with the bending moments that develop in the pier columns. Work $W$ depends on force $P$ and deflection $\Delta$, whereas strain energy is independent of deflection $\Delta$. Large magnitudes of strain energy develop at the support piers under relatively small deflections, which is a direct result of high pier rigidity. The rigidity offered by the pier columns is preventing the required deflection necessary to make $U_{M}$ and $W_{P}$ equitable. This inequality suggests that thermal forces are resulting in behaviors outside of lateral pier deflection. In such a 
scenario, a certain amount of force is transmitted to the bearing anchor bolts, steel Igirders, and concrete piercaps.

In the anchor bolts, a certain amount of strain energy develops as the bolts undergo deformation and bending. If assumed to act in a purely axial manner, thermal forces in the steel I-girders lead to the development of strain energy in the bottom flanges near the bearings. Lastly, strain energy also develops in the concrete piercaps as forces from are transmitted from the anchor bolts to the surrounding concrete media. The amount of strain energy contributed by each of these actions is difficult to accurately calculate, however, the total strain energy in the system at each support location resulting from the development of thermal forces can be roughly approximated using Equations $5.9-5.13$

$$
\begin{gathered}
U_{\text {System }}=U_{M}=U_{\text {Flange }}+U_{\text {Bolts }}+U_{\text {Piercap }}+U_{\text {PierFlexure }} \\
U_{\text {Flange }}=\frac{1}{2} \int_{L} \frac{N}{E A} d l \\
U_{\text {Bolts }}=\int_{0}^{L} \frac{M_{\text {Bolts }}^{2}}{2 E I} d x \\
U_{\text {Piercap }}=\frac{1}{2} \int_{V}\{\sigma\}^{T}\{\varepsilon\} d V \\
U_{\text {PierFlexure }}=\int_{0}^{L} \frac{M_{\text {PierFlexure }}^{2} d x}{2 E I} d x
\end{gathered}
$$


In Equations 5.9-5.13, $U_{\text {Flange }}$ is the strain energy due to axial force in the bottom flanges of the steel I-girders near the bearings, $U_{\text {Bolts }}$ is the strain energy due to bending in the anchor bolts, $U_{\text {Piercap }}$ is the strain energy in the concrete piercap due to a general state of stress and $U_{\text {PierFlexure }}$ is the strain energy due to bending in the pier column. When summed, these values represent the total strain energy at each support location due horizontal forces acting on the bridge bearings. Theoretically, if thermal forces were absent and pier flexure accommodated all thermal deformation of the superstructure, $U_{\text {PierFlexure }}$ would equal $W_{P}$. According to the principle of conservation of energy an imbalance between these values cannot exist when an elastic structural system is in equilibrium.

The fact that data from the FE model approximates the total strain energy in the system at the support piers due to thermal forces is greater than $W_{P}$ confirms actions in addition to pier flexure are taking place. The extent of such actions is investigated in the following sections. The development of thermal stresses in the steel I-girders is studied in detail in Section 5.5, while stresses in the piercaps are investigated in Section 5.6. 


\subsection{Flange Stress at the Bearings}

When thermal deformation in a steel I-girder bridge is restrained by the bearings, thermal stresses will develop in the superstructure. Dependent on a multitude of factors, such as boundary conditions and magnitude of the thermal loads, these thermal stresses may bring about undesirable responses within the steel girder superstructure.

Investigations by William et al. (2005) and McBride (2013) demonstrated that restrained thermal deformation in steel girder superstructures with integral abutments can markedly reduce the expected structural capacity the girders. The Man Bridge is slab-on-girder type structure, so its behavior under thermal loads is not directly comparable to integral abutment style bridges. However, the main premise that thermal stresses develop as a result of restrained thermal deformation remains acceptable. In a slab-on-girder bridge the bearing arrangement is assumed to minimize thermal stresses, and so the development of such stresses is not anticipated and, subsequently, their effects are not included in design calculations. The elevated level of stress in the steel girders will decrease their expected their expected structural capacity. Such a response needs to be clearly demonstrated to show the possible consequences of restrained thermal deformation.

The most significant thermal stresses will occur near the support locations in the vicinity of where the flanges are attached to the bearing assembly. In a typical slab-ongirder steel bridge, the bottom flange is welded to the bearing assembly's sole plate, as illustrated in Figure 5.15. In a fixed or guided bearing, horizontal forces are transferred through the bearing device into the substructure. This action can place excessive stress on the weld lines and lead to a higher-than-expected magnitudes of stress in the flange, as discussed above. This section examines the state of stress in the bottom flanges at each 
support location, providing insight into the influence of restrained of thermal deformation at the bearings.



Figure 5.15. Fixed pot bearing assembly

First, effective stress $\left(\sigma_{\mathrm{e}}\right)$ at the fixed and guided bearings is determined from the FE model. Examination of effective stress provides basic data regarding the development of thermal stresses. For each thermal load case, the approximate magnitude of $\sigma_{\mathrm{e}}$ is determined from the FE model and compared to similar values when the bridge is subject to only gravity loading (i.e. bridge self-weight). Such a comparison quantifies the effects of the applied thermal loads. In ADINA, and most other FEA software, effective stress is defined according to the distortional energy density criterion, otherwise known as the von Mises yield criterion, and is calculated using the global Cartesian stress components as seen in Equation 5.14. This value is a measure of the total state of stress across a particular element. Effective stress values may be compared directly to the yield stress of the steel material to determine how significant the development of thermal stresses may be. The approximate magnitude of effective stress at each support location is shown in Figure 5.16. 


$$
\sigma_{e}=\sqrt{\frac{1}{2}\left(\left(\sigma_{x x}-\sigma_{y y}\right)^{2}+\left(\sigma_{x x}-\sigma_{z z}\right)^{2}+\left(\sigma_{y y}-\sigma_{z z}\right)^{2}+6\left(\sigma_{x y}^{2}+\sigma_{x z}^{2}+\sigma_{y z}^{2}\right)\right)}
$$

Figure 5.16 reveals two key pieces of information about the effect of the thermal loads throughout the Man Bridge. At the fixed bearings, $\sigma_{\mathrm{e}}$ in the bottom flange is appreciably greater when thermal loads are present. Effective stress in the flanges at Pier 9 is roughly 53\% larger. A more dramatic contrast is observed at Piers 2-5, where the development of thermal stresses increases $\sigma_{\mathrm{e}}$ by approximately $73 \%$, compared to when only bridge self-weight is present. Thermal stresses also develop in the flanges at the guided bearings, excluding at Pier 6. Compared to when thermal loads are absent, $\sigma_{\mathrm{e}}$ at Abutment 1 and Abutment 2 increase 15-20\%, and 41\% increase is shown at Pier 1. Similar, albeit less stark results are found at the remaining locations where guided bearings are employed. These results are tabulated in Table 5.13.

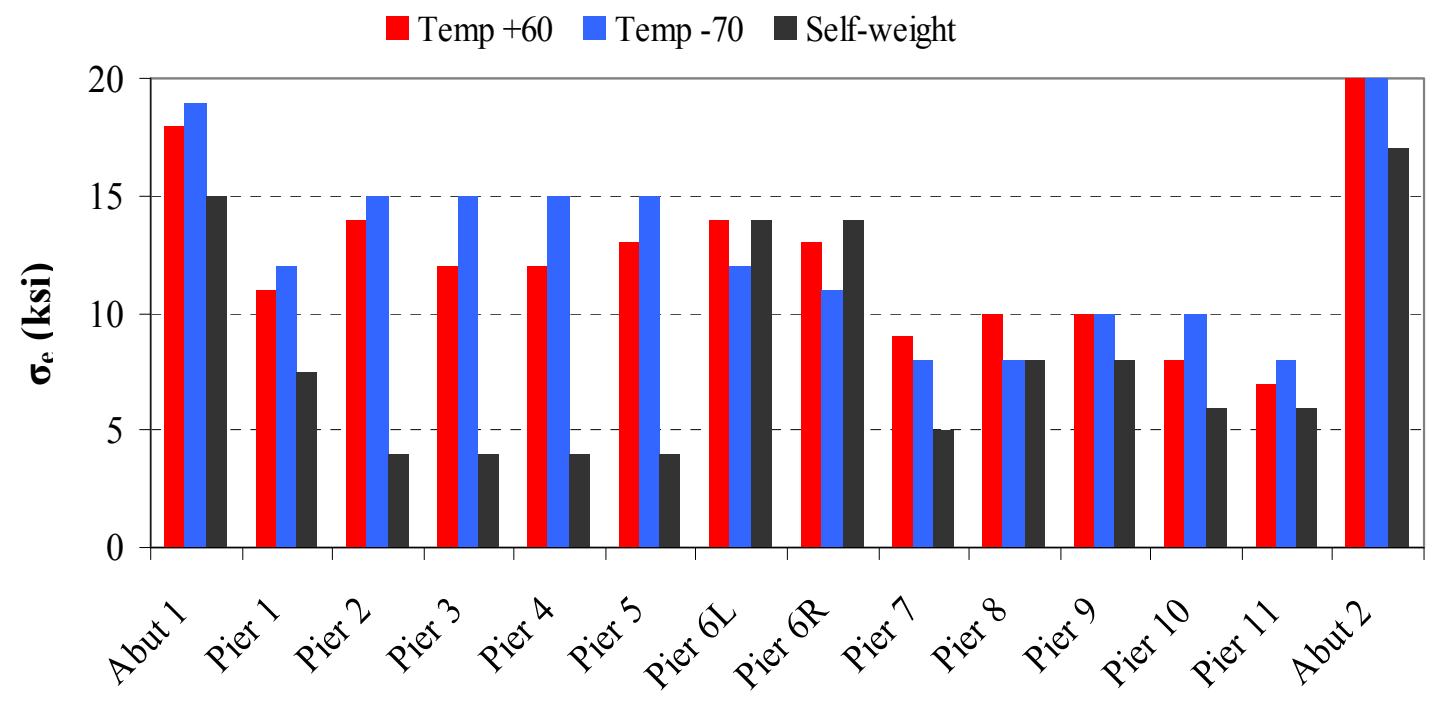

Figure 5.16. Effective stress in the bottom flanges at the bearings 
Table 5.13. Magnitude of thermal stress at each support

\begin{tabular}{|c|c|c|c|c|c|c|}
\hline & Temp +60 & Self-weight & $\boldsymbol{\sigma}_{\text {THERMAL }}$ & Temp -70 & Self-weight & $\boldsymbol{\sigma}_{\text {THERMAL }}$ \\
\hline Abut 1 & 18 & 15 & $\mathbf{3}$ & 19 & 15 & $\mathbf{4}$ \\
Pier 1 & 11 & 7.5 & $\mathbf{3 . 5}$ & 12 & 7.5 & $\mathbf{4 . 5}$ \\
Pier 2 & 14 & 4 & $\mathbf{1 0}$ & 15 & 4 & $\mathbf{1 1}$ \\
Pier 3 & 12 & 4 & $\mathbf{8}$ & 15 & 4 & $\mathbf{1 1}$ \\
Pier 4 & 12 & 4 & $\mathbf{8}$ & 15 & 4 & $\mathbf{1 1}$ \\
Pier 5 & 13 & 4 & $\mathbf{9}$ & 15 & 4 & $\mathbf{1 1}$ \\
Pier 6L & 14 & 14 & $\mathbf{0}$ & 12 & 14 & $\mathbf{- 2}$ \\
\hline Pier 6R & 13 & 14 & $\mathbf{- 1}$ & 11 & 14 & $\mathbf{- 3}$ \\
Pier 7 & 9 & 5 & $\mathbf{4}$ & 8 & 5 & $\mathbf{3}$ \\
Pier 8 & 10 & 8 & $\mathbf{2}$ & 8 & 8 & $\mathbf{0}$ \\
Pier 9 & 10 & 8 & $\mathbf{2}$ & 10 & 8 & $\mathbf{2}$ \\
Pier 10 & 8 & 6 & $\mathbf{2}$ & 10 & 6 & $\mathbf{4}$ \\
Pier 11 & $\mathbf{7}$ & 6 & $\mathbf{1}$ & 8 & 6 & $\mathbf{2}$ \\
Abut 2 & 20 & 17 & $\mathbf{3}$ & 20 & 17 & $\mathbf{3}$ \\
\hline
\end{tabular}

Closer scrutiny of the data provides signifcant information regarding the thermal response of the bridge. First, it is apparent that lateral deflection of the supporting piers is not permitting stress free thermal deformation of the superstructure. Thermal stresses develop at every interior support pier. Second, the fact that thermal stresses develop at the guided bearings definitively shows that expansion devices are restraining thermal deformation of the superstructure. This is most apparent at Pier 1, which leads to a third significant finding. The increase in $\sigma_{\mathrm{e}}$ due to the thermal loads is much more significant at Pier 1, compared to Piers 10 and 11, likely due to the rigidity of the respective pier columns. The effect of pier flexibility was covered in detail in Section 5.3.

Also shown in Figure 5.16 is peculiar behavior at the abutments and Pier 6. At these locations, abnormally high stresses develop in the bottom flanges when only the bridge self-weight is present. Additionally, during the field inspection, plastic deformation in the bottom flanges was observed and recorded. The reason behind this behavior is currently unknown, and a detailed analysis lies outside the scope of this 
dissertation. Nonetheless, the behavior warranted acknowledgement. Similar behavior takes place at Pier 6 .

The magnitude of effective stress is directly compared to the yield strength of the steel material used in the bottom flanges of the steel I-girders and is plotted in Figure 5.17. The I-girders are constructed of AASHTO M270 Gr. 50 and HPS70W steel, which have yield strengths of $50 \mathrm{ksi}$ and $70 \mathrm{ksi}$, respectively. Grade 70 steel is used in the negative moment regions of the superstructure, over the interior piers, while Gr. 50 is used in positive moment regions, throughout the midspans and near the abutments and Pier 6. At the flanges at the interior piers, less than $20 \%$ of the yield strength is consumed by thermal stresses alone. This is significant due to the fact that thermal stresses are typically considered to be minimal during design.

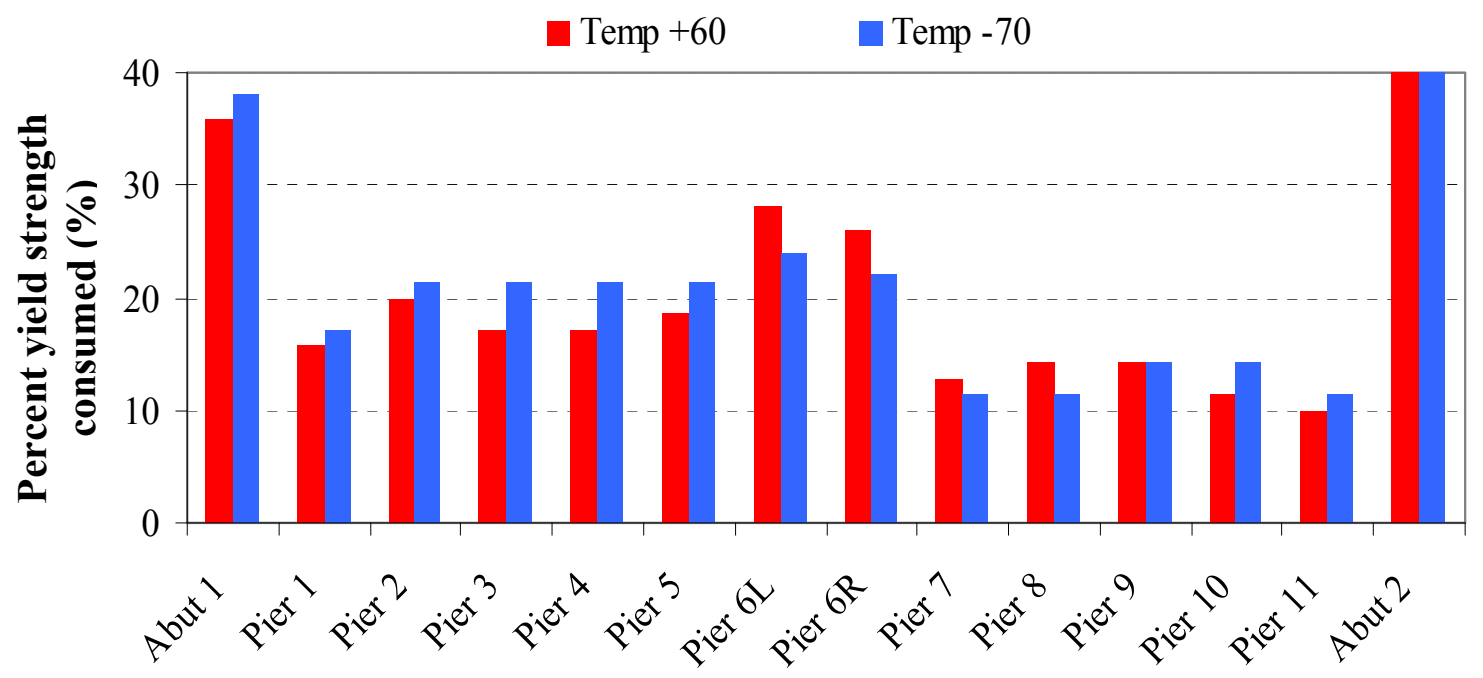

Figure 5.17. Percentage of yield strength consumed by thermal stress 
While scrutinizing effective stresses provides valuable intelligence regarding the effect of thermal stress, analyzing the magnitude of stress in the longitudinal and transverse directions in the flanges at the bearings yields more detailed information regarding the thermal response of the bridge. More specifically, examining these stresses at the guided bearings provides essential information regarding the development of thermal stresses in horizontally curved bridges, most of all. Studies by Moorty and Roeder $(1991,1992 a, 1992 b)$ investigating the thermal response of horizontally curved bridges noted the tendency of such structures to displace transversely (or radially)

Accommodating such movements is difficult with unidirectional (guided) bearings, so their orientation is crucial, as discussed in Chapter Two. Determining the magnitude of stress in a transverse and longitudinal direction provides vital information concerning the effectiveness of the current alignment of the guided bearings in the Man Bridge FE model. The orientation of the longitudinal (RR) and transverse (SS) axes is illustrated in Figure 5.18.

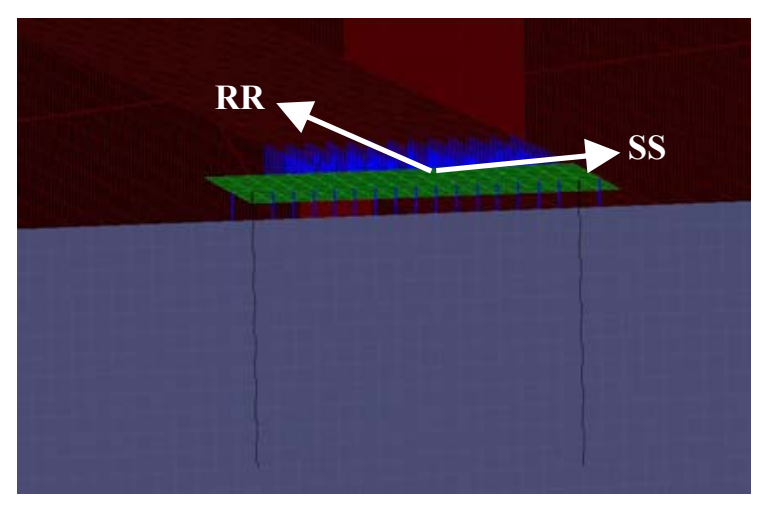

Figure 5.18. Orientation of longitudinal and transverse axes 
Figures 5.19-5.20 plot the magnitude of longitudinal and transverse stress for each thermal load case. The longitudinal stress due to bridge self-weight is also plotted. These values are included because longitudinal stress is the major stress when only bridge self-weight is present. Within AASHTO design specifications, longitudinal stress in the bottom flange is a chief design parameter, especially near the interior piers in a continuous structure where the bottom flange is in compression. Therefore, it is necessary to compare these stresses under thermal loads and bridge self-weight to accurately determine the effect of thermal stresses alone. Stresses that develop in a transverse direction would be a result of thermal loads as the structure's self-weight has little influence on transverse stresses. These values are plotted in Figure 5.20

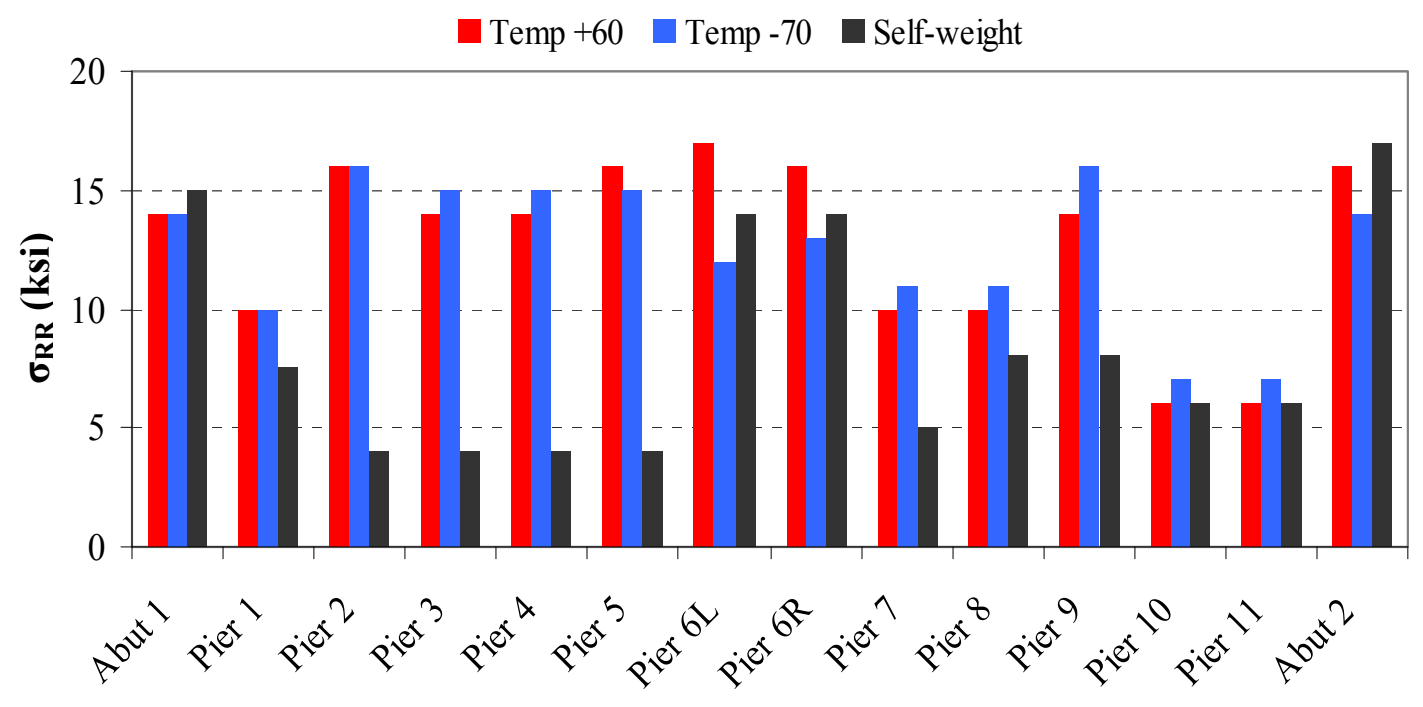

Figure 5.19. Longitudinal stress in the bottom flanges at the bearings 


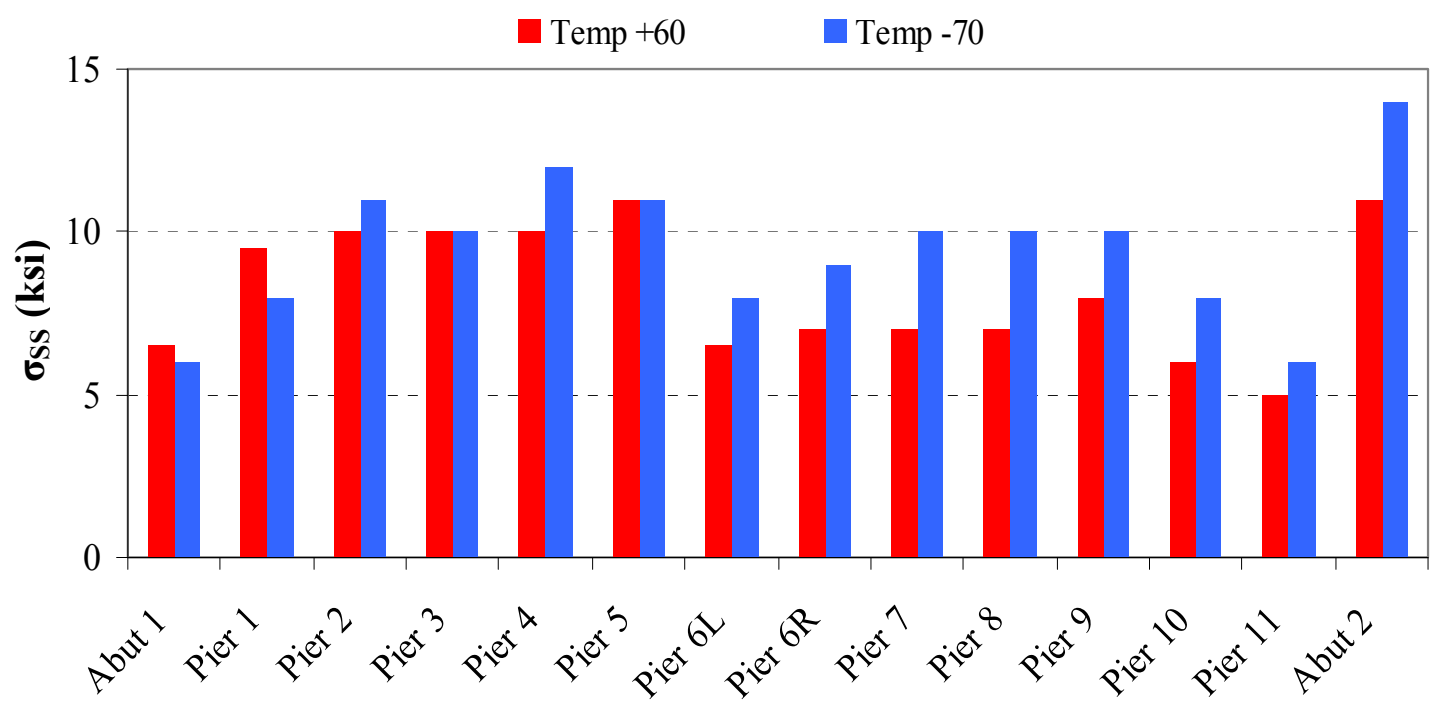

Figure 5.20. Transverse stress in the bottom flanges at the bearings

These figures make clear that significant magnitudes of thermal stress develop at each support throughout the bridge. The presence of thermal loads increases longitudinal stress at every interior pier, most notably at the piers where fixed bearings are located (Piers 2-5, Piers 7-9). The application of the thermal loads leads to longitudinal stress increases of anywhere between 30-75\%. Thermal stresses also develop at the guided bearings; however, the increase compared to the stresses due to bridge self-weight is less severe. The magnitude of longitudinal thermal stress is less than $12 \mathrm{ksi}$ at the fixed bearings, and less than $3 \mathrm{ksi}$ at the guided expansion bearings, as seen in Table 5.14. The development of longitudinal thermal stresses at the guided bearings is a significant finding given that the guided bearings are meant to prevent such stresses from occurring. As seen in Figure 5.20, transverse thermal stresses reach 14 ksi at Abutment 2.

Elsewhere throughout the bridge, stresses are approximately $10 \mathrm{ksi}$ or less. At all guided bearings, transverse stress is over $5 \mathrm{ksi}$. 
Table 5.14. Magnitude of longitudinal thermal stress at each support

\begin{tabular}{|c|c|c|c|c|c|c|}
\hline & Temp +60 & Self-weight & $\boldsymbol{\sigma}_{\text {THERMAL }}$ & Temp -70 & Self-weight & $\boldsymbol{\sigma}_{\text {THERMAL }}$ \\
\hline Abut 1 & 14 & 15 & $\mathbf{- 1}$ & 14 & 15 & $\mathbf{- 1}$ \\
Pier 1 & 10 & 7.5 & $\mathbf{2 . 5}$ & 10 & 7.5 & $\mathbf{2 . 5}$ \\
Pier 2 & 16 & 4 & $\mathbf{1 2}$ & 16 & 4 & $\mathbf{1 2}$ \\
Pier 3 & 14 & 4 & $\mathbf{1 0}$ & 15 & 4 & $\mathbf{1 1}$ \\
Pier 4 & 14 & 4 & $\mathbf{1 0}$ & 15 & 4 & $\mathbf{1 1}$ \\
Pier 5 & 16 & 4 & $\mathbf{1 2}$ & 15 & 4 & $\mathbf{1 1}$ \\
Pier 6L & 17 & 14 & $\mathbf{3}$ & 12 & 14 & $\mathbf{- 2}$ \\
\hline Pier 6R & 16 & 14 & $\mathbf{2}$ & 13 & 14 & $\mathbf{- 1}$ \\
Pier 7 & 10 & 5 & $\mathbf{5}$ & 11 & 5 & $\mathbf{6}$ \\
Pier 8 & 10 & 8 & $\mathbf{2}$ & 11 & 8 & $\mathbf{3}$ \\
Pier 9 & 14 & 8 & $\mathbf{6}$ & 16 & 8 & $\mathbf{8}$ \\
Pier 10 & 6 & 6 & $\mathbf{0}$ & 7 & 6 & $\mathbf{1}$ \\
Pier 11 & 6 & 6 & $\mathbf{0}$ & 7 & 6 & $\mathbf{1}$ \\
Abut 2 & 16 & 17 & $\mathbf{- 1}$ & 14 & 17 & $\mathbf{- 3}$ \\
\hline
\end{tabular}

The proceeding data regarding thermal stresses at the bearings throughout the bridge provides further evidence that the bearing arrangement is restraining thermal deformation of the superstructure, and thermal stresses are not fully alleviated through by the substructure. Thermal stresses were likely not considered during the design of the bridge as AASHTO provisions state that thermal stresses within the superstructure are minimal. However, the data produced by the FE model is contradicts this position.

As shown here, longitudinal thermal stresses are not negligible, reaching approximately $12 \mathrm{ksi}$. Similarly, transverse thermal stress cannot be neglected either. A transverse stress of over $5 \mathrm{ksi}$ at the guided bearings places a significant amount of stress on the bearing guides and weld lines within the bearing assemblies (see Figure 5.15). Recall that in AASHTO design specifications it is stated that when guided expansion bearings are oriented in a chordal manner with respect to a fixed point, thermal forces 
will not develop if the superstructure is subject to uniform thermal loads. The investigation in this section has clearly shown that this assumption is invalid for the Man Bridge and that thermal stresses have developed in the steel I-girders.

\subsection{Stresses in the Support Piers}

Due to the significant amount of cracking in the support piers covered in Chapter Three, a determination of the stress-state that develops in the reinforced concrete piercaps is a focal point of this study. The ability of the concrete support piers to deflect laterally, thereby allowing the steel girder superstructure to undergo a full range of thermal movement is widely recognized, however, the piers supporting the Man Bridge have already been shown to be unaccommodating of such movements. Additionally, local stresses that accompany thermal deformation of the superstructure have not been

previously investigated. Analysis in the previous sections demonstrated that the bearing arrangement and rigid piers are restraining thermal deformation of the superstructure leading to large horizontal shear force in the bearing anchor bolts. Under the action of this horizontal shear force, the bearing anchor bolts undergo a certain magnitude of deformation resulting in bending. Since the anchor bolts are embedded a certain depth into the top of the concrete piers, this bending action results in localized stresses in the concrete media surrounding the bolts. Within this section, the stress state in the concrete support piers is examined so that a determination can be made whether or not cracking may be prevalent in the piercaps, as observed during the field investigation.

First, stresses in the concrete piercaps are determined according to the Man Bridge FE model. As discussed in Chapter Four, the concrete piers are modeled using 4- 
node shell elements with the embedded anchor bolts sharing nodes with the shells (see Figure 4.9-4.10). While this modeling strategy yields adequate results regarding stresses in the piercaps, it has two particular limitations. First, this method is conducive for the development of stress concentrations. Second, the stress state in the concrete media immediately surrounding the anchor bolts cannot be accurately described using this modeling strategy. At the bearings, each bolt group contains either four or six anchor bolts. The current FE model cannot describe the stresses within the bolt group. Therefore, a 3D solid model of the top of a representative piercap is also utilized to more accurately study the stress state in the concrete media around the anchor bolts. Details regarding the 3D solid model are provided later in this section.

At this juncture, the assumption of a perfect bond between the anchor bolts and surrounding concrete media is established. Under this assumption, tensile as well as compressive stresses are allowed to develop in the vicinity of the anchor bolts as they deform (either in an elastic or inelastic manner) without any debonding developing between the concrete and steel bolts. A consideration of the effects of de-bonding or contact stresses is outside the scope of this investigation. It is acknowledged that while this is a very significant assumption, it must be made in order to complete the analysis inherent in this work.

Figure 5.21 illustrates a horizontal thermal force acting on the anchor bolts at the top of the piercaps. When shear force acts on the bolts, under the scenario of a perfect bond between concrete and steel bolts, tensile stresses develop at point ' $\mathrm{A}$ ' and compressive stresses develop at point 'B'. Recall the discussion regarding material modeling from Chapter Four. Failure in a concrete media can be considered to have 
occurred once the material fractures. For brittle materials that fail by fracture rather than yielding, the maximum principal stress criterion (i.e. Rankine's criterion) may adequately predict fracture under tensile stress. This is represented by the yield function shown in Equation 5.15

$$
f=\max \left(\left|\sigma_{1}\right|,\left|\sigma_{2}\right|,\left|\sigma_{3}\right|\right)-\sigma_{y}
$$

Equation 5.15 infers that fracture occurs in a brittle material occurs when the maximum principal stress at any point reaches a value equal to the material's yield strength in either tension or compression. At this point, unstable crack prorogation will commence. The tensile strength of concrete is traditionally taken as $7.5 \sqrt{ } f_{c}^{\prime}$. The 28-day compressive strength $\left(f_{c}^{\prime}\right)$ of the concrete is $4 \mathrm{ksi}$, giving a tensile strength of $474 \mathrm{psi}$, Using Rankine's criterion, when the tensile stress at point 'A' reaches 474 psi fracture of the concrete will occur. It is recognized that compression failure (i.e. concrete crushing) in the concrete can occur if compressive stress at Point ' $\mathrm{B}$ ' reaches $4 \mathrm{ksi}$. While it is yet unknown which failure mode will occur, tensile failure at Pont 'A', for now, is presumed.

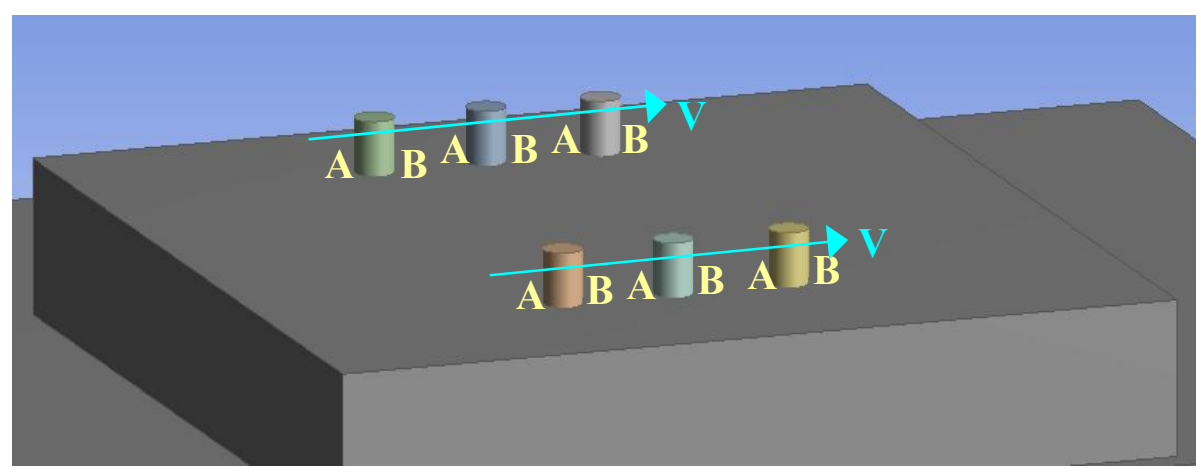

Figure 5.21. Stress development under anchor bolt shear force 


\subsubsection{Stresses in the Piercaps}

The maximum principal stress is first determined in the piercaps of the Man Bridge FE model. ADINA calculates the necessary stresses during solution computation, making these values readily accessible during post-processing, as is typical in most commercially available FEA software, principal stresses are determined using the six Cartesian stress components, represented by stress tensor T. Principal stress values are found by setting the determinant of $\mathbf{T}$ equal to zero and calculating the roots of Equation 5.19 , where $I_{1,2,3}$ are the stress invariants.

$$
T=\left[\begin{array}{ccc}
\sigma_{x x}-\sigma & \sigma_{x y} & \sigma_{x z} \\
\sigma_{x y} & \sigma_{y y}-\sigma & \sigma_{y z} \\
\sigma_{x z} & \sigma_{y z} & \sigma_{z z}-\sigma
\end{array}\right]
$$

$$
\left|\begin{array}{ccc}
\sigma_{x x}-\sigma & \sigma_{x y} & \sigma_{x z} \\
\sigma_{x y} & \sigma_{y y}-\sigma & \sigma_{y z} \\
\sigma_{x z} & \sigma_{y z} & \sigma_{z z}-\sigma
\end{array}\right|=0
$$

$$
\sigma^{3}-I_{1} \sigma^{2}+I_{2} \sigma-I_{3}=0
$$


Illustrative principal stress contour plots are shown in Figures 5.22-5.24 for several piercaps throughout the bridge. Most noticeable is the concentration of stresses near the bearing devices, as anticipated. Stresses in the piercaps where fixed bearings are employed are significantly higher than at piers where expansion bearings are used. Stress contour plots for Pier 1 and Pier 5 are shown in Figure 5.23. Similar plots for Pier 7 and Pier 10 are shown in Figure 5.24. Comparing these plots, it is very apparent that stresses in Pier 1 and Pier 10, which have guided bearings, are much lower than Pier 5 and Pier 7, which have fixed bearings. It is evident that the guided bearings are transferring less force to the substructure than are the fixed bearings, which is to be expected. This finding further suggests that lateral deflection of the support piers is not accommodating thermal deformation of the superstructure, leading to the development of thermal forces.

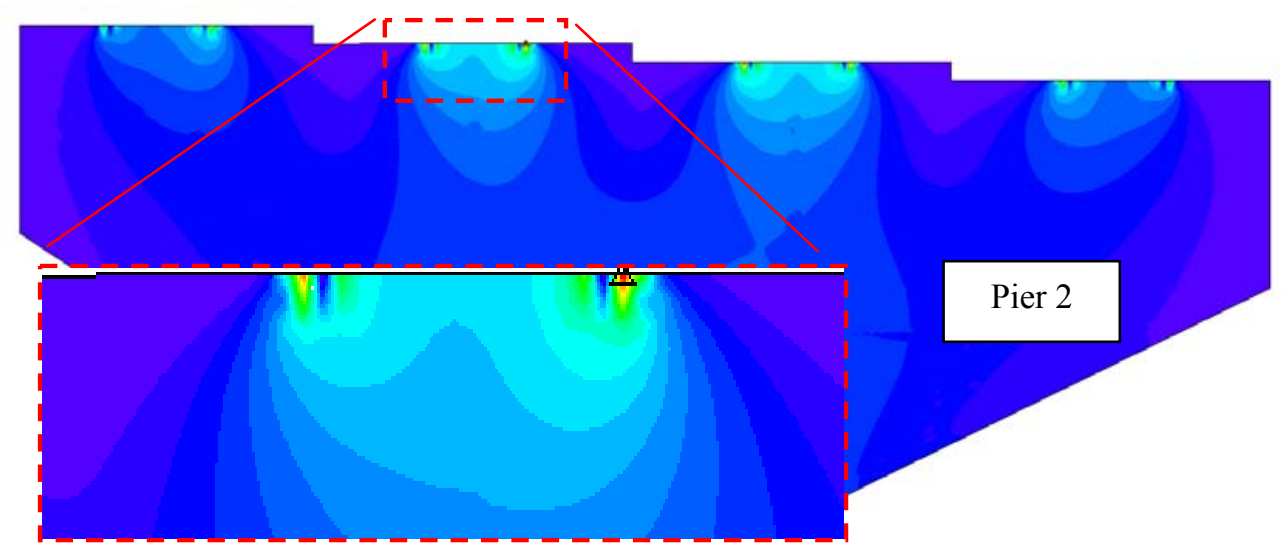

Figure 5.22. Sample contour plots - Pier $2\left(\mathrm{Temp}-70^{\circ} \mathrm{F}\right)$ 


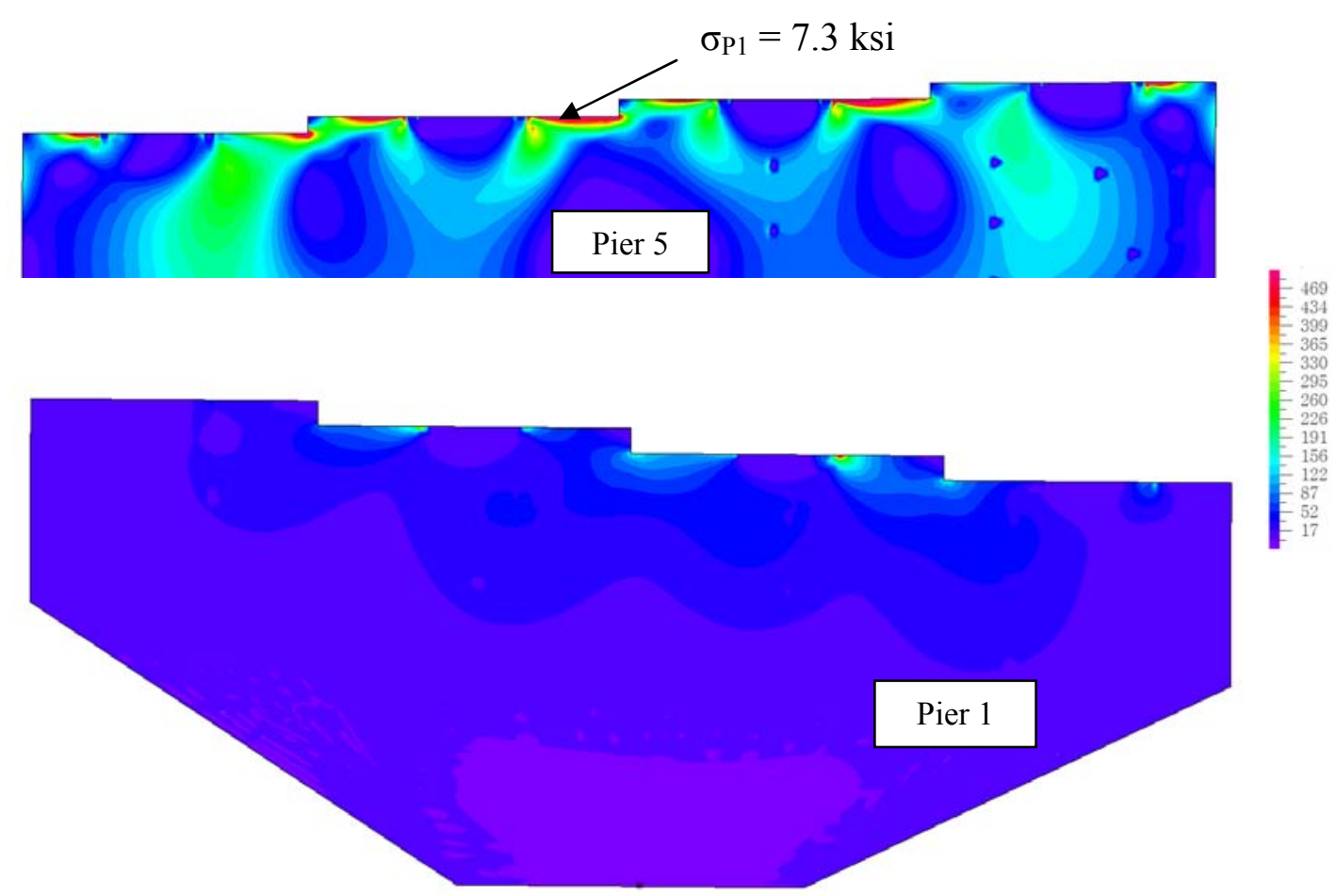

Figure 5.23. Maximum principal stress $\left(\sigma_{1}\right)$ contour plots - Pier $1,5\left(\mathrm{Temp}-70^{\circ} \mathrm{F}\right)$
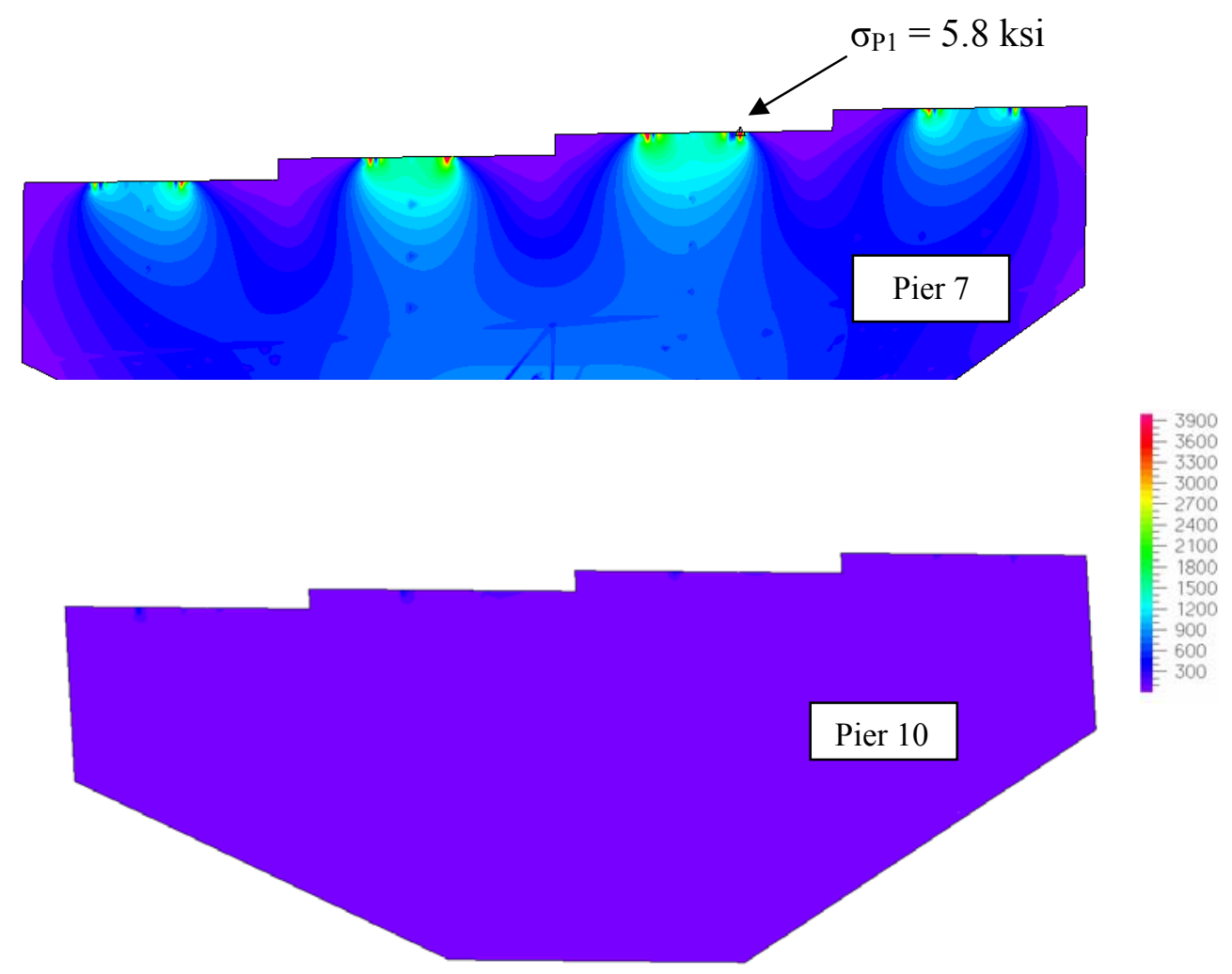

Figure 5.24. Maximum principal stress $\left(\sigma_{1}\right)$ contour plots - Pier 7, $10\left(\right.$ Temp $\left.-70^{\circ} \mathrm{F}\right)$ 
Table 5.15 presents the approximate maximum principal stress recorded in each piercap as predicted by the FE model. The maximum principal stress in the piers with guided bearings is less than the tensile fracture strength of the concrete material, excluding Pier 1. At the piers where fixed bearings are installed, the maximum principal stress far exceeds the tensile rupture of the concrete. The maximum principal stress in any pier is found at Pier 2 and Pier 3, where $\sigma_{1}$ reaches $7.3 \mathrm{ksi}$ and $7.2 \mathrm{ksi}$, respectively, when the $-70^{\circ} \mathrm{F}$ temperature load is applied to the steel superstructure. The FE model stress data can now be compared to behavior documented during the field investigation, where cracking was recorded in Piers 1-5. The maximum principal stress in Piers 1-5 exceeds the tensile strength of the concrete, as seen in Table 5.15. According to the stress values shown here and using Rankine's criterion to predict tensile fracture, the signifcant amount of cracking observed throughout the bridge is most likely due to thermal stresses resulting from restrained thermal deformation of the steel I-girder superstructure.

Table 5.15. Maximum principal stress in each piercap

\begin{tabular}{|c|c|c|c|c|}
\hline & \multicolumn{2}{|c|}{ Temp $-70^{\circ} \mathrm{F}$} & \multicolumn{2}{|c|}{ Temp $+60^{\circ} \mathrm{F}$} \\
\hline & $\sigma_{p, \max }(p s i)$ & $\% \sigma_{p, \max } / \sigma_{T}$ & $\sigma_{p, \max }(p s i)$ & $\% \sigma_{p, \text { max }} / \sigma_{T}$ \\
\hline Pier 1 & 600 & 127 & 600 & 127 \\
\hline Pier 2 & 7300 & 1540 & 7000 & 1477 \\
\hline |Pier 3 & 2200 & 464 & 2400 & 506 \\
\hline Pier 4 & 350 & 74 & 2000 & 422 \\
\hline Pier 5 & 7200 & 1519 & 7000 & 1477 \\
\hline Pier 6L & 200 & 42 & 200 & 42 \\
\hline Pier 6R & 300 & 63 & 250 & 53 \\
\hline Pier 7 & 5800 & 1224 & 4300 & 907 \\
\hline Pier 8 & 500 & 105 & 400 & 84 \\
\hline |Pier 9 & 5100 & 1076 & 5000 & 1055 \\
\hline Pier 10 & 400 & 84 & 400 & 84 \\
\hline Pier 11 & 200 & 42 & 200 & 42 \\
\hline
\end{tabular}




\subsubsection{D Solid Model}

The previous analysis provided further data supporting the hypothesis that thermal forces are the primary action leading to the adverse conditions observed on the Man Bridge. Limitations regarding the Man Bridge FE model were recognized and discussed as well. While the model is very useful, the strategy used to model the bearing anchor bolts allowed for the development of stress concentrations in the shell elements representing the concrete piercaps. The stress concentrations have the ability to significantly influence the accuracy of the results.

The development of such stress concentrations can exaggerate the actual magnitude of the stress recorded. Furthermore, because single layer shell elements were used to represent the piercaps, the region around the anchor bolts was not effectively replicated in the Man Bridge FE model. Therefore, a linear-elastic 3D solid model of the top portion of a typical piercap was constructed, as shown in Figures 5.25-5.26. As seen in the figures, the piercap geometry is perfectly replicated. Additionally, the steel anchor bolts are embedded the appropriate depth into the piercap. The key intention of this model is to provide a near perfect representation of a concrete piercap with the embedded bearing anchor bolts. Such a model will allow for a more true determination of the stress state in the concrete media.

Modeling an entire support piercap was completed, as illustrated in Figure 5.25. However, computation time proved to be too unmanageable due to the large number of solid elements, hampering the usefulness of such a model. Results in Section 5.6 demonstrated that stresses are most significant in the vicinity of the anchor bolts, and decrease rapidly through the depth of the piercap. So, it was decided to model only a 
depth of concrete equal to the embedment length of the anchor bolts. Such a model would more accurately capture the behavior around the anchor bolts and allow computational expediency.

Further illustrations of the solid model are provided in Figure 5.26. Basic geometrical dimensions are given in Figure 5.27. The piercap is $34.5 \mathrm{ft}$ in length with a width of $7.5 \mathrm{ft}$. On this particular piercap (modeled after Pier 5), the steps between each girder are nearly 6 in. with a pedestal height of exactly 6 in. All dimensions were taken directly from the bridge's design drawings. The geometry volumes were created using surface extrusions. Seen in Figure 5.28, a 2" mesh is applied to all volumes. This particular mesh size was chosen in order to strike a balance between solution accuracy and computation time. The material model for the steel anchor bolts and concrete is linear-elastic, similar to the Man Bridge FE model. The reasons behind using a linearelastic material model for the concrete were discussed in Chapter Four. 


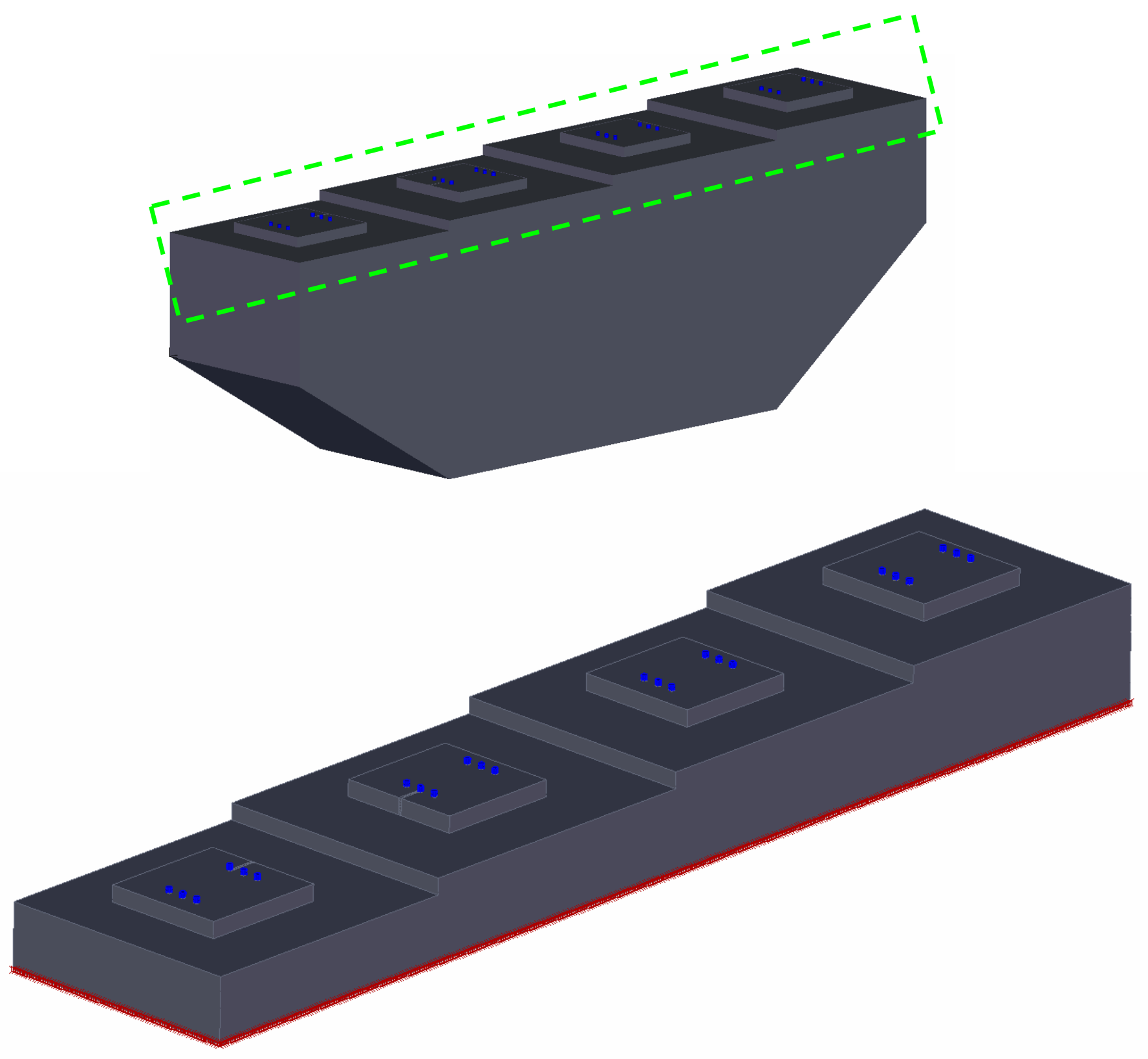

Figure 5.25. 3D solid model of a typical piercap 


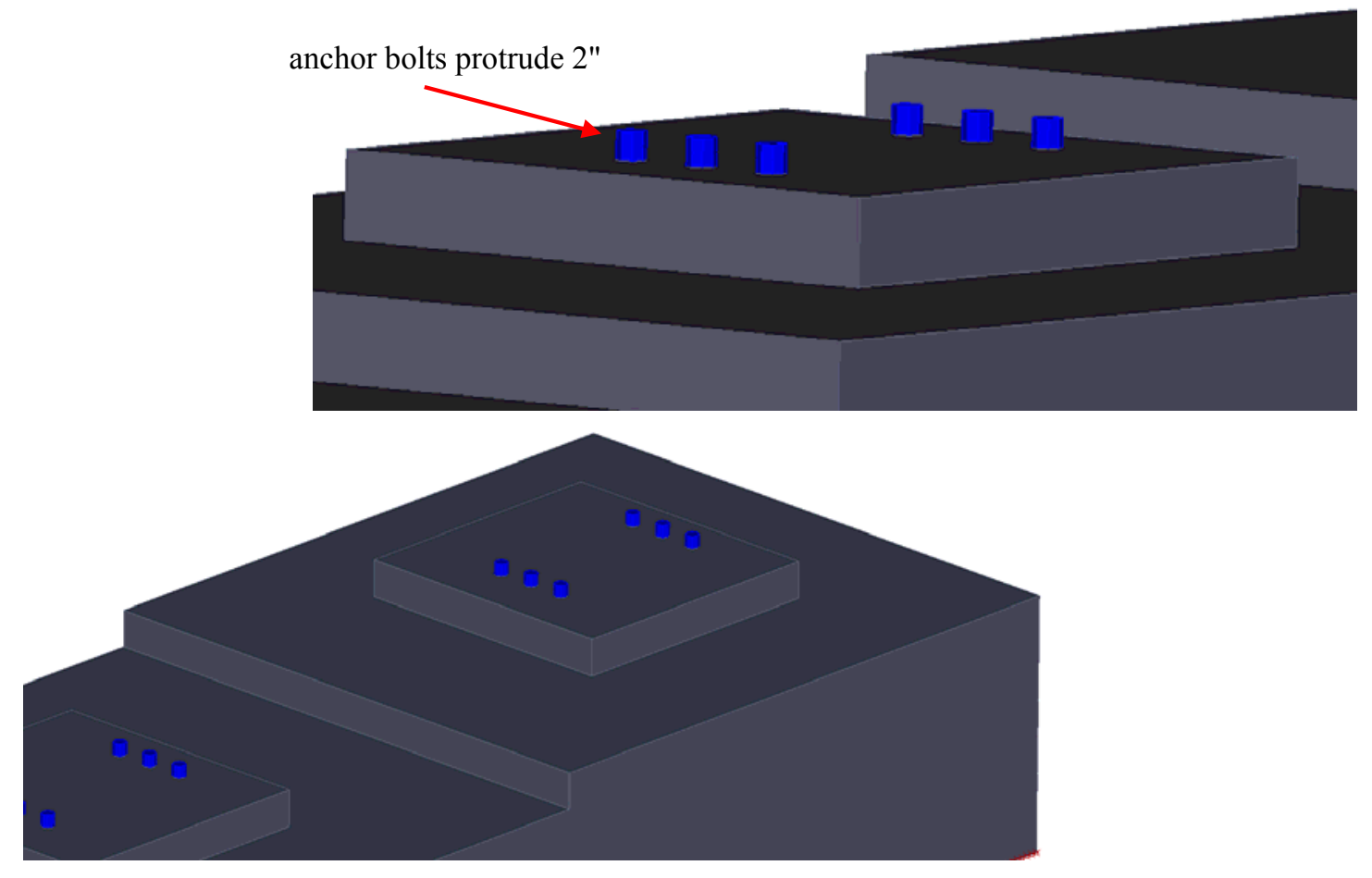

Figure 5.26. Solid model anchor bolts
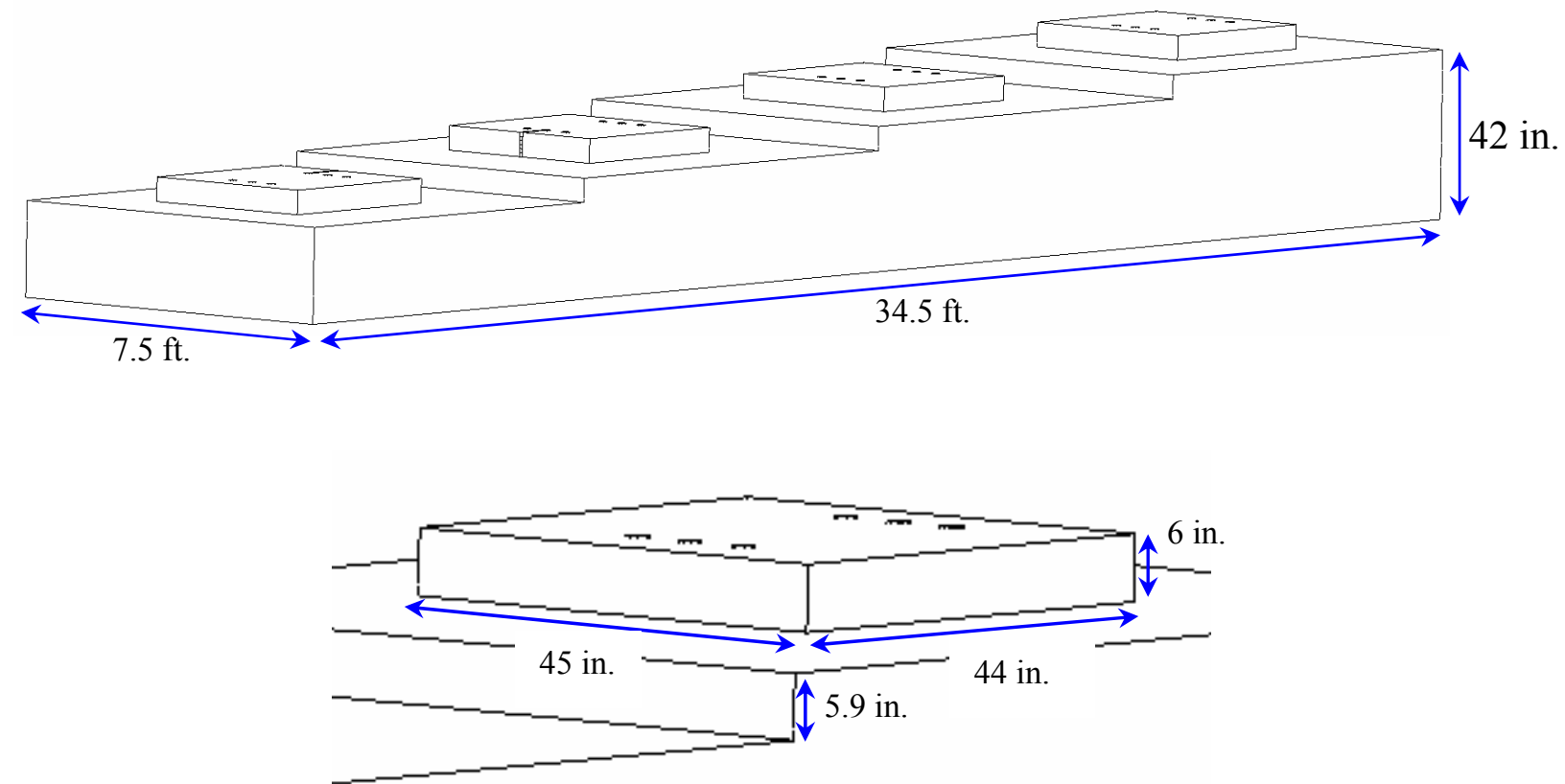

Figure 5.27. Solid model piercap dimensions 


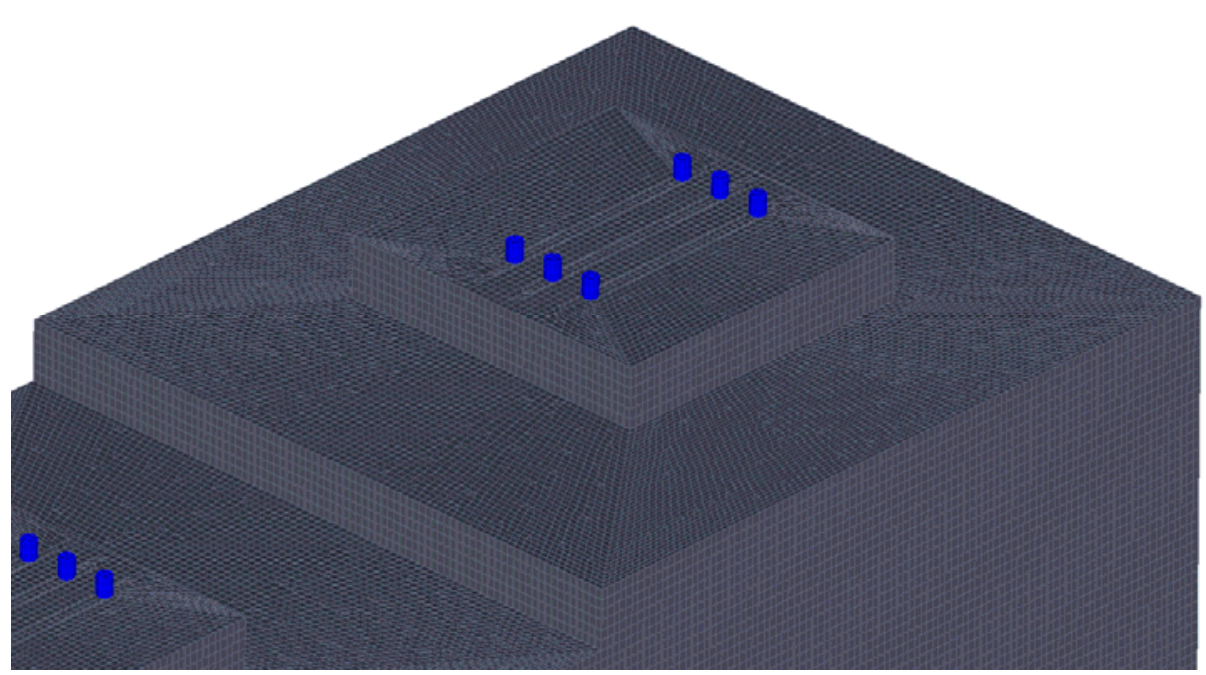

Figure 5.28. Solid model mesh

Perhaps the most signifcant aspect of creating a suitable solid model was determining how to apply the boundary conditions. Since the pier column is not included in the model, a method for representing the stiffness provided by the column was needed. To accomplish this, grounded spring elements were input at each node on the mesh comprising the bottom surfaces. The total stiffness provided by the pier column was calculated and divided according to the number of nodes. The total stiffness of the pier column is given by Equation 5.20, where $E$ is the modulus of elasticity of the concrete, $I$ is the second moment of inertia of the circular cross-section and $L$ is the length of the pier column. After performing the calculation, a stiffness of $8.84 \mathrm{lb} / \mathrm{in}$ is applied to each spring element DOF, pictured in Figure 5.29. 
Shear force data from Section 5.3 was used to determine the magnitude of horizontal force to be applied to the anchor bolts. A simple manipulation of these forces was needed in order to correctly apply the loads. The horizontal loads are input as nodal forces and applied to the nodes on the mesh representing the anchor bolts To determine the correct magnitude of force to apply, the shear force acting on a bolt group is divided among the number of bolts in the group. This value provides the magnitude of force acting on each bolt, which is then divided by the number of nodes on the perimeter of the bolt over which the force acts. In this case, a total of 15 nodes would be in bearing contact with the masonry plate at the given time under horizontal forces Therefore, the total force acting on any bolt is divided by 15 , providing the necessary nodal force. This is illustrated in Figure 5.30. A sample calculation of the required nodal force is provided below for a bolt group under Girder 4 at Pier 5 due to the $+60^{\circ} \mathrm{F}$ temperature load. Using this method to apply the loads, each bolt group in the bridge can be investigated separately simply by adjusting the nodal force acting on the bolts and the stiffness of the grounded spring elements.

- Total horizontal force acting on bolt group $=46 \mathrm{kips}$

- Force per bolt $=46$ kips $/ 6$ bolts $=7.66$ kips per bolt

- Nodal force $=7.66$ kips per bolt $/ 15$ nodes $=0.511$ kips $=\mathbf{5 1 1} \mathbf{l b s}$ per node 


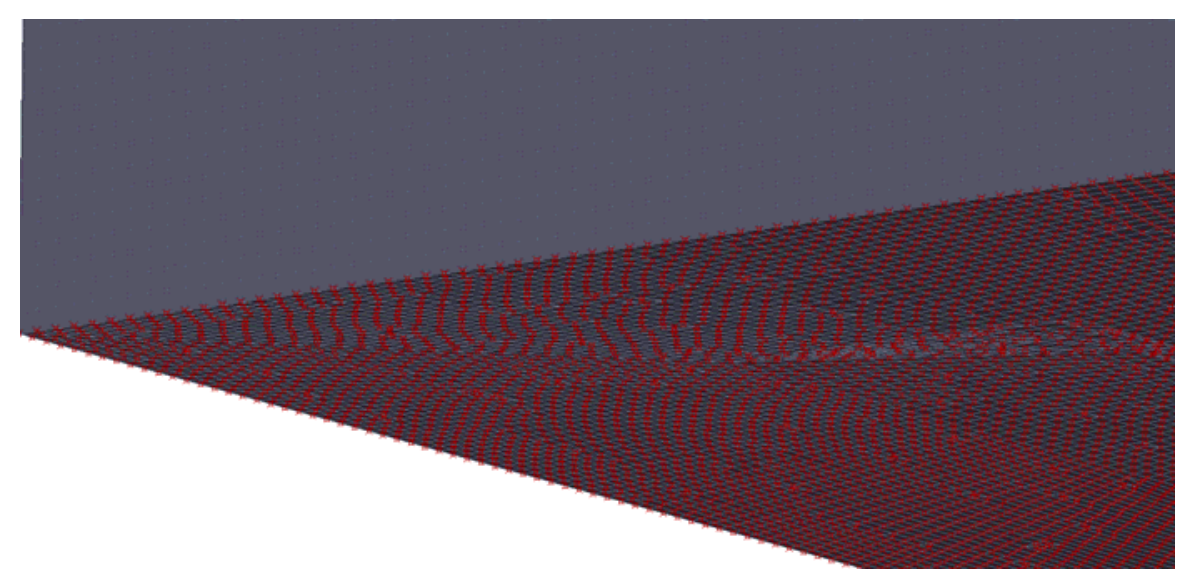

Figure 5.29. Grounded spring elements representing pier column stiffness

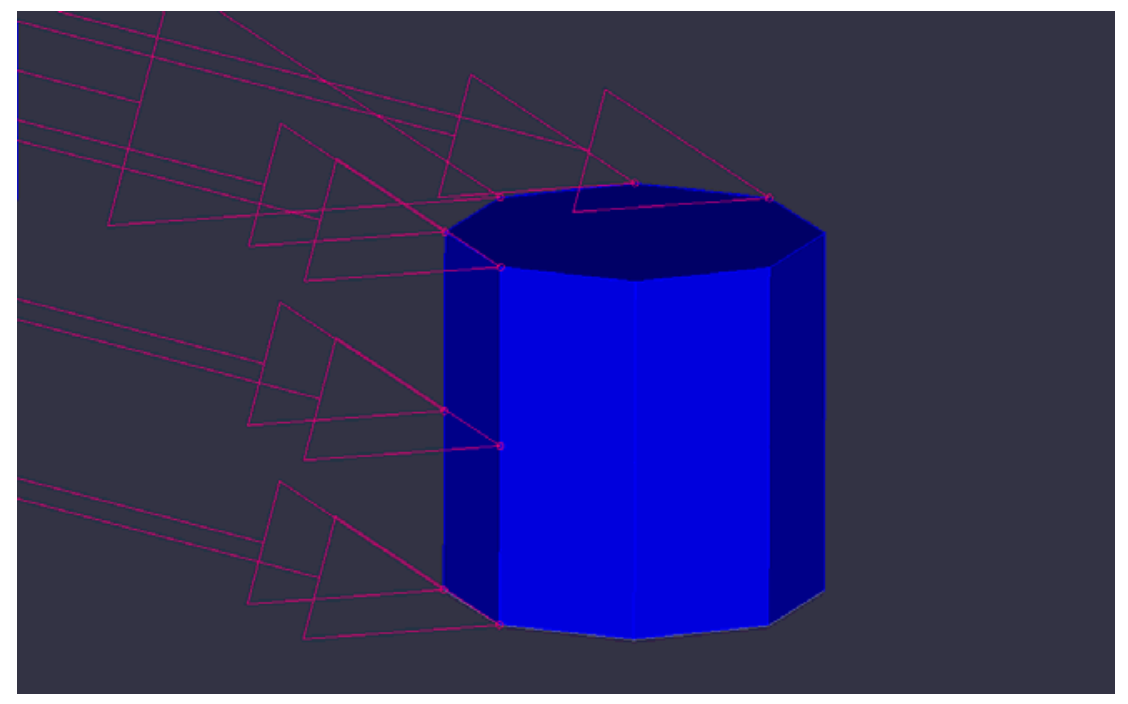

Figure 5.30. Application of nodal forces acting on each bolt 


\subsubsection{D Solid Model Results}

Figure 5.31 illustrate a contour plot for $\sigma_{1}$ in the solid model with the horizontal loads associated with Pier 5 acting on the anchor bolts. First, it is seen that stresses diminish fairly rapidly through the depth of the piercap. High levels of stress appear to subside at a depth of around 2 in. Additionally, the development of tensile stresses, $\sigma_{\mathrm{T}}$, is clearly visible. Figures 5.32 and 5.33 present principal stress contour plots at two separate bolt groups of Pier 5, Girder 4 and Girder 1, respectively.

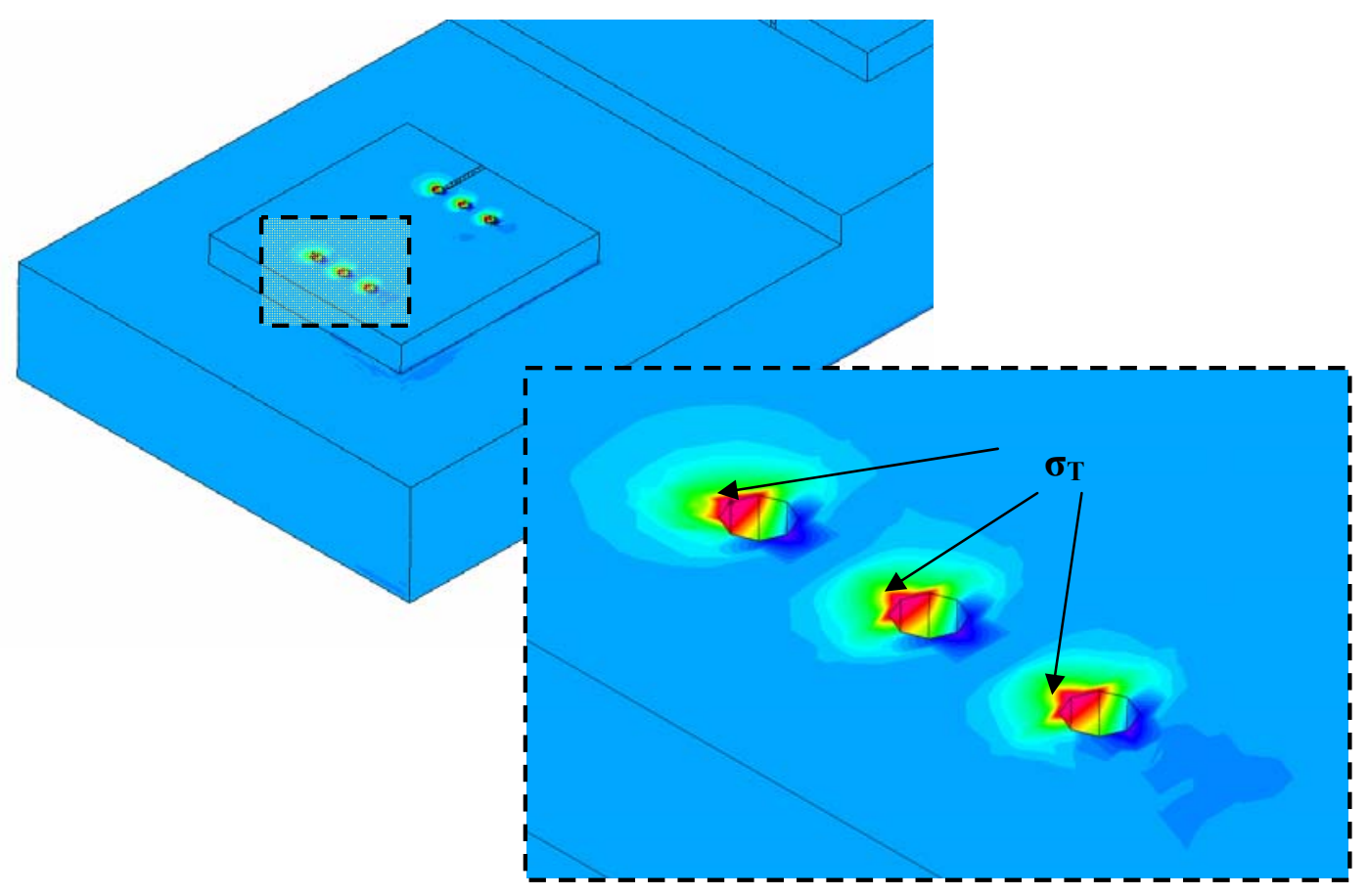

Figure 5.31. $\sigma_{1}$ development in the concrete surrounding the anchor bolts 




Figure 5.32. $\sigma_{1}$ under Girder 4 at Pier 5

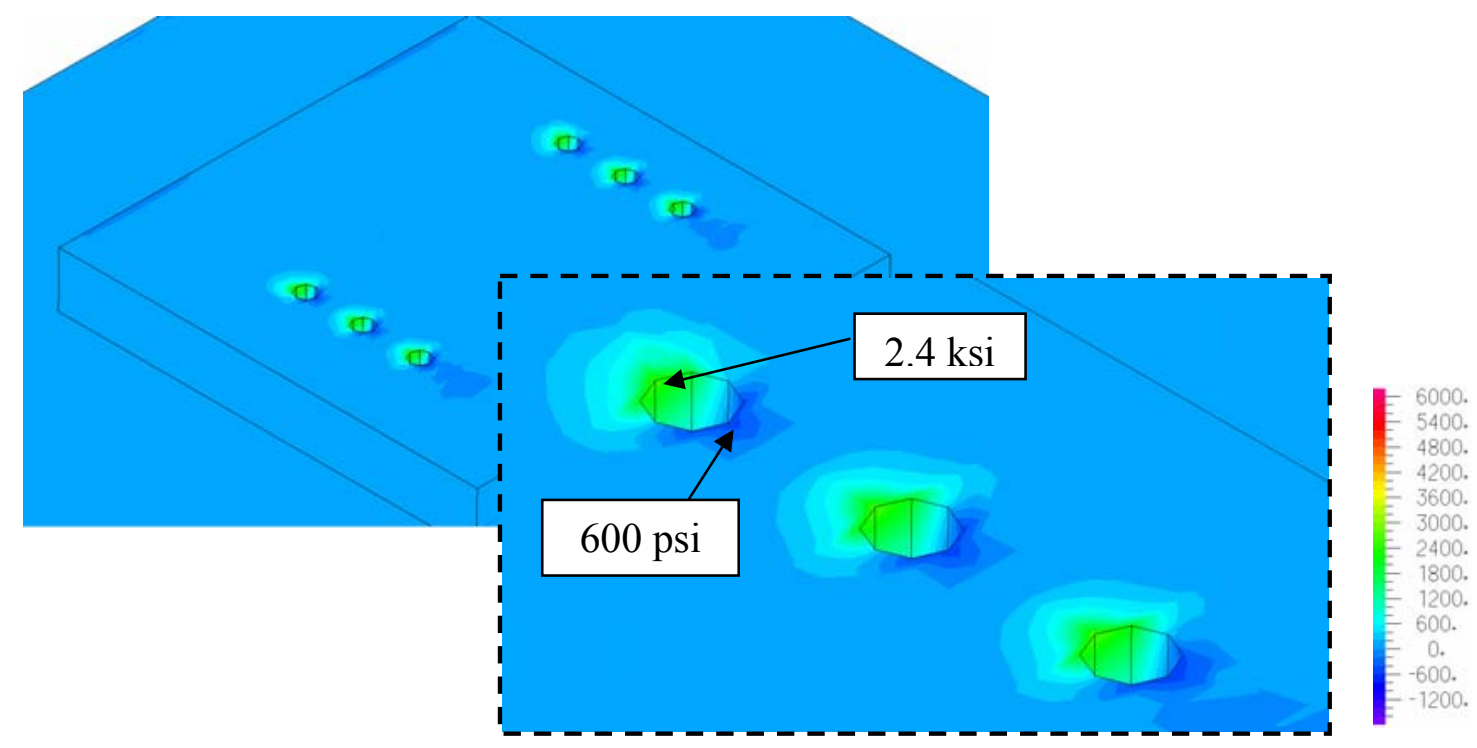

Figure 5.33. $\sigma_{1}$ under Girder 1 at Pier 5 
Tensile stresses in the concrete piercap under Girder 4 reach 8 ksi, while a stress of $2.4 \mathrm{ksi}$ develops at Girder 1. Compressive stress at each location is less than the $4 \mathrm{ksi}$, so compressive failure (i.e. concrete crushing) is not a concern. The magnitude of the two tensile stress values is well above the tensile rupture strength of the concrete material. This finding further supports the proposal that thermal forces are the main action behind the signifcant levels of cracking. These results are also in good agreement with the stress values determined from the Man Bridge FE model, where the concrete support piers were modeled using shell elements.

It has been shown that thermal forces acting on the bearing anchor bolts have the potential to cause cracking in the concrete support piers. The horizontal force data analyzed in Section 5.3 can be used to determine the resultant stress-state within each of the concrete piercaps throughout the bridge. While performing such an analysis may provide confirmation of cracking in additional support piers throughout the bridge, it would prove cumbersome and repetitive. A more beneficial analysis would be to determine the minimum horizontal load that may lead to cracking. This minimum horizontal load could then be considered a maximum design load, ensuring that the stress-state within the piers remains at an acceptable level. This would produce information that bridge designers could rely on when considering thermal loads and designing a bridge's substructure. With knowledge of the maximum safe horizontal design load, the support piers can be designed with an appropriate stiffness so that thermal forces are minimized, lessening the potential for adverse behaviors (i.e. cracking in the piers). 


\subsection{Summary and Conclusions}

This chapter provided a comprehensive investigation into the response of the Man Bridge under uniform thermal loading. Results of a field investigation, documented in Chapter Three, lead to the hypothesis that thermal forces were the cause of several adverse behaviors, including deformed bearing anchor bolts and significant amounts of cracking throughout the concrete support piers. The analysis within this chapter presented clear evidence substantiating this hypothesis.

Longitudinal thermal deformation of the steel I-girder superstructure is up to $55 \%$ less than the design temperature movement range, indicating that the guided expansion bearings are not permitting movement in the manner expected when thermal loads are present. Large magnitudes of horizontal shear force were found to develop at each support location. However, the shear force in the bolts was shown to be at an acceptable level, well below the nominal capacity of the bolts. Additionally, elevated levels of stress were generated in the bottom flanges of the steel I-girders near the bearing devices. The elevated stresses were compared to stresses that develop in the absence of thermal loading, and supported the initial hypothesis. Thermal stresses of up to $11 \mathrm{ksi}$ were recorded. This finding is notable in that $16 \%$ of the steel girder's yield strength is consumed by only thermal loads which are typically assumed insignificant.

Work and energy principles were introduced to demonstrate that flexure of the support piers does not fully mitigate the development of thermal forces at the fixed bearings, mainly due to the rigidity of the pier columns. The amount of strain energy due to flexure of the pier was shown to be larger than the amount of work done to cause deflection of the pier, indicating that a certain amount of strain energy must have 
developed in components other than the pier columns. This behavior is supported by the elevated stresses in the I-girder flange and large shear forces in the bearing anchor bolts, and confirms that pier flexibility may not always accommodate thermal deformation of a slab-on-girder bridge's superstructure. Lastly, it was shown that the cracking in the concrete support piers may be a result of thermal forces transmitted from the superstructure, through the anchor bolts. Using the maximum principal stress failure criterion (Rankine's criterion), as is applicable to brittle materials like concrete, it was found that the stress-state within the concrete media surrounding the bearing anchor bolts is such that the potential for fracture exists. While each pier was not studied specifically, tensile stresses around the anchor bolts in Pier 5 reach $8 \mathrm{ksi}$, which is well above the tensile rupture strength of concrete. 


\section{CHAPTER SIX}

\section{FEA Case Study}

\subsection{Introduction}

The second major goal of this work is to determine how best to prevent the development of thermal forces in a horizontally curved continuous steel I-girder bridge. To achieve this, finite element analysis (FEA) is once again utilized to conduct a case study using Unit 2 of the Man Bridge. The main purpose behind employing bridge expansion bearings is to minimize the development of thermal forces with a bridge's superstructure and substructure. As was illustrated in Chapter Five, the original bearing arrangement employed on the Man Bridge consisted of numerous fixed bearings at multiple consecutive support locations with relatively few guided expansion bearings. This particular bearing arrangement resulted in large thermal forces that were shown to be the likely cause of adverse conditions within the bridge. In order to prevent the development of thermal forces, the guided bearings must be oriented in a particular manner. However, this process can be challenging on horizontally curved continuous structures due to the complex nature of their response under thermal loading. Current AASHTO design specifications do not adequately specify the proper method with which to align the guided bearings. Within this chapter, a specific determination will be made concerning the preferred orientation of guided expansion bearings on a horizontally curved continuous steel I-girder bridge.

The case study presented in this chapter compares the thermal response of Unit 2 under the influence of two additional bearing arrangement schemes. The boundary 
conditions are modified so that a minimal number of fixed bearings are employed while using as many expansion bearings as possible. A key focal point of this chapter is to determine where the fixed bearings should be located within a curved I-girder bridge. Once the boundary conditions within the Man Bridge FE model have been modified, data similar to that discussed in Chapter Five is analyzed, including bearing displacement, stresses in the bottom flanges near the bearing devices, horizontal shear force in the bearing anchor bolts and stresses in the support piers. The two new bearing arrangements are compared with one another and with results from Chapter Five to demonstrate what type of bearing scheme best accommodates thermal deformation and mitigates thermal forces within a curved steel I-girder superstructure

\subsection{New Bearing Arrangement Schemes}

The two new bearing arrangements are illustrated in Figures 6.1 and 6.2. These arrangements were designed to allow the bridge's horizontally curved steel superstructure to displace in a freer manner when subjected to thermal loading, thereby minimizing the potential development of thermal forces. Most notably, two sets of fixed bearings were removed and replaced with expansion bearings, leaving fixed bearings at only a single interior pier. The new bearing arrangements are implemented in close accordance with AASHTO (2007), where it is stated within a horizontally curved bridge, all expansion bearings should be oriented to permit translation relative to a single point and that any other orientation will allow the development of thermal forces. However, this point, thru which the guided bearings should be aligned is not clearly defined. However, it is presumed that this point should be a location where fixed bearings are placed. Since 
thermal forces need to be minimized, fixed bearings will only be utilized at one interior pier and all guided bearings are be oriented to allow translation relative to this point. When considering at which interior pier the fixed bearings should be placed, two options were considered most acceptable. First, as shown in Figure 6.1, fixed bearings were placed at Pier 9 so that an equal number of supports (3) is located on either side. Pier 9 is also the support nearest to the geometric center of the bridge. A second new bearing arrangement places fixed bearings at Pier 8 and expansion bearings at all other support locations, as illustrated in Figure 6.2. Pier 8 is very near the stationary point of the bridge as it is subject to thermal loading, therefore, placing the fixed bearings here may result in minimal magnitudes of resultant thermal forces throughout the bridge. The bearing arrangement with fixed bearings at Pier 9 is termed "Case 1" and "Case 2" is used to denote the other arrangement.

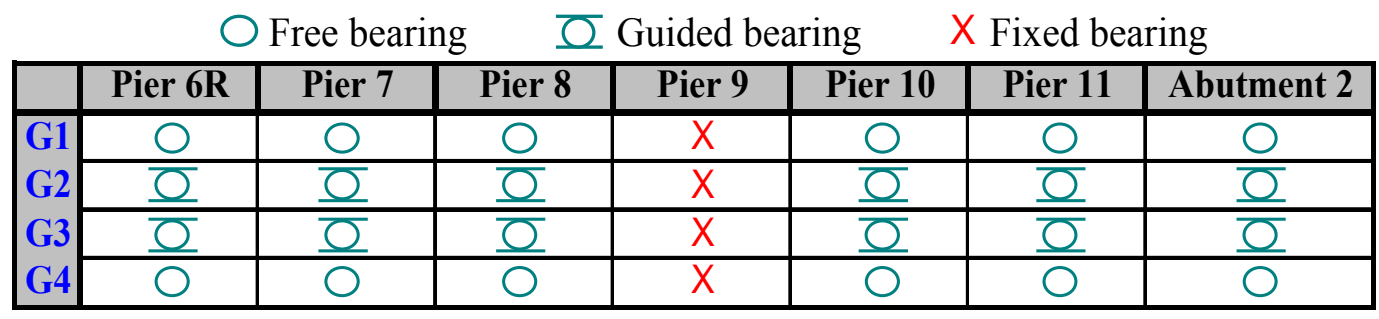



Figure 6.1. Bearing arrangement modification Case 1 


\begin{tabular}{|c|c|c|c|c|c|c|c|}
\hline & \multicolumn{3}{|c|}{ Free bearing } & \multicolumn{2}{|c|}{ () Guided bearing } & \multicolumn{2}{|c|}{ Fixed bearing } \\
\hline & Pier 6R & Pier 7 & Pier 8 & Pier 9 & Pier 10 & Pier 11 & Abutment 2 \\
\hline G1 & O & 0 & X & $\mathrm{O}$ & $\mathrm{O}$ & $\mathrm{O}$ & $\mathrm{O}$ \\
\hline G2 & $\overline{0}$ & ర & X & O & O & $\overline{0}$ & $\sigma$ \\
\hline G3 & $\bar{\sigma}$ & $\overline{0}$ & $\mathrm{X}$ & $\bar{\sigma}$ & $\bar{\sigma}$ & $\bar{\sigma}$ & $\overline{0}$ \\
\hline G4 & O & O & $\mathrm{X}$ & O & O & $\mathrm{O}$ & $\bigcirc$ \\
\hline
\end{tabular}

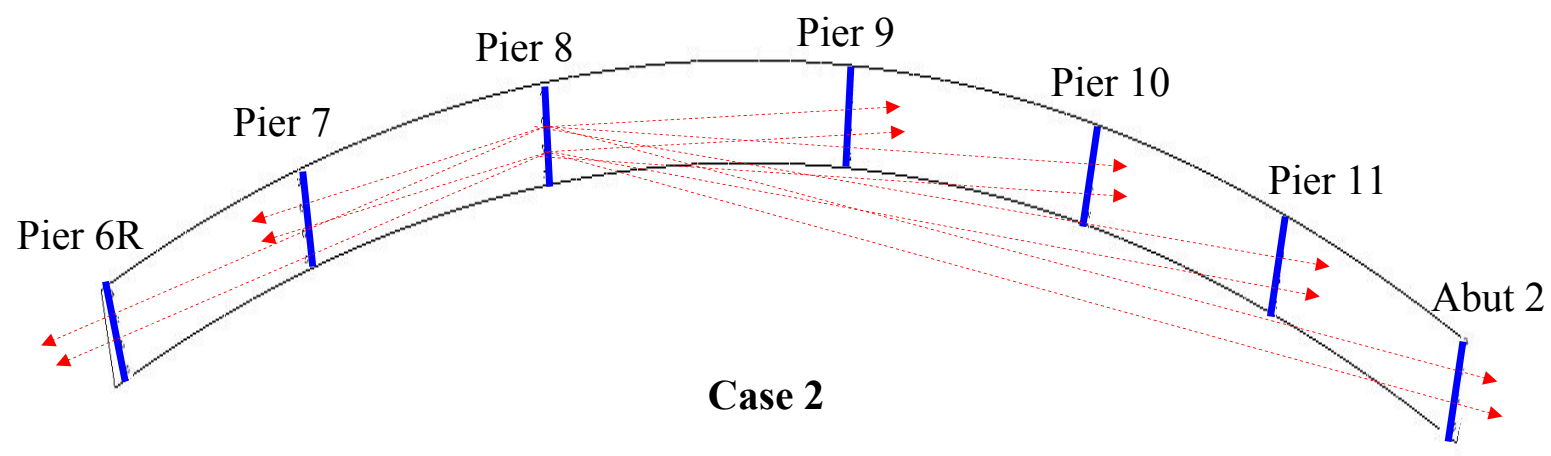

Figure 6.2. Bearing arrangement modification Case 2

\subsection{Superstructure Translation at the Bearings}

Before investigating the development of thermal forces and the related effects, data pertaining to bearing displacement throughout the bridge under the new bearing arrangements is presented. The deformed shapes of the concrete bridge deck for Case 1 and Case 2 under each load case are shown in Figures 6.3-6.6. Firstly, these figures show that there is practically no lateral deflection in the pier where the fixed bearings are located. Lack of movement at this support means that the guided bearings are likely to remain keep their initial orientation and function in the expected manner.

Second, these deformed shapes can be compared to Figures 5.4 and 5.6 to understand the effect of the new bearing arrangements in comparison to the original 
bearing scheme. Two keys findings are readily discernable from these figures. Clearly, the replacement of many of the fixed bearings in the new bearing arrangements is allowing a much greater degree of thermal deformation within the superstructure. A major positive outcome of this is that thermal forces in the steel I-girders, bearing anchor bolts and support piers will likely be significantly lower compared to values produced by the FE model under the original bearing arrangement. In addition, the influence of radial (i.e. transverse) bearing displacement appears to be less under the new bearing arrangements. This section also examines the displacement of the superstructure subject to the uniform thermal loads after the introduction of the new bearing arrangements. 


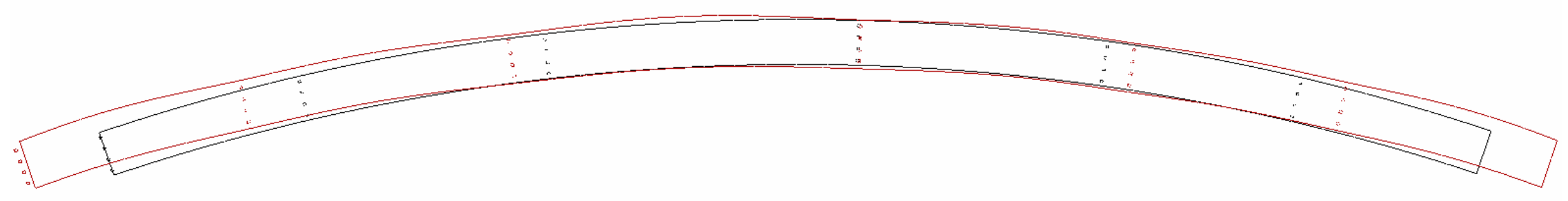

Figure 6.3. Case 1 thermal movement under the $+60^{\circ} \mathrm{F}$ thermal load

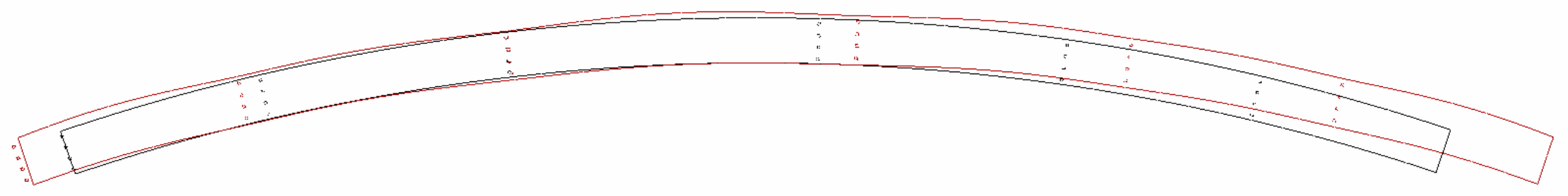

Figure 6.4. Case 2 thermal movement under the $+60^{\circ} \mathrm{F}$ thermal load 


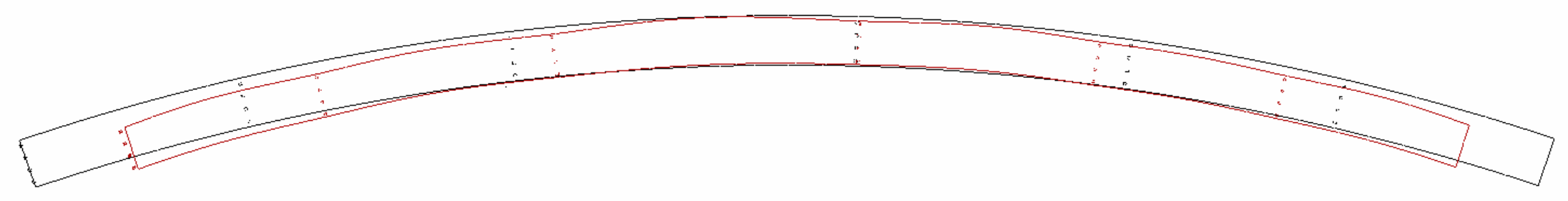

Figure 6.5. Case 1 thermal movement under the $-70^{\circ} \mathrm{F}$ thermal load

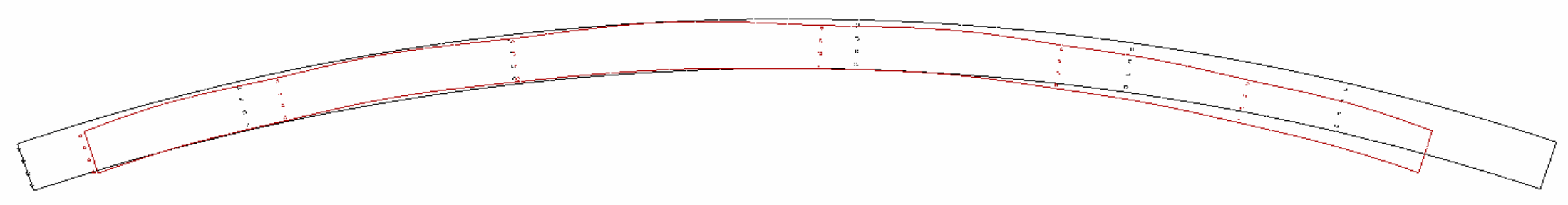

Figure 6.6. Case 2 thermal movement under the $-70^{\circ} \mathrm{F}$ thermal load 
Figures 6.7 and 6.8 plot the magnitude of longitudinal bearing displacement at Piers 6-11 and Abutment 2. Bearing displacement for Case 1 and Case 2 (as noted above) are compared against one another and bearing displacement values from Chapter 5 (the original bearing arrangement provided in the design drawings). The displacement data confirms that the point of zero translation within the superstructure is very near Pier 8. Under the original bearing arrangement, longitudinal displacement at Pier 8 is approximately $0.20 \mathrm{in}$. Comparing this to Case 2 , where displacement is $0.11 \mathrm{in}$., demonstrates that this new bearing arrangement has little effect on displacement at Pier 8, unlike the rest of the structure. Additionally, it is clearly shown that in Case 1 and Case 2 the displacement of the guided bearings at Piers 7-9 is greater than the original values. Such a response indicates that the support piers were in fact restraining thermal deformation at these locations.

It is also seen that the location of the fixed bearings has a considerable impact on the magnitude of bearing displacement throughout the bridge. For example, look closely at bearing displacement Abutment 2. Bearing displacement, which can be approximated using Equation 5.1, depends on the expansion length $L$. This length is variable depending on where the fixed bearings are placed. When the fixed bearings are placed at Pier 8 , length $\mathrm{L}$ is larger than if the fixed bearings were placed at Pier 9, resulting in a larger value for bearing displacement. For reasons such as this, determining which bearing arrangement is more suitable for permitting thermal deformation of the superstructure can be difficult to achieve. Examining the magnitude of theoretical longitudinal bearing displacement may provide a better understanding as to which arrangement is preferable. 


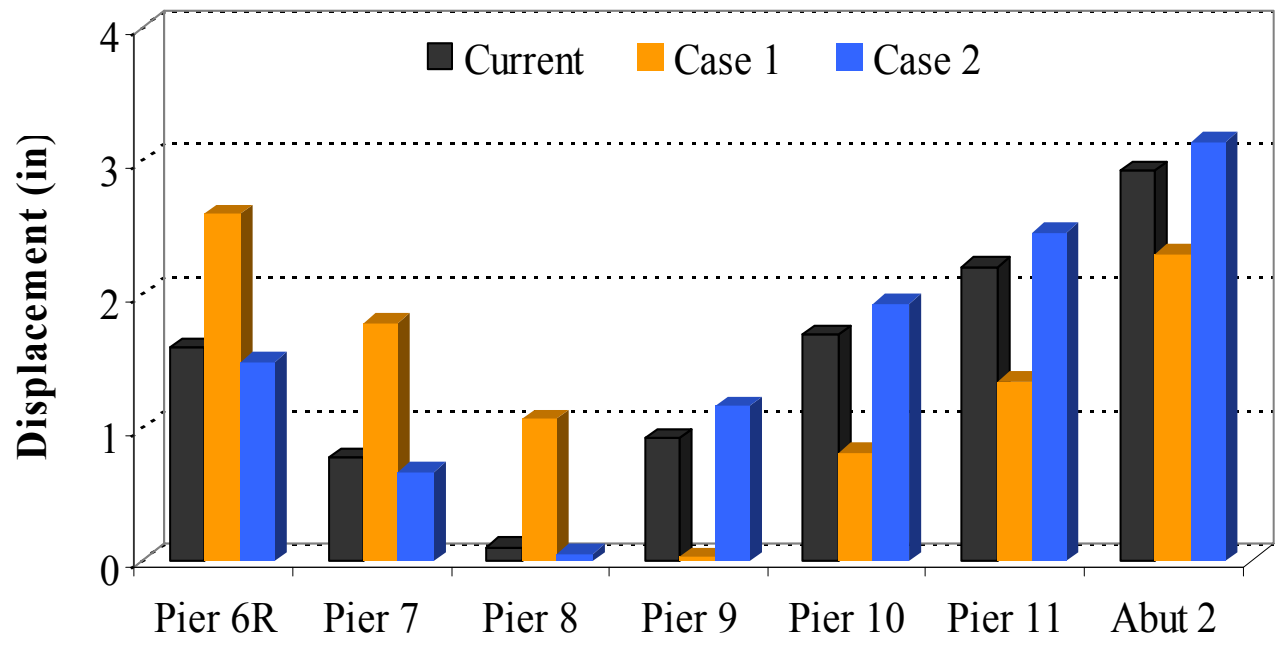

Figure 6.7. Bearing displacement under the $+60^{\circ} \mathrm{F}$ thermal load

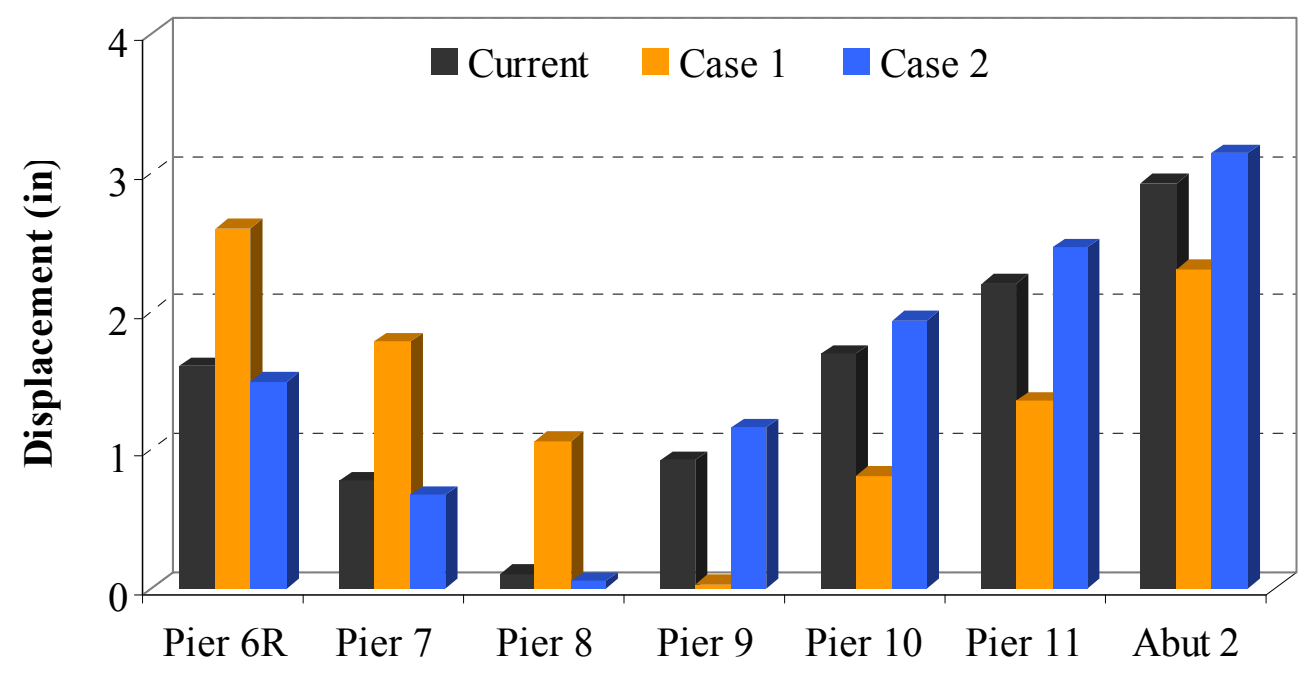

Figure 6.8. Bearing displacement under the $-70^{\circ} \mathrm{F}$ thermal load 
Figures 6.9 and 6.10 plot the maximum theoretical bearing displacement range against FE model predictions for each new bearing arrangement. Similar to Chapter Five, the theoretical bearing displacement range is determined using Equation 5.1 with expansion length L measured relative to either Pier 9 (Case 1) or Pier 8 (Case 2). It is clear that Equation 5.1 overestimates the magnitude of bearing displacement predicted by the FE model.

Table 6.1. Theoretical vs FE predicted bearing displacement - Case 1

\begin{tabular}{|l|c|c|c|}
\hline & \multicolumn{3}{|c|}{ Longitudinal Displacement (in) } \\
& Theoretical & \multicolumn{1}{c|}{ FE model prediction } & \% Diff \\
\hline Pier 6R & 5.90 & 5.37 & $\mathbf{9}$ \\
Pier 7 & 4.31 & 3.89 & $\mathbf{1 0}$ \\
Pier 8 & 2.41 & 2.20 & $\mathbf{9}$ \\
Pier 9 & 0 & 0.08 & - \\
Pier 10 & 1.91 & 1.67 & $\mathbf{1 2}$ \\
Pier 11 & 3.42 & 2.92 & $\mathbf{1 5}$ \\
Abut 2 & 4.93 & 4.37 & $\mathbf{1 1}$ \\
\hline
\end{tabular}

Table 6.2. Theoretical vs FE predicted bearing displacement - Case 2

\begin{tabular}{|l|c|c|c|}
\hline & \multicolumn{3}{|c|}{ Longitudinal Displacement (in) } \\
& Theoretical & \multicolumn{1}{c|}{ FE model prediction } & \% Diff \\
\hline Pier 6R & 3.49 & 3.21 & $\mathbf{8}$ \\
Pier 7 & 1.91 & 1.73 & $\mathbf{9}$ \\
Pier 8 & 0 & 0.13 & - \\
Pier 9 & 2.41 & 2.15 & $\mathbf{1 1}$ \\
Pier 10 & 4.31 & 3.84 & $\mathbf{1 1}$ \\
Pier 11 & 5.83 & 5.09 & $\mathbf{1 3}$ \\
Abut 2 & 7.34 & 6.28 & $\mathbf{1 4}$ \\
\hline
\end{tabular}






Figure 6.9. Maximum bearing displacement range for Case 1

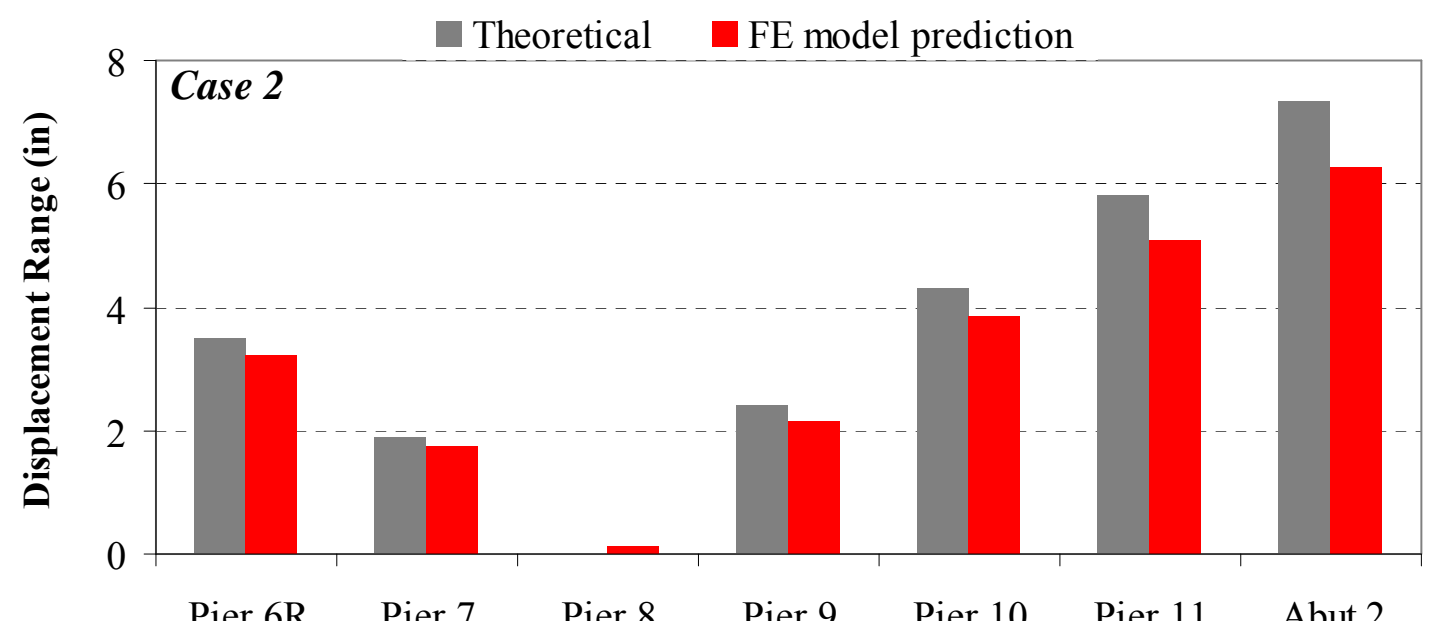

Figure 6.10. Maximum bearing displacement range for Case 2 
The difference between bearing displacement values is tabulated in Table 6.1 and 6.2 for Case 1 and Case 2, respectively. Thermal movement computed using Equation 5.1 is $8-14 \%$ larger than predicted values, with Case 2 providing the more agreeable values. The analysis of bearing displacement under each new bearing arrangement confirms that the equation included in AASHTO design specifications for determining thermal movement (Equation 5.1) does not provide accurate predictions for horizontally curved I-girder bridges. As seen here, Equation 5.1 overestimates the actual magnitude of thermal deformation. A key consequence of this may occur during the design process when bearing devices are over-designed, reducing overall bridge economy.

\subsection{Shear Force in the Bearing Anchor Bolts}

As discussed in Chapter Five, the magnitude of horizontal shear force that develops in the bearing anchor bolts due to thermal loading can be very important. As horizontal forces act on the anchor bolts, force effects are transferred into the concrete piers, which lead to unexpected stresses, since thermal forces are not typically given significant attention. The original bearing arrangement employed on the bridge allowed for the development of large thermal forces, especially at locations where fixed bearings were placed. The two new bearing arrangements removed most of these fixed bearing devices and replaced them with expansion bearings. This section examines the shear force in the bearing anchor bolts under the newly designed bearing arrangements.

Figures 6.11-6.14 plot the magnitude of horizontal shear force that develops in each anchor bolt group. In Case 1, the total shear force generated at any of the guided bearings is less than 100 kips. For Case 2, the total shear force climbs to 130-158 kips at 
each pier where guided bearings are located. Note that these values are the total magnitude of horizontal force that develops at the bearing. As seen in the figures, the distribution of this force is mostly even between the two guided bearing devices at each support. The same shear force values are compared against one another in Figures 6.15 and 6.16. Shear force that develops in the anchor bolts under the original bearing arrangement is also plotted. The reduction in shear force where the fixed bearings were replaced is very clear. Under the original bearing arrangement, a total shear force of approximately 600 kips developed at Pier 7 and Pier 9. Under the new arrangements, shear force is around 200 kips. It is evident that Case 1 results in lower magnitudes of shear force in the bearing anchor bolts.

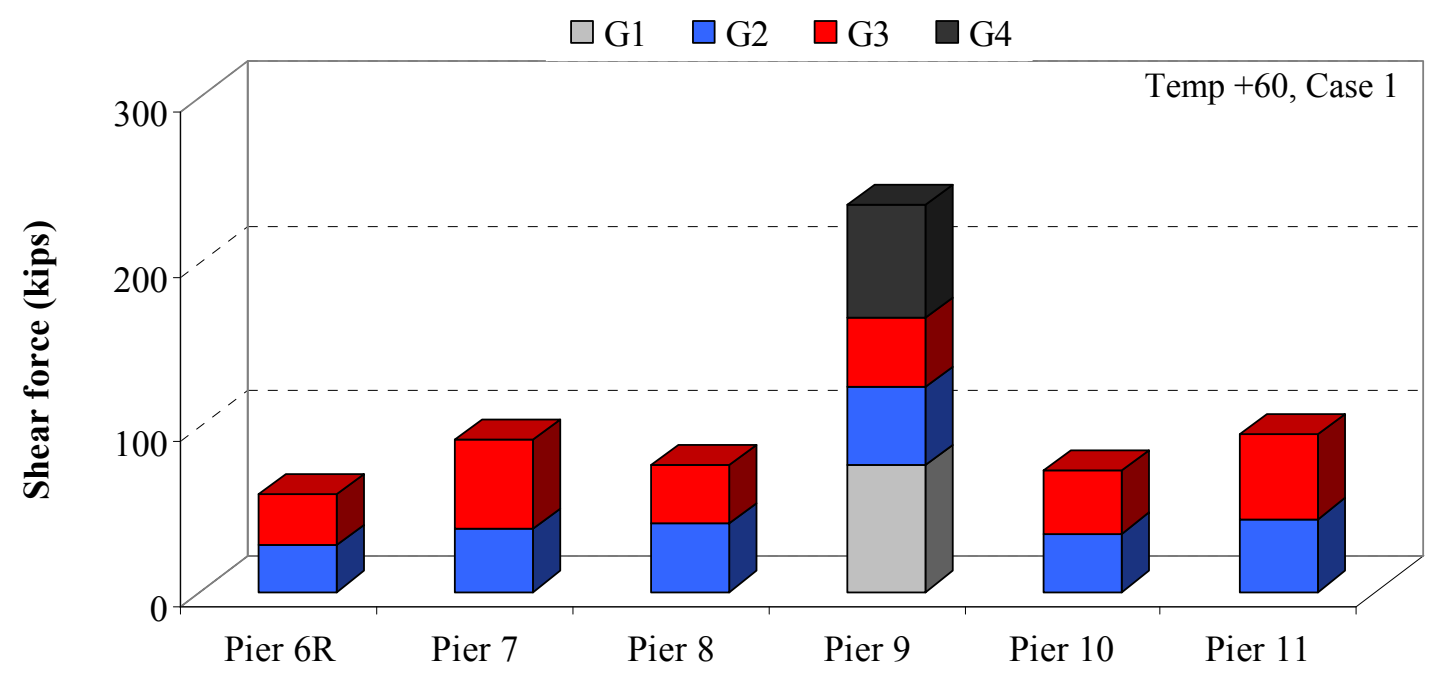

Figure 6.11. Shear force acting at each bearing under the $+60^{\circ} \mathrm{F}$ load - Case 1 


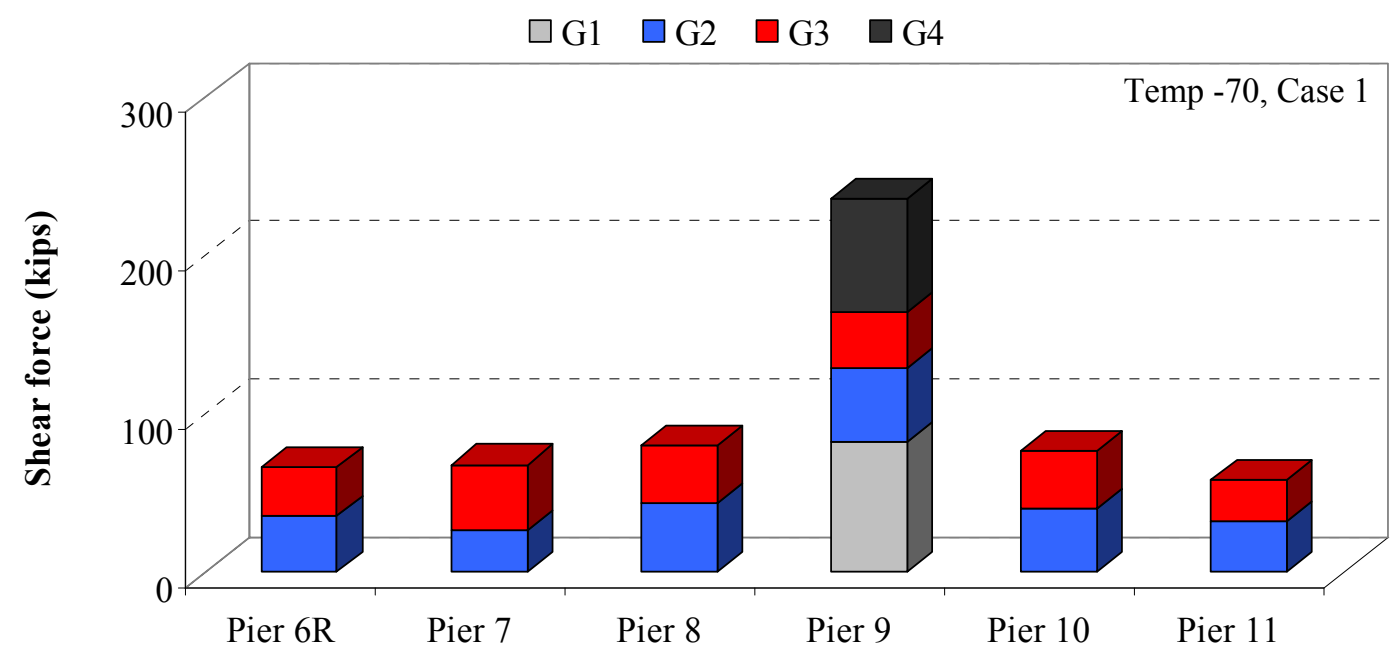

Figure 6.12. Shear force acting at each bearing under the $-70^{\circ} \mathrm{F}$ load - Case 1



Figure 6.13. Shear force acting at each bearing under the $+60^{\circ} \mathrm{F}$ load - Case 2 


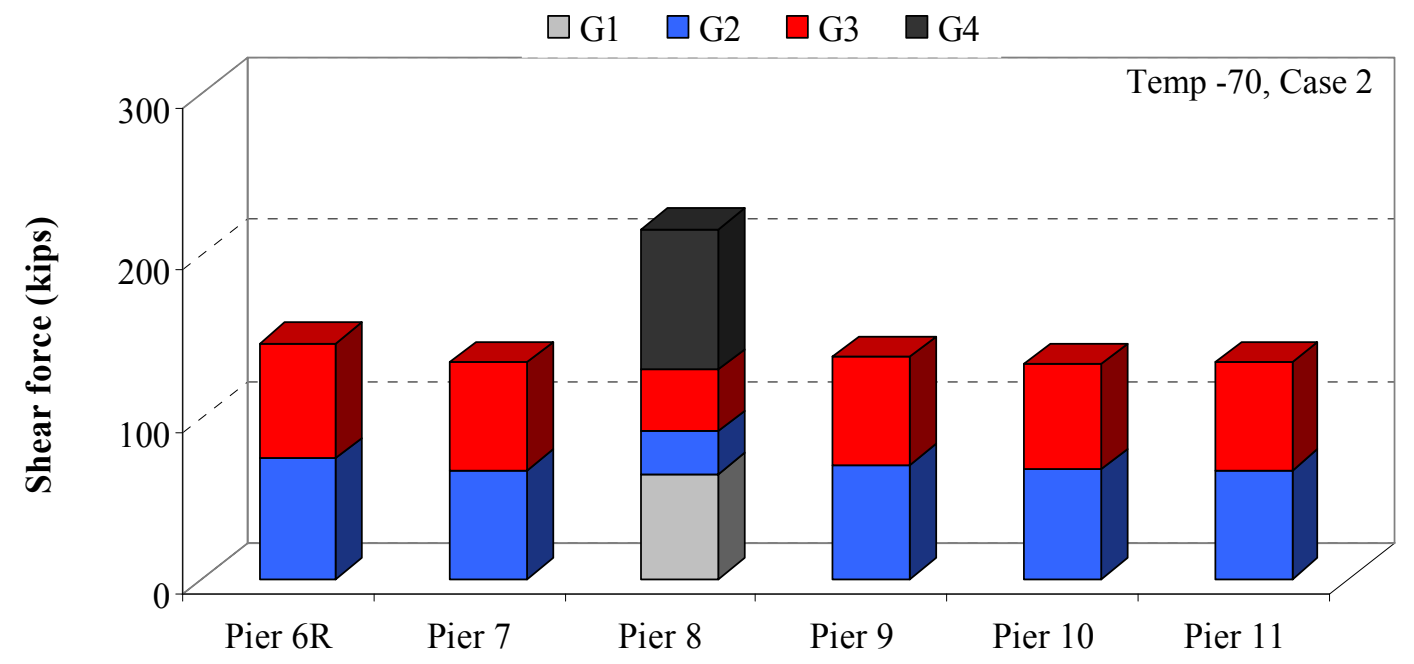

Figure 6.14. Shear force acting at each bearing under the $-70^{\circ} \mathrm{F}$ load - Case 2



Figure 6.15. Total shear force acting at each support (Temp $\left.+60^{\circ} \mathrm{F}\right)$ 


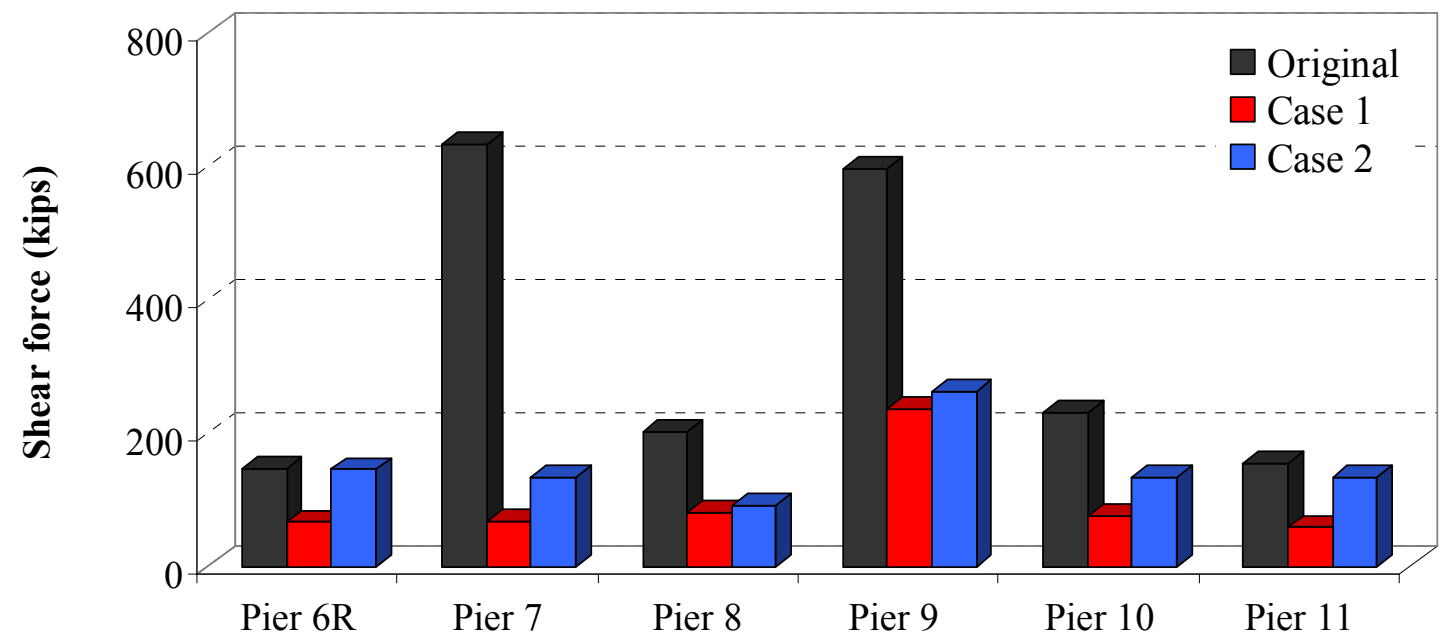

Figure 6.16. Total shear force acting at each support $\left(\mathrm{Temp}-70^{\circ} \mathrm{F}\right)$

\subsection{Flange Stress at the Bearings}

The two new bearing arrangements were designed in order to prevent the development of thermal stresses throughout the horizontally curved steel superstructure. This section investigates the stress-state in the bottom flange of the steel I-girders at each bearing to help determine which of the two bearing arrangements is more preferable for minimizing thermal stresses. Effective stress, as well as stresses in a longitudinal and transverse direction, are extracted from the FE models to provide a comprehensive description of the thermal response at each support. All of these stress values are plotted in Figures 6.16-6.22. 


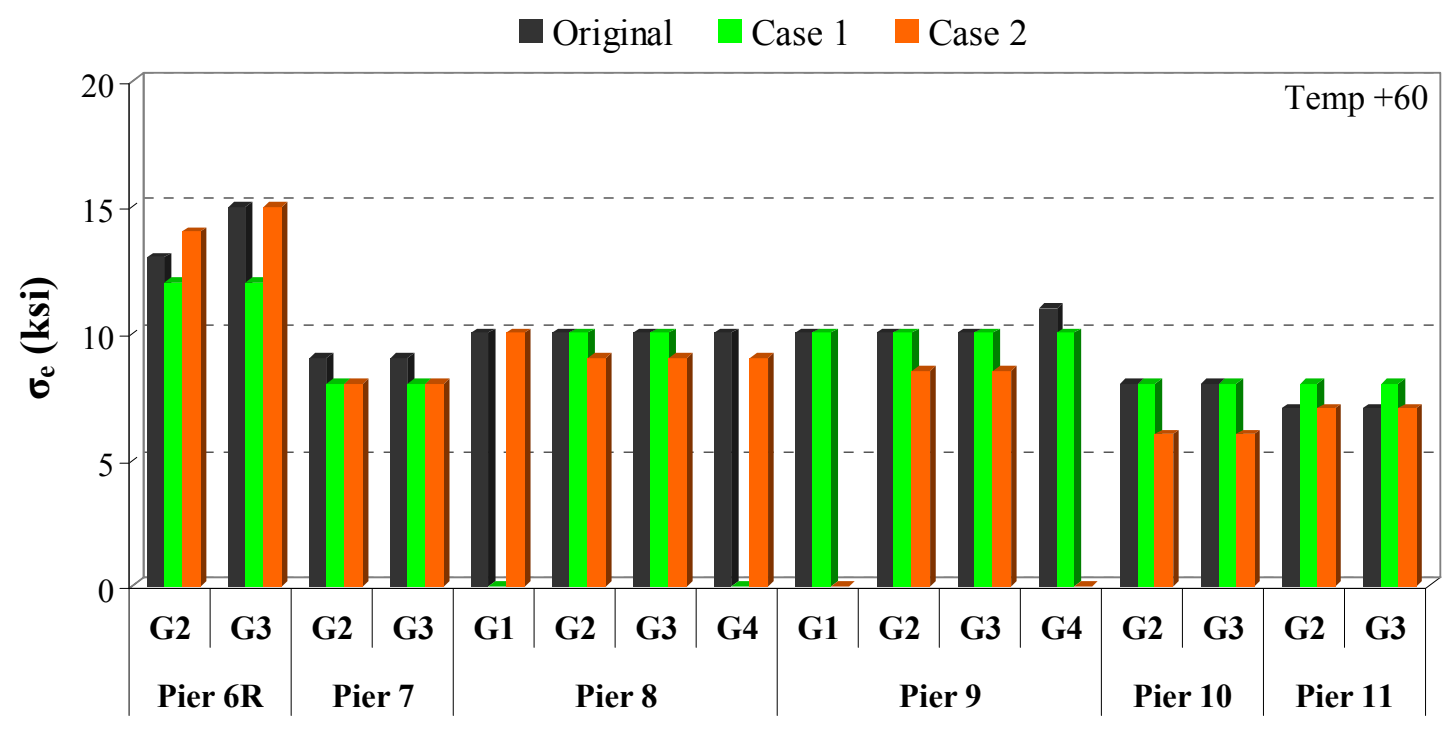

Figure 6.16. Effective stress at the bearings under $+60^{\circ} \mathrm{F}$ load

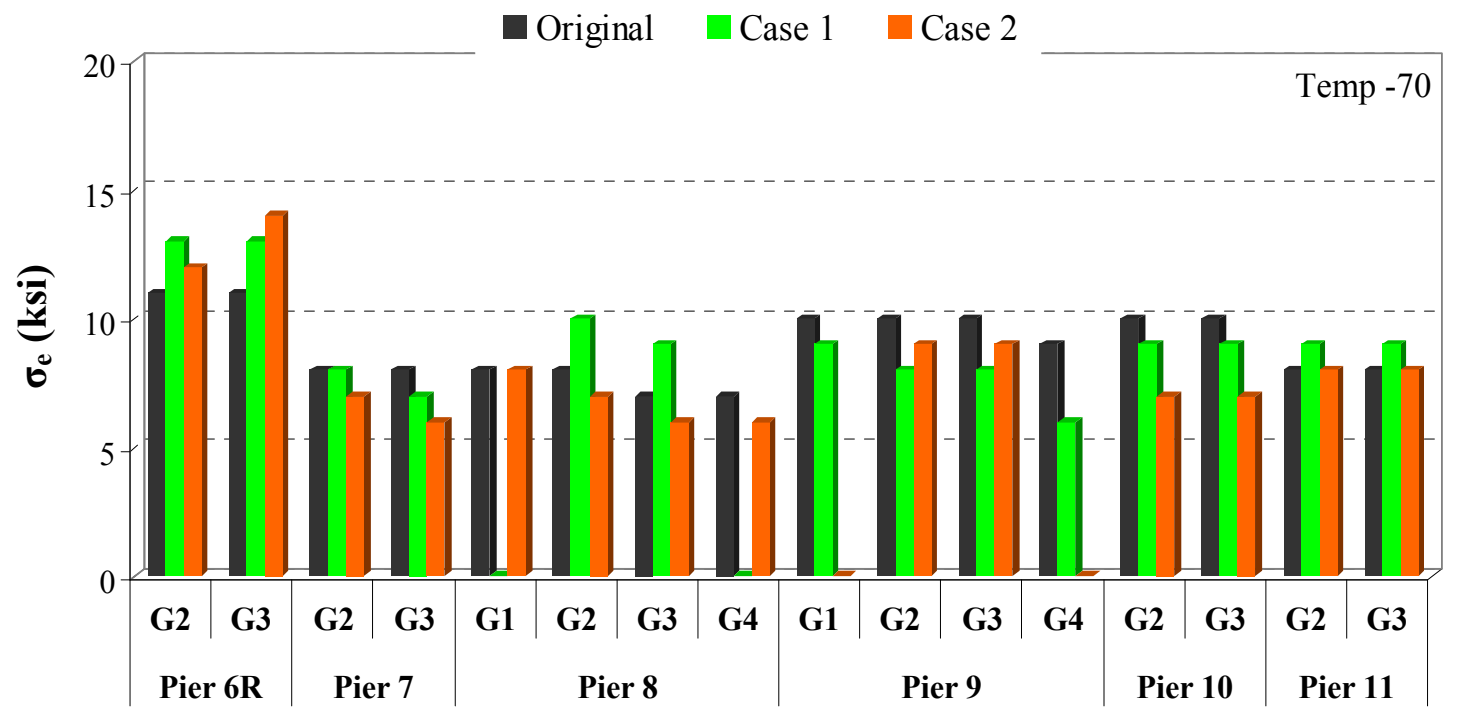

Figure 6.17. Effective stress at the bearings under $-70^{\circ} \mathrm{F}$ load 


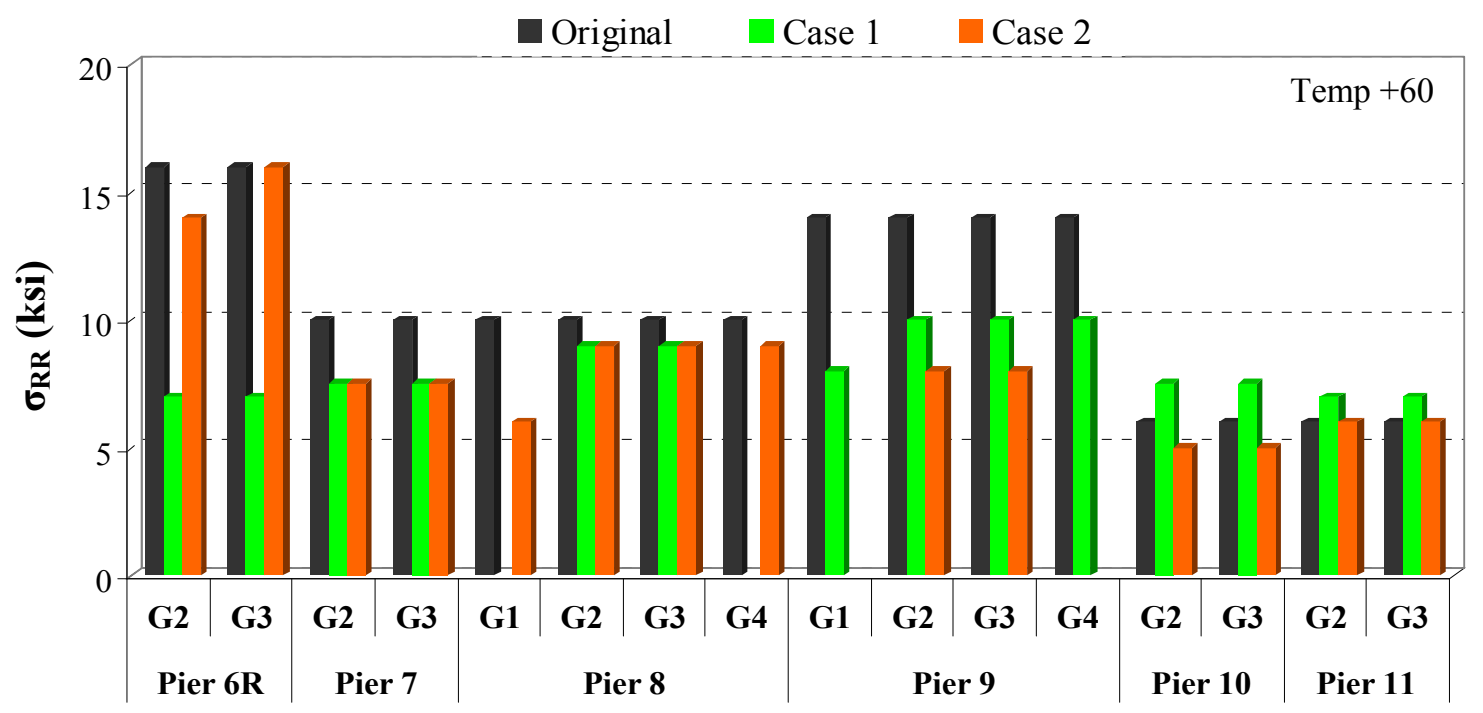

Figure 6.18. Longitudinal stress at the bearings under $+60^{\circ} \mathrm{F}$

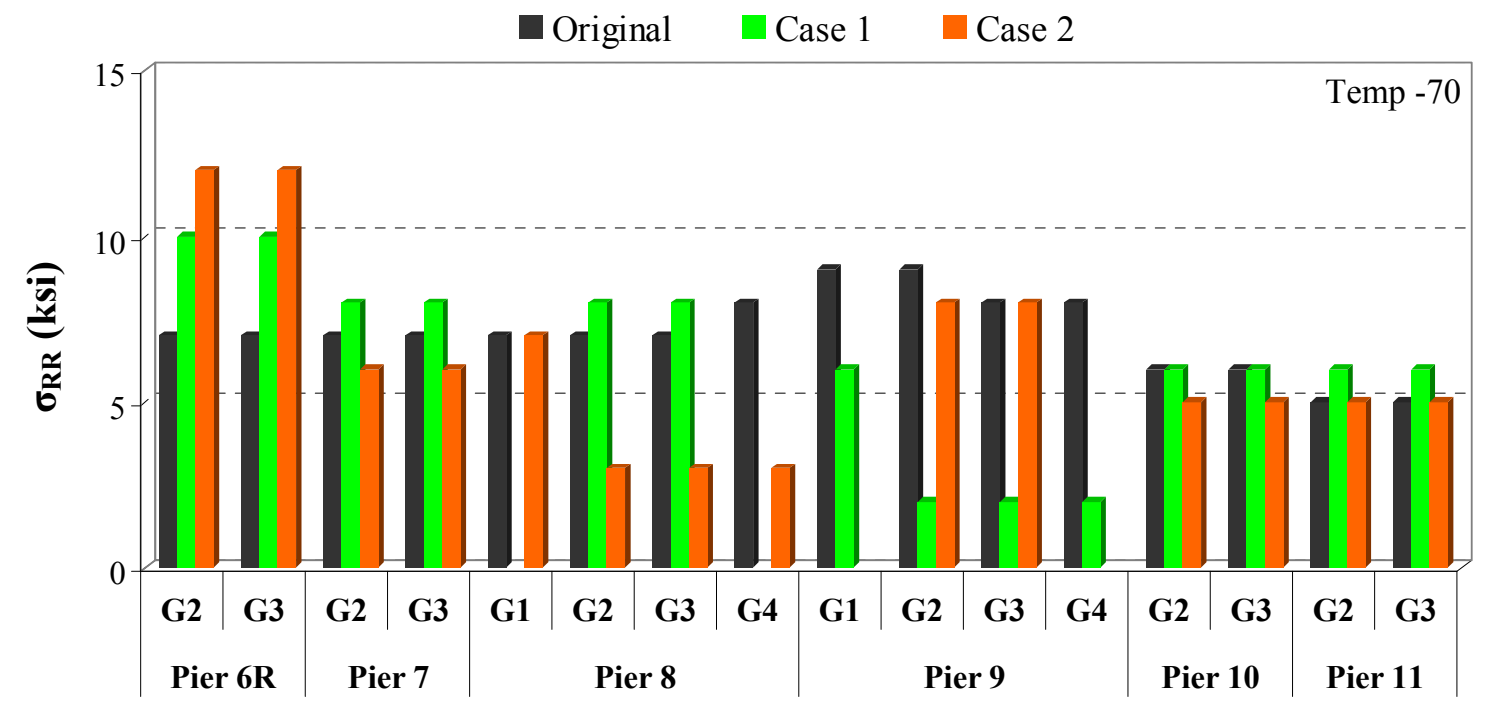

Figure 6.19. Longitudinal stress at the bearings under $-70^{\circ} \mathrm{F}$ 




Figure 6.21. Transverse stress at the bearings under $+60^{\circ} \mathrm{F}$

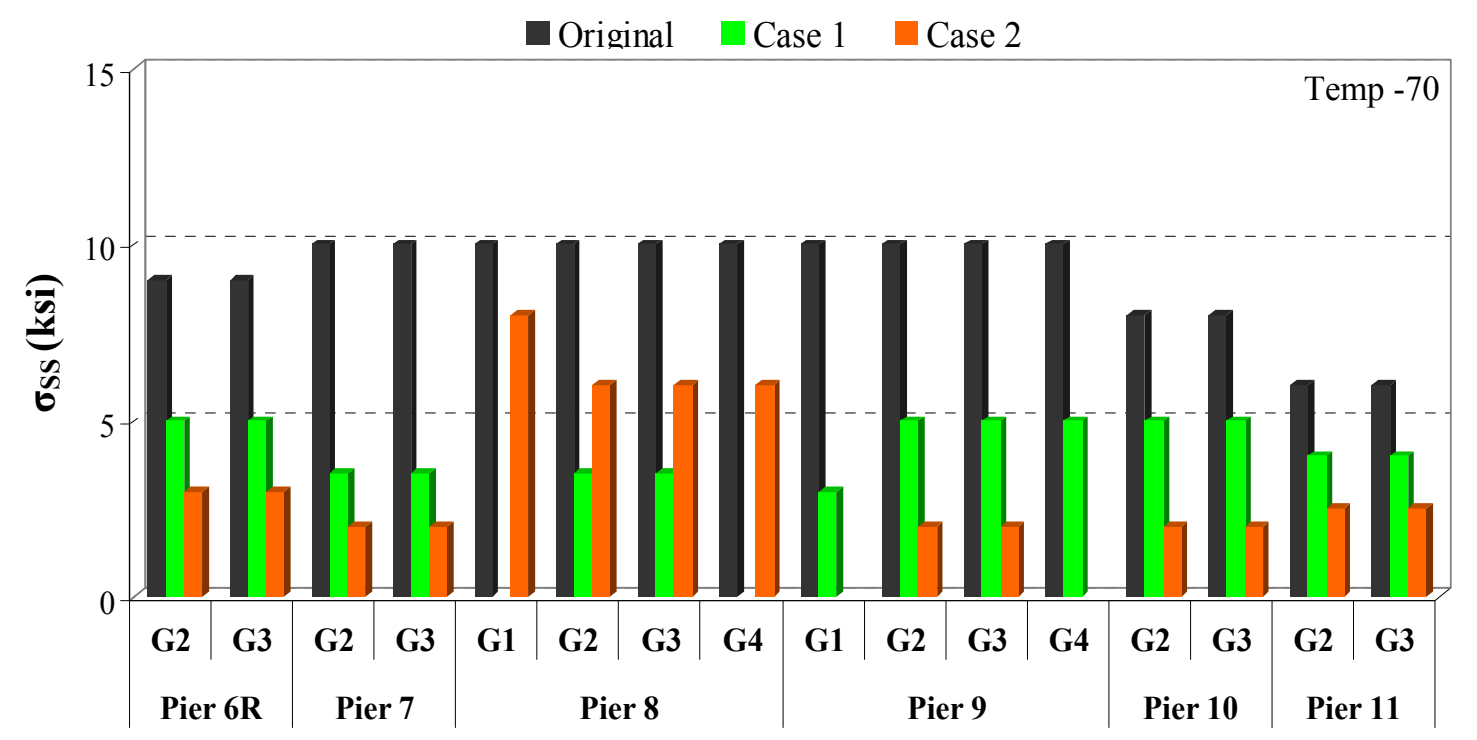

Figure 6.22. Transverse stress at the bearings under $-70^{\circ} \mathrm{F}$ 
The approximate magnitude of effective stress at each bearing is plotted in Figures 6.17 and 6.18. Most intriguing from these plots is that the effective stress at Pier 7 and Pier 9 is not significantly reduced with the introduction of the new bearing arrangements. Recall that in the originally, fixed bearings were employed at these locations. Now that expansion bearings have been implemented, effective stress remains near $10 \mathrm{ksi}$ under the $+60^{\circ} \mathrm{F}$ load case. In fact, effective stress is above 5 ksi throughout the Unit 2, and actually increases notably at Pier 6 under the $-70^{\circ} \mathrm{F}$ load case. There are two probable explanations for this behavior. First, when the fixed bearings are replaced, two guided bearings are input in place of four fixed devices. Therefore, any thermal force that does develop is resisted by two bearing devices, rather than four. Stress at Pier 6 is elevated because the expansion length is measure from Pier 8 or Pier 9, rather than Pier 7, therefore, any thermal stresses that develop will likely be larger.

Longitudinal stress is plotted in Figures 6.19 and 6.20. The significant reduction in longitudinal stress at Pier 7 and Pier 9 is apparent in these figures, most notably under the $+60^{\circ} \mathrm{F}$ thermal load. At Pier 9, a 28\% drop in stress is recorded. Stress at Pier 7 is reduced $30 \%$. This is clearly a result of introducing expansion bearings at these locations. Stress at Pier 8 is also reduced, if only slightly. At the guided bearings at Pier 10 and Pier 11, longitudinal stress is 5-6 ksi under both new bearing arrangements. Under Case 1, the guided bearings at Pier 7 and Pier 8 develop stresses of approximately 7 ksi. Under Case 2, stress at Pier 7 is 6 ksi, while stress at Pier 9 reaches 7 ksi.

Significant information is learned by examining the transverse stresses throughout the bridge, shown in Figures 6.21 and 6.22. With the bearing arrangement in Case 2 applied, transverse stress does not exceed $3 \mathrm{ksi}$ at any guided bearing. This is compared 
to results obtained from the original FE model where transverse stress approached $10 \mathrm{ksi}$ at Piers 6-9 and was 6-7 ksi at Pier 10 and Pier 11. Additionally, it is evident that the bearing arrangement provided in Case 2 minimizes the development of transverse stresses more so than Case 1. With the Case 1 bearing arrangement applied to the FE model, transverse stress approaches $5 \mathrm{ksi}$ at Piers 6, 9, 10 and 11 (4 ksi). This is more than $100 \%$ larger than stresses generated under the bearing arrangement in Case 2 . The low levels of transverse stress shown indicate that the bearing arrangement in Case 2 reduces the influence of transverse movement of the superstructure as it undergoes thermal deformation. Recall from Chapter Two that a major problem on horizontally curved bridges is reducing the impact of restrained radial (i.e. transverse) movement. Clearly, this newly designed bearing arrangement reduces the potential for adverse effects due to radial movement of the superstructure. Nonetheless, contrary to AASHTO design specifications, although small, thermal stresses are not zero.

\subsection{Stresses in the Support Piers}

As demonstrated in Chapter Five, the cracking prevalent in the bridge's concrete support piers was substantiated using data generated by the Man Bridge FE model (Section 5.6). The use of numerous fixed bearings is the primary cause behind this behavior. Large horizontal shear force in the bearing anchor bolts were transmitted into the support piers through bending. The two new bearing arrangements replace many of the fixed bearings with guided expansion bearings in order to prevent the development of thermal forces at the support piers. Even so, the most preferable method for orienting the guided bearings is still unclear. Throughout this chapter, two newly designed bearing 
arrangements have been compared based on their effect towards 1) maximizing superstructure displacement at the bearings, 2) minimizing shear force development in the bearing anchor bolts and 3) minimizing thermal stresses in the bottom flange of the steel I-girders. However, the most signifcant behavior documented during the field investigation of the Man Bridge, and in the literature presented in Chapter Two, pertains to cracking in the concrete support piers. This section compares effective stress $\left(\sigma_{\mathrm{e}}\right)$ and the maximum principal stress at each support pier under the new bearing schemes. Examining the effective stress in the piers provides a general comparison of the total stress state in the piers, while the maximum principal stress is compared to the tensile strength of the concrete material to determine the potential for fracture.

An example effective stress contour plot of Pier 7 is shown in Figure 6.23. It is clearly seen that replacing the fixed bearings with guided bearings has significantly reduced the magnitude of effective stress throughout the piers. Under the original bearing arrangement, $\sigma_{\mathrm{e}}$ at Pier 7 is over $3.5 \mathrm{ksi}$. With the new arrangements implemented, $\sigma_{\mathrm{e}}$ is below $400 \mathrm{psi}$ in both cases. Table 6.3 summarizes the approximate maximum values for $\sigma_{\mathrm{e}}$ at each pier, where the reduction in stress at Pier 7 and Pier 9 is very apparent. At Pier 9 and Pier 8, which are locations where the fixed bearings are placed in the new bearing arrangements, $\sigma_{\mathrm{e}}$ is $600-975 \mathrm{psi}$. At the guided bearings, $\sigma_{\mathrm{e}}$ is generally less than $400 \mathrm{psi}$, with smaller values developing under Case 2. It should be noted that stress in Pier 10, at the guided bearing under Girder 3, is relatively high (700$800 \mathrm{psi}$ ), especially under the $+60^{\circ} \mathrm{F}$ thermal load. The precise actions leading to this response are unknown, but likely result from the bearing becoming restrained in some manner. 

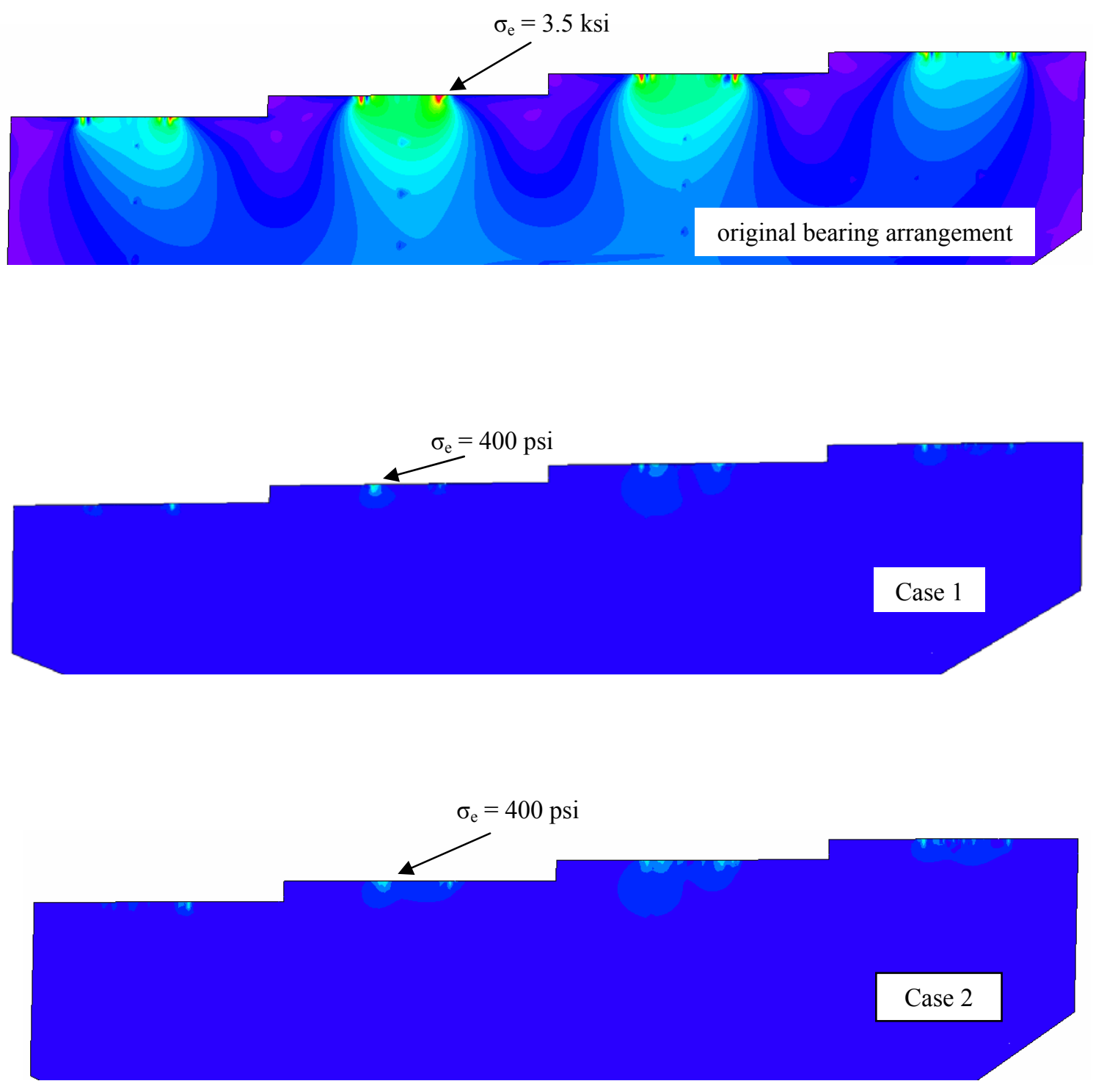

Figure 6.23. Effective stress contour plot of Pier 7 
Table 6.3. Effective stress $\left(\sigma_{\mathrm{e}}\right)$ at each pier

\begin{tabular}{|l|ccc|}
\hline \multirow{2}{*}{ Temp +60 } & \multicolumn{3}{|c|}{$\boldsymbol{\sigma}_{\mathrm{e}, \text { max }}$ (psi) } \\
\cline { 2 - 4 } & Original & Case 1 & Case 2 \\
\hline Pier 6R & 350 & 300 & 200 \\
Pier 7 & 3500 & 375 & 300 \\
Pier 8 & 700 & 400 & 890 \\
Pier 9 & 4500 & 600 & 475 \\
Pier 10 & 1000 & 700 & 300 \\
Pier 11 & 600 & 350 & 300 \\
\hline & & $\boldsymbol{\sigma}_{\mathrm{e}, \text { max }}(\mathbf{p s i})$ & \\
Temp -70'F & Original & Case 1 & Case 2 \\
\cline { 2 - 4 } & 200 & 300 & 250 \\
Pier 6R & 5100 & 400 & 300 \\
Pier 7 & 500 & 300 & 975 \\
Pier 8 & 4000 & 900 & 300 \\
Pier 9 & 600 & 800 & 250 \\
Pier 10 & 200 & 350 & 250 \\
Pier 11 & & &
\end{tabular}

While the effective stress comparisons in Table 6.3 provide valuable information regarding the general state of stress in the piers, principal stresses must be studied as well. Similar to Section 5.6, the maximum principal stress failure criterion (Rankine's criterion) is utilized to determine if the thermal stresses in the piers are large enough to cause fracture of the concrete. Table 6.4 tabulates the approximate maximum principal stress $\left(\sigma_{\mathrm{p}, \max }=\sigma_{1}\right)$ that develops in each support pier. The data provided here shows that the maximum principal stress at Piers 6-8 and at Pier 11 is $74-84 \%$ of the tensile strength of the concrete under the Case 1 bearing arrangement. Under Case 2, 49-74\% of the tensile strength is consumed due to thermal stresses. Replacing the fixed bearings at Pier 7 and Pier 9 significantly reduces the maximum value of $\sigma_{1}$. The bearing arrangement in 
Case 2 is clearly produces the more preferable stress state in the piers. Values of $\sigma_{\mathrm{p}, \max }$ are lower compared to the original FE model, excluding Pier 11 where stress increases. This is especially true to the $+60^{\circ} \mathrm{F}$ load case, where $\sigma_{\mathrm{p}, \max }$ increases from 200 psi to 400 psi. The increase in stress at Pier 11 is likely due to the greater expansion length $L$. Maximum principal stress at the fixed bearings is large enough that fracture of the concrete is probable at these locations.

Table 6.4. Maximum principal stress $\left(\sigma_{\mathrm{p}, \max }\right)$ at each pier

\begin{tabular}{|c|c|c|c|c|c|}
\hline \multirow{2}{*}{ Temp $+60^{\circ} \mathrm{F}$} & \multicolumn{5}{|c|}{$\sigma_{p, \max }(p s i)$} \\
\hline & Original & Case 1 & $\% \sigma_{p} / \sigma_{T}$ & Case 2 & $\% \sigma_{\mathrm{P}} / \sigma_{\mathrm{T}}$ \\
\hline Pier 6R & 250 & 350 & 74 & 200 & 42 \\
\hline Pier 7 & 4300 & 400 & 84 & 300 & 63 \\
\hline Pier 8 & 400 & 400 & 84 & 820 & 173 \\
\hline Pier 9 & 5000 & 800 & 169 & 500 & 105 \\
\hline Pier 10 & 400 & 500 & 105 & 400 & 84 \\
\hline Pier 11 & 200 & 400 & 84 & 400 & 84 \\
\hline \multirow{2}{*}{ Temp $-70^{\circ} \mathrm{F}$} & \multicolumn{5}{|c|}{$\sigma_{p, \max }(p s i)$} \\
\hline & Original & Case 1 & $\% \sigma_{\mathrm{P}} / \sigma_{\mathrm{T}}$ & Case 2 & $\% \sigma_{\mathrm{P}} / \sigma_{\mathrm{T}}$ \\
\hline Pier 6R & 300 & 350 & 74 & 230 & 49 \\
\hline Pier 7 & 5800 & 400 & 84 & 350 & 74 \\
\hline Pier 8 & 500 & 350 & 74 & 1100 & 232 \\
\hline Pier 9 & 5100 & 960 & 203 & 500 & 105 \\
\hline Pier 10 & 400 & 500 & 105 & 250 & 53 \\
\hline Pier 11 & 200 & 350 & 74 & 250 & 53 \\
\hline
\end{tabular}




\subsection{Summary and Conclusions}

This chapter provided a straightforward investigation to determine what bearing arrangement scheme is most preferable for preventing the development of thermal force effects in a horizontally curved continuous steel I-girder bridge. Proper orientation of the guided expansion bearings in a curved continuous girder bridge is often a difficult task due to the complexity of bridge movements under thermal loads. If not aligned correctly, thermal stresses will develop at the bearings, possibly leading to unfavorable behaviors. AASHTO (2007) suggests that guided bearings be oriented toward a single point within a curve bridge, but the preferred location of this point is unclear.

Within this study, the fixed point mentioned in AASHTO (2007) is assumed to be located at a single interior support pier, where fixed bearings are then placed. Then, without altering the span configuration of the bridge two new bearing arrangements were designed with the intention of maximizing thermal deformation of the steel I-girder superstructure. In Case 1, the fixed bearings are placed at Pier 9, nearest to the bridge's geometrical center. In Case 2, the fixed bearings are at Pier 8, near the bridge's point of zero translation. All the remaining supports employed guided and free expansion bearings, with the guided bearings oriented on rays emanating from the fixed bearings.

Longitudinal displacement of the guided bearings is difficult to compare between the new bearing arrangements, mostly because the expansion length relative to the fixed bearings varies. It was shown, however, that the design equation for computing the temperature movement range in curved bridges underestimates the magnitude of bearing displacement, with more agreeable values offered by the arrangement in Case 2. When 
applying this equation to longitudinal movements in horizontally curved steel girder bridges, it may be appropriate to consider introducing a reduction factor.

The horizontal shear force that develops in the bearing anchor bolts under the bearing arrangement in Case 1 is more desirable than that of Case 2. However, when contrasted with values from Chapter Five, very little of the bolts' nominal shear capacity is consumed. Comparing thermal stresses that develop in the bottom flanges near the bearing devices, it is shown that the bearing arrangement in Case 2 results in lower magnitudes of stress. Transverse stress is less than $3 \mathrm{ksi}$ in the flanges at each support, compared to 5-6 ksi in Case 1. The data demonstrates that transverse (i.e. radial) movement within the curved superstructure is mostly insignificant. This is a significant outcome because restrained transverse movement within a bridge's superstructure is a key factor in the development of adverse behavior in curved girder bridges.

Lastly, the stress-state in the concrete piers is evaluated. Rankine's criterion was utilized to determine whether not tensile fracture is probable in the concrete piercaps. Once more, the bearing arrangement in Case 2 produces more preferable results. For Case 1 and Case 2, four out of six piers developed stresses below the tensile strength of the concrete material. However, stresses in the piers under the bearing arrangement in Case 2 were lower compared to Case 1.

Considering all the findings made within this chapter, the preferable bearing arrangement places fixed bearings at or near the structure's point of zero translation and guided (and free) expansion bearings at all other supports. The guided bearings should be oriented as suggested in AASHTO design specifications, which minimizes, but does 
not prevent the development of thermal forces. Additionally, the use of fixed bearings at multiple consecutive support piers is undesirable and should be avoided. 


\section{CHAPTER SEVEN}

\section{Conclusions, Recommendations, and Future Work}

\subsection{Conclusions}

The main goal of this work was to demonstrate that thermal deformation of a slabon-girder continuous steel I-girder superstructure, when restrained against thermal deformation, can lead to detrimental conditions throughout a bridge. During a field investigation of the Man Bridge, an in-service steel I-girder structure, several undesirable behaviors were documented. These behaviors included deformed bearing anchor bolts, deformation at the bridge bearing devices, and significant amounts of cracking throughout many of the concrete support piers. After ruling out other loading conditions that could have caused such behavior, it was hypothesized that thermal forces were the probable culprit. In order to substantiate this claim, 3D finite element modeling and analysis of the 12-span continuous steel I-girder bridge was completed. This included modeling the steel I-girders, concrete bridge deck, concrete support piers, and bridge bearing devices using ADINA (2009) FEA software.

After investigating the behavior of the Man Bridge under two uniform thermal loads, a second objective was pursued. This involved modifying the bearing arrangement (i.e. boundary conditions) of a horizontally curved portion of the bridge to determine what arrangement minimizes the development of thermal forces. Such an investigation was warranted due to certain vagueness within AASHTO bridge design specifications and past literature. This chapter summarizes the chief findings discovered during the FEA investigations performed throughout this dissertation. 


\subsubsection{FEA of the Man Bridge}

The foremost objective of this work was to determine whether or not the observations made during the field investigation were a result of thermal forces. AASHTO bridge design specifications state that thermal forces are minimal when expansion bearings are placed throughout a bridge in a particular manner. Many bridge designers posit that substructure flexibility will alleviate any thermal forces that happen to develop. As the interior support piers deflect laterally, thermal forces within a bridge's superstructure are relieved. However, little consideration is given to the potential consequences of this action. Additionally, established literature has not considered the effects of thermal forces on elements within the substructure. According to the field investigation covered in Chapter Three, such consequences can be harmful and may include deformation of the anchor bolts and around the bearing devices, and cracking throughout the concrete piercaps.

To determine the effect of thermal forces within the Man Bridge, five key responses were examined. These included superstructure translation, shear force development in the bearing anchor bolts, the effect of pier flexure, thermal stresses in the steel superstructure, and stresses in the support piers. Analysis of the FE model data concerning the bridge's response in these areas provided the following conclusions regarding bridge behavior when subject to uniform thermal loading:

1. Bearing displacement throughout the bridge is significantly less than the design temperature movement range. This indicates that the bearing arrangement is 
constraining thermal deformation of the steel superstructure, a response that was not anticipated during the bridge's design.

2. The magnitude of shear force in the bearing anchor bolts exceeds the minimum horizontal design loads, proving that the development of thermal forces was underestimated. This is true at the guided expansion bearings, as well as the fixed bearings. However, the shear resistance provided by the anchor bolts is well above the resultant shear forces.

3. The ability of the support piers to deflect laterally, thereby alleviating thermal forces due to the placement of fixed bridge bearings, is misjudged on the Man Bridge. Thermal stresses in the superstructure reach $11 \mathrm{ksi}$ and the effect of thermal forces is very evident throughout the substructure. Principles of work and energy were used to demonstrate that a large amount of thermal force is imparted to the bearing anchor bolts and piercaps. The flexural rigidity of the pier columns is too high to effectively permit the needed magnitude of lateral deflection in order to fully accommodate thermal deformation of the attached superstructure.

4. At several of the supports with fixed bearings, the development of thermal forces due to uniform thermal load leads to a $275 \%$ increase in effective stress, compared to stresses when a thermal load is absent. This is a clear indication that lateral deflection of the support piers does not alleviate thermal stresses within the bridge's superstructure. 
5. Using Rankine's failure criterion, the stress-state generated in the concrete support piers was shown to be favorable for tensile fracture, which could lead cracking as observed during the field investigation. The FE model(s) produced stresses of over 7 ksi in the concrete, which has a tensile rupture strength of 474 psi. This was substantiated using an additional 3D solid model of a representative support piercap.

The preceding conclusions offer very firm evidence that the behaviors documented during the field investigation of the Man Bridge are highly likely to be the result of restrained thermal deformation within the bridge's steel I-girder superstructure.

\subsubsection{FEA Case Study}

The second major objective of this dissertation is to determine what bearing arrangement scheme is most preferable when attempting to minimize thermal forces within a horizontally curved continuous steel I-girder bridge. When subject to thermal loading, the response of these types of bridges is complex. Superstructure translation occurs in multiple directions but must be accommodated by unidirectional (i.e. guided) bridge bearings. Properly aligning the guided bearings is a difficult task. Since AASHTO bridge design specifications are unclear regarding the most preferable bearing arrangements for curved bridges, and very little research has been conducted on the topic using large structures, the conclusions provided here should greatly assist bridge designers when selecting a satisfactory bearing design. To accomplish the stated objective, various bearing arrangements were introduced and applied the horizontally curved portion of the Man Bridge FE model. Data pertaining to bearing displacement, 
shear force in the anchor bolts, stresses in the steel I-girders, and stresses in the support piers were extracted and compared between the two new arrangements to establish which set of boundary conditions produced the more acceptable results.

The key conclusion reached during the completion of this objective is that placing fixed bearings at one interior support, near the bridge's point of zero translation, and orienting the remaining guided bearings in a chordal manner offers the most acceptable structural response to uniform thermal loads. A major concern in horizontally curved bridges is the development of transverse force effects. However, with a bearing arrangement implemented as described above, transverse stress at the bearings is fairly low, at 2-3 ksi. Additionally, it was shown that the design equation in AASHTO specifications for computing the maximum temperature movement range is not directly applicable to horizontally curved members. According to the data, if this particular equation is to be used for curved bridges, a reduction factor needs be applied in order to prevent over-designing the bridge bearings.

\subsection{Recommendations for Minimizing Thermal Forces}

A final objective of this dissertation is to put forth recommendations on how best to minimize thermal forces in continuous steel I-girders bridges with and without horizontal curvature. The following recommendations were formulated in light of analysis from the FE models and the conclusions provided in Section 7.1. They are meant to provide guidance to bridge designers when considering temperature loads on steel I-girder bridges with individual support piers. 
1. Minimize the use of fixed bearing devices. Placing fixed bearings at multiple consecutive interior piers introduces a large amount of restraint against thermal movement. This will result in the development of thermal forces and the potential for adverse behaviors, as shown throughout this work.

2. If substructure flexibility is a desired method for alleviating thermal forces, ensure that the flexural rigidity of the pier columns is such that they can undergo the magnitude of deflection required to minimize thermal force effects in all structural components.

3. When using the traditional equation to calculate superstructure movement due to temperature loads horizontally curved bridges, note that the magnitude of longitudinal displacement is overestimated.

4. When designing a bearing arrangement for employment on horizontally curved steel Igirder bridges, the most preferable arrangement places fixed bearings near the bridge's stationary point and aligns the guided bearings in a chordal manner relative to this point. This bearing scheme minimizes the development the thermal stresses in the superstructure and the substructure

\subsection{Future Work}

The work presented in this dissertation, while comprehensive and detailed, is not without potential improvements and expanded analyses. The following are suggestions on how to approach further investigations relating to the work performed throughout this study. 
1. It is well-established that a temperature gradient through the depth of a steel I-girder superstructure elicits more complex structural responses compared to uniform thermal loads. The application of a temperature gradient in the Man Bridge FE model would be a logical next step regarding bridge analysis under thermal loading.

2. The stiffness of the spring elements used to model the guided bridge bearings could be adjusted in order to account for friction forces within the bearing devices.

3. The technique chosen for modeling the bridge bearings could be modified so that thermal forces are imparted into elements representing the actual bearing guides. This would allow for a more precise determination of the effects of thermal forces within the actual bearing assemblies.

4. Although accounted for and mostly non-influential, the transfer of vertical load from the superstructure to the substructure should not occur through the elements representing the bearing anchor bolts. Removing what little vertical load that currently develops in these elements would allow for more accurate results from the FE model.

5. The material model of the $3 \mathrm{D}$ solid model could be modified and a crack propagation analysis could be completed to more precisely investigate fracture within the concrete piers.

6. Along with the above suggestion (5), a crack propagation analysis under cyclical loading would be very useful. The investigations performed in this dissertation relied 
on static loading conditions. It is recognized that bridge temperature varies gradually on a 24-hour and seasonal cycle. The effects of such cyclical behavior were not captured in this dissertation. 


\section{REFERENCES}

1. AASHTO-NSBA Steel Bridge Collaboration (2004). Steel Bridge Bearing Design and Detailing Guidelines, Washington D.C.

2. ADINA Research and Development, Inc. (2009). "Theory and Modeling Guide, Volume 1: ADINA." Rep. No. ARD 09-07, Watertown, MA.

3. American Association of State Highway and Transportation Officials (1993). Guide Specifications for Horizontally Curved Highway Bridges, Washington D.C.

4. American Association of State Highway and Transportation Officials (2003). AASHTO Guide Specifications for Horizontally Curved Steel Girder Highway Bridges, Washington D.C.

5. American Association of State Highway and Transportation Officials (2007). AASHTO LRFD Bridge Design Specifications, $4^{\text {th }}$ ed., Washington D.C.

6. AISI Steel Bridge Bearing Selection and Design Guide. American Iron and Steel Institute, Highway Structures Design Handbook, vol. 2, chap. 4.

7. Beckett, C.L. (2011). Effect of Temperature Variation on the Structural Capacity of a Multi-Span Horizontally Curved Steel I-girder Bridge.. MS Thesis. West Virginia University, Morgantown.

8. Boresi, A.P., and Schmidt, R.J. (2003). Advanced Mechanics of Materials. $6^{\text {th }}$ Ed. New Jersey: John Wiley and Sons, Inc. 
9. Chen, Q. (2008). Effects of Thermal Loads on Texas Steel Bridges. Ph.D. Dissertation. University of Texas at Austin, Austin, 2008.

10. Chen. W.F., and Han, D.J. (2007). Plasticity for Structural Engineers. Ft. Lauderdale, FL: J. Ross Publishing Inc.

11. Croft, R. (1994). Temperature Effects on Skewed and Curved Slab-Girder Bridges. MS Thesis. University of Wyoming, Laramie, 1994.

12. Emanuel, J.H. and Hulsey, J.L. (1976). Thermal Stresses and Deformations in Nonprismatic Indeterminate Composite Bridges. Transportation Research Record, vol. 607, Transportation Research Board, Washington D.C.

13. Emanuel, J.H. and Hulsey, J.L. (1978). Temperature Distributions in Composite Bridges. Journal of the Structural Division. vol 104. no. st1. pp. 65-78.

14. Emanuel, J.H. and Taylor, C.M. (1985). Length-Thermal Stress Relations for Composite Bridges. Journal of Structural Engineering. vol. 111, no. 4, pp. 788804.

15. Hendy, C.R. and Iles, D.C. (Eds). (2010). Steel Bride Group: Guidance Notes on Best Practice in Steel Bridge Construction. no. 5. Berkshire. Steel Construction Institute.

16. Hulsey, J. and Emanuel, J. (1978). Environmental Stresses in Flexibly Supported Bridges, Transportation Research Record, vol. 664, Transportation Research Board, Washington D.C. 
17. Li, X.F., Liu, F., and Zao, Y.H. (2007). Analytical Solution for In-plane Displacement of Multi-Span Curved Bridge. The Second International Conference on Transportation Engineering, July 25-27, 2007, Chengdu, 10221027.

18. Li, X.F. and Zao, Y.H. (2009). Exact Solutions for In-plane Displacements of Curved Beams under Thermo Load. 2009 International Conference on Engineering Computation, May 2-3, 2009, Hong Kong, 193-196.

19. Kennedy, J. and Soliman, M.H. (1987). Temperature Distribution in Composite Bridges. Journal of Structural Engineering. vol 113. no 3. pp. 475-482.

20. McBride, K. (2005). Thermal Stresses in the Superstructure of Integral Abutment Bridges. MS Thesis. West Virginia University, Morgantown.

21. McBride, K.C. (2013). Effect of Thermal Loading on the Performance of Horizontally Curved I-Girder Bridges. Ph.D. Dissertation. West Virginia University, Morgantown.

22. Moorty, S. (1990). Thermal Movements in Bridges. Ph.D. Dissertation. University of Washington. Ann Arbor.

23. Moorty, S. and Roeder, C.W. (1992a). Thermal Movements in Bridges, Transportation Research Record, vol. 1290, Transportation Research Board, Washington D.C.

24. Moorty, S. and Roeder, C.W. (1992b). Temperature-Dependent Bridge Movements, Journal of Structural Engineering, vol. 118, no. 4, pp. 1090-1105. 
25. Moulton, L.K. (1983). Observations of Highway Bridge Movements and Their Effects on Joints and Bearings, Transportation Research Record, vol. 903, Transportation Research Board, Washington D.C.

26. NYSDOT (2005) Partial Failure of Ramp AC Dunn Memorial Bridge Interchange, New York Department of Transportation, Albany, NY.

27. Puckett, J.A. and Barker, R.M. (2006). Design of Highway Bridges: An LRFD Approach. $2^{\text {nd }}$ Ed. New Jersey: Wiley, John \& Sons, Inc.

28. Rahman, F. and George, K. (1979). Thermal Stress Analysis of Continuous Skew Bridge. Journal of the Structural Division. vol. 105, st7, pp. 1525-1541.

29. Rahman, F. and George, K. (1980). Thermal Stresses in Skew Bridge by Model Test. Journal of the Structural Division, vol 106, st1, pp. 39-58.

30. Reynolds, J.D. and Emanuel, J.H. (1974). Thermal Stresses and Movements in Bridges. Journal of the Structural Division, vol 100. no. st1. pp. 63-78.

31. Roeder, C.W. (2002a). Proposed Design Method for Thermal Bridge Movements, Journal of Bridge Engineering, vol. 8, no. 1, pp. 12-19.

32. Roeder, C.W. (2002b). Thermal Movement Design Procedure for Steel and Concrete Bridges, Rep. No. NCHRP 20-07/106, National Cooperative Highway Research Program, Washington, D.C.

33. Salmon, C.G. and Johnson, J.E. (1996). Steel Structures: Design and Behavior Emphasizing Load and Resistance Factor Design. 4th Ed. New York: HarperCollins College Publishers. 
34. Samaan, M., Sennah, K., and Kennedy, J.B. (2002). Positioning of Bearings for Curved Continuous Spread-Box Girder Bridges, Canadian Journal of Civil Engineering, vol. 29, pp. 641-652.

35. Shoukry, S. N., William, G.W., Riad, M.Y., and Beckett, C.L. (2012) Evaluation of Empirically Designed Bridge Decks and Bearings for Horizontally Curved Bridges, Rep. No. RP\#245, West Virginia Department of Transportation, Charleston, WV.

36. Southeastern U.S. Seismic Network Operators. (2006). Southeastern U. S. Seismic Network Bulletin No. 40, (compiled by M. C. Chapman, E. C. Mathena and J. A. Snoke), Virginia Tech Seismological Observatory, Dept. Geological Sciences, Blacksburg, VA,

37. Tao, Z. (2009). Thermal Behavior of Composite Girder Bridges. Second International Conference on Information and Computing Science, May 21-22, 2009, Manchester, 327-330.

38. Thepchatri, T., Johnson, C.P., and Matlock, H. (1977). Prediction of Temperature and Stresses in Highway Bridges By a Numerical Procedure Using Daily Weather Reports. Rep. No. 23-1, Center for Highway Research, University of Texas at Austin. Austin, TX.

39. William, G.W., Shoukry, S.N., and Riad, M.Y. (2005). Thermal Stresses in Steel Girder Bridges With Integral Abutments, Bridge Structures, vol 1, no. 2, pp. 103-119. 